\title{
ESTABILIDADE DA ENTOMOFAUNA NUM MOSAICO DE PLANTAÇÃO DE EUCALIPTO E ÁREAS NATURAIS DE CONSERVAÇÃO
}

\section{ALBERTO JORGE LARANJEIRO}

Tese apresentada à Escola Superior de Agricultura "Luiz de Queiroz", Universidade de São Paulo, para obtenção do título de Doutor em Ciências, Área de Concentração: Entomologia.

PIRACICABA

Estado de São Paulo - Brasil

Fevereiro 2003 


\title{
ESTABILIDADE DA ENTOMOFAUNA NUM MOSAICO DE PLANTAÇÃO DE EUCALIPTO E ÁREAS NATURAIS DE CONSERVAÇÃO
}

\author{
ALBERTO JORGE LARANJEIRO \\ Engenheiro Florestal
}

Orientador: Prof. Dr. EVONEO BERTI FILHO

Tese apresentada à Escola Superior de Agricultura "Luiz de Queiroz", Universidade de São Paulo, para obtenção do título de Doutor em Ciências, Área de Concentração: Entomologia.

\section{PIRACICABA}

Estado de São Paulo - Brasil

Fevereiro 2003 
Dados Internacionais de Catalogação na Publicação (CIP) DIVISÃO DE BIBLIOTECA E DOCUMENTAÇÃO - ESALQ/USP

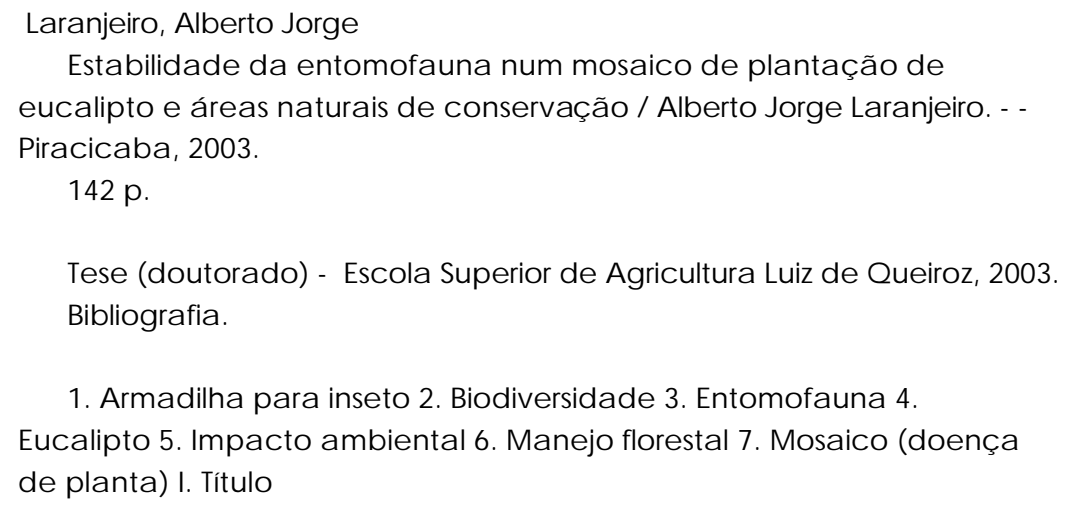

1. Ama dilha para inseto 2. Biodiversidade 3. Entomofa una 4. Euca lipto 5. Impacto ambiental 6. Manejo florestal 7. Mosa ico (doença de planta) I. Título

CDD 634.9734

\section{"Permitida a cópia total ou parcial deste documento, desde que citada a fonte - $O$ autor"}


Aos meus pais, Jorge e Maria de Lourdes,

pelas atitudes contínuas de apoio e confiança,

OFEREÇO.

Aos meus filhos, Alex, Bruno e Camila, pela compreensão do presente $e$ esperança no futuro, 


\section{AGRADECIMENTOS}

Agradeço a todas as pessoas que, de forma direta ou indireta, contribuíram para a realização deste trabalho, especialmente:

Ao Prof. Dr. Evoneo Berti Filho pela orientação e confiança demonstrada, durante o desenvolvimento deste trabalho.

À equipe do Centro de Pesquisas da Aracruz Celulose, com destaque ao Dr. Ergilio Claudio-da-Silva Jr. e Ms. Fernando de Lellis Garcia Bertolucci, pelo apoio e confiança, ao Eng. Florestal Robert Cardoso Sartório, pela contribuição técnica ao longo do trabalho e aos analistas de pesquisa, João Bosco da Silva, Jurandir Floriano Ramos e Jailson Antônio Ciarelli Simões, pela imprescindível atuação nos trabalhos de campo e laboratório.

Ao Prof. Dr. Sinval Silveira Neto, do Departamento de Entomologia, Fitopatologia e Zoologia da ESALQ - USP, pela contribuição na área de ecologia de insetos.

Ao Prof. Dr. Álvaro Fernando de Almeida, do Departamento de Ciências Florestais da ESALQ - USP, pelas estimulantes discussões na área ambiental florestal.

Ao Eng. Agrônomo Marcelo Corrêa Alves, do CIAGRI - ESALQ - USP, pela orientação na análise estatística dos dados. 
LISTA DE FIGURAS............................................................................. vii

LISTA DE TABELAS...............................................................................

RESUMO

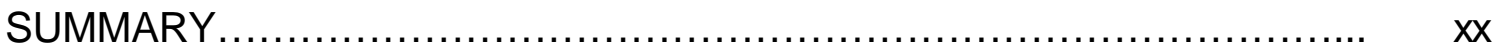

1 INTRODUÇÃO

2 REVISÃO DE LITERATURA................................................................

2.1 Estabilidade ambiental das florestas plantadas..................................... 3

2.2 Entomofauna em florestas plantadas e áreas de reserva natural........... 6

2.3 Levantamento da entomofauna com armadilhas................................... 13

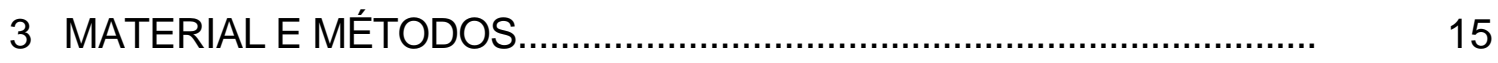

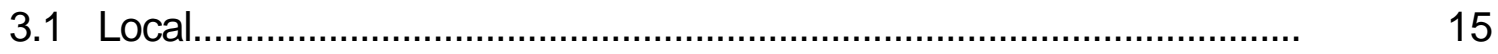

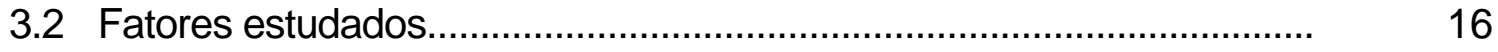

3.3 Pontos de levantamento.................................................................... 19

3.4 Levantamento da entomofauna........................................................ 22

3.5 Identificação do material entomológico..................................................... 22

3.6 Período de levantamento da entomofauna............................................ 26

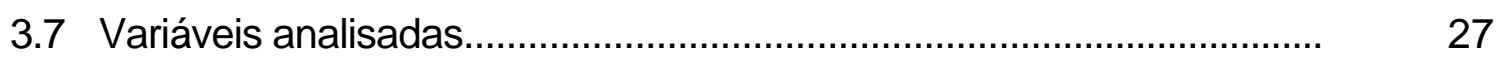

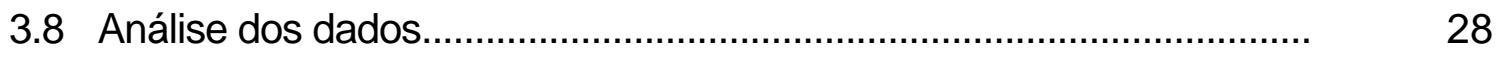




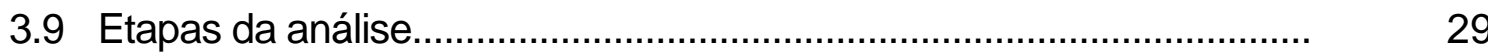

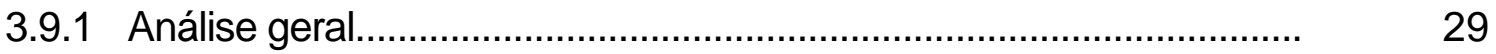

3.9.2 Armadilhas luminosas e de Malaise.................................................... 29

3.9.3 Mata, borda e eucalipto................................................................ 30

3.9.4 Temperatura e precipitação.............................................................. 30

3.9.5 Fase silvicultural........................................................................ 30

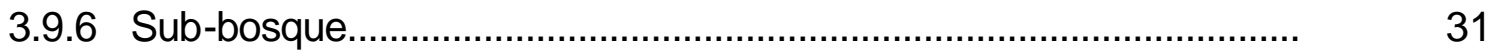

4 RESULTADOS E DISCUSSÃO............................................................... 32

4.1 Resultado geral das coletas............................................................ 32

4.2 Armadilhas luminosas e de Malaise ...................................................... 48

4.3 Mata, eucalipto e borda............................................................... 57

4.4 Temperatura e precipitação............................................................. 81

4.5 Fase silvicultural........................................................................

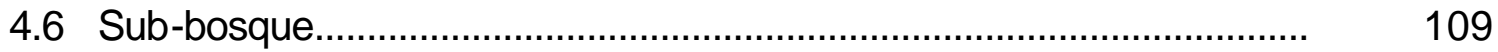

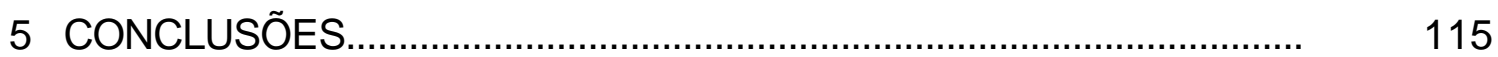

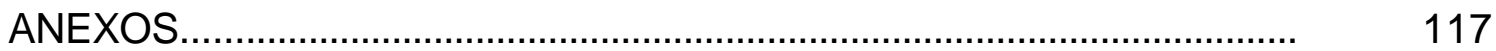

REFERÊNCIAS BIBLIOGRÁFICAS........................................................... 136 
1 Vista aérea da microbacia, onde o estudo foi efetuado

2 Mapa da área da microbacia, com a identificação dos locais e pontos de levantamento a rede experimental..................................... 20

3 Cronograma das coletas e operações silviculturais associadas aos fatores estudados

4 Foto da armadilha luminosa................................................................ 24

5 Foto da armadilha de Malaise................................................................. 25

6 Porcentagem de indivíduos por ordem............................................... 33

7 Porcentagem de indivíduos identificados em diferentes níveis, em cada uma das seis ordens mais abundantes.

8 Porcentagem de famílias, morfoespécies, gêneros e espécies, em cada uma das seis ordens mais abundantes, em relação ao total de cada nível de identificação

9 Número acumulado de morfoespécies classificadas, ao longo do

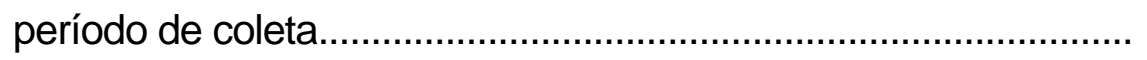

10 Porcentagem de morfoespécies por classe de constância (total: 87 coletas) 
11 Porcentagem de morfoespécies por classe de densidade relativa.

12 Número de morfoespécies por valor de densidade relativa, destacando os limites dos intervalos de confiança da média, para $5 \%$ e $1 \%$ de probabilidade.

13 Número de indivíduos classificados em diversas guildas.

14 Número de indivíduos classificados em pragas, inimigos naturais e polinizadores/decompositores, por ordem

15 Número de morfoespécies classificadas em diversas guildas

16 Número de morfoespécies classificadas em pragas, inimigos naturais e polinizadores/decompositores, por ordem

17 Índice de diversidade acumulado, para morfoespécies, ao longo do período de coleta.

18 Correlação entre o índice de diversidade, para morfoespécies, de Lepidoptera e Coleoptera, com o índice de diversidade total das 15 ordens.

19 Correlação entre índice de diversidade, para morfoespécies, de famílias selecionadas de Lepidoptera e Coleoptera, com o índice de diversidade total das 15 ordens.

20 Porcentagem de indivíduos coletados com cada tipo de armadilha, luminosa e de Malaise. 
21 Número acumulado de morfoespécies por classe de constância, para cada tipo de armadilha (armadilha luminosa: 87 coletas;

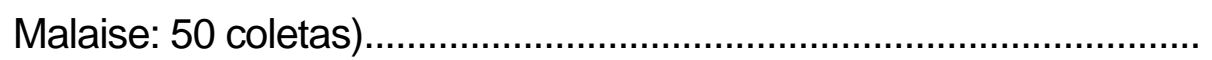

22 Número acumulado de morfoespécies por classe de densidade relativa, para cada tipo armadilha.................................................. 50

23 Porcentagem de morfoespécies e famílias, comuns e exclusivas entre as armadilhas luminosas e Malaise.

24 Número de indivíduos classificados em guildas, por tipo de armadilha

25 Número de morfoespécies classificadas em guildas, por tipo de armadilha.

26 Correlação entre índice de diversidade de Lepidoptera, da armadilha luminosa, com o índice total das 15 ordens com os dois tipos de armadilhas - luminosa e de Malaise -

27 Correlação entre índice de diversidade, para morfoespécies, de famílias selecionadas de Lepidoptera e Coleoptera, coletadas com as armadilhas luminosas, com o índice de diversidade total das 15 ordens, da coleta com armadilhas luminosas e de Malaise.

28 Porcentagem de morfoespécies comuns e exclusivas entre a mata, a borda e o eucalipto, por tipo de armadilha (luminosa e de Malaise): média dos pontos de levantamento, das coletas mensais e o total.

29 Número de indivíduos, por ordem e ambiente (Mata: local 1; Borda: 2; Eucalipto: 6) 
30 Porcentagem acumulada de morfoespécies em função da classe de constância

31 Porcentagem acumulada de morfoespécies em função da classe de densidade relativa.

32 Número de indivíduos, em cada estação do ano, do grupo de pragas e de inimigos naturais, por ambiente.

33 Relação entre o número de indivíduos de insetos pragas e o de inimigos naturais, por estação do ano e coleta mensal...

34 Número de indivíduos, para cada guilda e ambiente, na primavera....

35 Número de indivíduos, para guilda e ambiente, no verão.

36 Número de indivíduos, para cada guilda e ambiente, no outono..........

37 Número de indivíduos, para cada guilda e ambiente, no inverno.

38 Número acumulado de morfoespécies classificadas, ao longo do período de coleta

39 Número de morfoespécies comuns e exclusivas entre ambientes ( $\mathrm{M}=$ mata, $\mathrm{B}=$ borda, $\mathrm{E}=$ eucalipto).

40 Número de morfoespécies comuns e exclusivas entre locais no eucalipto (código dos locais: 3, 4 e 5, conforme padronização no capítulo 3)

41 Número de morfoespécies comuns e exclusivas entre pontos de levantamento, em cada ambiente ( $M=$ mata, $B=b o r d a, ~ E=e u c a l i p t o) . .$. 
42 Porcentagem de morfoespécies comuns e exclusivas entre mata, borda e eucalipto (local 6), em função do período de coleta

43 Porcentagem de morfoespécies exclusivas, entre mata e eucalipto (local 6), e entre os pontos de levantamento 1 e 2, na mata, destacando a diferença entre os valores em cada comparação.

44 Porcentagem de morfoespécies comuns e diferença na porcentagem de morfoespécies exclusivas, entre pontos de levantamento dentro do ambiente e entre pontos de levantamento de ambientes diferentes: comparação de pontos de coleta dois a dois (coleta com armadilhas luminosas).

45 Índice de diversidade para morfoespécies, acumulado ao longo do período de coleta

46 Índice de diversidade médio para morfoespécies, por ponto de levantamento, para cada guilda e ambiente, na primavera...................

47 Índice de diversidade médio para morfoespécies, por ponto de levantamento, para cada guilda e ambiente, no verão.

48 Índice de diversidade médio para morfoespécies, por ponto de levantamento, para cada guilda e ambiente, no outono

49 Índice de diversidade médio para morfoespécies, por ponto de levantamento, para cada guilda e ambiente, no inverno.

50 Índice de diversidade médio para morfoespécies, dos pontos de levantamento, nas famílias selecionadas, por ambiente (códigos dos locais na mata, borda e eucalipto: 1,2 e 6 , respectivamente), na primavera 
51 Índice de diversidade médio para morfoespécies, dos pontos de levantamento, nas famílias selecionadas, por ambiente (códigos dos locais na mata, borda e eucalipto: 1,2 e 6 , respectivamente), no verão.

52 Índice de diversidade médio para morfoespécies, dos pontos de levantamento, nas famílias selecionadas, por ambiente (códigos dos locais na mata, borda e eucalipto: 1,2 e 6 , respectivamente), no outono.

53 Índice de diversidade médio para morfoespécies, dos pontos de levantamento, nas famílias selecionadas, por ambiente (códigos dos locais na mata, borda e eucalipto: 1,2 e 6 , respectivamente), no inverno

54 Temperatura $\left({ }^{\circ} \mathrm{C}\right)$ média diária em cada mês do período de levantamento.

55 Precipitação $(\mathrm{mm})$ total em cada mês do período de levantamento....

56 Porcentagem de morfoespécies em função da classe de densidade relativa, em períodos de três meses (agosto a outubro), em cinco anos, identificados em relação ao ano do corte do eucalipto

57 Porcentagem de morfoespécies em função da classe de densidade relativa, para eucalipto no local 5 , em períodos de três meses (agosto a outubro), em cinco anos, identificados em relação ao ano do corte do eucalipto no local 6 (coletas com armadilhas luminosas).. 
58 Porcentagem de morfoespécies em função da classe de densidade relativa, em períodos de nove meses (novembro a julho), em sete anos, identificados em relação ao ano do corte do eucalipto no local 6 (coletas com armadilhas luminosas)..................................................

59 Porcentagem de morfoespécies em função da classe de densidade relativa, nos três pontos de levantamento no eucalipto, local 5 (sem corte), em períodos de nove meses (novembro a julho), em sete anos, identificados em relação ao ano do corte do eucalipto no local 6 (coletas com armadilhas luminosas).

60 Porcentagem de morfoespécies em função da classe de densidade relativa, nos três pontos de levantamento na mata, em períodos de nove meses (novembro a julho), em sete anos, identificados em relação ao ano do corte do eucalipto no local 6 (coletas com armadilhas luminosas).

61 Porcentagem de morfoespécies em função da classe de densidade relativa, nos três pontos de levantamento na borda mata-eucalipto, em períodos de nove meses (novembro a julho), em sete anos, identificados em relação ao ano do corte do eucalipto no local 6 (coletas com armadilhas luminosas)

62 Número de morfoespécies em períodos de nove meses antes (9A e 9B) e depois (9C e 9D) do corte do eucalipto no local 6 (coletas com armadilhas luminosas).

63 Intervalo de confiança (5\% probabilidade) do número de morfoespécies em períodos de nove meses antes (9A e 9B) e depois $(9 \mathrm{C}$ a $9 \mathrm{H})$ do corte do eucalipto no local 6 (coletas com armadilhas luminosas). 
64 Número de indivíduos pragas e inimigos naturais, em períodos de noves meses (novembro a julho, períodos 9A a 9D), em quatro anos, identificados em relação ao ano de corte do eucalipto no local 6 (coletas com armadilhas luminosas e de Malaise).

65 Intervalo de confiança (5\% probabilidade) da relação entre número de indivíduos pragas e o de inimigos naturais, em períodos de nove meses antes (9A e 9B) e depois $(9 \mathrm{C}$ a $9 \mathrm{H})$ do corte do eucalipto no local 6 (coletas com armadilhas luminosas).

66 Número de morfoespécies exclusivas de cada período, na comparação de períodos de nove meses (julho a novembro), dois a dois.

67 Número de morfoespécies por classe de densidade relativa, separadas em relação àsua ocorrência antes (períodos $9 \mathrm{~A}$ e $9 \mathrm{~B}$ ) e depois (9C e 9D) do corte do eucalipto no local 6 (armadilhas luminosas e de Malaise).

68 Número de morfoespécies, separadas em relação àsua ocorrência antes (períodos 9A e 9B) e depois (9C e 9D) do corte do eucalipto no local 6 (armadilhas luminosas e de Malaise)

69 Freqüência de ocorrência de Bleptina caradrinalis (Lepidoptera, Noctuidae), ao longo do período de levantamento, para vários locais.

70 Porcentagem de morfoespécies comuns e diferença entre morfoespécies exclusivas, na comparação entre mata e eucalipto e entre mata e borda, em quatro períodos de 21 meses (armadilhas luminosas. 
71 Intervalo de confiança (5\% probabilidade) do índice de diversidade para morfoespécies, em períodos de nove meses antes (9A e 9B) e depois $(9 \mathrm{C} \mathrm{a} 9 \mathrm{H})$ do corte no eucalipto no local 6 (coletas com armadilhas luminosas).

72 Intervalo de confiança (5\% probabilidade) do índice de diversidade para morfoespécies do grupo de pragas (primárias, secundárias e potenciais), em períodos de nove meses antes (9A e 9B) e depois $(9 \mathrm{C} \mathrm{a} 9 \mathrm{H}$ ) do corte no eucalipto no local 6 (coletas com armadilhas luminosas).

73 Intervalo de confiança (5\% probabilidade) do índice de diversidade para morfoespécies do grupo de inimigos naturais, em períodos de nove meses antes (9A e 9B) e depois $(9 \mathrm{C}$ a $9 \mathrm{H})$ do corte no eucalipto no local 6 (coletas com armadilhas luminosas).

74 Índice de diversidade para morfoespécies, em cada família que apresentou diferença significativa, ao nível de 5\% de probabilidade, entre pelo menos dois períodos de nove meses, dentre os quatro primeiros avaliados, dois antes (9A e 9B) e dois depois (9C a 9H) do corte do eucalipto no local 6 (coletas com armadilhas luminosas)........

75 Porcentagem acumulada de morfoespécies por classe de densidade relativa, para cada ponto de levantamento dos locais 3 e 4 , com e sem sub-bosque, respectivamente.

76 Intervalo de confiança (5\% probabilidade) da relação entre número de indivíduos do grupo de pragas e o de inimigos naturais, para cada estação do ano e condição do sub-bosque 
77 Intervalo de confiança (5\% probabilidade) do número de morfoespécies, por estação do ano e condição de sub-bosque (com e sem)

78 Porcentagem de morfoespécies comuns e exclusivas entre os locais 3 e 4 , com e sem sub-bosque, respectivamente.

79 Intervalo de confiança (5\% probabilidade) do índice de diversidade para todas as morfoespécies, por estação do ano e condição de sub-bosque (com e sem).

80 Intervalo de confiança (5\% probabilidade) do índice de diversidade para morfoespécies do grupo de pragas e de inimigos naturais, por estação do ano e condição de sub-bosque (com e sem). 
1 Locais do levantamento da entomofauna e fatores de estudo envolvidos

2 Níveis de identificação dos indivíduos de insetos e critérios para considera-los no estudo.

3 Número de indivíduos de insetos, identificados em diferentes níveis..

4 Número de morfoespécies, famílias, gêneros e espécies identificados

5 Resultados da análise de regressão entre o índice de diversidade de toda a coleta (15 ordens) e o de cada uma das quatro ordens, selecionadas em função de sua abundância e da porcentagem de indivíduos classificados em morfoespécies.

6 Resultados da análise de regressão entre o índice de diversidade de toda a coleta ( 15 ordens) e o resultante de famílias selecionadas das ordens Lepidoptera e Coleoptera.........................................................

7 Análise de regressão entre 0 índice de diversidade para morfoespécies das famílias de Lepidoptera e Coleoptera selecionadas e o índice de diversidade total: comparação das famílias selecionadas com captura pelos dois tipos de armadilhas, contra coleta apenas com as armadilhas luminosas. 
8 Resultados da análise de regressão entre três variáveis estudadas na entomofauna e a precipitação e temperatura (modelo: variável transformada $=\mathrm{a}+\mathrm{b} \cdot \mathrm{P} 0+\mathrm{c} \cdot \mathrm{PM} 1+\mathrm{d} \cdot \mathrm{PM} 3+\mathrm{e} \cdot \mathrm{PM} 6+\mathrm{f} \cdot \mathrm{T} 0+\mathrm{g} \cdot \mathrm{TM} 1+$

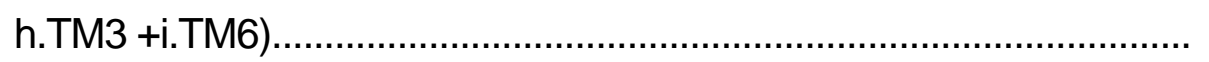

9 Relação de espécies muito abundantes, em relação ao padrão local (Figura 12), selecionadas em função de sua ocorrência exclusiva, na fase de plantação madura de eucalipto (antes do corte), ou na fase inicial até dois anos de idade (após corte) e a situação com seis

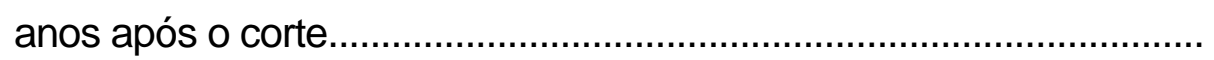




\title{
ESTABILIDADE DA ENTOMOFAUNA NUM MOSAICO DE PLANTAÇÃO DE EUCALIPTO E ÁREAS NATURAIS DE CONSERVAÇÃO
}

\author{
Autor: ALBERTO JORGE LARANJEIRO \\ Orientador: Prof. Dr. EVONEO BERTI FILHO
}

\section{RESUMO}

A partir da grande expansão da área de florestas plantadas no Brasil nas últimas décadas, vem ocorrendo uma grande pressão ambientalista e governamental por estudos de avaliação e de monitoramento ambiental de empreendimentos florestais. Por outro lado, as próprias empresas florestais vêm preocupando-se com a estabilidade das florestas plantadas, como forma de garantir a sustentabilidade do negócio. A expansão muito recente das áreas de plantio faz com que muitas pragas e doenças, nativas ou introduzidas, ainda estejam no início do processo de colonização e adaptação. Por outro lado, o equilíbrio ambiental é fundamental dentro do manejo integrado das pragas florestais. Assim, este estudo teve o objetivo de conhecer as interações entre os principais ambientes do ecossistema onde as plantações estão inseridas, assim como os efeitos do manejo silvicultural sobre a comunidade de insetos, na plantação e nas reservas naturais contíguas a ela. Para tanto, a entomofauna foi monitorada em uma microbacia de uma região com grande atividade silvicultural, no norte do Estado do Espírito Santo, Brasil, através de coletas mensais com armadilhas luminosas e de Malaise, de 1994 a 2002. 


\title{
STABILITY OF THE ENTOMOFAUNA IN A REGION COMPOSED BY EUCALYPT PLANTATIONS AND CONSERVATION AREAS
}

\author{
Author: ALBERTO JORGE LARANJEIRO \\ Adviser: Prof. Dr. EVONEO BERTI FILHO
}

\section{SUMMARY}

Due to the large spreading of commercial forests in Brazil, in the last decades, one can detect a enormous pressure from the environmentalists and the governmental agencies for evaluation studies and environmental monitoring of forestry enterprises. On the other hand, the forestry enterprises are concerned with the stability of such forests in order to ensure the goals of this agribusiness. The recent spreading of forest planted areas give chance to a number of pests, either native or introduced ones, to start a process of colonization and adaptation. And one knows that the environmental equilibrium is fundamental for the integrated forest pest management. Therefore this research was carried out to determine the interactions among the main environments of the ecosystem where the plantations are located, as well as the influence of the silvicultural management on the insect communities of the eucalypt plantation and the neighboring natural reservoirs. The entomofauna was monitored by using light and Malaise traps in a watershed of a region with high silvicultural activity, located in the north of the State of Espirito Santo, Brazil, from 1994 to 2002. 


\section{INTRODUÇÃO}

O Brasil tem cerca de seis milhões de hectares de florestas plantadas com fins comerciais. Como qualquer outra plantação homogênea, os plantios florestais reduzem a diversidade vegetal $e$, conseqüentemente, tornam o ambiente menos estável, com menor capacidade de absorver distúrbios.

Soma-se às características de plantação homogênea, o fato de ocuparem grandes áreas contíguas e serem formadas de espécies florestais exóticas, basicamente de apenas dois gêneros, Eucalyptus e Pinus. Esse quadro faz com que exista uma grande pressão da sociedade para a realização de estudos dos impactos ambientais, sociais e econômicos das florestas comerciais.

A preocupação da estabilidade ambiental em relação æ̀ pragas nas plantações florestais no Brasil é pertinente, pois sua grande expansão é muito recente, a partir dos anos 70 , onde insetos nativos ou introduzidos, ainda estão no início do processo de colonização e adaptação. Além desse risco emergente, as florestas comerciais, para garantir a produção e o retorno econômico, não podem depender de operações freqüentes de controle de pragas, como ocorre em várias culturas agrícolas.

A estabilidade ambiental é fundamental dentro do manejo integrado das pragas florestais. Para tanto, o modelo de manejo de florestas plantadas não pode estar próximo das visões radicais, que enxergam esse ambiente como um deserto verde, ou uma ilha. $\mathrm{Na}$ realidade, os empreendimentos florestais, apresentam quatro aspectos básicos, que geralmente os diferem de outras culturas e propiciam uma maior biodiversidade: $1^{\circ}$ - ciclo longo; $2^{\circ}$ - maior 
contato com áreas naturais conservadas; $3^{\circ}$ - maior estratificação vertical; e, $4^{\circ}$ formação de sub-bosque. Portanto, o grau de estabilidade num ambiente formado por floresta plantada e áreas de reserva natural, vai depender da distribuição espacial desses dois ambientes, das características das reservas naturais e do sub-bosque no interior do eucalipto, assim como do manejo desta cultura. Desse modo, existe uma grande possibilidade de erro ao generalizar o ambiente onde as florestas plantadas estão inseridas, seja como deserto verde ou ilhas, ou mesmo o oposto.

A hipótese central deste trabalho foi a de que é possível, dentro de uma configuração adequada desses fatores, uma interação entre floresta plantada e áreas naturais adjacentes, que leve a um nível de riqueza, distribuição e abundância das populações de insetos, que proporcione uma comunidade de insetos capaz de absorver os distúrbios provenientes das atividades de manejo florestal, ou mesmo de condições naturais adversas, como ocorre eventualmente com o clima.

Esta hipótese foi idealizada, com base nas características da área de estudo, que compreende uma microbacia, com cerca de 32\% de áreas de reserva natural, bem distribuídas junto ao eucalipto e diversidade vegetal elevadíssima.

Testar esta hipótese foi conhecer o efeito, sobre a entomofauna, da interação entre eucalipto, seu sub-bosque e as reservas naturais, da reforma da plantação e da eliminação do sub-bosque, indicando padrões para monitoramento e práticas de manejo, que levem a maior estabilidade ambiental.

Este trabalho com a entomofauna fez parte de um estudo muito mais amplo, envolvendo outros fatores bióticos, como vegetação e avifauna, assim como aspectos abióticos, como o clima. Todo este estudo foi realizado em uma microbacia que representa uma região com grande atividade florestal, no litoral norte do Estado do Espírito Santo. 


\section{REVISÃO DE LITERATURA}

\subsection{Estabilidade ambiental das florestas plantadas}

A teoria da diversidade-estabilidade postula que quanto maior é a diversidade biológica de uma comunidade, maior é a sua estabilidade. Associada a essa teoria, uma doutrina central na ecologia de populações diz que a estabilidade está associada aos relacionamentos na cadeia alimentar (Larsen, 1995).

A estabilidade, por sua vez, é definida por Pimm (1984), como um dos aspectos do equilíbrio ecológico, junto com a própria complexidade do ecossistema.

Pinto-Coelho (2000) resumiu as principais medidas da estabilidade propostas por Pimm (1984):

$1^{\text {a }}$ - estabilidade: quando as variáveis retornam ao estado de equilíbrio após um distúrbio;

$2^{\mathrm{a}}$ - resilência: rapidez com a qual o sistema retorna ao equilíbrio após um distúrbio;

$3^{\mathrm{a}}$ - persistência: o tempo em que uma variável permanece inalterada após um distúrbio;

4a - resistência: o grau de mudança exibido por uma variável após um distúrbio;

$5^{\text {a }}$ - variabilidade: qualquer medida de dispersão associada à variações das densidades populacionais no tempo ( $\mathrm{s}$ - desvio padrão, $\mathrm{s}^{2}$ - variância, CV - coeficiente de variação). 
A complexidade, que envolve o assunto estabilidade, faz com que sua abordagem precise ser bem definida. Conceitos associados àestabilidade, nem sempre têm o mesmo entendimento e definição. Ao contrário do conceito apresentado por Pinto-Coelho (2000), resistência foi definida por Larsen (1995), como a habilidade do sistema, ou do componente selecionado, de resistir ao estresse externo.

Equilíbrio é outro conceito, associado à própria definição de estabilidade, que tem diferentes significados. Estabilidade pode ser definida como a capacidade do sistema permanecer perto do ponto de equilíbrio, ou de retornar a ele, após um distúrbio. No entanto, ecossistemas são sistemas termodinamicamente abertos, caracterizados por entradas e saídas de energia e matéria (Larsen, 1995). Assim, o equilíbrio na definição da estabilidade de um ecossistema é bem diferente do equilíbrio da termodinâmica, sistema fechado em termos energéticos e químicos, associado ao aumento da entropia (aumento da desordem). A teoria biogeográfica pressupõe, junto com outros modelos recentes em ecologia, a existência de equilíbrio dinâmico (PintoCoelho, 2000). Esse equilíbrio é caracterizado por processos que se autoregulam e por perda de entropia (Addiscott, 1995).

Qualquer impacto nesse equilíbrio dinâmico, que produza danos ou perdas nas populações de espécies nativas animais ou vegetais, traduz-se em degradação ambiental ou da diversidade (Brienza Jr. et. al., 1998). Segundo Nepstad et al. (1992), a degradação ambiental desestabiliza estruturalmente e funcionalmente $\mathrm{o}$ ecossistema e modifica a habilidade de regular 0 armazenamento e os fluxos de água, energia, carbono e nutrientes.

A história do manejo florestal é longa, mas somente nas últimas décadas a produção florestal tem sido fortemente orientada para o estabelecimento da estabilidade ambiental, destacando-se a manutenção da biodiversidade. $O$ interesse por florestas que mantenham os recursos naturais tem aumentado e conduzido o desenvolvimento de critérios e indicadores de sustentabilidade para o manejo florestal (Kneeshan et al., 2000). 
Nesse contexto, as plantações florestais foram enquadradas em teorias ecológicas, como a de biogeografia de ilha e sucessão de comunidades.

Com base nessas teorias, Forti (1990) justifica que culturas perenes, incluindo as plantações florestais, podem ser consideradas como ilhas, apresentando longo período de duração de tempo. A cada ciclo, o silvicultor estaria decidindo quanto seria o início e término da sucessão ecológica.

Patterson (1987), com base em estudos em ilhas na Nova Zelândia, descreveu o "princípio de subconjuntos aninhados", onde a biota de uma ilha menor e ou mais alterada, apresenta-se como um subconjunto da biota de uma ilha maior e mais rica que, por sua vez, apresenta-se como um subconjunto de uma outra ilha, numa seqüência de riqueza crescente. Nesse ponto, foi apenas mais um passo para o autor fazer uma analogia teórica entre ilhas e áreas de conservação, que são "feitas ilhas" pelos distúrbios ocorridos em sua volta.

Por outro lado, Lawton (2000), baseado em padrões de distribuição e abundância estabelecidos por princípios de macroecologia, afirmou que nenhuma reserva natural é uma ilha. Isso porque, mesmo que isolada, não estaria livre dos efeitos da vizinhança. Os padrões a que ele se referiu estão relacionados àexistência de:

$1^{\circ}$ - Para cada espécie, uma correlação positiva entre a medida de abundância local e o tamanho e alcance geográfico de cada espécie.

$2^{\circ}$ - Uma correlação positiva entre a riqueza regional de espécies de um táxon e a riqueza local.

$3^{\circ}$ - Uma relação entre as espécies e sua área de ocupação.

Procurar estabilidade é manter a biodiversidade. A biodiversidade depende da manutenção da riqueza de espécies. A abundância é efetiva para prevenir a extinção por causas demográficas e ubiqüidade é a segurança contra extinção de recursos naturais (Patterson, 1987).

Os princípios da macroecologia, que une biogeografia, ecologia e biologia evolucionista, mostram a importância de evitar o isolamento e que não 
só grandes reservas são necessárias, mas também o estabelecimento de uma rede entre as reservas, promovendo o fluxo das populações (Lawton, 2000).

A demanda internacional por florestas comerciais que mantenha os recursos naturais é crescente, o que tem conduzido o desenvolvimento de critérios e indicadores de sustentabilidade do manejo florestal (Kneeshaw et al., 2000). Dentro da sustentabilidade, a conservação da biodiversidade é um dos pontos prioritários. Preservar a biodiversidade passa por estabelecer padrões de riqueza, abundância, distribuição e interação dos componentes da biota local, que orientem o manejo ao longo do tempo.

Segundo Kneeshaw (2000), o estabelecimento de critérios e indicadores de sustentabilidade de manejo florestal passam pelas seguintes dificuldades:

$1^{\mathrm{a}}$ - Existência de indicadores para uma escala muito ampla, em relação à realidade ou necessidade local.

$2^{\mathrm{a}}$ - Rigidez dos programas de certificação, para aceitação de adaptações locais de sistemas de manejo.

$3^{\mathrm{a}}$ - Programas de certificação baseados em formadores de opinião pública, ao invés de conhecimento científico.

\subsection{Entomofauna em florestas plantadas e áreas de reserva natural}

Teorias sobre os fatores que controlam a abundância de artrópodos herbívoros, especialmente insetos, têm sido manifestadas durante toda a história da ecologia. Recentemente, particular atenção tem sido dispensada aos efeitos da diversidade de vegetação ou diversidade vegetacional sobre fitófagos e seus inimigos naturais (Russel, 1989).

A forma positiva, geralmente demonstrada pela relação abundânciaocupação, intraespecífica ou interespecífica, tem conseqüências para várias 
áreas da ecologia aplicada, incluindo conservação, colheita, invasões biológicas e inventários da biodiversidade (Gaston et al., 2000).

Gaston et al. (2000) citam que a abundância e distribuição de espécies tendem a se unir, tal que espécies declinando em abundância freqüentemente tendem também a mostrar declínio no número de sítios que ocupam, enquanto espécies aumentando em abundância tendem também a aumentar em ocupação.

De acordo com Andow (1991), a teoria ecológica sugere fatores importantes que levam a uma maior riqueza de espécies em locais mais heterogêneos, tendo estes a maior diversidade de habitats e a maior densidade de inimigos naturais, levando ao aumento do controle de populações de organismos dominantes.

Jactel et al. (2002) verificaram que a diversidade do habitat em plantações florestais de pinus marítimo reduz infestações do cavador do caule do pinus Dioryctria sylvestrella, sugerindo que a conservação e restauração de áreas com espécies não produtivas, adjacentes æ̀ plantações manejadas intensivamente, são métodos preventivos úteis no manejo de pragas em monoculturas florestais.

Russel (1989) citou que diversos estudos têm demonstrado que populações de insetos herbívoros alcançam maiores níveis populacionais em agroecossistemas simples do que em diversificados. Root (1973), citado por Russel (1989), propôs duas teorias como possíveis explicações para este modelo: $1^{\mathrm{a}}$ - a hipótese dos inimigos naturais: predadores e parasitóides são mais efetivos em sistemas diversos; $2^{\mathrm{a}}$ - a hipótese da concentração de recursos: herbívoros especialistas encontram mais facilmente, permanecem e se reproduzem mais em monoculturas de suas plantas hospedeiras.

$\mathrm{Na}$ revisão feita por Russel (1989), sobre a hipótese dos inimigos naturais, a grande maioria dos trabalhos revisados pelo autor permite concluir que os poucos estudos que têm sido desenvolvidos geralmente sustentam a afirmativa de que predadores e parasitos matam herbívoros em maiores taxas 
em policulturas do que em monoculturas, mas os estudos não fornecem subsídios para concluir se essa diferença de mortalidade é que reduz o número de herbívoros adultos em sistemas complexos.

Hunter Jr. (1990) cita que a redução da diversidade em plantações florestais pode ter sérias conseqüências para as próprias árvores, pois o preço da baixa diversidade pode ser a diminuição da resistência ao estresse.

Hunter Jr. (1990) cita que o efeito das árvores exóticas torna-se mais dramático quando as plantações são consideradas como um todo. Na Austrália, populações de pássaros são maiores e mais diversificadas nas florestas nativas de eucalipto do que nas plantações introduzidas de pinus monterey.

Altieri \& Letourneau (1982), citam que em sistemas diversificados os estímulos químicos e visuais das plantas hospedeiras e não hospedeiras afetam a taxa de colonização de herbívoros e seu comportamento. Um inseto herbívoro num habitat diversificado frequentemente terá grande dificuldade em localizar a planta hospedeira quando a concentração relativa do recurso é mais baixa.

De acordo com Andow (1991), inimigos naturais generalistas e especialistas podem ser mais abundantes em policulturas pela maior quantidade ou maior tempo de disponibilidade de pólen e néctar durante o período de produção em policulturas do que em monoculturas. Apesar disto, o autor evidenciou que a maioria das hipóteses estudadas não foi confirmada.

Ratsirarson et al. (2002) compararam a riqueza de espécies de invertebrados (Hymenoptera, Opiliones e Amphipoda) coletados na serrapilheira da floresta nativa e das florestas de eucalipto e pinus, encontrando 22 espécies na nativa, 19 no eucalipto e 17 no pinus. Através da aplicação do índice (ICE), que estima o número máximo potencial de espécies, foram estimadas $52 \mathrm{spp}$. na nativa, 2,4 vezes mais que as 22 spp. no pinus e 1,8 vezes mais que no eucalipto. 
Bonham et al. (2002) verificaram a diversidade e a abundância de alguns invertebrados em plantações de eucalipto, de pinus e na floresta nativa, na Tasmânia, Austrália. Caramujos nativos e milipedes foram menos diversos nas plantações do que na floresta nativa, e caramujos introduzidos foram mais abundantes nas plantações.

Miller \& Stephen (1983), estudaram o efeito da vegetação competidora nas populações da mariposa Rhyacionia frustana, em plantações de Pinus, chegando à conclusão de que as diferenças nos níveis da vegetação não foram aparentemente o fator principal na determinação dos níveis populacionais da praga.

Já os experimentos realizados por Mezzomo (1995), avaliando faixas de regeneração entremeadas aos talhões de eucalipto, revelaram maior diversidade de espécies e menor abundância de indivíduos por espécie, inclusive daquelas consideradas pragas primárias na eucaliptocultura. A presença de sub-bosque em florestas de eucalipto pode apresentar semelhanças com estas áreas de borda para a ocorrência de insetos.

Neumann (1978), realizou levantamentos com armadilhas de "Malaise" para estudar a estrutura de comunidades de coleópteros em florestas de Pinus e Eucalyptus, e argumentou que a ecologia e sobrevivência dos coleópteros devem estar relacionadas com as plantas nativas que ocorrem no sub-bosque destas florestas, necessitando de maiores estudos para esclarecer esta hipótese.

Mezzomo (1995), cita que no caso de parasitóides é viável supor que a manutenção de maior porção de vegetação em regeneração facilite a manutenção de maiores populações destes insetos. $O$ aumento da diversidade e diminuição da abundância, em comunidades de lepidópteros, observada em plantios com faixa de vegetação e/ou próximos àáreas remanescentes tem sido atribuído æ̀ maiores populações de parasitóides nestas áreas.

De acordo com Leius (1967), as populações de predadores e parasitóides aumentam nas proximidades de áreas remanescentes de 
vegetação florestal nativa, sendo os inimigos naturais, mais eficientes em áreas onde existe abundância de flores silvestres, as quais proporcionam alimentos na forma de néctar e pólen.

Estudos da composição florística de sub-bosque em culturas de Eucalyptus são escassos. Quase todos os trabalhos restringem-se a levantamentos prévios de plantas associadas predominantes, objetivando o seu controle quando consideradas competidoras (Ramalho \& Zunti, 1975), citados por Alves (1998).

Schlittler (1984), realizou em levantamento da composição florística e estrutura fitossociológica do sub-bosque de uma plantação de E. tereticornis Sm. no Município de Rio Claro - SP. Foi encontrado um total de 100 espécies, 22 no estrato arbustivo e herbáceo e 63 no estrato arbóreo, pertencentes à 33 famílias, concluindo que os talhões de E. tereticornis se constituem atualmente em reservatórios relevantes para a manutenção de espécies da flora primitiva do Estado e, particularmente, da região de Rio Claro - SP.

Estudando a composição florística e estrutura da comunidade de plantas daninhas em florestas de E. grandis, Nordi (1996), concluiu que as comunidades de plantas ocorrentes nestas condições apresentam diferenças na composição florística e na estrutura de comunidade, sendo essas diferenças, na maior parte quantitativa e não qualitativa, devido a grande similaridade entre os diferentes sub-bosques. $O$ autor observou ainda que à medida em que os sub-bosques foram evoluindo no tempo, instalaram-se plantas de mata e de cerrado, além das plantas daninhas tipicamente presentes em áreas agrícolas.

Alves (1988) fez uma ampla revisão, mostrando a relação direta da heterogeneidade ou diversidade, tanto em áreas naturais como em culturas, entre a vegetação e os insetos, descrevendo várias hipóteses para explicar esse fato. Também apresentou trabalhos que defendem a teoria da diversidadeestabilidade. No entanto, também levantou questionamentos sobre a falta de dados empíricos, assim como outros contraditórios, para sustentar essa teoria. Esse quadro certamente é função da dificuldade de estabelecer relações 
determinísticas, frente à complexidade das interações entre as populações, aumentada ainda mais pela influência de fatores abióticos. $O$ autor concluiu que o impacto da diversificação em um agroecossistema depende do grau de polifagia ou monofagia dos herbívoros e do tipo de sistema de cultivo, se perene ou anual.

Para determinadas condições, a relação entre diversidade e estabilidade foi demonstrada em algumas culturas, como o estudo desenvolvido por Pimentel (1961), avaliando o efeito da ausência e presença de plantas daninhas na cultura de Brassica oleracea, sobre explosões demográficas das pragas.

Em relação aos ambientes naturais, primitivos, as florestas plantadas simplificam o ambiente e, sem dúvida, provocam certo grau de degradação. No entanto, em relação a ambientes muito degradados, podem levar a uma maior conservação das populações, devido principalmente a quatro de suas características: ciclo longo, maior contato com áreas naturais conservadas, maior estratificação vertical e formação de sub-bosque.

Alves (1998) estudou a influência do sub-bosque em plantios de Eucalyptus grandis e de fragmentos de mata nativa vizinha a talhões plantados, na comunidade de inimigos naturais (parasitóides e predadores) das Ordens Díptera e Hymenoptera e de pragas do eucalipto da ordem Lepidóptera, nas regiões de Telêmaco Borba/PR e Itatinga/SP. Utilizou dois tipos de armadilhas, para os estudos da estrutura de comunidade e dinâmica populacional das espécies: armadilhas luminosas para coleta de lepidópteros-praga do eucalipto e armadilhas Malaise para a coleta de inimigos naturais, durante dois anos, com coletas quinzenais.

Experimentos planejados para avaliar faixas de regeneração, entremeadas aos talhões de eucalipto, revelaram maior diversidade e menor abundância por espécie, inclusive daquelas consideradas pragas primárias na eucaliptocultura (Mezzomo, 1995). 
Bragança (1995) estudou as populações de Lepidoptera e Hymenoptera em plantação de eucaliptos, na reserva de mata natural adjacente e na borda entre os dois ambientes, na região de Aracruz/ES. Observou gradiente decrescente de riqueza de espécies e índice de diversidade da mata para o interior do eucalipto. Constatou também as espécies na mata são mais igualmente abundantes e existindo uma baixa dominância e alta diversidade. $O$ trabalho mostrou a importância do contato da plantação de eucalipto com a mata natural, para manter a diversidade e, conseqüentemente, a sua estabilidade.

Majer \& Recher (1999) fizeram uma ampla revisão e análise dos aspectos ambientais das plantações de eucalipto no Brasil. Com relação à entomofauna, concluíram que a plantação causa impacto significativo sobre a biodiversidade, riqueza e distribuição das espécies, proporcionando desequilíbrio e tornando a floresta susceptível a diversas pragas.

Ambientes mais ricos são considerados mais adequados para o cultivo de eucalipto, baseado no conceito de que sistemas mais ricos são mais complexos e apresentam maior estabilidade. Nesse sistema, o crescimento populacional exagerado de uma espécie (surto) não seria esperado (MacArthur, 1955; Pimm, 1979), já que os mecanismos de controle de densidade regulariam suas populações.

Segundo Kageyama et al. (1992), a regeneração artificial na recuperação de áreas degradas, aliada às ações ambientalistas e de pressão da sociedade, vem sendo considerada prioritária em função do grau avançado de perturbação que atinge grandes áreas de proteção permanente. Os autores definem área degradada, como aquela que, após um distúrbio, perdeu a capacidade de regeneração natural, e área perturbada, a que sofreu distúrbio, mas manteve meios de regeneração biótica.

Na recuperação de uma área degradada é possível encontrar espécies específicas para cada etapa da recuperação (Sautter, 1998). Considerando que bioindicadores são organismos ou comunidades de organismos cujas funções 
vitais são tão estreitamente correlacionadas com os fatores abióticos, que podem ser utilizados como indicadores de mudanças destes fatores (Schubert, 1991), é de fundamental importância o estudo desses organismos, para monitoramento ambiental e indicação da necessidade de práticas de manejo que visem a conservação das populações.

Os insetos fitófagos, quando específicos para determinadas plantas, são os organismos mais adequados para serem usados como bioindicadores, principalmente lepidópteros, que são taxonomicamente bem estudados e podem ser facilmente amostrados através de armadilhas luminosas (Holloway et al., 1987).

A análise faunística permite a avaliação do impacto ambiental, tendo por base espécies de insetos como indicadores ecológicos (Silveira Neto et al., 1995).

\subsection{Levantamento da entomofauna com armadilhas}

Existem dois princípios básicos de funcionamento de armadilhas para captura de insetos: interceptação e atração. As armadilhas luminosas agem nos dois modos e a de Malaise através apenas de interceptação.

O movimento de um inseto a um estímulo produzido por luz é chamado de fototropismo, que é positivo quando o movimento ocorre em direção àluz e negativo em caso contrário (Matioli \& Silveira Neto, 1988).

Os insetos de hábito noturno, os mais importantes para captura em armadilhas luminosas, têm como fonte primária de atração a luz da lua. As espécies migrantes voam procurando manter sempre constante um ângulo entre a linha de vôo e a lua (Matioli \& Silveira Neto, 1988).

Cada tipo de inseto pode ser atraído por um tipo de luz diferente, ou seja, luz com diferentes comprimentos de onda. A maior parte dos insetospraga é fototrópica positiva, sendo as mariposas um bom exemplo. Geralmente, esses insetos podem ser monitorados e até controlados por meio de armadilhas luminosas (Nakano \& Leite, 2000). 
Matioli (1986) afirma que, além dos fatores ligados exclusivamente às armadilhas luminosas, existem outros que interferem na captura de insetos e que podem determinar seu êxito ou fracasso: temperatura, chuvas, neblina, luar, altura e posição de instalação das armadilhas e período de instalação das armadilhas, em relação ao período de vôo.

Silveira Neto et al. (1976) afirmaram que é praticamente impossível contar todos os insetos de um habitat e que os levantamentos devem ser realizados mediante estimativas de populações por meio de amostras.

O emprego das armadilhas luminosas é bastante antigo, tendo sido usado pela primeira vez por Lallement, em 1874. As armadilhas luminosas mais comumente utilizadas são baseadas nos modelos norte-americanos, padronizados pela Sociedade Americana de Entomologia, com luz vertical e multidirecional (Silveira Neto, 1989). No Brasil, as armadilhas luminosas são utilizadas desde 1964, pelo Departamento de Entomologia da ESALQ/USP e outras instituições (Vendramim et al, 1992). Segundo Almeida et al. (1998), existem vários tipos de armadilhas que utilizam a luz como atrativo para captura de insetos. A armadilha luminosa mais comum é a do modelo "Luiz de Queiroz", desenvolvida pelo Departamento de Entomologia da ESALQ, Piracicaba/SP.

Outro modelo de armadilha utilizado e comercializado no Brasil é o modelo "Al Intral" com lâmpada fluorescente FT15T12 BL, alimentada por uma bateria de 12 volts (Silveira Neto, 1989).

As armadilhas luminosas vêm sendo utilizadas em levantamentos populacionais de lepidópteros em plantações de Eucalyptus spp. no Brasil (Berti Filho, 1981; Menezes et al. 1986a; Menezes et al., 1986b; Wilcken, 1991; Zanúncio et al., 1993a; Zanúncio et al., 1993b; Alves, 1998; Baena, 1982). 


\section{MATERIAL E MÉTODOS}

\subsection{Local}

O estudo foi realizado em uma microbacia do Município de Aracruz/ES, em área pertencente à Aracruz Celulose $S / A$, situada a uma distância aproximada de $6 \mathrm{~km}$ da cidade de Aracruz, $14 \mathrm{~km}$ da costa e $15 \mathrm{~km}$ da fábrica de celulose da empresa.

A microbacia tem ao todo 281,81 ha, sendo 189,14 hectares de plantios clonais de eucalipto e 90 ha cobertos por um fragmento de mata de tabuleiros, que se situa nas vertentes (grotas) dos canais de drenagem (Figura 1).

O clima da região é caracterizado por uma estação seca de dois a três meses e precipitação média anual de $1350 \mathrm{~mm}$. A temperatura média anual da é de $26^{\circ} \mathrm{C}$. Os solos predominantes são Podzólicos amarelos, bem drenados, com baixa fertilidade, sendo álicos e distróficos (Engel, 2002).

Segundo Engel (2002), a microbacia apresentava, durante este estudo, altos valores de índice de diversidade de Shannon-Wiener, chegando a $H^{\prime}=5,267$, um valor nunca registrado na literatura nacional e internacional. Ainda, era caracterizada por alta dinâmica, com taxas de renovação elevadas, indicando um regime de distúrbio, processo próprio de fragmentação do mosaico florestal. Segundo o mesmo autor, o sub-bosque do eucalipto era heterogêneo entre os talhões da microbacia, quanto à riqueza de espécies e diversidade. Mesmo assim, no geral, a riqueza dentro dos talhões era alta, 
sendo identificadas 125 espécies lenhosas de 51 famílias, numa densidade total de 1.017 indivíduos/ha. No entanto, a distribuição espacial dos indivíduos era bastante variável, com tendência à agregação próximo às bordas dos talhões, principalmente na faixa até $60 \mathrm{~m}$, junto àdivisa com a mata.

\subsection{Fatores estudados}

Os principais fatores do estudo foram:

a-) Ambiente da microbacia: mata, eucalipto e borda entre eles.

b-) Fase silvicultural da plantação de eucalipto.

d-) Sub-bosque do eucalipto.

Complementarmente, outros quatro fatores foram estudados:

a-) Tipo de armadilha: luminosa e de Malaise.

b-) Estação do ano.

c-) Temperatura.

d-) Precipitação.

O estudo de tipo de armadilha teve foco na representatividade, quantitativa e qualitativa, de cada uma, junto àcoleta total dos insetos.

A estação do ano foi considerada no modelo como uma medida de controle local já que ela pode interferir nos resultados, apesar de não fazer parte do estudo.

A avaliação da temperatura e precipitação objetivou verificar a existência de efeitos significativos sobre a entomofauna, que pudessem auxiliar na explicação de resultados com a análise dos fatores principais.

$O$ estudo foi realizado através do levantamento da entomofauna em seis locais, conforme apresentado na Tabela 1. O mapa do local é apresentado na Figura 2. 


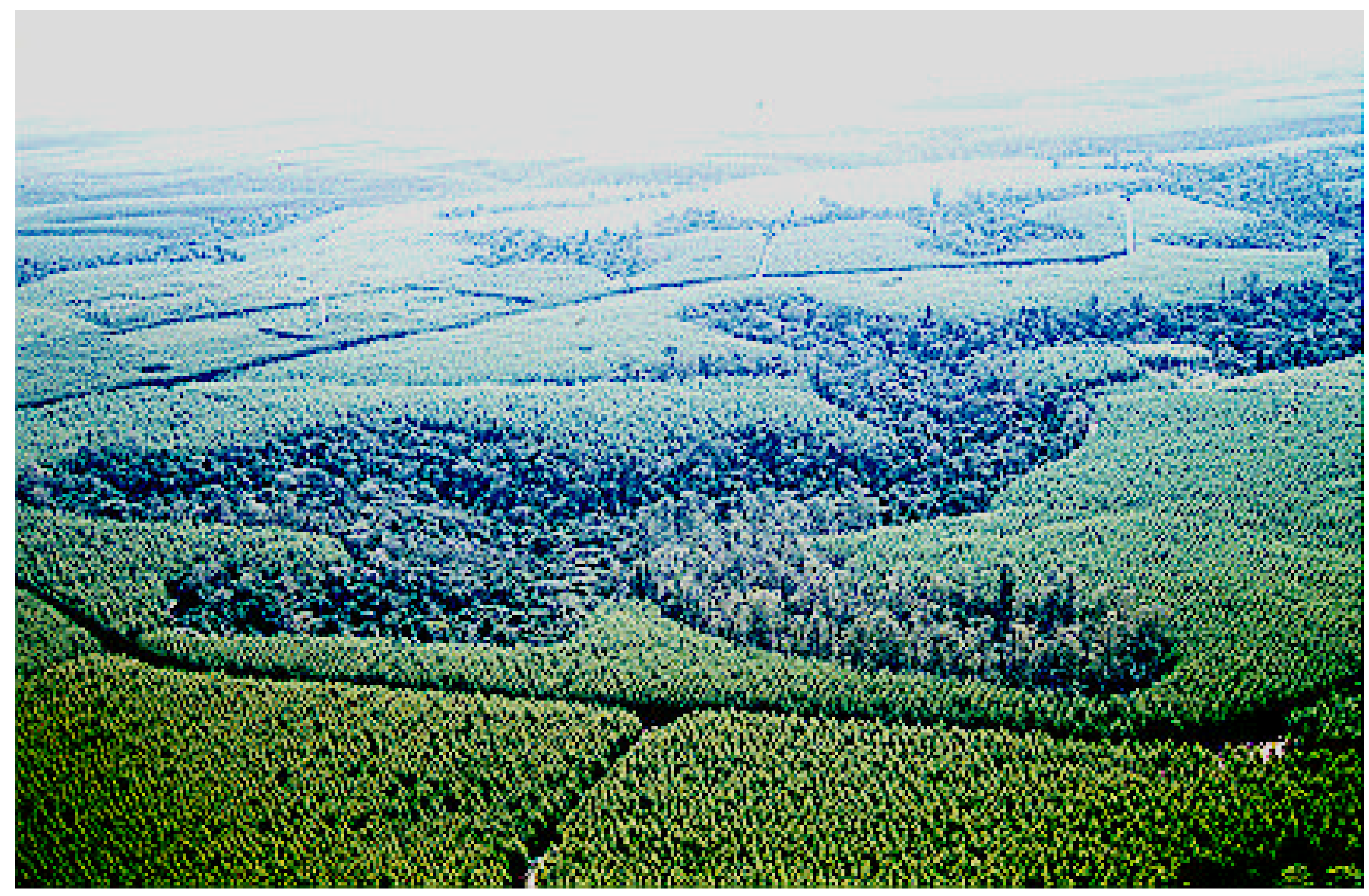

Figura 1 - Vista aérea da área da microbacia, onde o estudo foi realizado. 
No início do estudo, o local 6 estava com plantação do clone de código 2277 , enquanto que os outros três talhões, com o clone 1248. O material genético plantado, não foi um fator de estudo, nem utilizado para controle local.

O ambiente 1 representou o ecossistema natural característico da região. Os locais 1, 2 e 6 ficavam dentro da microbacia e os demais, em áreas adjacentes, por falta de condições de avaliar, na microbacia, o efeito da idade, como também para evitar interferência em outros estudos, neste caso, devido à eliminação do sub-bosque, além das operações normais de manejo de ervas infestantes da empresa.

Tabela 1. Locais do levantamento da entomofauna e fatores de estudo envolvidos.

\begin{tabular}{|c|c|c|c|c|}
\hline $\begin{array}{l}\text { Código } \\
\text { Local }\end{array}$ & $\begin{array}{l}\text { Código da } \\
\text { área/talhão }{ }^{1}\end{array}$ & Ambiente & Fase silvicultural $^{2}$ & Sub-bosque ${ }^{3}$ \\
\hline 1 & $007 / 05$ e 06 & Mata & $\begin{array}{l}1^{\circ} \text { Ciclo: } 7,8 \text { anos a } 9,8 \text { anos. } \\
2^{\circ} \text { Ciclo: do plantio a 4,6 anos }\end{array}$ & \\
\hline 2 & $007 / 06$ & Borda & $\begin{array}{l}1^{\circ} \text { Ciclo: } 7,8 \text { anos a } 9,7 \text { anos. } \\
2^{\circ} \text { Ciclo: do plantio a } 4,6 \text { anos }\end{array}$ & - \\
\hline 3 & $007 / 01$ & Eucalipto & $\begin{array}{l}1^{\circ} \text { Ciclo: } 7,8 \text { anos a } 9,7 \text { anos. } \\
2^{\circ} \text { Ciclo: do plantio a } 5,4 \text { anos }\end{array}$ & Com \\
\hline 4 & $007 / 01$ & Eucalipto & $\begin{array}{l}1^{\circ} \text { Ciclo: } 7,8 \text { anos a } 9,7 \text { anos. } \\
2^{\circ} \text { Ciclo: do plantio a } 5,4 \text { anos }\end{array}$ & Sem \\
\hline 5 & $006 / 04$ & Eucalipto & $\begin{array}{l}1^{\circ} \text { Ciclo: } 1,8 \text { anos a } 7,4 \text { anos } \\
\Rightarrow \text { desbaste } \Rightarrow 9,4 \text { anos }\end{array}$ & Com \\
\hline 6 & $004 / 01$ & Eucalipto & $\begin{array}{l}1^{\circ} \text { Ciclo: } 7,0 \text { anos a } 8,7 \text { anos. } \\
2^{\circ} \text { Ciclo: do plantio a } 4,7 \text { anos } \\
\Rightarrow \text { desbaste } \Rightarrow 5,6 \text { anos }\end{array}$ & Com \\
\hline
\end{tabular}

${ }^{1} \mathrm{O}$ primeiro número, de três dígitos, corresponde à "área de identificação", um conjunto de talhões, geralmente, em mesma fase silvicultural; o segundo número, de dois dígitos, ao número do talhão, dentro da área de identificação.

2 Para mata e borda, foram especificados ciclos/idades dos plantios de eucalipto adjacentes.

${ }^{3} \mathrm{Na}$ coluna, são especificados os locais de eucalipto mantidos "com" e "sem" sub-bosque, neste caso, com roçadas freqüentes, não usuais. No estudo do fator sub-bosque, as roçadas e as capinas manuais, ou químicas, também foram abordadas. 
Além desses dos 6 locais especificados na Tabela 1, oito coletas foram realizadas no talhão de eucalipto 124-02, na mata adjacente e na borda entre mata e eucalipto, da mesma região de Aracruz/ES.

O cronograma das operações silviculturais, associadas aos fatores estudados, é apresentado na Figura 3.

\subsection{Pontos de levantamento}

A entomofauna foi levantada em três pontos (repetições) em cada local (locais especificados na Tabela 1). Assim, o total de pontos, onde foram instaladas as armadilhas, foi de18, desconsiderando-se os pontos de coleta no levantamento extra no talhão 124-02.

$\mathrm{Na}$ mata, os pontos 1 e 2 foram instalados adjacentes ao talhão 00706 e o ponto 3, ao talhão 007-05.

Nos talhões de eucalipto, os pontos de levantamento ficaram a cerca de $80 \mathrm{~m}$ da mata. Na borda, na beira do carreador, que dividia eucalipto e mata, ao lado do eucalipto. Na mata, as armadilhas ficaram a uma distância entre 50 e 80 m do eucalipto. 


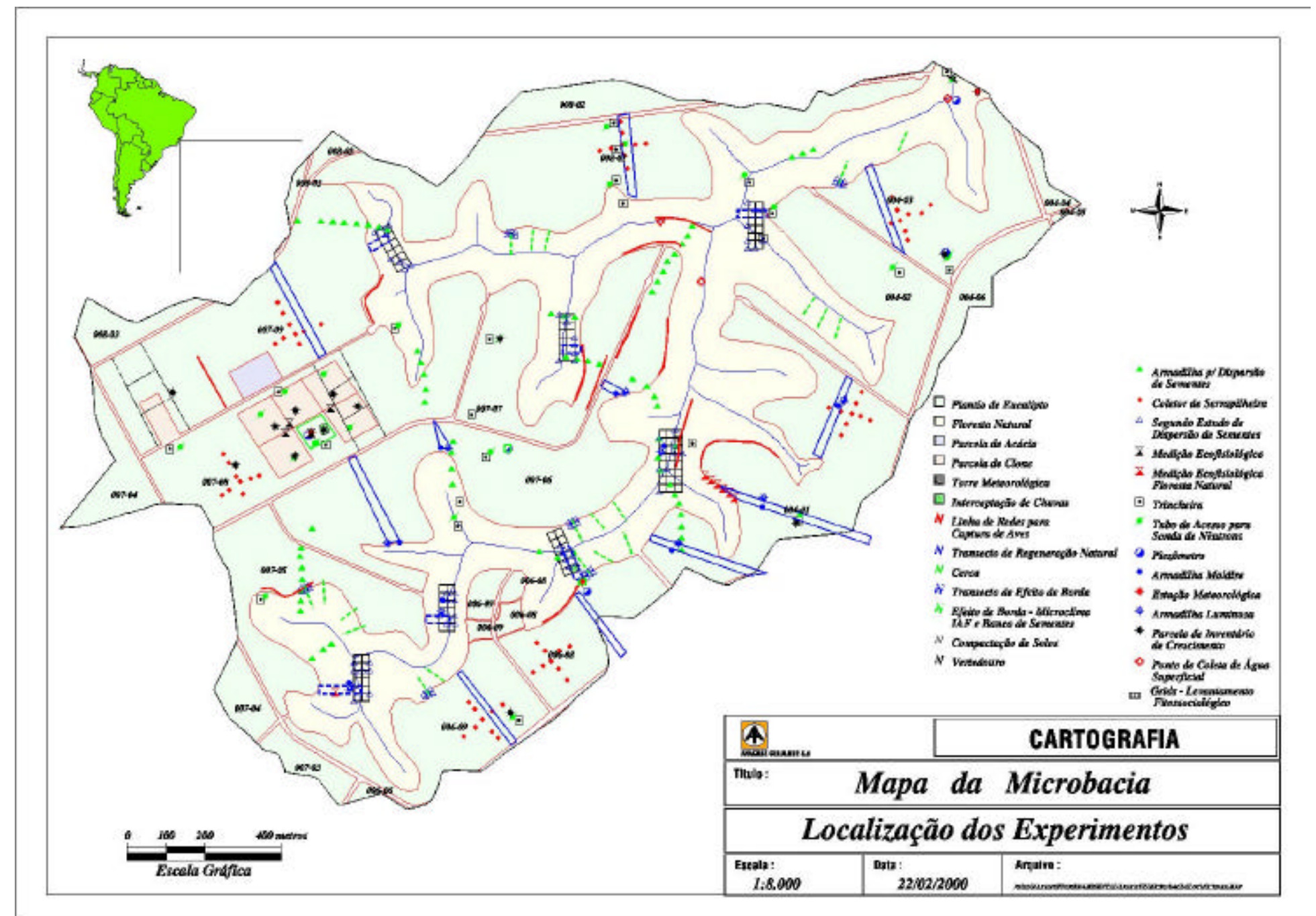

Figura 2 - Mapa da área da microbacia, com a identificação dos locais e pontos de levantamento da entomofauna, dentro de uma rede experimental mais abrangente. 


\begin{tabular}{|c|c|c|c|c|c|c|c|c|c|c|c|c|c|c|c|c|c|c|c|c|c|c|c|c|c|c|}
\hline ANO & \multicolumn{2}{|c|}{1994} & \multicolumn{12}{|c|}{1995} & \multicolumn{12}{|c|}{1996} \\
\hline MÊS & 11 & 12 & 01 & 02 & 03 & 04 & 05 & 06 & 07 & 08 & 09 & 10 & 11 & 12 & 01 & 02 & \begin{tabular}{|l|l|}
03 \\
\end{tabular} & 04 & 05 & 06 & 07 & 08 & 09 & 10 & 11 & $\sqrt{12}$ \\
\hline Coleta & 01 & 02 & 03 & 04 & 05 & 06 & 07 & 08 & 09 & 10 & 11 & 12 & 13 & 14 & 15 & 16 & 17 & 18 & 19 & 20 & 21 & 22 & 23 & 24 & 25 & 26 \\
\hline Período & \multicolumn{9}{|c|}{$9 \mathrm{~A}$} & \multicolumn{3}{|c|}{$3 A$} & \multicolumn{9}{|c|}{$9 B$} & \multicolumn{3}{|c|}{$3 B$} & \multicolumn{2}{|c|}{$9 \mathrm{C}$} \\
\hline
\end{tabular}

\begin{tabular}{|c|c|c|c|c|c|c|c|c|c|c|c|c|c|c|c|c|c|c|c|c|c|c|c|c|}
\hline ANO & \multicolumn{12}{|c|}{1997} & \multicolumn{12}{|c|}{1998} \\
\hline MÊS & 501 & 02 & 03 & 504 & $\sqrt{05}$ & $\sqrt{206}$ & 07 & 08 & 09 & $\checkmark 10$ & 11 & 12 & 01 & 02 & 03 & 04 & 05 & 06 & 07 & 08 & 09 & 10 & 11 & 12 \\
\hline Coleta & 27 & 28 & 29 & 30 & $>31$ & 32 & 33 & 34 & 35 & 36 & 37 & 38 & 39 & 40 & 41 & 42 & 43 & 44 & 45 & 46 & 47 & 48 & 49 & 50 \\
\hline Período & \multicolumn{7}{|c|}{$9 \mathrm{C}$} & \multicolumn{3}{|c|}{$3 C$} & \multicolumn{9}{|c|}{ 9D } & \multicolumn{3}{|c|}{$3 D$} & \multicolumn{2}{|c|}{$9 \mathrm{E}$} \\
\hline
\end{tabular}

\begin{tabular}{|c|c|c|c|c|c|c|c|c|c|c|c|c|c|c|c|c|c|c|c|c|c|c|c|c|}
\hline ANO & \multicolumn{12}{|c|}{1999} & \multicolumn{12}{|c|}{2000} \\
\hline MÊS & 01 & 02 & 03 & 04 & 05 & 06 & 07 & 08 & 09 & 10 & 11 & 12 & 801 & 02 & 03 & 04 & 05 & 06 & 07 & 08 & 09 & 10 & 11 & 12 \\
\hline Coleta & 51 & 52 & 53 & 54 & 55 & 56 & 57 & 58 & 59 & 60 & 61 & 62 & 63 & 64 & 65 & 66 & 67 & 68 & 69 & 70 & & & 71 & \\
\hline Período & \multicolumn{7}{|c|}{$9 \mathrm{E}$} & \multicolumn{3}{|c|}{$3 E$} & \multicolumn{9}{|c|}{$9 \mathrm{~F}$} & \multicolumn{3}{|c|}{$3 F$} & \multicolumn{2}{|c|}{$9 G$} \\
\hline
\end{tabular}

\begin{tabular}{|l|l|l|l|l|l|l|l|l|l|l|l|l|l|l|l|l|l|l|l|}
\hline ANO & \multicolumn{10}{|c|}{2001} & \multicolumn{1}{c|}{2002} \\
\hline MÊS & 01 & 02 & 03 & 04 & 05 & 06 & 07 & 08 & 09 & 10 & 11 & 12 & 01 & 02 & 03 & 04 & 05 & 06 & 07 \\
\hline Coleta & 72 & 73 & 74 & 75 & & 76 & 77 & 78 & & 79 & & 80 & 81 & 82 & 83 & 84 & 85 & 86 & 87 \\
\hline Período & \multicolumn{10}{|c|}{$9 \mathrm{G}$} & \multicolumn{10}{|c|}{$3 \mathrm{G}$} & \multicolumn{10}{|c|}{$9 \mathrm{H}$} \\
\hline
\end{tabular}

Corte/colheita, nos talhões referentes aos locais 1, 2, 3, 4 e 6 Plantio: 12/1996: local 6; 01/1997: 1 e 2; 02/1997: 3 e 4 Novo plantio: local 2 e no ponto de coleta 1 e 2 , do local 1.

Desbastes: 07/2000: local 5; 09 a 11/2001: 2, 6, ponto 2-3 local 1

\begin{tabular}{|l|l|}
\hline & Controle mecânico de ervas (talhão 004-01, local 6) \\
\cline { 1 - 1 } & $\begin{array}{l}\text { Controle químico de ervas (talhão 004-01, local 6) } \\
\text { Coleta Malaise passa de } 30 \text { para } 15 \text { dias de coleta } \\
\text { Coleta passa a ser somente com luminosa }\end{array}$ \\
\hline
\end{tabular}

Figura 3 - Cronograma das coletas e operações silviculturais associadas com os fatores estudados. 


\subsection{Levantamento da entomofauna}

Para proceder ao levantamento da entomofauna, foram utilizadas armadilhas luminosas e armadilhas de Malaise ilustradas nas Figuras 4 e 5, respectivamente. As armadilhas luminosas eram do modelo INTRAL AL (12 volts), providas de lâmpadas fluorescentes $(42 \mathrm{~cm}$ de comprimento por $3,5 \mathrm{~cm}$ de diâmetro), com luz negra, ligadas a uma bateria de 12 volts cada uma.

As armadilhas luminosas foram utilizadas durante todo o estudo, de novembro de 1994 a julho de 2001, totalizando 87 coletas mensais. A cada mês foi realizada uma noite de captura, na fase de lua nova. As armadilhas foram instaladas no final da tarde e o material foi recolhido no início da manhã do dia seguinte.

As armadilhas de Malaise foram utilizadas desde o início dos levantamentos, até a $50^{\mathrm{a}}$ coleta mensal, sendo que nesse período passaram por dois procedimentos de instalação, recolhimento dos insetos e tempo mensal de captura:

$1^{\circ}$ ) nas primeiras 30 coletas mensais, elas ficavam capturando insetos por todo o tempo, com recolhimento a cada 15 dias (14 a 16 dias);

$2^{\circ}$ ) da $31^{\text {a }}$ à $50^{\text {a }}$ coletas, as armadilhas ficavam coletando por apenas 15 dias (14 a 16); eram armadas no dia da instalação das armadilhas luminosas e o recolhimento dos insetos ocorria duas semanas depois.

\subsection{Identificação do material entomológico}

Os insetos coletados foram triados, contados e classificados através das respectivas ordens, famílias, gêneros e espécies. A identificação foi realizada com auxílio de uma coleção entomológica regional formada e mantida pela Aracruz Celulose S.A. 
A classificação em nível de ordem e de família foi possível em, praticamente, todos os casos, no entanto, em decorrência da impossibilidade de identificação do gênero e espécie de todos os indivíduos, dois procedimentos foram efetuados:

$1^{\circ}$-) classificação dos insetos coletados em morfoespécies codificadas e com exemplares conservados na coleção entomológica da região;

$2^{\circ}$-) estabelecimento de limites para consideração de certos grupos de insetos, onde até a classificação em morfoespécies seria impraticável - critérios apresentados na Tabela 2.

Além da identificação anterior, os indivíduos foram classificados nas seguintes guildas:

- polinizadores (POL);

- decompositores (DEC);

- hematófagos (HEM);

- parasitóides (PAR);

- parasitóides/polinizadores (PAR-POL);

- predadores (PRE);

- predadores/polinizadores (PRE-POL);

- parasitóides/predadores/polinizadores (PAR-PRE-POL);

- pragas potenciais do eucalipto (PIII);

- pragas secundárias do eucalipto (PII);

- pragas primárias do eucalipto (PI).

Os critérios de classificação em morfoespécies e guildas foram mantidos constantes durante todas as coletas. 


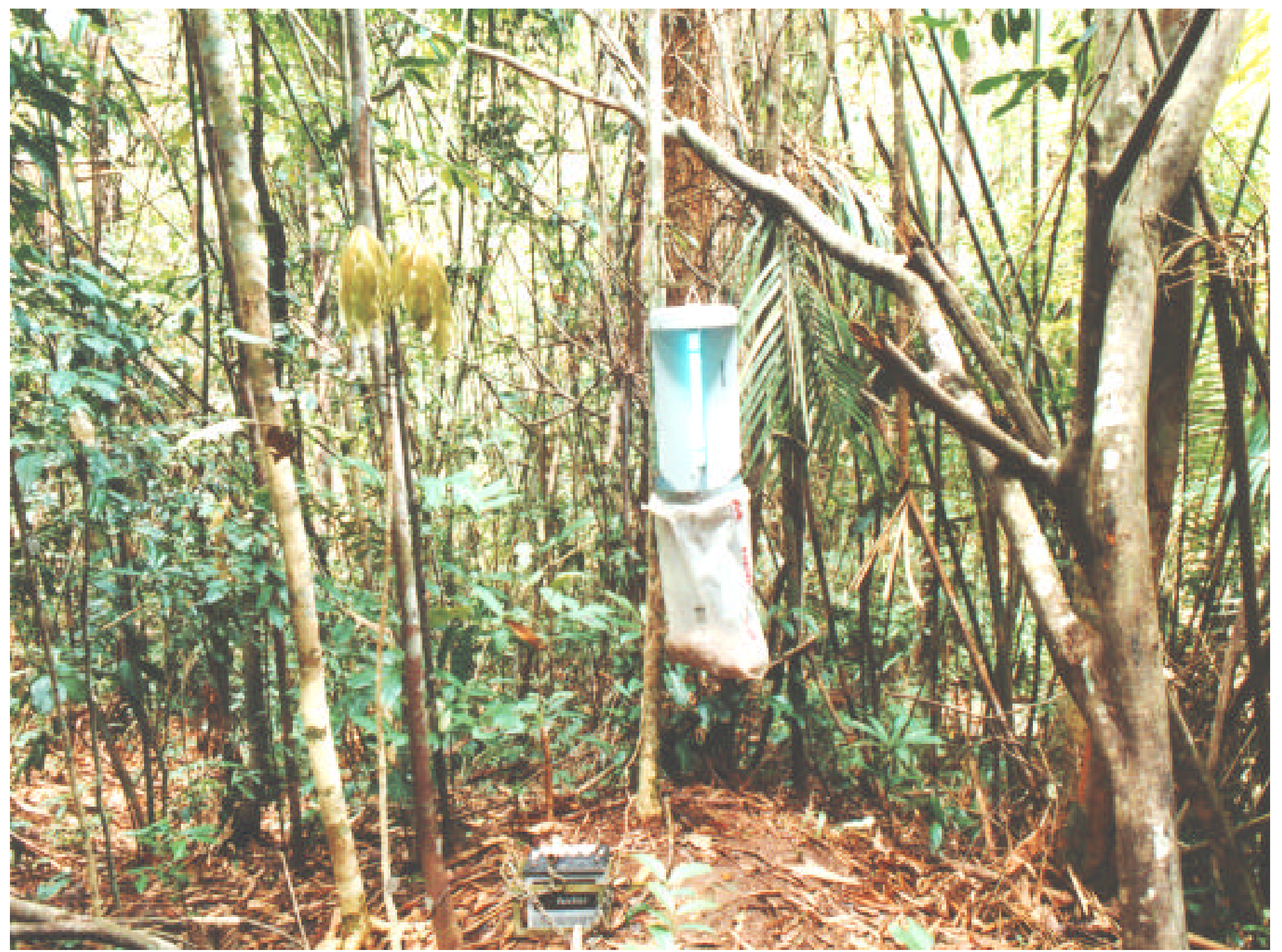

Figura 3 - Armadilha luminosa instalada na mata. 


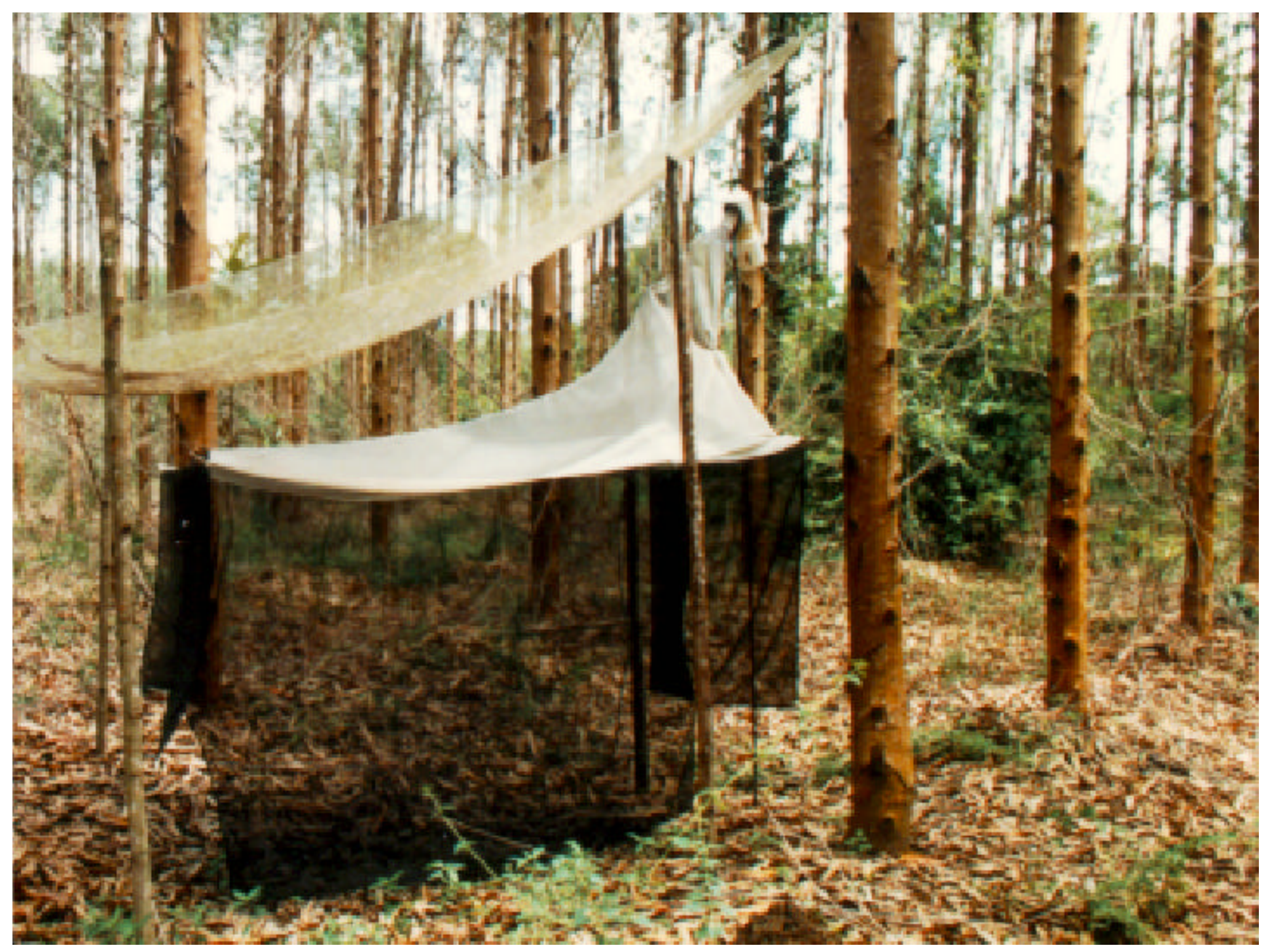

Figura 4 - Armadilha de Malaise instalada no eucalipto. 


\subsection{Período de levantamento da entomofauna}

Os levantamentos ocorreram de 4 de novembro de 1994 a 8 de julho de 2002, totalizando 93 meses e 87 coletas, fechando o ciclo da cultura do eucalipto.

As coletas extras, relacionadas ao talhão 124-02, ocorreram nos meses de julho e agosto de 1998.

Tabela 2. Níveis de identificação dos indivíduos de insetos e critérios para considerar-los no estudo.

\begin{tabular}{|c|c|c|}
\hline Ordem & Nível de identificação & Indivíduos considerados \\
\hline Blattodea & Família / morfoespécie & Todos \\
\hline Coleoptera & Família / morfoespécie & $\begin{array}{l}\text { Todos da família Scolytidae e } \\
\text { outros maiores que } 5 \mathrm{~mm}\end{array}$ \\
\hline Dermaptera & Família / morfoespécie & Todos \\
\hline \multirow[t]{2}{*}{ Diptera } & Família & $\begin{array}{l}\text { Todos das famílias Tachinidae } \\
\text { Bombyliidae }\end{array}$ \\
\hline & Morfoespécie & Todos da família Asilidae \\
\hline Hemiptera & Família / morfoespécie & Maiores que $5 \mathrm{~mm}$ \\
\hline Hymenoptera & Família / morfoespécie & Todos \\
\hline Isoptera & Família / morfoespécie & Todos \\
\hline Lepidoptera & Família / morfoespécie & Maiores que $10 \mathrm{~mm}$ \\
\hline Neuroptera & Família / morfoespécie & Todos \\
\hline Odonata & Família / morfoespécie & Todos \\
\hline Orthoptera & Família / morfoespécie & Todos \\
\hline Phasmatodea & Família / morfoespécie & Todos \\
\hline Mantódea & Família / morfoespécie & Todos \\
\hline
\end{tabular}




\subsection{Variáveis analisadas}

As variáveis estudadas foram:

- número de indivíduos, famílias e morfoespécies;

- constância das morfoespécies (C):

$C_{i}=N C_{i} \cdot 100 / N C$, onde:

$\mathrm{C}_{\mathrm{i}}=$ constância da morfoespécie $\mathrm{i}$;

$\mathrm{NC}_{\mathrm{i}}$ = número de coletas mensais com ocorrência da espécies i;

$\mathrm{NC}$ = número total de coletas;

- densidade relativa, ou freqüência (DR):

$\mathrm{DR}=\mathrm{N}_{\mathrm{i}} ; 100 / \mathrm{N}$, onde:

$\mathrm{N}_{\mathrm{i}}$ = número de indivíduos da morfoespécie $\mathrm{i}$;

$\mathrm{N}$ = número total de indivíduos;

- índice de diversidade de Shannon-Wiener, para morfoespécies $(\mathrm{H})$ :

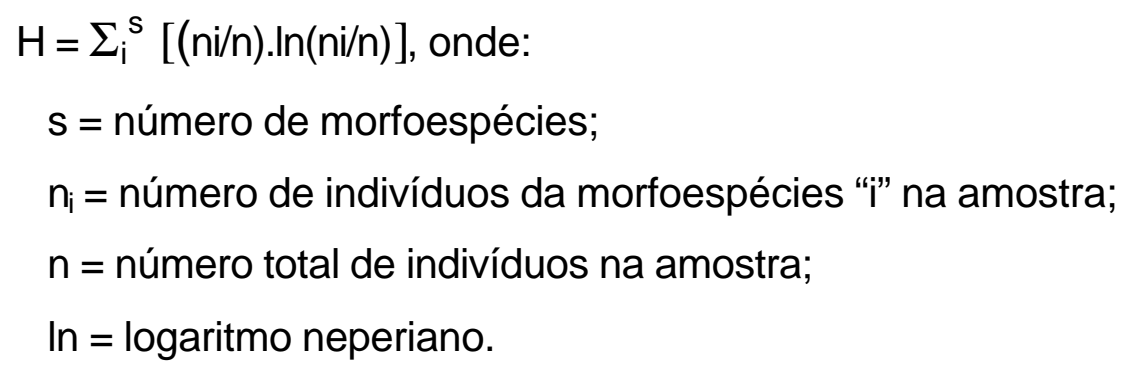

A constância foi calculada, considerando o número de coletas com presença da morfoespécie, sobre o número total de coletas do conjunto de dados selecionados.

A densidade relativa foi calculada em relação ao total de indivíduos coletados, para cada conjunto de dados em questão, considerando também os indivíduos que não foram classificados em morfoespécies.

Para cada nível dos fatores estudados, procurou-se estabelecer um padrão de comparação, através das variáveis especificadas acima. 


\subsection{Análise dos dados}

Para o estudo dos fatores, a análise estatística dos dados envolveu:

$1^{\circ}$ - Estatísticas descritivas: média e intervalo de confiança.

$2^{\circ}$ - Comparação de médias, através de método não-paramétrico (teste de Wilcoxon), calculado pelo procedimento NPAR1WAY do sistema SAS. O nível de significância adotado foi o de $5 \%$ de probabilidade.

Observações:

$1^{\mathrm{a}}$ - A abordagem não-paramétrica foi adotada em vista da freqüente ocorrência do valor zero, além do não atendimento a outras suposições estatísticas para aplicação da análise de variância e testes paramétricos de comparação de médias.

$2^{a}$ - Para médias entre os níveis dos fatores estudados, houve padronização da intensidade de amostragem e tipos de armadilhas, considerando 0 período de comparação, em relação aos procedimentos diferentes, de tempo mensal de captura da armadilha Malaise, alterado na $31^{\text {a }}$ coleta, e de tipos de armadilhas utilizados, com modificação a partir da $50^{a}$ coleta (item 3.4).

$3^{\text {a }}$ - Sempre que cabível, a estação do ano foi utilizada como controle local.

$3^{\circ}$ - Análise de regressão, calculada pelo procedimento REG do sistema SAS, com prévio estudo das suposições estatísticas que embasam sua aplicação. O estudo de suposições foi feito através do software SAS LAB e, se- adequada foi feita a transformação dos dados, selecionando-se a transformação mais adequada através da técnica de BOX-COX.

$4^{\circ}$ - Análise gráfica, incluindo a curva do coletor através do número acumulado de espécies (SAMWAYS, 1983). 


\subsection{Etapas da análise}

A análise dos dados foi realizada em cinco etapas:

$1^{\mathrm{a}}$ - Análise geral.

$2^{\mathrm{a}-}$ Comparação das coletas entre armadilhas luminosas e de Malaise.

$3^{\mathrm{a}}$ - Comparação dos ambientes: mata, eucalipto e borda entre mata e eucalipto.

$4^{\mathrm{a}}$ - Avaliação do efeito da temperatura e precipitação.

$5^{\text {a }}$ - Efeitos da idade, ou fase silvicultural, do eucalipto.

$6^{a}$ - Presença de sub-bosque.

\subsubsection{Análise geral}

$\mathrm{Na}$ análise geral, todas as coletas foram empregadas, sem consideração de fatores de estudo ou de métodos utilizados na coleta. Houve uma caracterização geral da entomofauna coletada, com base nas variáveis definidas para a análise (item 3.8) e nos níveis de identificação e de classificação dos indivíduos. Grupos de insetos mais representativos da coleta geral foram selecionados.

\subsubsection{Armadilhas luminosas e de Malaise}

Comparações quantitativas e qualitativas, dos dois tipos de armadilhas foram realizadas, com isto, foi estabelecida a contribuição de cada tipo para representar as variáveis e padrões estudados.

A comparação dos dois tipos de armadilhas foi realizada com todos os dados até a coleta mensal 50, a partir da qual apenas a armadilha luminosa foi utilizada. Nos contrastes onde poderia haver influência do corte dos plantios da 
microbacia e talhões adjacentes, os dados foram considerados até antes dele ocorrer, ou seja, até a $21^{\text {a }}$ coleta.

\subsubsection{Mata, borda e eucalipto}

As comparações, entre mata, eucalipto e borda, foram realizadas com os dados das coletas antes do corte na região da microbacia (até a coleta 21).

O número de insetos e o índice de diversidade foram aplicados a toda a comunidade de insetos de cada ambiente e também a grupos específicos, considerando guildas ou níveis de identificação, visando identificar os mais sensíveis às mudanças no ambiente.

Como na comparação das armadilhas, houve padronização na intensidade de amostragem.

\subsubsection{Temperatura e precipitação}

Os efeitos da temperatura e precipitação foram avaliados sobre 0 número de insetos, número de morfoespécies e índice de diversidade, através de análise de regressão linear múltipla.

\subsubsection{Fase silvicultural}

$\mathrm{Na}$ análise envolvendo os quatro primeiros anos de levantamento, foram utilizados os dados provenientes dos dois tipos de armadilhas e, quando além desse período, apenas as armadilhas luminosas foram consideradas. 


\subsubsection{Sub-bosque}

A avaliação do efeito da presença e ausência de sub-bosque sobre a comunidade de insetos foi realizada com os locais 3 e 4 (Tabela 1), no talhão 007-01. Os pontos de levantamento sem sub-bosque (local 4) foram instalados no centro de faixas de aproximadamente $150 \mathrm{~m}$, dentro do talhão, mantidas sem sub-bosque por meio de roçadas freqüentes.

A análise restringiu-se à primeiras 21 coletas, antes do corte. 


\section{RESULTADOS E DISCUSSÃO}

\subsection{Resultado geral das coletas}

O resultado das coletas, em número de indivíduos de insetos por ordem, família, gênero, espécie e morfoespécie, encontra-se na Tabela 3.

Tabela 3. Número de indivíduos de insetos, identificados em diferentes níveis.

\begin{tabular}{lrrrrr}
\hline \multicolumn{1}{c}{ Ordem } & Total & Família & Morfoespécie & Gênero & Espécie \\
\hline Blattodea & 683 & 683 & 683 & 4 & 3 \\
Coleoptera & 41.853 & 41.852 & 41.853 & 17.282 & 12.722 \\
Dermaptera & 14 & 14 & 14 & 1 & 1 \\
Diptera & 5.520 & 5.520 & 1.145 & 81 & 1 \\
Hemiptera & 5.908 & 5.907 & 5.908 & 221 & 83 \\
Hymenoptera & 74.404 & 74.403 & 12.885 & 1118 & 403 \\
Isoptera & 7.013 & 7.013 & 3.936 & 3 & 0 \\
Lepidoptera & 88.101 & 88.101 & 88.095 & 58.037 & 48.800 \\
Mantodea & 605 & 605 & 605 & 132 & 79 \\
Megaloptera & 5 & 5 & 5 & 5 & 0 \\
Neuroptera & 397 & 394 & 397 & 42 & 0 \\
Odonata & 90 & 89 & 90 & 0 & 0 \\
Orthoptera & 960 & 951 & 960 & 111 & 94 \\
Phasmatodea & 49 & 48 & 49 & 0 & 0 \\
Thysanoptera & 3 & 3 & 3 & 0 & 0 \\
\hline Total & 225.605 & 225.588 & 156.628 & 77.037 & 62.186 \\
\hline
\end{tabular}

Apesar da coleta envolver 15 ordens, apenas três delas - Coleoptera, Hymenoptera e Lepidoptera - correspondem a $90,58 \%$ de todos os insetos 
coletados (Figura 6). Evidentemente que esse número está relacionado com o desempenho dos dois tipos de armadilhas empregados nas coletas.

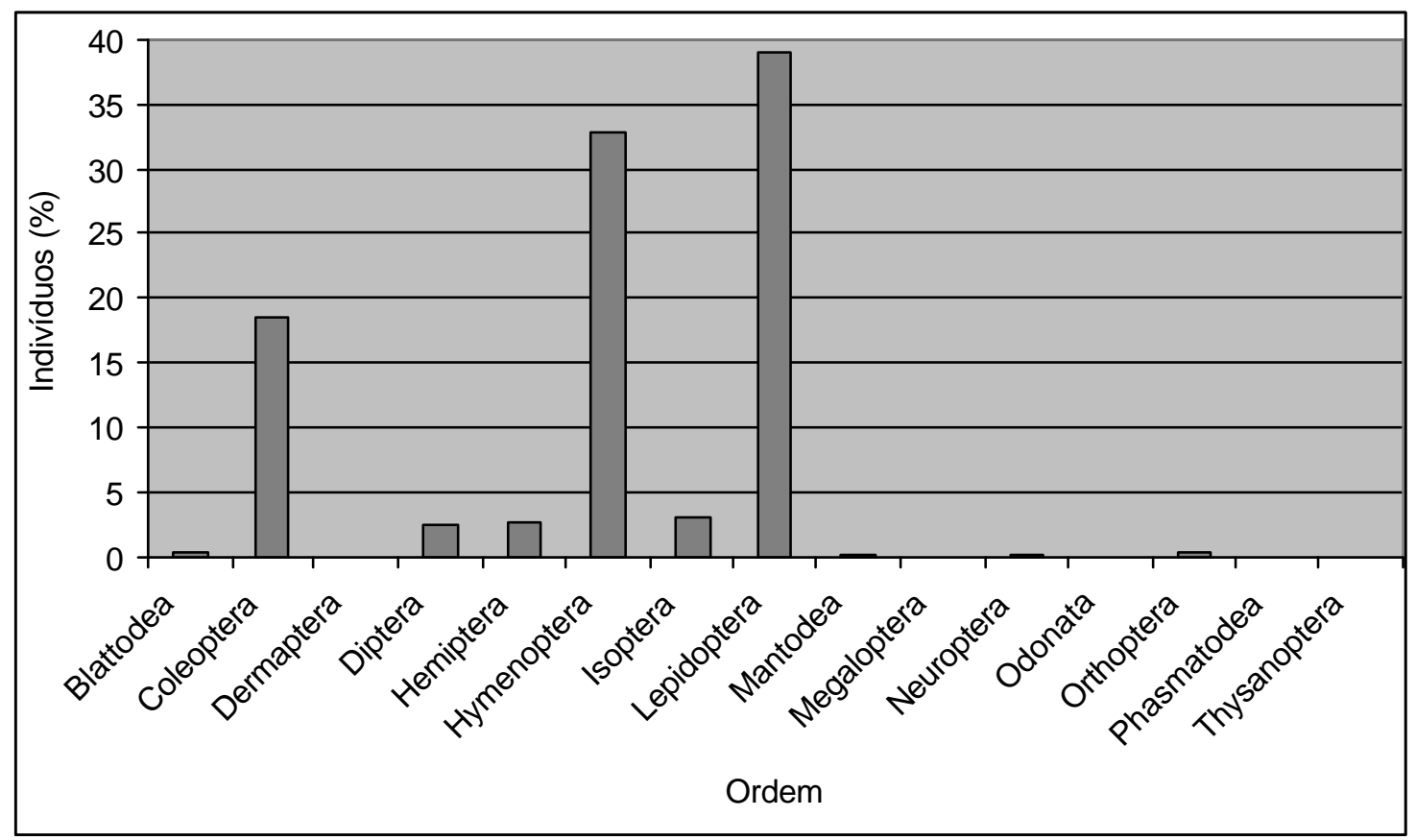

Figura 6 - Porcentagem de indivíduos por ordem.

Praticamente, todos os insetos foram classificados em famílias. Nas seis ordens mais abundantes, a separação em morfoespécies foi próxima a 100\% para Coleóptera, Lepidoptera e Hemiptera (Figura 7). Para Hymenoptera, uma das três ordens mais abundantes, foi possível apenas a classificação de $17,32 \%$ em morfoespécies o que, certamente, prejudicou as análises do grupo a esse nível, principalmente a análise do índice de diversidade. O mesmo ocorreu com Díptera, embora tenha sido bem menos abundante. Já Hemiptera, com abundância próxima à de Díptera, teve todos os indivíduos classificados em morfoespécies. 
O maior número de insetos com gênero e espécie identificados ocorreu em Lepidoptera, seguida de Coleoptera. Nas outras ordens a proporção de insetos identificados nesses níveis foi baixa (Figura 7).

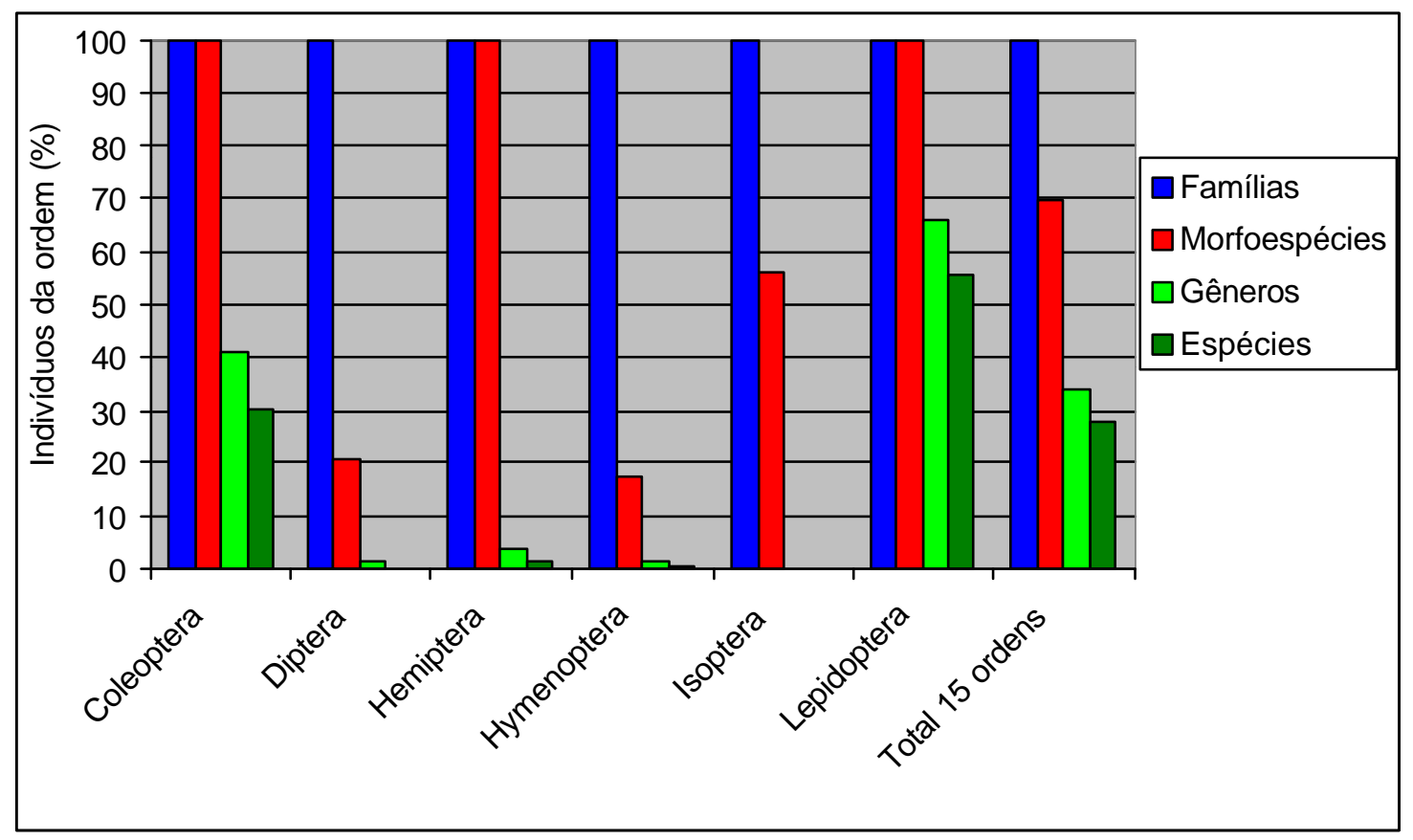

Figura 7-Porcentagem de indivíduos identificados em diferentes níveis, em cada uma das seis ordens mais abundantes.

O número total de morfoespécies identificadas no estudo foi de 4.457 (Tabela 4), sendo 4.327 distribuídas em 190 famílias e 130 sem identificação da família.

A ordem de maior número de morfoespécies, gêneros e espécies foi Lepidoptera, seguida da Coleoptera. Apenas em relação ao número de famílias houve uma inversão, passando Hymenoptera para o primeiro lugar e, na seqüência, Coleoptera e Lepidoptera (Figura 8).

A participação de Hymenoptera ficou prejudicada, no número de morfoespécies, gêneros e espécies, não pela sua baixa diversidade ou abundância, mas pela dificuldade de classificação nesses níveis (Figura 7), 
resultando em apenas $12,3 \%, 4,71 \% 1,54 \%$ de toda a coleta, respectivamente (Figura 8).

Tabela 4. Número de morfoespécies, famílias, gêneros e espécies identificados.

\begin{tabular}{lcccc}
\hline Ordem & Famílias & Morfoespécies & Gêneros & Espécies \\
\hline Blattodea & 3 & 65 & 1 & 1 \\
Coleoptera & 40 & 1.356 & 118 & 91 \\
Dermaptera & 2 & 7 & 1 & 1 \\
Diptera & 11 & 85 & 3 & 1 \\
Hemiptera & 30 & 309 & 18 & 13 \\
Hymenoptera & 47 & 548 & 21 & 7 \\
Isoptera & 3 & 34 & 2 & 0 \\
Lepidoptera & 33 & 1.741 & 271 & 336 \\
Mantodea & 2 & 28 & 4 & 2 \\
Megaloptera & 1 & 2 & 1 & 0 \\
Neuroptera & 4 & 65 & 1 & 0 \\
Odonata & 4 & 45 & 0 & 0 \\
Orthoptera & 7 & 155 & 5 & 2 \\
Phasmatodea & 2 & 16 & 0 & 0 \\
Thysanoptera & 1 & 1 & 0 & 0 \\
\hline Total & 190 & 4.457 & 446 & 454 \\
\hline
\end{tabular}




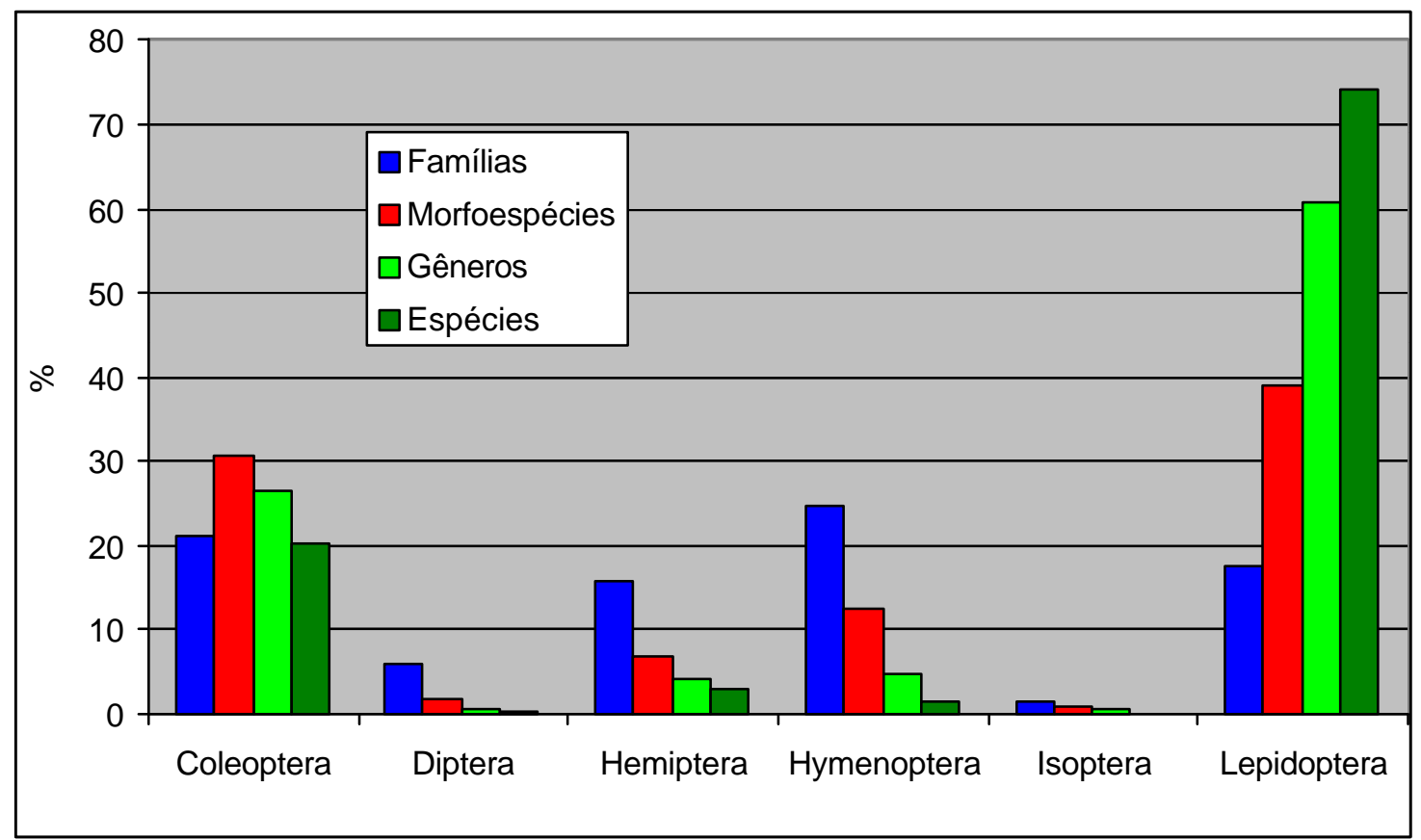

Figura 8 - Porcentagem de famílias, morfoespécies, gêneros e espécies, em cada uma das seis ordens mais abundantes, em relação ao total de cada nível de identificação.

Na Figura 9, o número acumulado de morfoespécies é apresentado a cada semestre de coleta. Embora as coletas tenham ocorrido por um longo período, de 93 meses, não existem evidências de que número de morfoespécies total tenha se estabilizado. Assim, seria necessário que os levantamentos continuassem além dos 93 meses, para comprovar uma amostragem com número estável de morfoespécies.

A não estabilidade do número de morfoespécies é um primeiro indício de grande diversidade e dinâmica populacional, nos ambientes estudados.

O número de novas espécies, a cada coleta, está relacionado com uma baixa constância da maioria das espécies (Figura 10). Cerca de $72 \%$ das morfoespécies apresentam constância de até $5 \%$; assim, é natural que tenham surgido muitas novas a cada coleta, durante todo o período de estudo. 


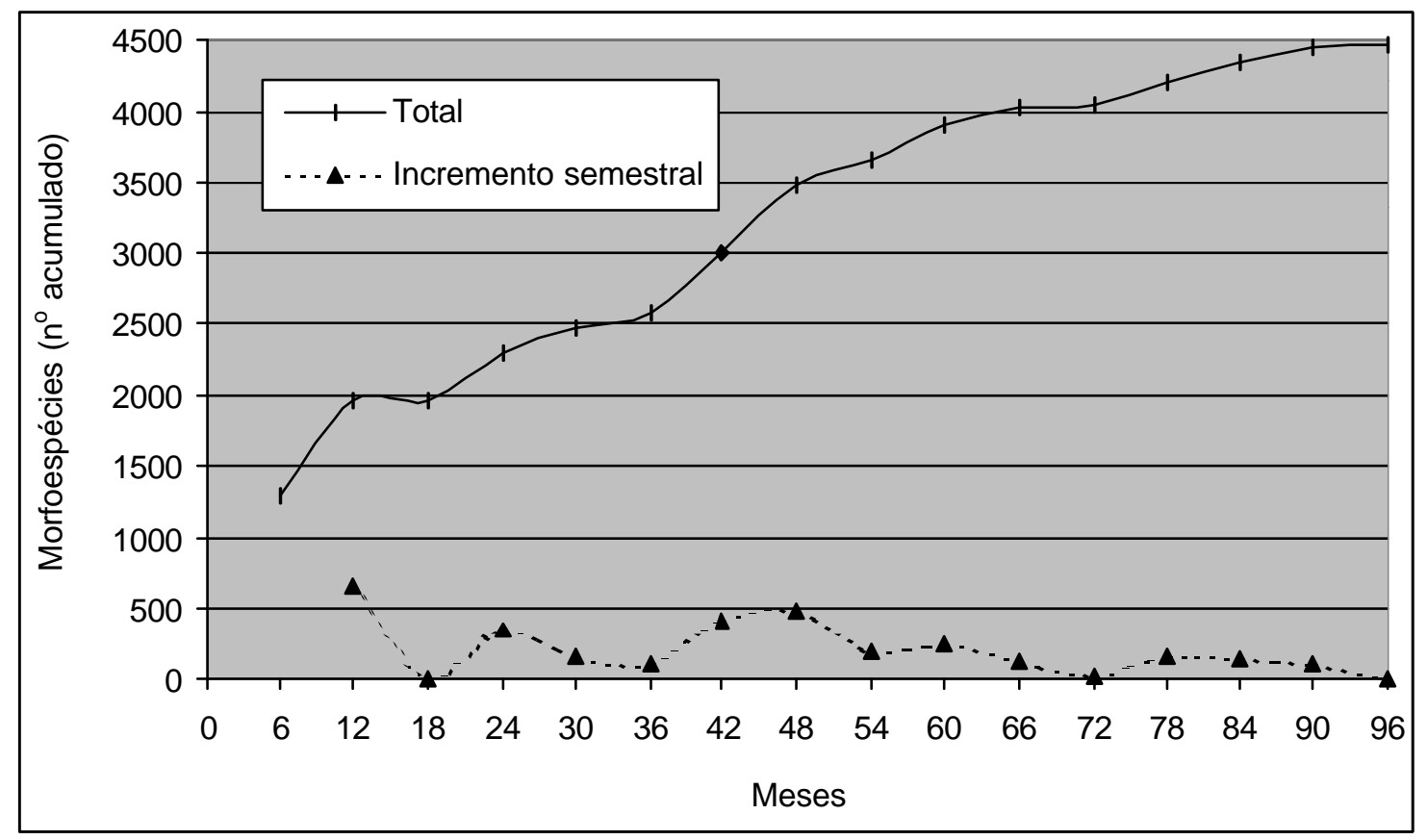

Figura 9 - Porcentagem de morfoespécies classificadas, ao longo do período de coleta (Curva do Coletor).

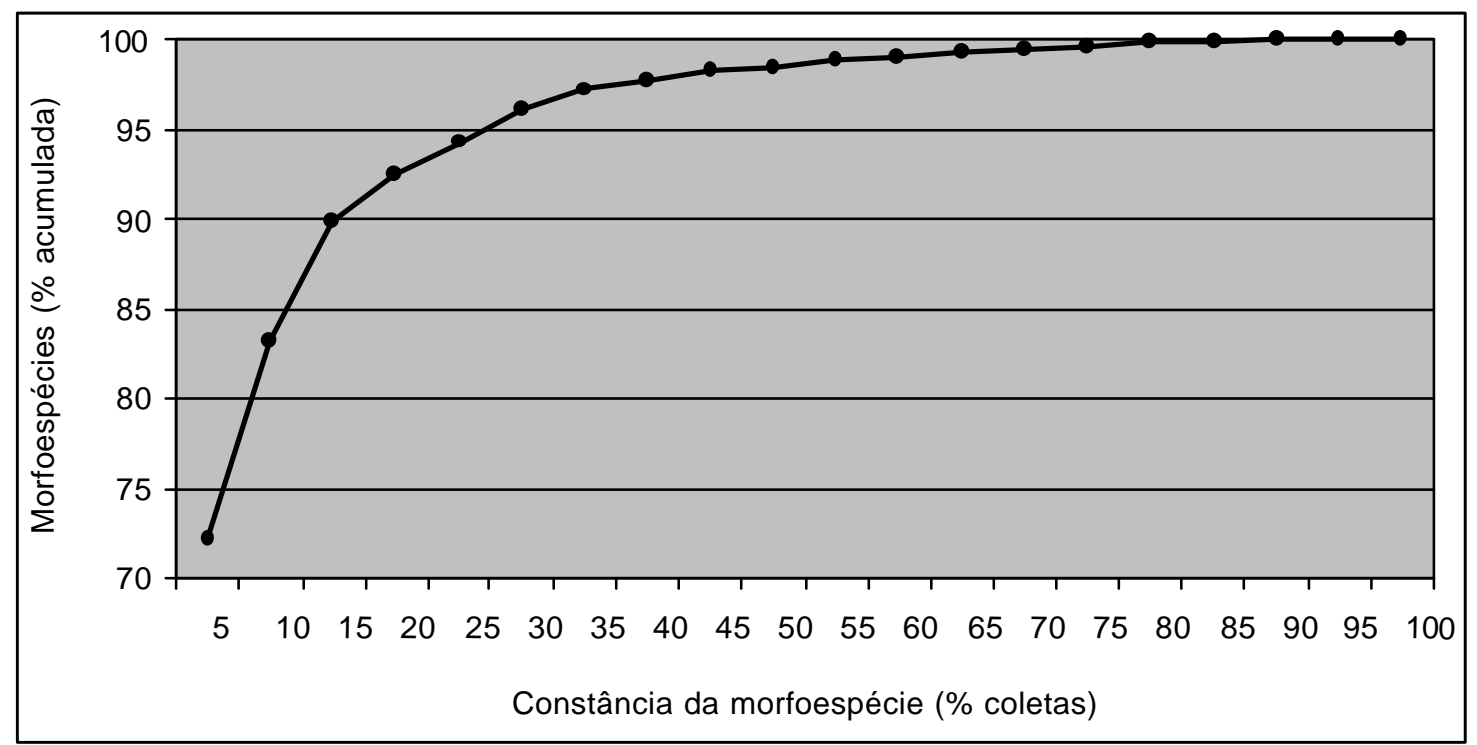

Figura 10 - Porcentagem de morfoespécies por classe de constância (total: 87 coletas).

O fato das coletas terem sido realizadas com dois tipos de armadilha, Luminosa e de Malaise, apenas até a $50^{\mathrm{a}}$ coleta mensal e a partir desse ponto, 
apenas com o primeiro tipo, tem impacto sobre a distribuição da constância, já que os dois tipos de armadilhas têm desempenho diferente para captura de várias espécies. Essas diferenças são abordadas no item seguinte (4.2).

Associada à baixa constância da maioria das morfoespécies, observase também baixa densidade relativa das mesmas, sendo que mais de $98 \%$ delas representam valores menores até $0,25 \%$ (Figura 11).

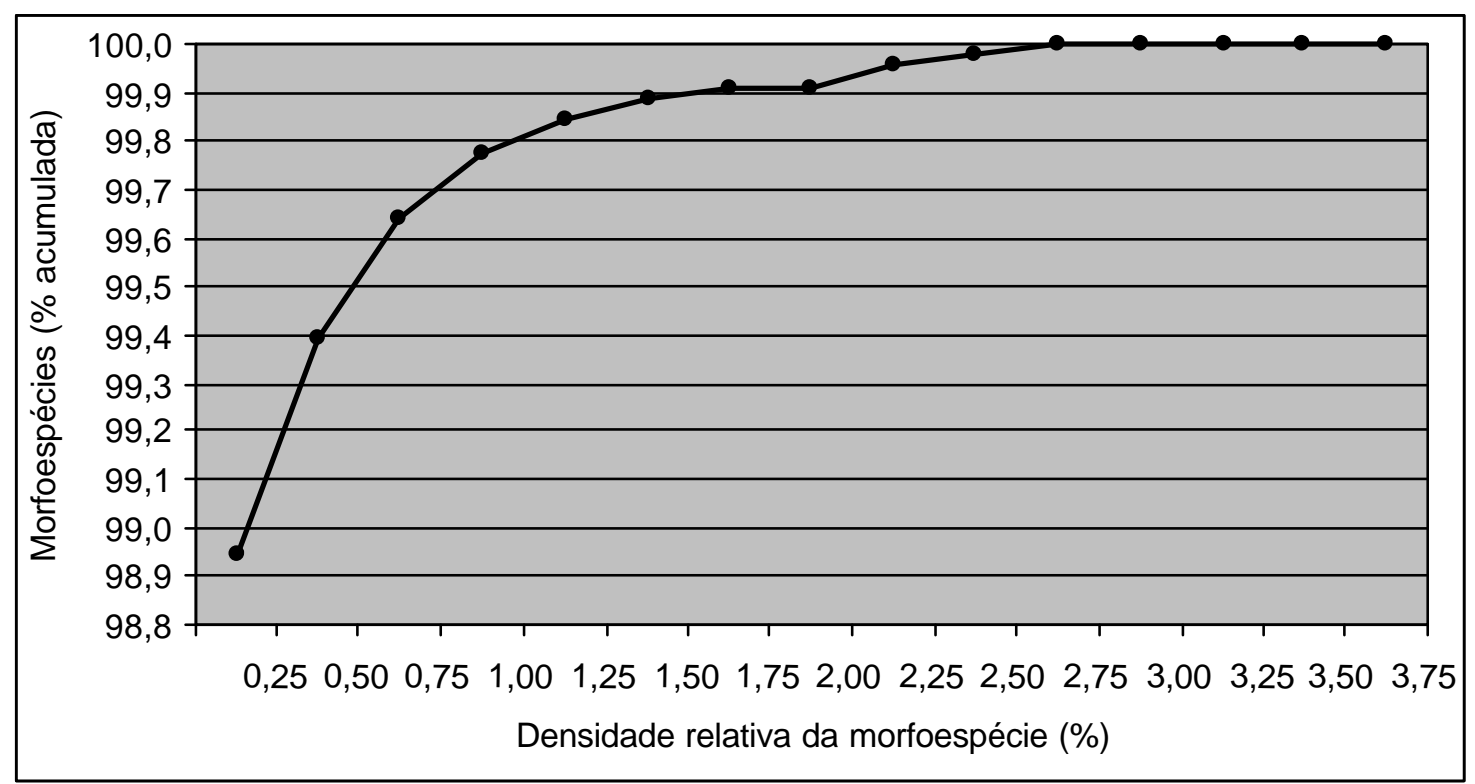

Figura 11 - Porcentagem de morfoespécies por classe de densidade relativa. 


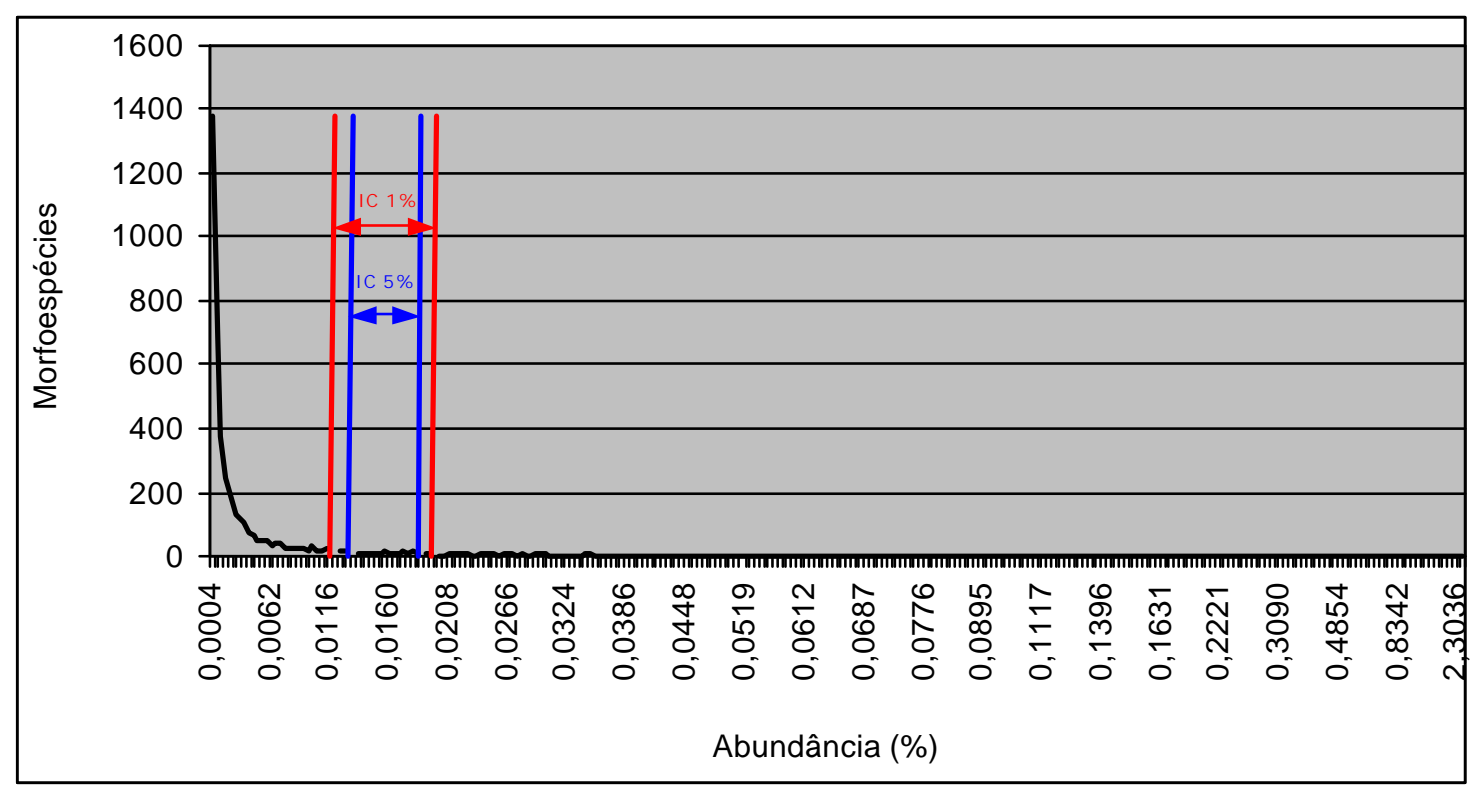

Figura 12 - Número de morfoespécies por valor de densidade relativa, destacando os limites dos intervalos de confiança da média, para $5 \%$ e $1 \%$ de probabilidade.

De todos os insetos coletados (225.605), apenas 32,4\% (55.204) foram classificados quanto a guilda, enquanto que, das morfoespécies estabelecidas (4.457), apenas 18,6\% (830) foram classificadas nesse aspecto.

Algumas famílias compreendem espécies atuando com diferentes funções ecológicas, principalmente da ordem Hymenoptera, como as famílias Vespidae (predadores e polinizadores) e Sphecidae (predadores, parasitas e polinizadores), e Coleoptera, como as famílias Scarabaeidae (fitófagos e decompositores) e Coccinelidae (predadores, fitófagos e fungívoros).

Destaca-se a maior proporção de inimigos naturais, em relação æ̀ pragas do eucalipto (Figura 13). Essa diferença fica ainda maior se for considerado, ao invés do número de indivíduos, o número de morfoespécies (Figura 15). 


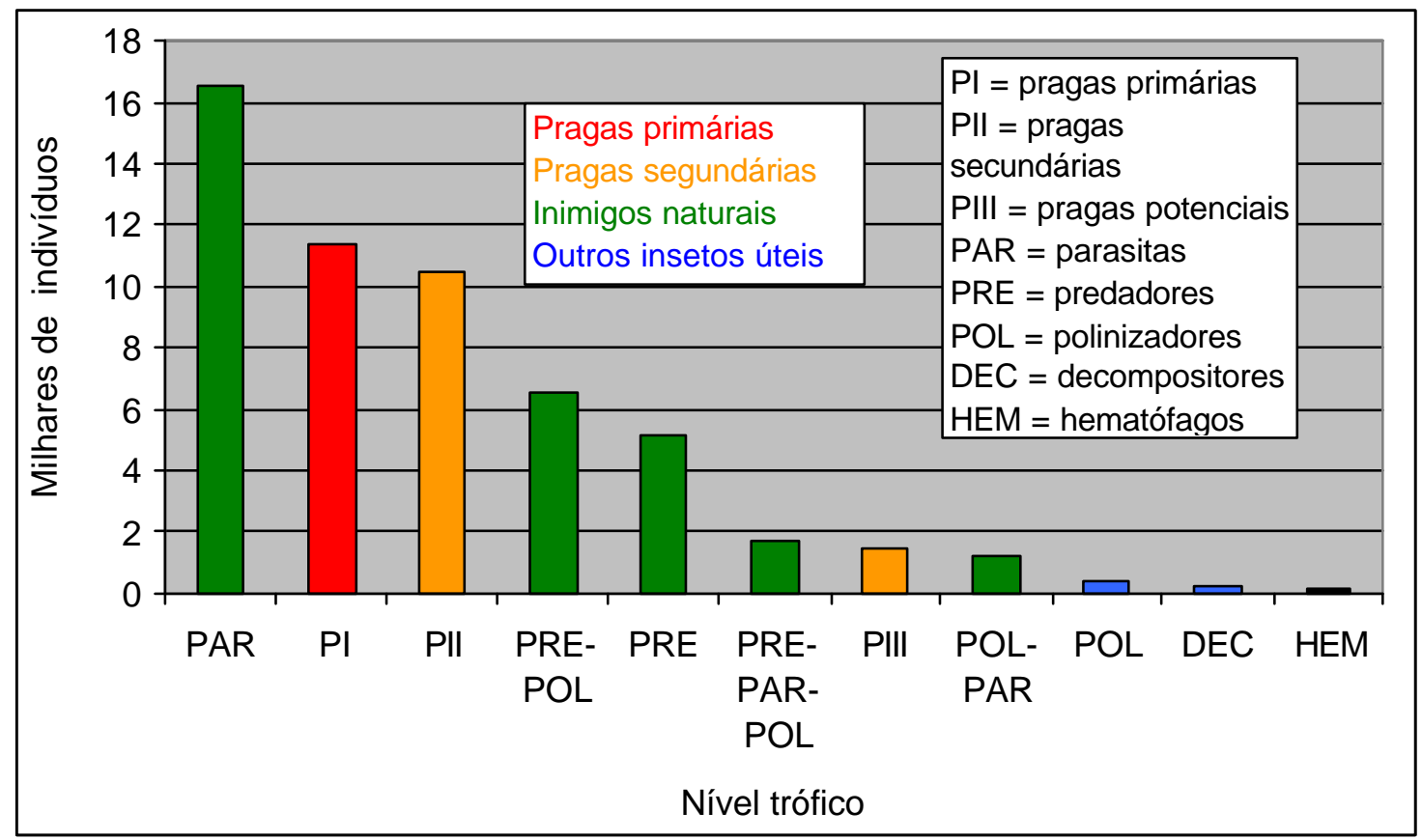

Figura 13 - Número de indivíduos classificados em diversas guildas.

Considerando o número de insetos, verifica-se uma maior abundância para pragas primárias (PI), em relação à secundárias (PII e PIII), ato natural, pois a condição de praga é inerente a uma densidade populacional mais elevada. No entanto, as pragas secundárias formam um grupo com maior riqueza de espécies, aumentando as possibilidades de adaptação à cultura, o que pode elevar espécies à categoria de praga (Figura 16). Para contrapor esta tendência, mantendo em baixa densidade populacional as pragas potenciais, é fundamental um ambiente diversificado.

A maior densidade de indivíduos pragas está na ordem Lepidoptera, seguida de Coleoptera, enquanto que a de inimigos naturais está na Hymenoptera, seguida de Diptera (Figura 14). O mesmo ocorre com o número de morfoespécies (Figura 16). 


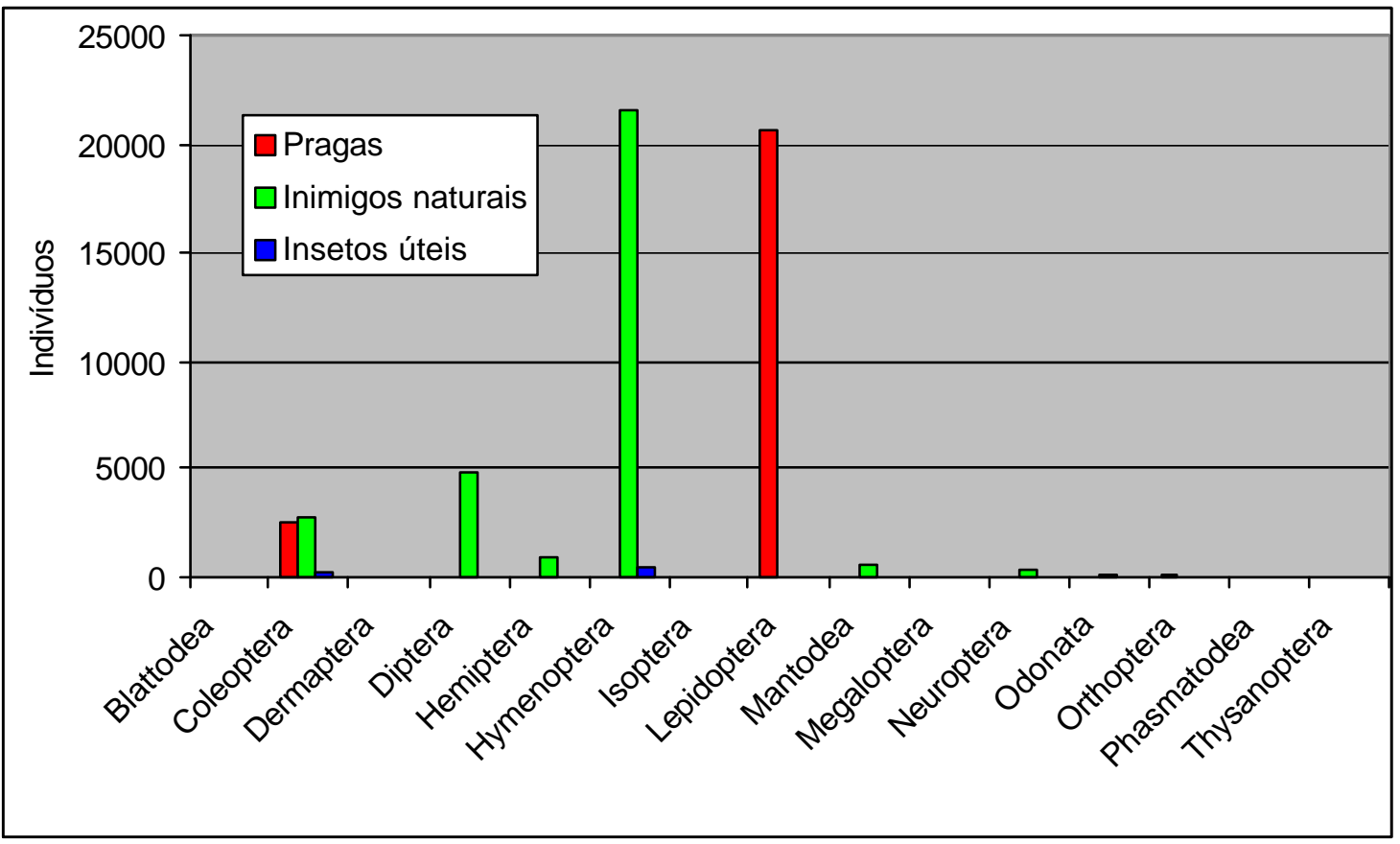

Figura 14 - Número de indivíduos classificados em pragas, inimigos naturais e polinizadores/decompositores, por ordem.

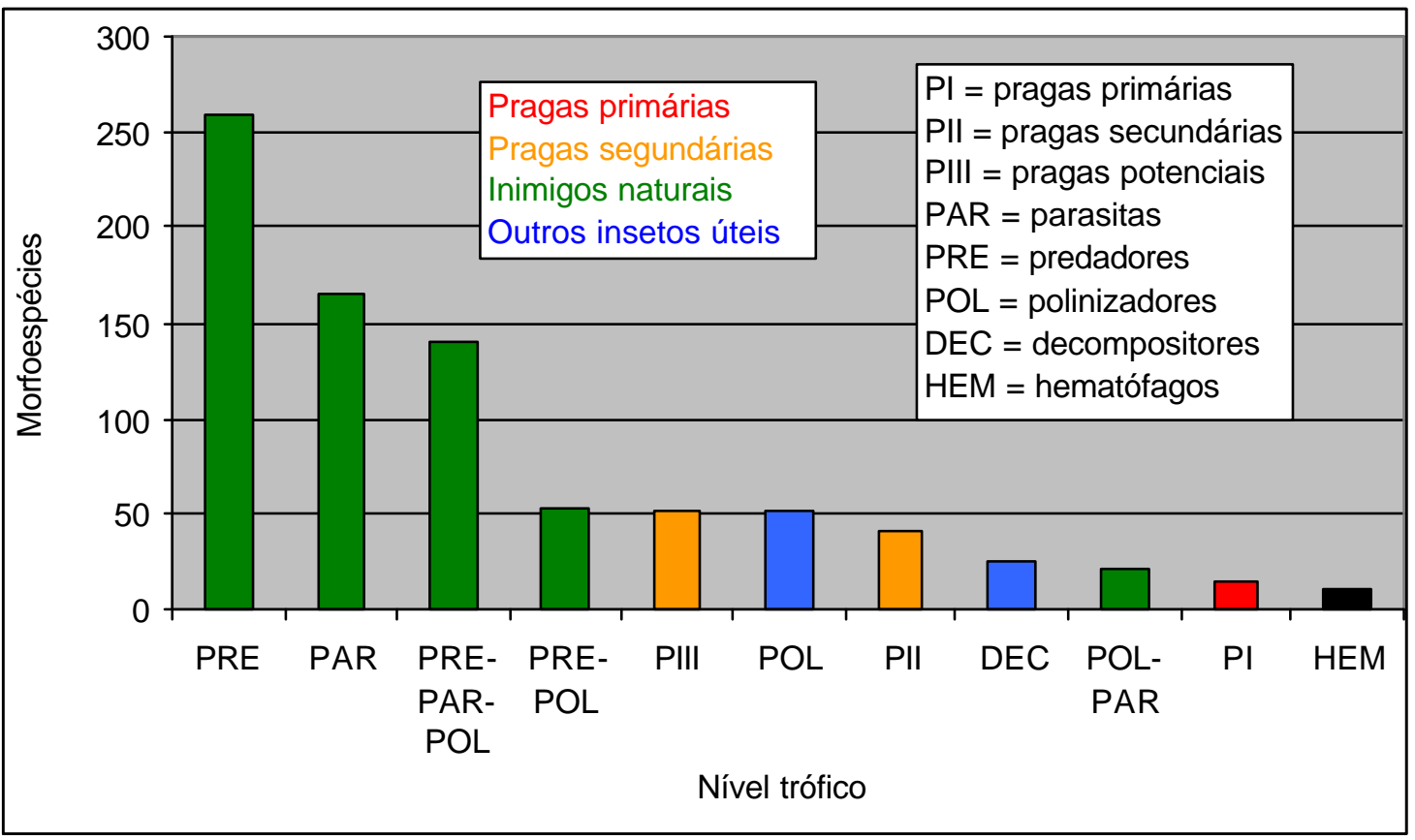

Figura 15 - Número de morfoespécies classificadas em diversas guildas. 


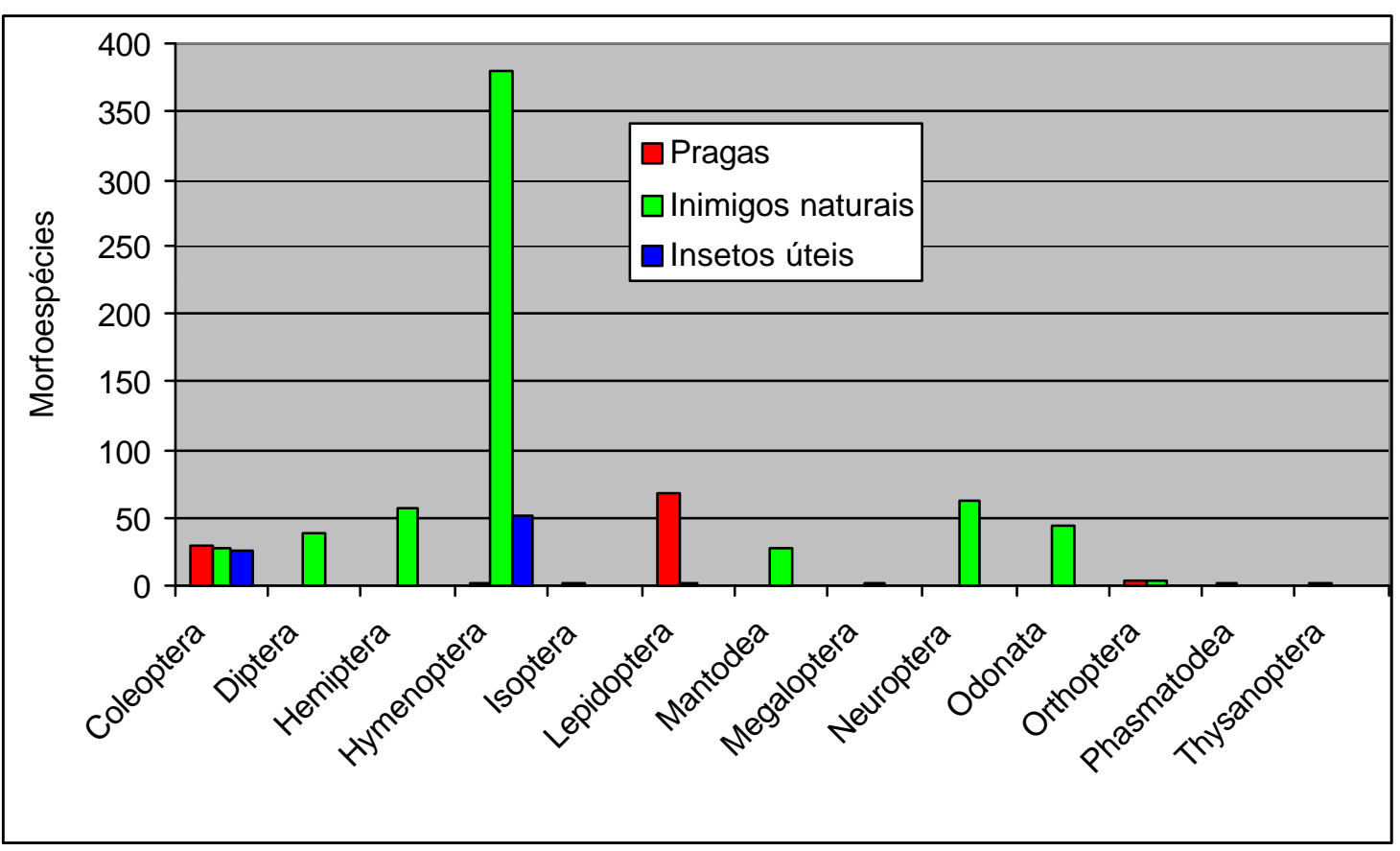

Figura 16 - Número de morfoespécies classificadas em pragas, inimigos naturais e polinizadores/decompositores, por ordem.

O índice de diversidade para morfoespécies, obtido no final das coletas, foi de 5,87 (Figura 17). Esta variável mostrou-se muito mais rapidamente estabilizada ao longo do estudo, do que o número de morfoespécies. Com seis meses de coleta, o índice de diversidade chegou a $74,70 \%$ do valor final $(5,87)$, enquanto que o número de morfoespécies representava apenas $28,99 \%$ do valor total (4.457 morfoespécies, Figura 9). Com 24 e 36 meses o chegou a 92,50\% e 95,57\% do valor final, enquanto que o índice equivalente para número de morfoespécies só foi obtido nas coletas 66 e 84, respectivamente.

Quatro ordens foram selecionadas para análise da correlação entre o índice de diversidade obtido com cada uma e o resultante de toda a coleta (15 ordens). A seleção foi resultado das três ordens mais abundantes Lepidoptera, Coleoptera e Hymenoptera -, com as três de maior classificação 
dos indivíduos em morfoespécies (100\%) - Lepidoptera, Coleoptera e Hemiptera - (Figura 7).

Dentre as quatro ordens, aquela que mais representou a diversidade total foi Lepidoptera (Tabela 5), seguida de Coleoptera. A representatividade de Hymenoptera foi prejudicada, certamente, pelo baixo nível de classificação dos indivíduos em morfoespécies (Figura 7) e Hemiptera devido à sua pequena abundância (Figura 6) e riqueza de espécies (Figura 8), em relação à duas ordens mais representativas.

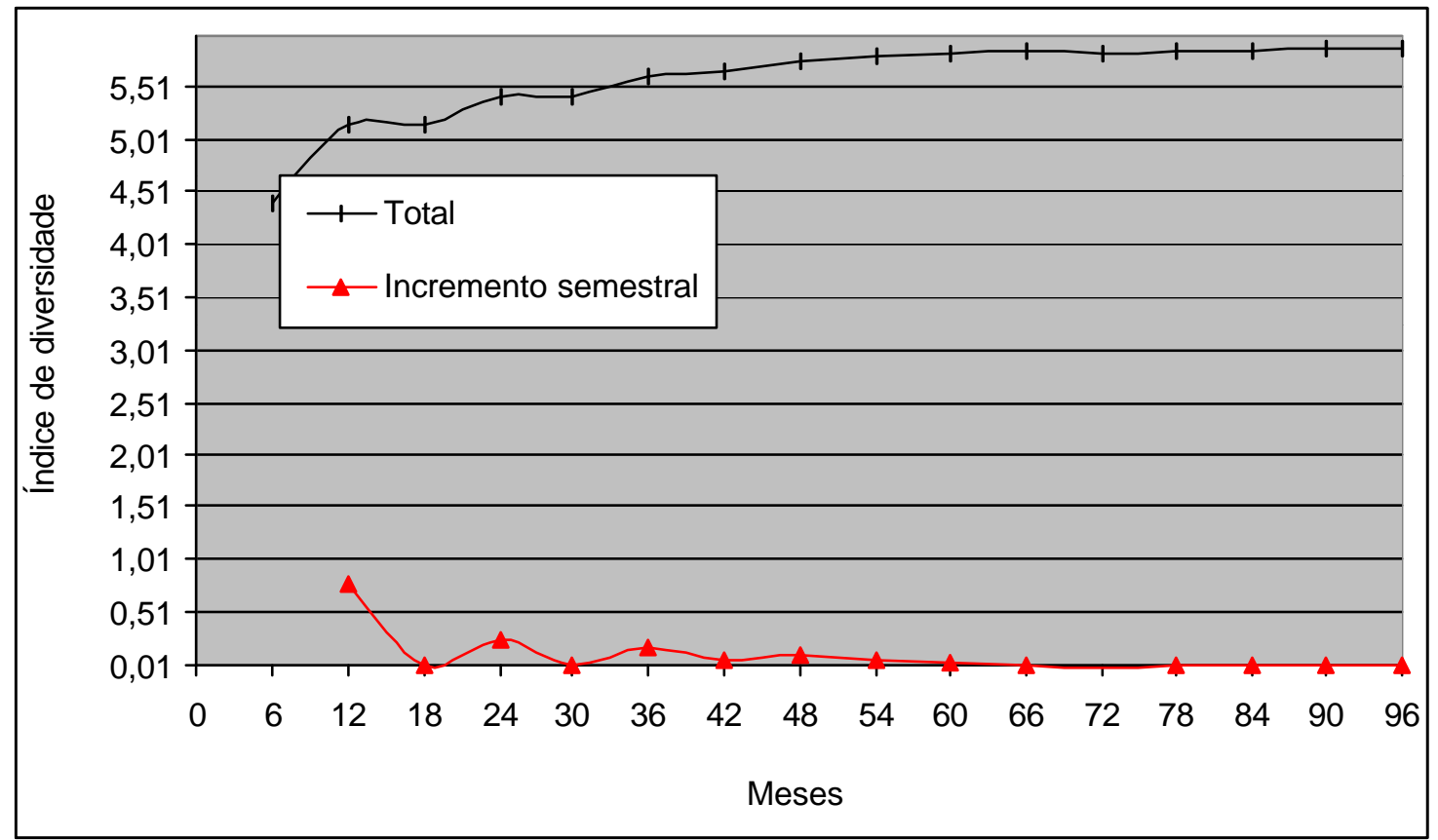

Figura 17 - Índice de diversidade acumulado, para morfoespécies, ao longo do período de coleta.

As análises de regressão mostraram que apenas Lepidoptera mostrou correlação altamente significativa, em todas as estações do ano, com a diversidade total. O melhor resultado foi obtido para a estação de outono, com coeficiente de determinação $\left(r^{2}\right)$ igual a 0,8510 , ou seja, explica cerca de $85 \%$ dos dados do índice de diversidade total. 
No geral, a representatividade de Lepidoptera foi bem superior à de Coleoptera (Figura 18), com exceção da estação primavera, onde $r^{2}$ com Coleoptera foi de 0,55 (Tabela 5). O desempenho da ordem Lepidoptera certamente está relacionado à sua maior riqueza de espécies e abundância. Isso é válido, mesmo considerando que as análises de índice de diversidade foram realizadas, com os dados até a coleta mensal de número 50 , a partir da qual, somente as armadilhas luminosas foram utilizadas, pois com os dois tipos de armadilhas o número de morfoespécies e de indivíduos de Lepidoptera também foram superiores.

Tabela 5. Resultados da análise de regressão entre o índice de diversidade de toda a coleta (15 ordens) e o de cada uma das quatro ordens, selecionadas em função de sua abundância e da porcentagem de indivíduos classificados em morfoespécies.

\begin{tabular}{|c|c|c|c|c|c|c|}
\hline \multirow{2}{*}{ Ordem } & \multirow{2}{*}{ Estações } & \multicolumn{3}{|c|}{ Número de observações } & \multirow{2}{*}{ Prob $>f$} & \multirow{2}{*}{$R^{2}$} \\
\hline & & Coletas & Repetições & Total & & \\
\hline \multirow{5}{*}{ Lepidoptera } & - & 49 & 3 & 147 & 0,0001 & 0,6710 \\
\hline & Primavera & 12 & 3 & 36 & 0,0001 & 0,5126 \\
\hline & Verão & 14 & 3 & 42 & 0,0001 & 0,6628 \\
\hline & Outono & 11 & 3 & 33 & 0,0001 & 0,8510 \\
\hline & Inverno & 12 & 3 & 36 & 0,0001 & 0,7139 \\
\hline \multirow{5}{*}{ Coleoptera } & - & 49 & 3 & 147 & 0,0059 & 0,0511 \\
\hline & Primavera & 12 & 3 & 36 & 0,0001 & 0,5545 \\
\hline & Verão & 14 & 3 & 42 & 0,0266 & 0,1170 \\
\hline & Outono & 11 & 3 & 33 & 0,0148 & 0,1770 \\
\hline & Inverno & 12 & 3 & 36 & 0,3766 & 0,0231 \\
\hline \multirow{5}{*}{ Hymenoptera } & - & 49 & 3 & 147 & 0,0597 & 0,0242 \\
\hline & Primavera & 12 & 3 & 36 & 0,7961 & 0,0020 \\
\hline & Verão & 14 & 3 & 42 & 0,8567 & 0,0008 \\
\hline & Outono & 11 & 3 & 33 & 0,7137 & 0,0044 \\
\hline & Inverno & 12 & 3 & 36 & 0,0308 & 0,1299 \\
\hline \multirow{5}{*}{ Hemiptera } & - & 49 & 3 & 147 & 0,0709 & 0,0223 \\
\hline & Primavera & 12 & 3 & 36 & 0,3025 & 0,0312 \\
\hline & Verão & 14 & 3 & 42 & 0,0691 & 0,0802 \\
\hline & Outono & 11 & 3 & 33 & 0,3713 & 0,0259 \\
\hline & Inverno & 12 & 3 & 36 & 0,5100 & 0,0129 \\
\hline
\end{tabular}




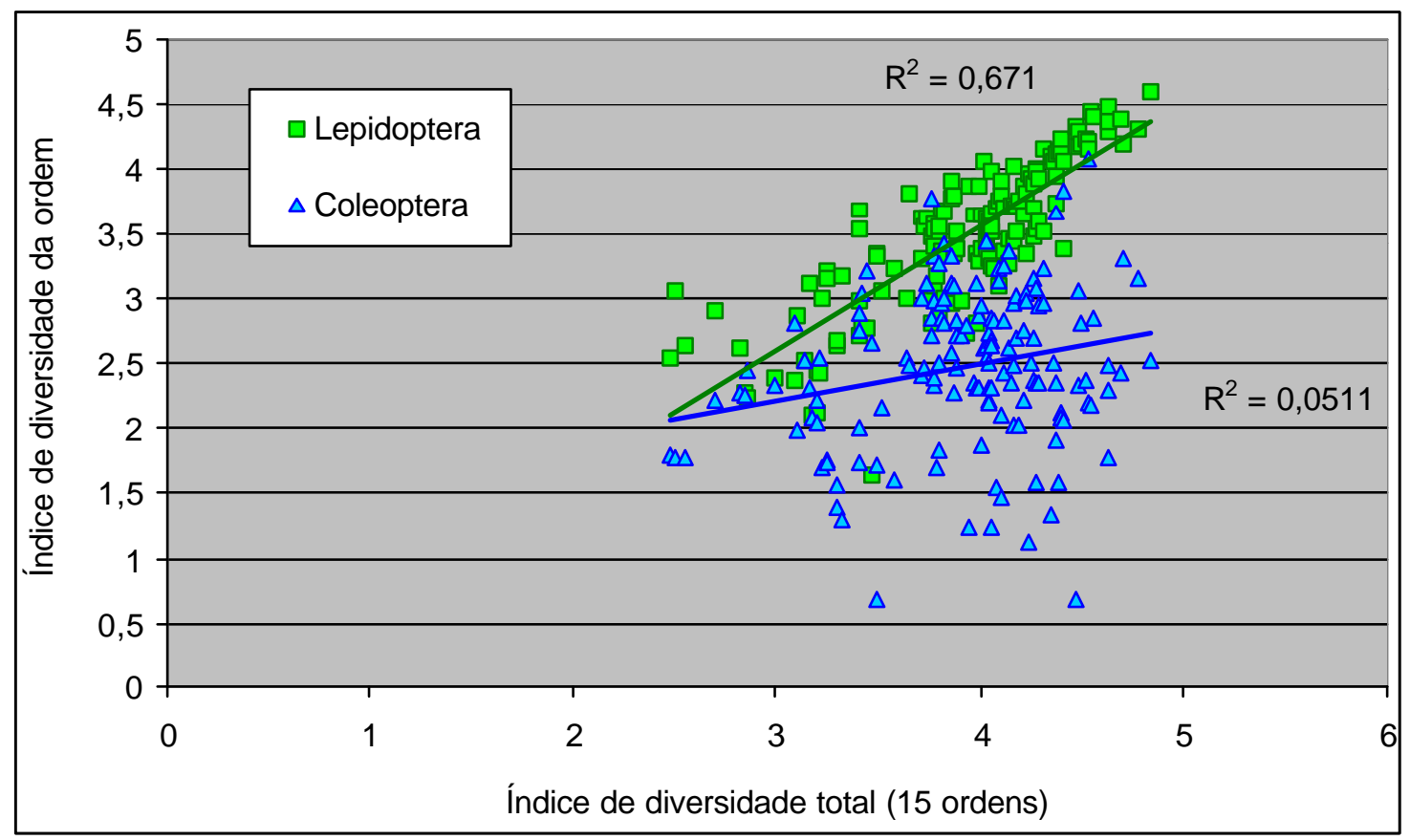

Figura 18 - Correlação entre o índice de diversidade, para morfoespécies, de Lepidoptera e Coleoptera, com o índice de diversidade total das 15 ordens.

A correlação, do índice de diversidade de cada uma das famílias de Lepidoptera e Coleoptera com o índice de diversidade total, permitiu selecionar aquelas de maior importância, para cada estação do ano. Foram 16 famílias selecionadas, sendo 10 de Lepidoptera e 6 de Coleoptera.

A Tabela 6 apresenta as famílias com efeito significativo, para cada estação do ano e o resultado da correlação entre o índice de diversidade dessas famílias com a diversidade total. Os resultados mostram que as informações das 16 famílias permitem explicar de 58 a $84 \%$ os valores de índice de diversidade total, dependendo da estação. Cabe ressaltar, que todas as 16 famílias não são importantes em todas as estações. Por exemplo, a melhor estimativa com $\mathrm{r}^{2}$ de 0,84 , na primavera, é obtida utilizando-se apenas seis famílias, três de cada uma das duas ordens (Figura 19). 
Tabela 6. Resultados da análise de regressão entre o índice de diversidade de toda a coleta (15 ordens) e o resultante de famílias selecionadas das ordens Lepidoptera e coleoptera.

\begin{tabular}{|c|c|c|c|c|c|}
\hline \multirow{2}{*}{ Estação } & \multirow{2}{*}{ Famílias } & \multicolumn{2}{|c|}{ Lepidoptera } & \multicolumn{2}{|c|}{ Lepidoptera + Coleoptera } \\
\hline & & $P>F$ & $\mathrm{R}^{2}$ & $\mathrm{P}>\mathrm{F}$ & $R^{2}$ \\
\hline Primavera & $\begin{array}{l}\text { Coleoptera: } \\
\text { Cerambycidae } \\
\text { Chrysomelidae } \\
\text { Scarabaeidae } \\
\text { Lepidoptera: } \\
\text { Geometridae } \\
\text { Notodontidae } \\
\text { Sphingidae }\end{array}$ & 0,0006 & 0,2985 & 0,0001 & 0,8400 \\
\hline Verão & $\begin{array}{l}\text { Coleoptera: } \\
\text { Bostrichidae } \\
\text { Curculionidae } \\
\text { Scarabaeidae } \\
\text { Scolytidae } \\
\text { Lepidoptera: } \\
\text { Arctiidae } \\
\text { Eupterotidae } \\
\text { Lasiocampidae } \\
\text { Noctuidae } \\
\text { Pyralidae } \\
\text { Sphingidae }\end{array}$ & 0,0001 & 0,5445 & 0.0001 & 0,6727 \\
\hline Outono & $\begin{array}{l}\text { Lepidoptera: } \\
\text { Eupterotidae } \\
\text { Geometridae } \\
\text { Limacodidae } \\
\text { Noctuidae } \\
\text { Notodontidae }\end{array}$ & 0,0001 & 0,6579 & - & - \\
\hline Inverno & $\begin{array}{l}\text { Coleoptera: } \\
\text { Curculionidae } \\
\text { Lepidoptera: } \\
\text { Lasiocampidae } \\
\text { Noctuidae } \\
\text { Notodontidae } \\
\text { Saturniidae }\end{array}$ & 0,0001 & 0,5680 & 0,0001 & 0,5828 \\
\hline
\end{tabular}




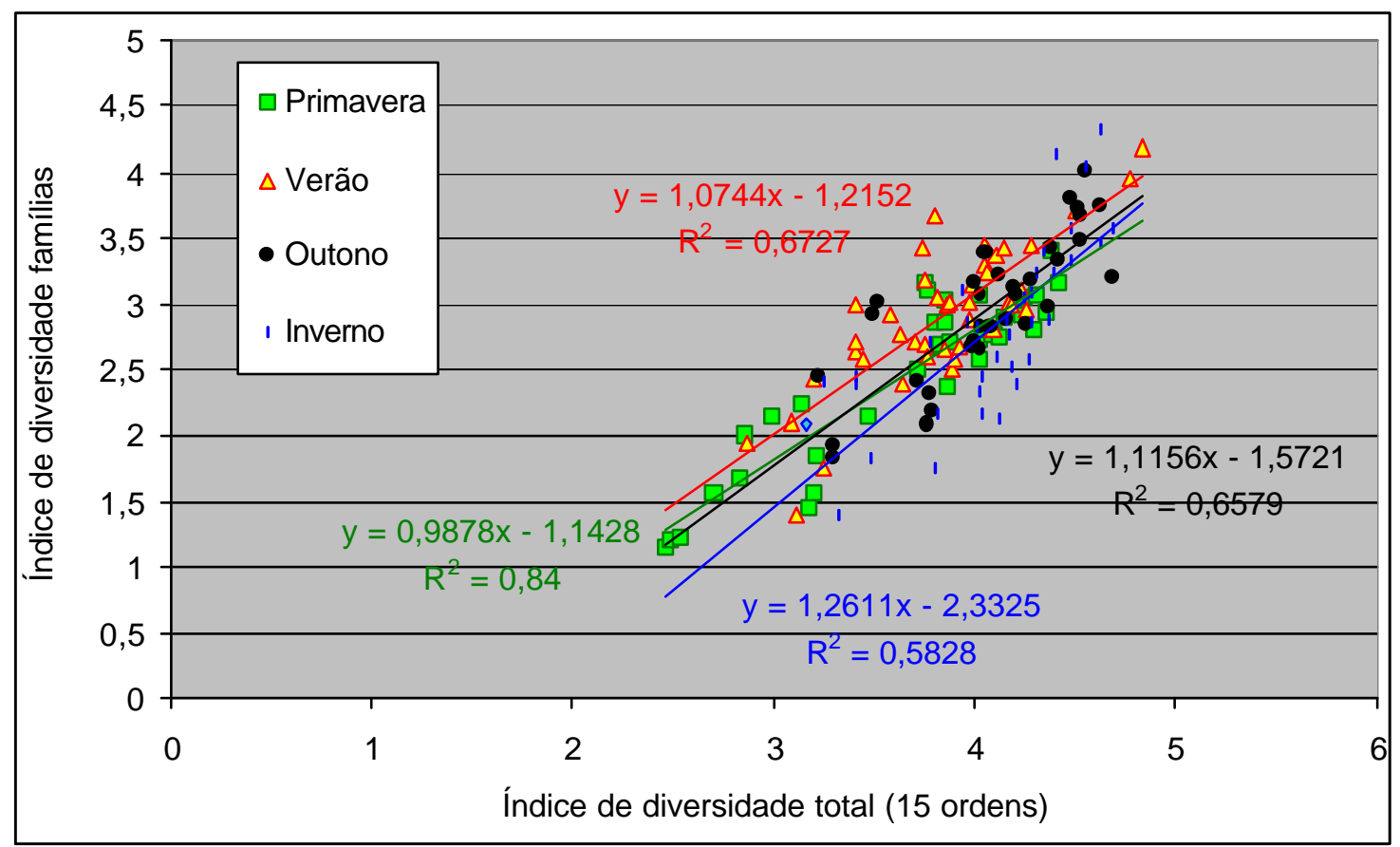

Figura 19 - Correlação entre índice de diversidade, para morfoespécies, de famílias selecionadas de Lepidoptera e Coleoptera, com o índice de diversidade total das 15 ordens.

As evidências estatísticas mostram que as 16 famílias representam bem o índice de diversidade total, não porque existe uma correlação significativa entre elas e todas as outras, mas porque pesam muito no índice de diversidade total, onde elas estão incluídas. Isso porque a análise de regressão entre as 16 famílias e todas as outras, excetuando-se as 16, mostrou-se significativa apenas ao nível de $10 \%$ (probabilidade $>F=0,0994$ ) e com $r^{2}$ de 0,0779 , muito baixo. Por outro lado, embora as 16 famílias representem apenas $11,9 \%$ do número total de famílias (143) do período estudado (primeiras 50 coletas), correspondem a $51,2 \%$ de todas as morfoespécies (1.625/3.174) e $70,8 \%$ de todos os indivíduos coletados (71.877/101.465). 


\subsection{Armadilha luminosa e de Malaise}

Até a coleta mensal número 50 , a armadilha luminosa e a de Malaise representaram $66,4 \%$ e $33,6 \%$, respectivamente, de todos os indivíduos capturados ( 15 ordens).

Das seis ordens mais abundantes (Figura 5), a armadilha Malaise coletou a maioria dos indivíduos apenas nas ordens Hymenoptera e Diptera (Figura 20). No entanto, essas duas ordens têm baixo nível de classificação dos indivíduos em morfoespécies (item 4.1), o que limita o uso da armadilha Malaise a esse nível de classificação, por exemplo, prejudicando a estimativa do índice de diversidade.

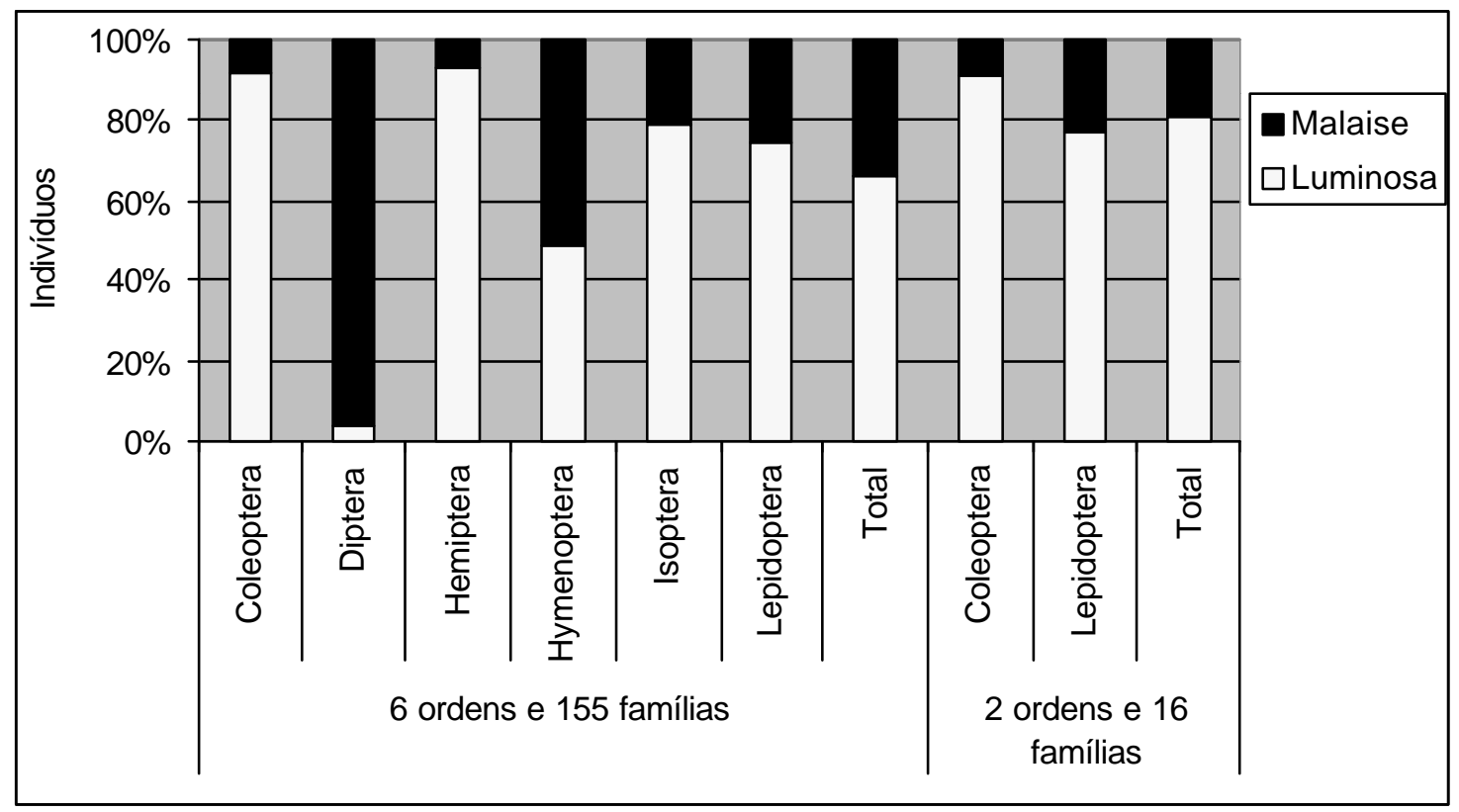

Figura 20 - Porcentagem de indivíduos coletados com cada tipo de armadilha, luminosa e de Malaise.

Os valores de freqüência nas coletas mensais, dos dois grupos de morfoespécies capturados com a armadilha Luminosa e a de Malaise, praticamente não diferem, com exceção para morfoespécies com constância 
abaixo de $5 \%$, onde a proporção na coleta com a luminosa é maior: $74,5 \%$ das morfoespécies contra 63,2\% na Malaise (Figura 21).

A freqüência de coletas (meses), com ocorrência de insetos não classificados em morfoespécies, foi de $90,8 \%$ e 98,0\% nas armadilhas luminosas e de Malaise, respectivamente.

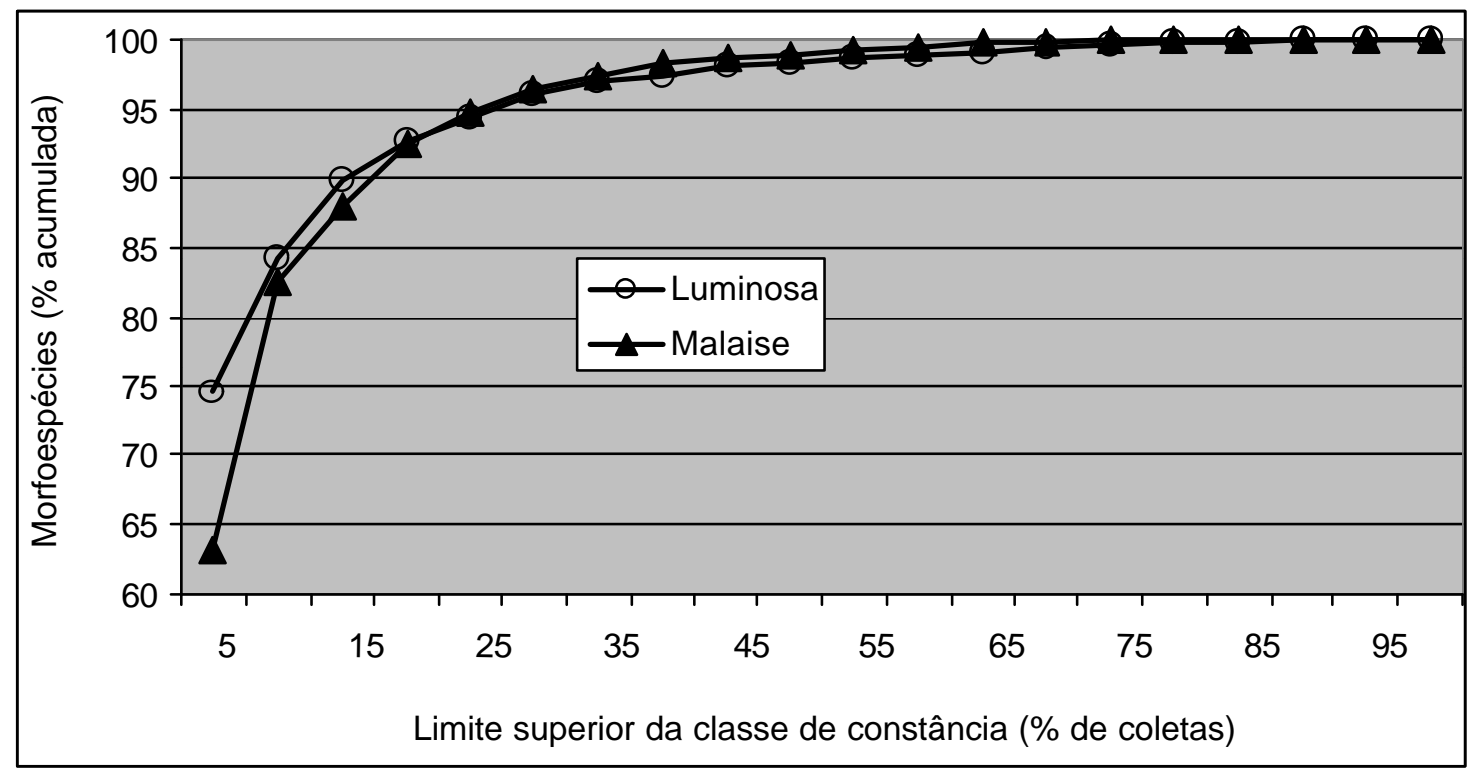

Figura 21 - Número acumulado de morfoespécies por classe de constância, para cada tipo de armadilha (armadilha luminosa: 87 coletas; Malaise: 50 coletas).

Ao contrário do que ocorreu para a constância, a proporção de morfoespécies com baixa densidade relativa é ligeiramente menor nas armadilhas luminosas do que nas de Malaise. 


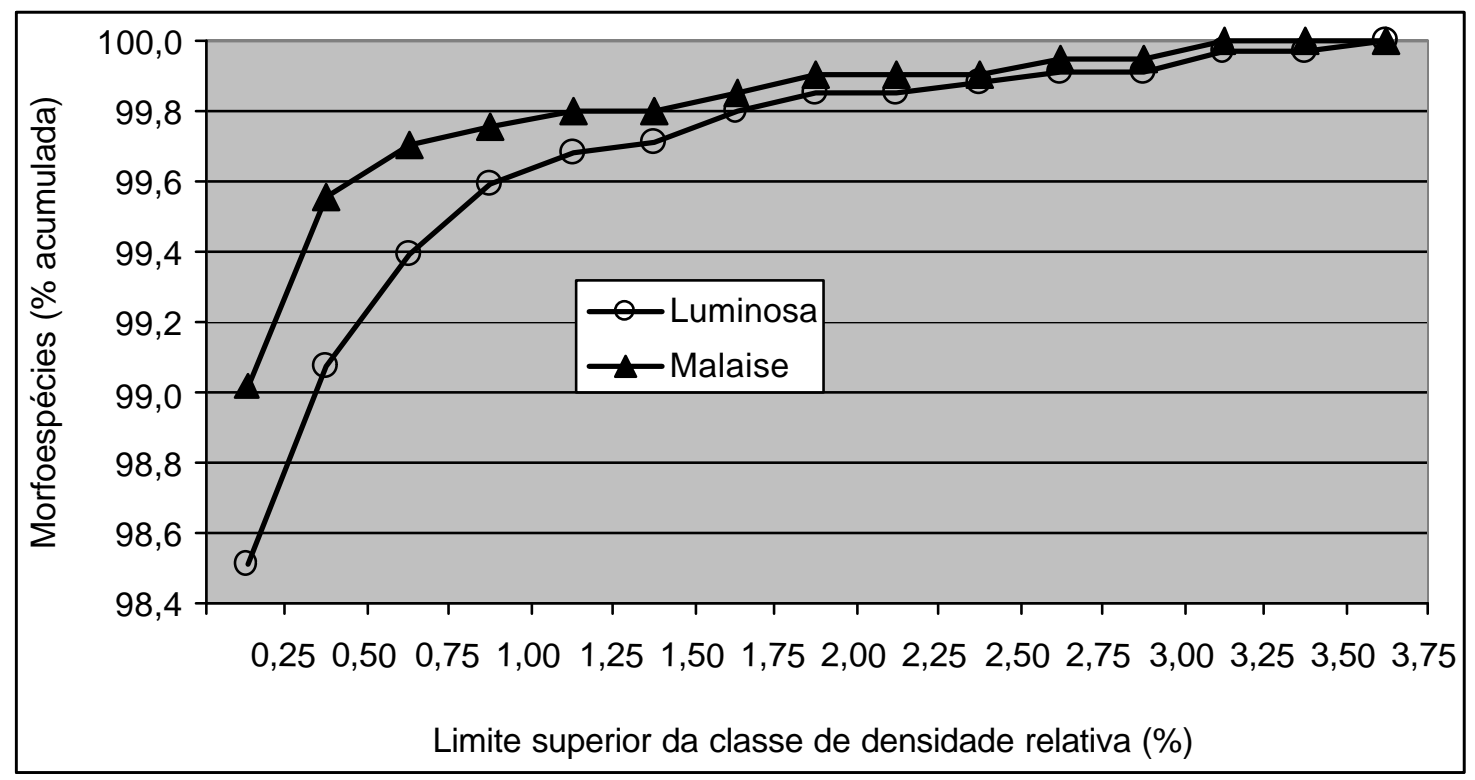

Figura 22 - Número acumulado de morfoespécies por classe de densidade relativa, para cada tipo armadilha.

A distribuição da constância e da densidade relativa das morfoespécies capturadas com a armadilha luminosa é mais próxima da distribuição considerando toda a coleta (item 4.1), do que a distribuição com a armadilha de Malaise, evidentemente, pela maior participação da armadilha luminosa na coleta total.

A Figura 23 mostra a proporção de famílias e de morfoespécies comuns e exclusivas entre as armadilhas uminosas e de Malaise. Cerca de $70 \%$ das morfoespécies e $82 \%$ das famílias foram capturadas pelas armadilhas luminosas.

Para as diferentes guildas, a grande contribuição da coleta, com armadilhas de Malaise, está nos parasitóides, tanto em termos de número de indivíduos (Figura 24), como em número de morfoespécies (Figura 25). 


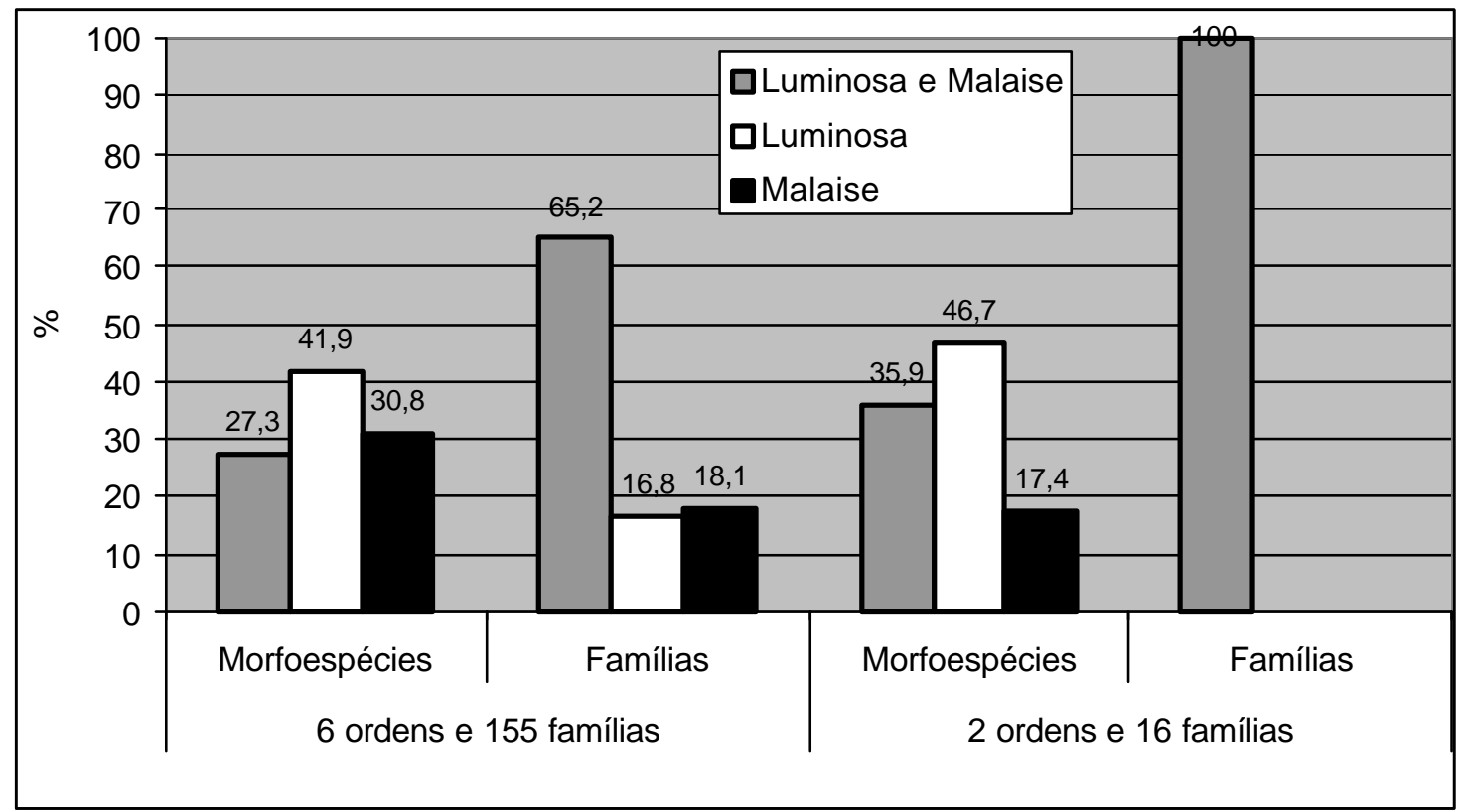

Figura 23 - Porcentagem de morfoespécies e famílias, comuns e exclusivas entre as armadilhas luminosas e Malaise.

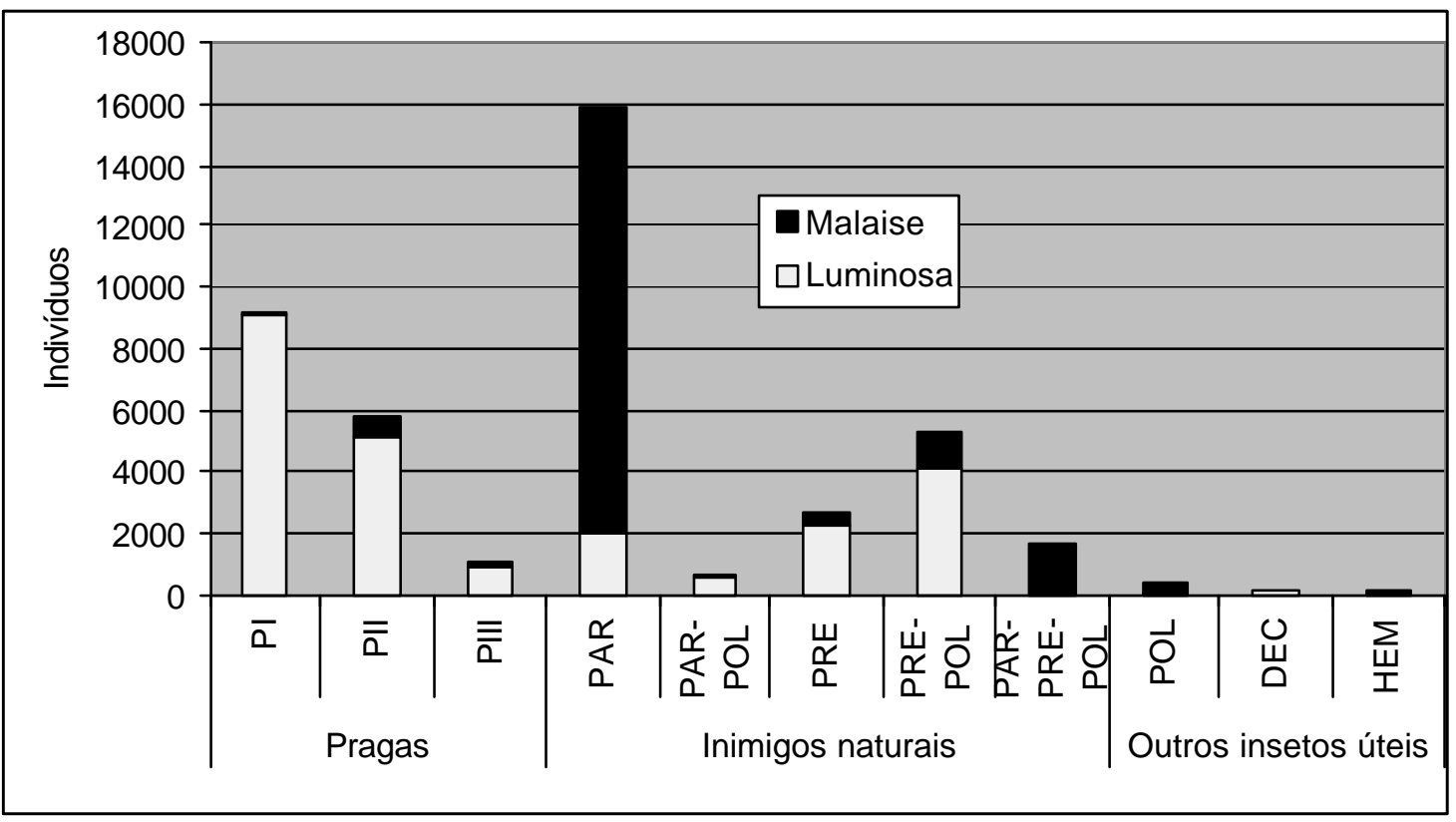

Figura 24-Número de indivíduos classificados em guildas, por tipo de armadilha. 


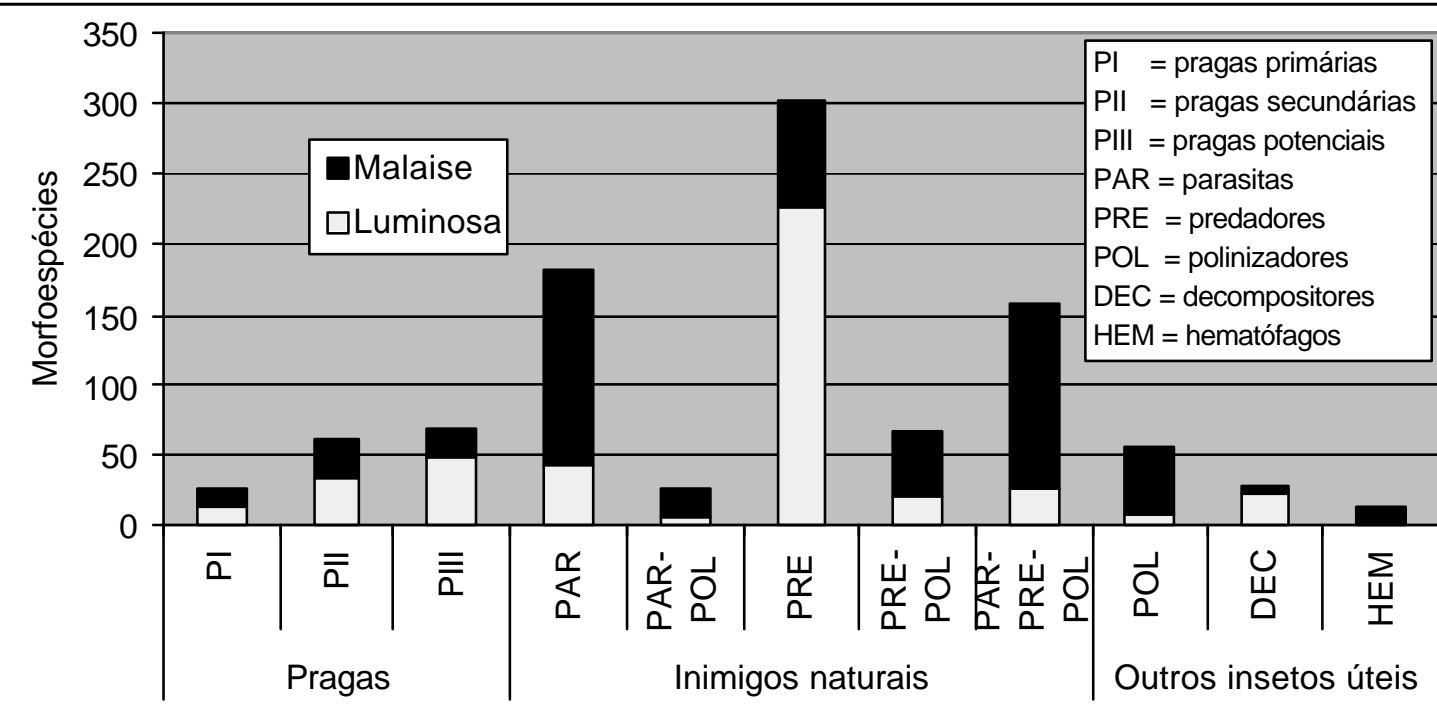

Figura 25 - Número de morfoespécies classificadas em guildas, por tipo de armadilha.

A desconsideração dos indivíduos de Lepidoptera coletados com as armadilhas de Malaise resultou, evidentemente, num menor ajuste da relação entre o índice de diversidade dessa ordem e o originado de toda a coleta (Figuras 26). O mesmo ocorre com o grupo formado pelas famílias selecionadas (item 4.1) das ordens Lepidoptera e Coleoptera (Figura 27). Considerando todas as morfoespécies de Lepidoptera, o modelo da regressão continuou sendo altamente significativo (probabilidade $>F=0,0001$ ), no entanto, existe uma perda na correspondência dos dados, onde o $r^{2}$ passou de $0,67 \%$ para 0,58 .

Quando utilizado o grupo de famílias selecionadas, das ordens Lepidoptera e Coleoptera (item 4.1), para estimar o índice de diversidade de toda a coleta, houve perda variável na representatividade dos dados, em função da estação do ano. 


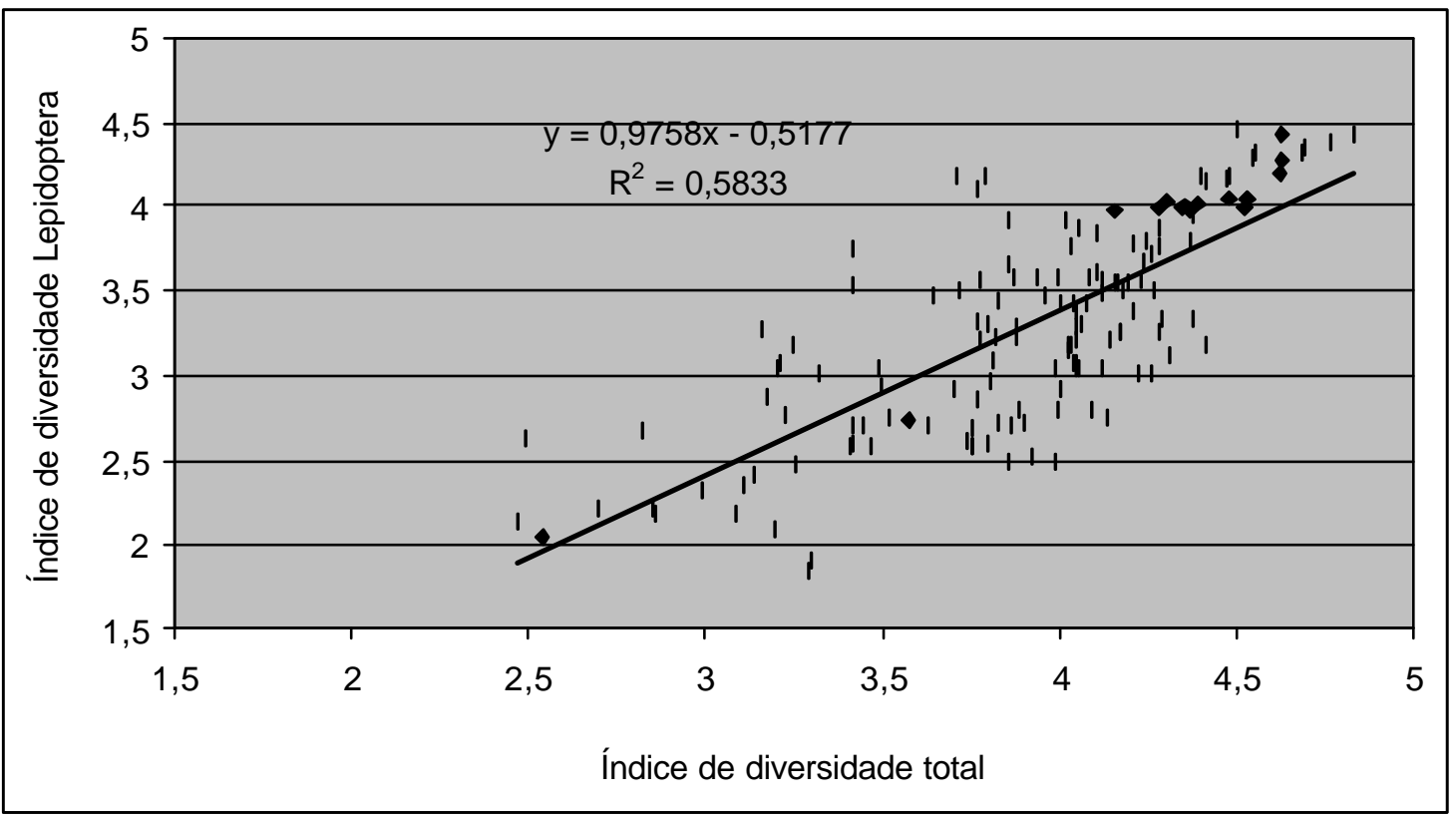

Figura 26-Correlação entre índice de diversidade de Lepidoptera, da armadilha luminosa, com o índice total das 15 ordens com os dois tipos de armadilhas - luminosa e de Malaise - .

Tabela 7. Análise de regressão entre 0 índice de diversidade para morfoespécies das famílias de Lepidoptera e Coleoptera selecionadas e o índice de diversidade total: comparação das famílias selecionadas com captura pelos dois tipos de armadilhas, contra coleta apenas com as armadilhas luminosas.

\begin{tabular}{lcccc}
\hline \multicolumn{1}{c}{ ESTAÇÃO } & \multicolumn{2}{c}{ LUMINOSA + MALAISE } & \multicolumn{2}{c}{ LUMINOSA } \\
\multicolumn{1}{c}{ DO ANO } & Prob. $>\mathrm{F}$ & $\mathrm{r}^{2}$ & Prob. $>\mathrm{F}$ & $\mathrm{r}^{2}$ \\
\hline Primavera & 0,0001 & 0,8400 & 0,0001 & 0,7795 \\
Verão & 0,0001 & 0,6727 & 0,0001 & 0,6718 \\
Outono & 0,0001 & 0,6579 & 0,0001 & 0,4393 \\
Inverno & 0,0001 & 0,5828 & 0,0001 & 0,5178 \\
\hline
\end{tabular}




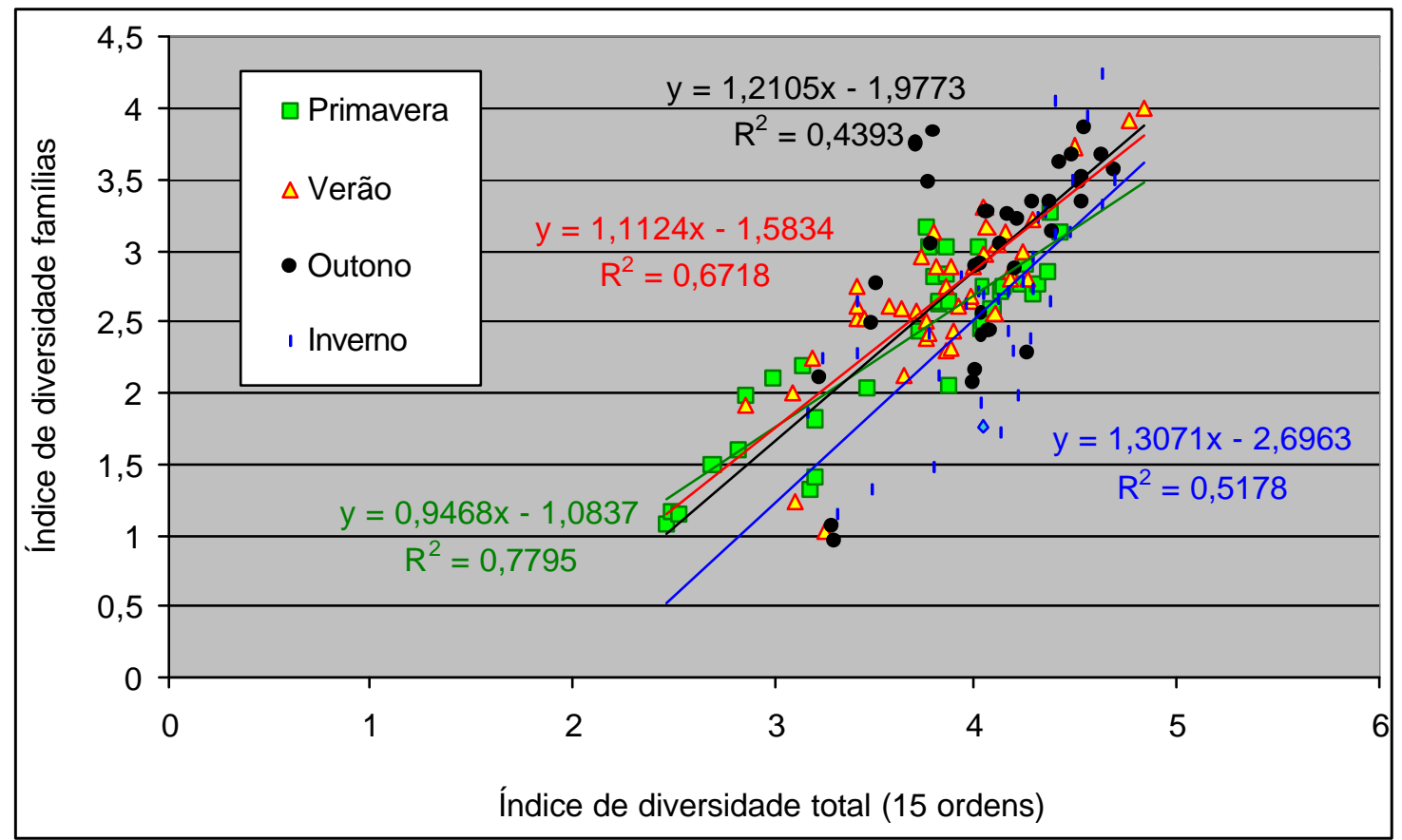

Figura 27 - Correlação entre índice de diversidade, para morfoespécies, de famílias selecionadas de Lepidoptera e Coleoptera, coletadas com as armadilhas luminosas, com o índice de diversidade total das 15 ordens, da coleta com armadilhas luminosas e de Malaise.

Um dos objetivos deste estudo foi o de caracterizar a entomofauna nos ambiente mata e eucalipto, assim como na borda entre eles. Nesse sentido, foi importante observar as diferenças dos dois tipos de armadilhas utilizadas, para poder interpretar os resultados da coleta em cada ambiente e a interação entre eles. As armadilhas foram instaladas dentro de um ambiente, ficando a uma distância de apenas cerca de 80 metros do outro. Assim, ação de atração da luminosa, poderia ter ação significativa sobre a entomofauna da área adjacente. A Figura 28 apresenta os dados das coletas nos três ambientes estudados, utilizando as armadilhas de Malaise como controle, pois funcionam apenas por interceptação. 


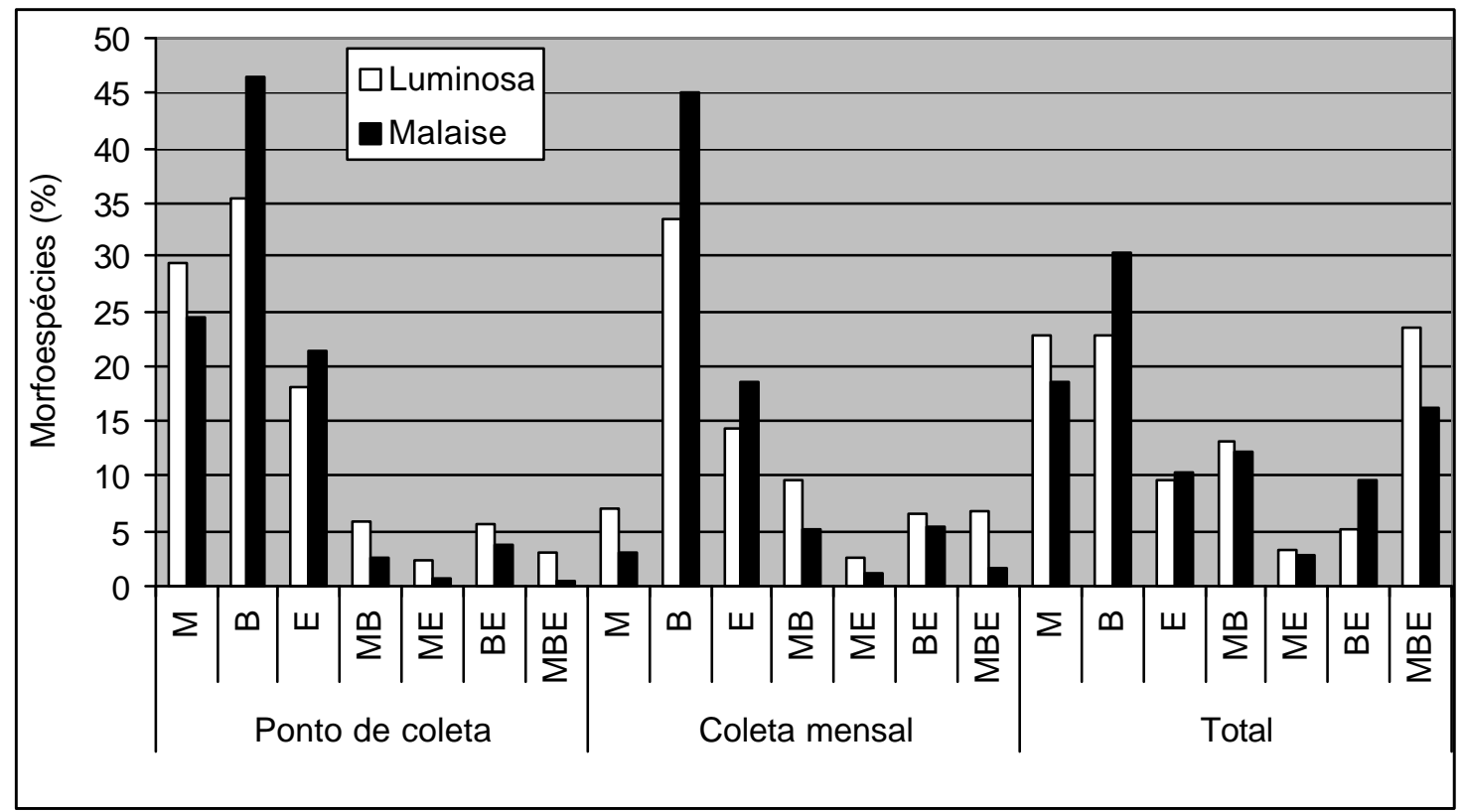

Figura 28 - Porcentagem de morfoespécies comuns e exclusivas entre a mata, a borda e o eucalipto, por tipo de armadilha (luminosa e de Malaise): média dos pontos de levantamento, das coletas mensais e o total.

A Figura 28 apresenta a proporção (\%) de morfoespécies exclusivas e comuns entre os ambientes, em três condições diferentes:

$1^{\mathrm{a}}$ - médias entre pontos de levantamento;

$2^{\mathrm{a}}$ - médias entre as coletas;

$3^{\mathrm{a}}$ - total das coletas.

As coletas somam os dados dos três pontos de levantamento, por ambiente, e o total, as 21 coletas, que foram consideradas nesta análise. Naturalmente, nessa seqüência, ocorre a elevação do grupo de morfoespécies comuns, destacando-se aquelas entre os três ambientes e, em seguida, as comuns entre mata e borda.

O teste de comparação das médias, entre pontos de levantamento e entre as coletas, revelou diferenças significativas (probabilidade $5 \%$ ) em todas as comparações entre as armadilhas, com duas exceções: 
$1^{a}$ - nos pontos de levantamento, para espécies comuns entre borda e eucalipto $(\mathrm{E})$;

$2^{\mathrm{a}}$ - nas coletas, para espécies exclusivas do eucalipto (BE).

Uma hipótese seria que as armadilhas luminosas resultam numa maior proporção de morfoespécies comuns e a Malaise, conseqüentemente, maior para morfoespécies exclusivas. Realmente, na maioria dos casos as morfoespécies comuns tiveram maior proporção na coleta com luminosas e as exclusivas com a Malaise. No entanto, considerando todas as coletas, para as morfoespécies comuns entre dois ambientes o desempenho das duas armadilhas foi semelhante, ou melhor, as comuns entre borda e eucalipto foram ainda maiores com a Malaise. Somando-se a isso, a luminosa proporcionou sempre, ao nível de ponto de levantamento, de coleta e total, um maior número de espécies exclusivas com a armadilha luminosa.

Essa comparação entre as duas armadilhas precisa ser considerada com ressalvas, pois cada uma tem eficiência diferenciada entre grupos da entomofauna e, além disso, os indivíduos foram pouco identificados na Malaise.

As armadilhas luminosas tiveram contribuição importante na coleta da ordem Hymenoptera, destacando o grupo de parasitóides. No entanto, a classificação da grande maioria indivíduos dessa ordem, não pode ir além de família. Assim, pela maior contribuição em termos quantitativos e qualitativos da coleta com as armadilhas luminosas e considerando que o estudo com armadilhas, independentemente de quantidades ou tipos das mesmas, baseiam-se em dados relativos, optou-se por continuar empregando apenas as armadilhas luminosas a partir da $50^{\mathrm{a}}$ coleta mensal. 


\subsection{Mata, eucalipto e borda}

Considerando as seis ordens mais abundantes em todas as coletas deste estudo, verifica-se que a região de borda, entre mata e eucalipto, apresenta, geralmente, maior número de indivíduos, destacando-se as ordens Hymenoptera e Lepidoptera (Figura 29). Esta primeira ordem encerra o maior número de indivíduos e de morfoespécies do grupo de inimigos naturais, enquanto que a segunda é a maior para o grupo de pragas do eucalipto (Figuras 14 e 16). Em menor número, os indivíduos de Diptera e de Coleoptera, em segundo lugar em inimigos naturais e pragas, respectivamente, seguem a mesma distribuição entre os três ambientes.

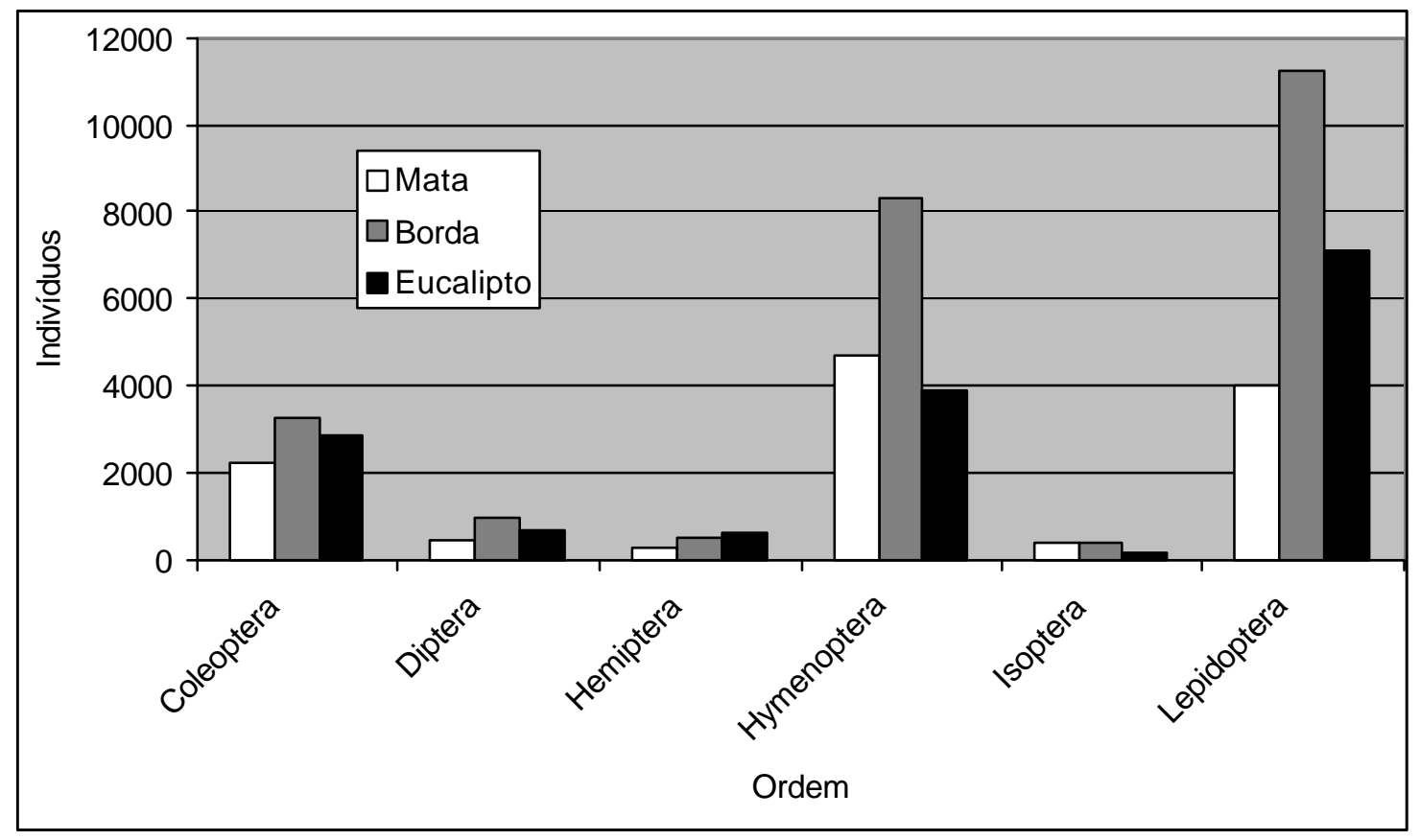

Figura 29 - Número de indivíduos, por ordem e ambiente (Mata: local 1; Borda: 2; Eucalipto: 6).

A distribuição dos indivíduos, das diferentes ordens nos três ambientes, indica que a maior densidade de pragas e inimigos naturais ocorre nas bordas (Figura 29). Essa informação sugere que pelo menos a maioria dos 
focos de pragas inicie, e ou tenha maior intensidade, nas bordas dos plantios de eucalipto. Esse é um fato freqüentemente observado nos surtos de Lepidoptera. Essa informação é importante para o manejo das pragas do eucalipto, particularmente no planejamento das vistorias, das avaliações de surto e dos controles.

Apesar de ser evidente a diferença na quantidade de indivíduos entre os três ambientes, o padrão de distribuição das morfoespécies em relação à constância, ao contrário, é bem semelhante (Figura 30).

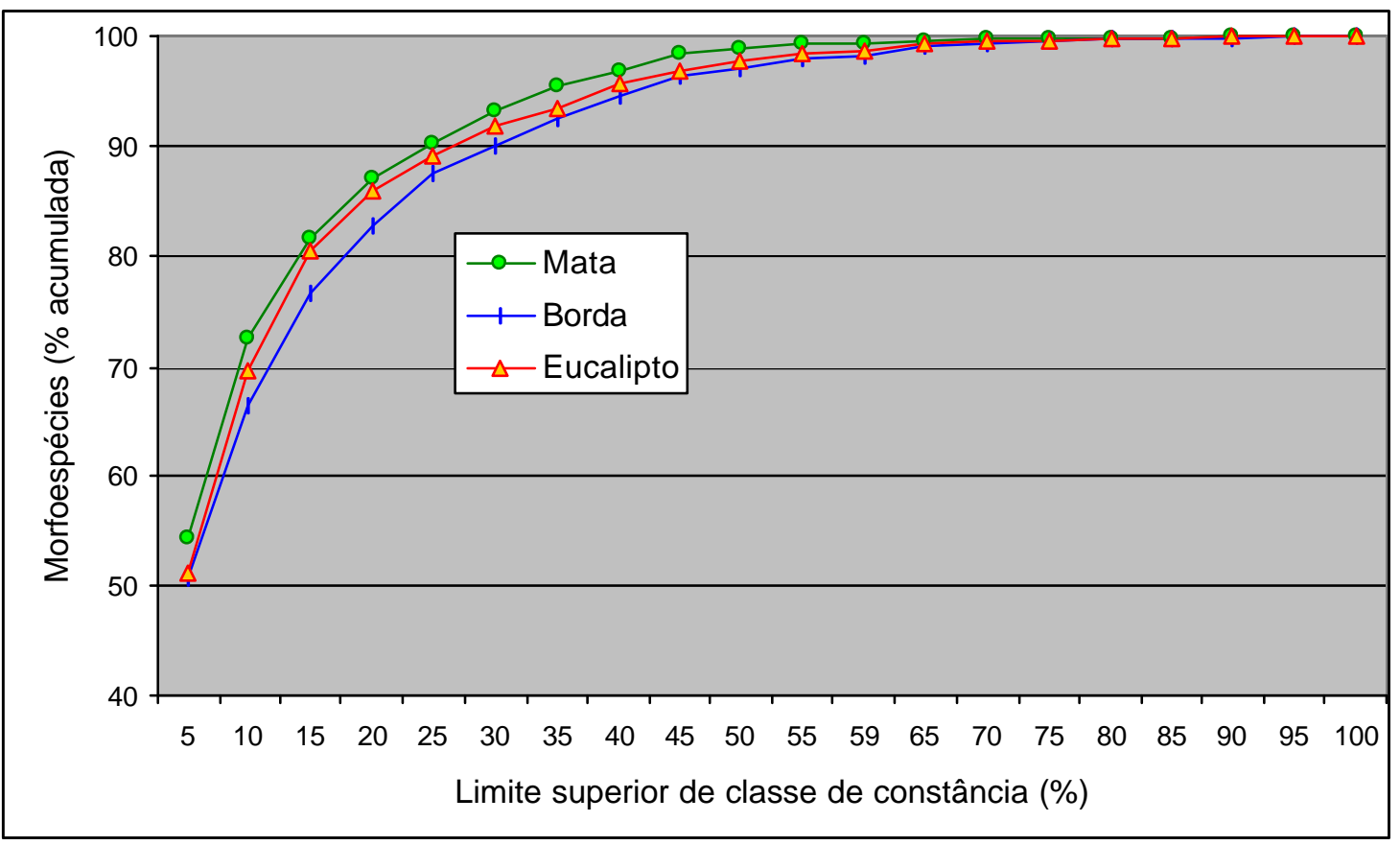

Figura 30 - Porcentagem acumulada de morfoespécies em função da classe de constância.

No caso da distribuição da densidade relativa, existe uma pequena diferença de padrão entre mata e os outros dois ambientes. A borda e o eucalipto mostram uma proporção um pouco maior de morfoespécies, cerca de $5 \%$ a mais do que a mata, nos menores valores de densidade relativa, até $0,1 \%$ (Figura 31). Seria esperado o contrário, ou seja, a mata com maior freqüência em classes de menor densidade relativa, o que normalmente está relacionado 
com diversidade e estabilidade. Voltando-se para as classes intermediárias de densidade relativa, verifica-se uma recuperação da distribuição de morfoespécies na mata, com tendência do eucalipto apresentar maior freqüência de morfoespécies com os maiores valores de densidade relativa. Assim, eucalipto e borda abrigam uma maior proporção de morfoespécies em valores extremos de densidade relativa, o que mostra maior estabilidade da mata. No entanto, as diferenças entre os três ambientes são muito pequenas, sendo cerca de $5 \%$ das morfoespécies, para os menores valores de densidade relativa e menos de $1 \%$, para os maiores.

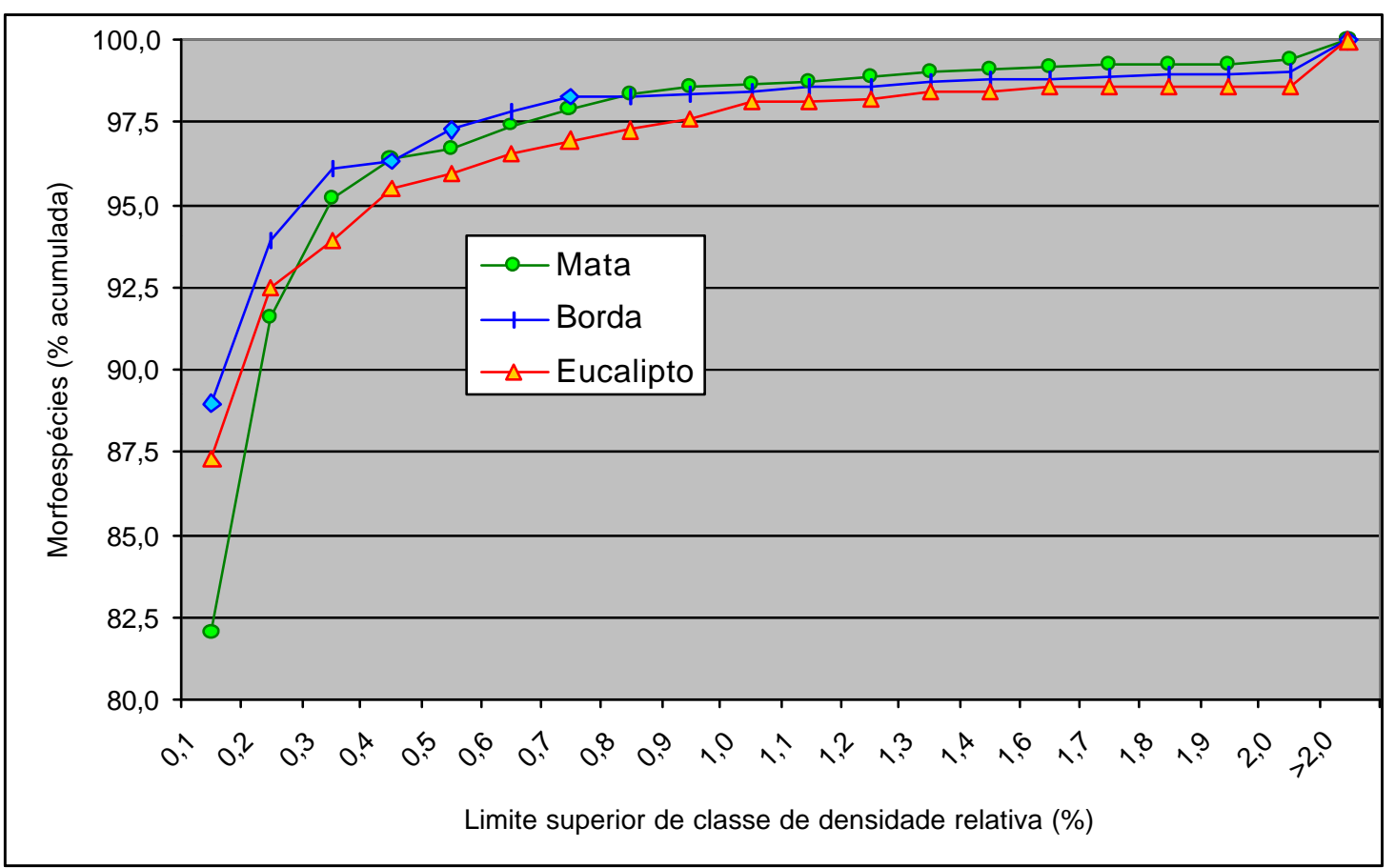

Figura 31 - Porcentagem acumulada de morfoespécies em função da classe de densidade relativa.

Os três ambientes, nas condições da área em estudo, apresentam padrões de distribuição de densidade relativa muito próximos, o que é muito favorável para o controle biológico e estabilidade dentro da floresta plantada. No entanto, esses padrões são quantitativos e não refletem as diferenças na 
ocorrência ou abundância de cada morfoespécie, entre os ambientes. Essas diferenças são indicadas pela análise inicial da distribuição de indivíduos por ordem (Figura 29).

A comparação dos ambientes, quanto ao número de indivíduos em cada guilda (Figura 32), mostra um equilíbrio dinâmico, onde a relação entre pragas e inimigos naturais alterna-se ao longo do tempo. Certos períodos apresentam uma relação bastante baixa (exemplo: coletas 02, 03 e 04, Figura 32) e muito semelhante entre os três ambientes, sendo que em outros, a relação muda, com as pragas em maior densidade relativa (Figura 32, coletas 07 a 11).

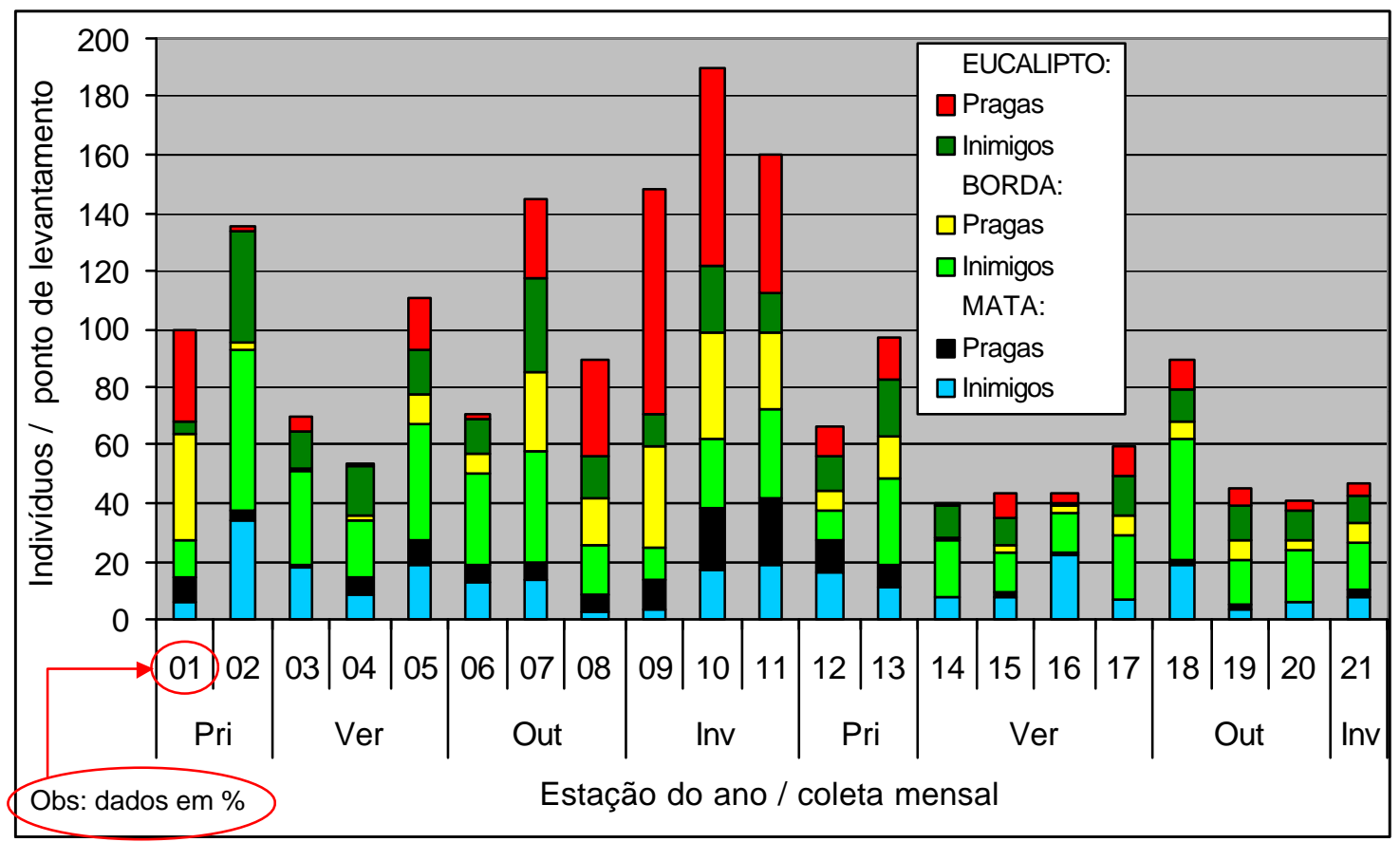

Figura 32 - Número de indivíduos, em cada estação do ano, do grupo de pragas e de inimigos naturais, por ambiente (Observação: para a coleta 01 , os valores estão em porcentagem, devido ao número elevado de indivíduos, no total de 1512).

As estações de outono e inverno foram as que apresentaram maior relação pragas/inimigos, no entanto, os dados mostram que a relação pode 
estar bem favorável ao controle biológico natural, em outros períodos nas mesmas estações (Figura 32, coletas 18 a 21). A estação pode favorecer o surgimento de surtos de pragas, como se observa para alguns lepidópteros (Baena, 1982 e Wilcken, 1991). Pelos dados obtidos, no geral, as pragas têm densidade associada a inúmeros outros fatores físicos e bióticos, além da época do ano.

A condição mais crítica, em termos de equilíbrio das populações de pragas, é observada na coleta 01 , onde o número médio de indivíduos por ponto de levantamento é 1512, sendo a relação pragas/inimigos na mata, borda e eucalipto, igual a 1,5; 2,9 e 7,3, respectivamente. (Figura 33).

É importante salientar que, apesar da flutuação da relação entre pragas e inimigos naturais, nenhum foco epidêmico ocorreu na microbacia, ao longo de todo o período de estudo.

A comparação dos três ambientes, quanto ao número de indivíduos em cada guilda, proporciona ainda uma demonstração da importância da interação da plantação de eucalipto com áreas conservadas de mata natural. A elevação da relação pragas/inimigos é observada claramente no eucalipto, ficando a mata numa condição mais estável (Figura 33). A borda representa a zona de tensão entre os dois ambientes. O mosaico, de plantação e mata natural, faz com que a mata apresente-se como uma barreira para a expansão das populações de pragas.

Comparando-se os diferentes grupos de insetos, quanto ao número de indivíduos em cada estação do ano, diferentes resultados são verificados entre as estações do ano, no período de 21 coletas mensais analisadas (figuras 34 , 35,36 e 37 ). 


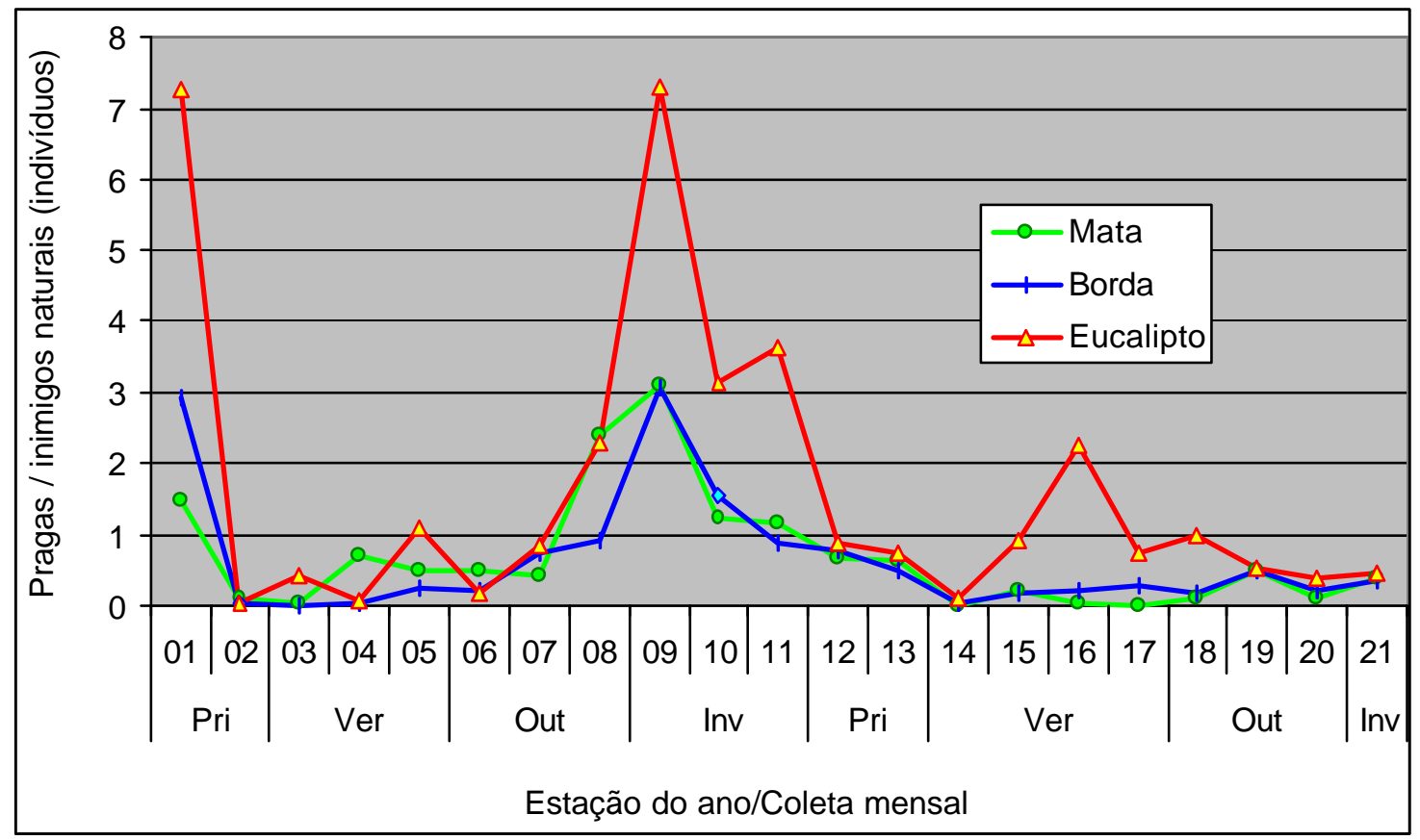

Figura 33 - Relação entre o número de indivíduos de insetos pragas e o de inimigos naturais, por estação do ano e coleta mensal.

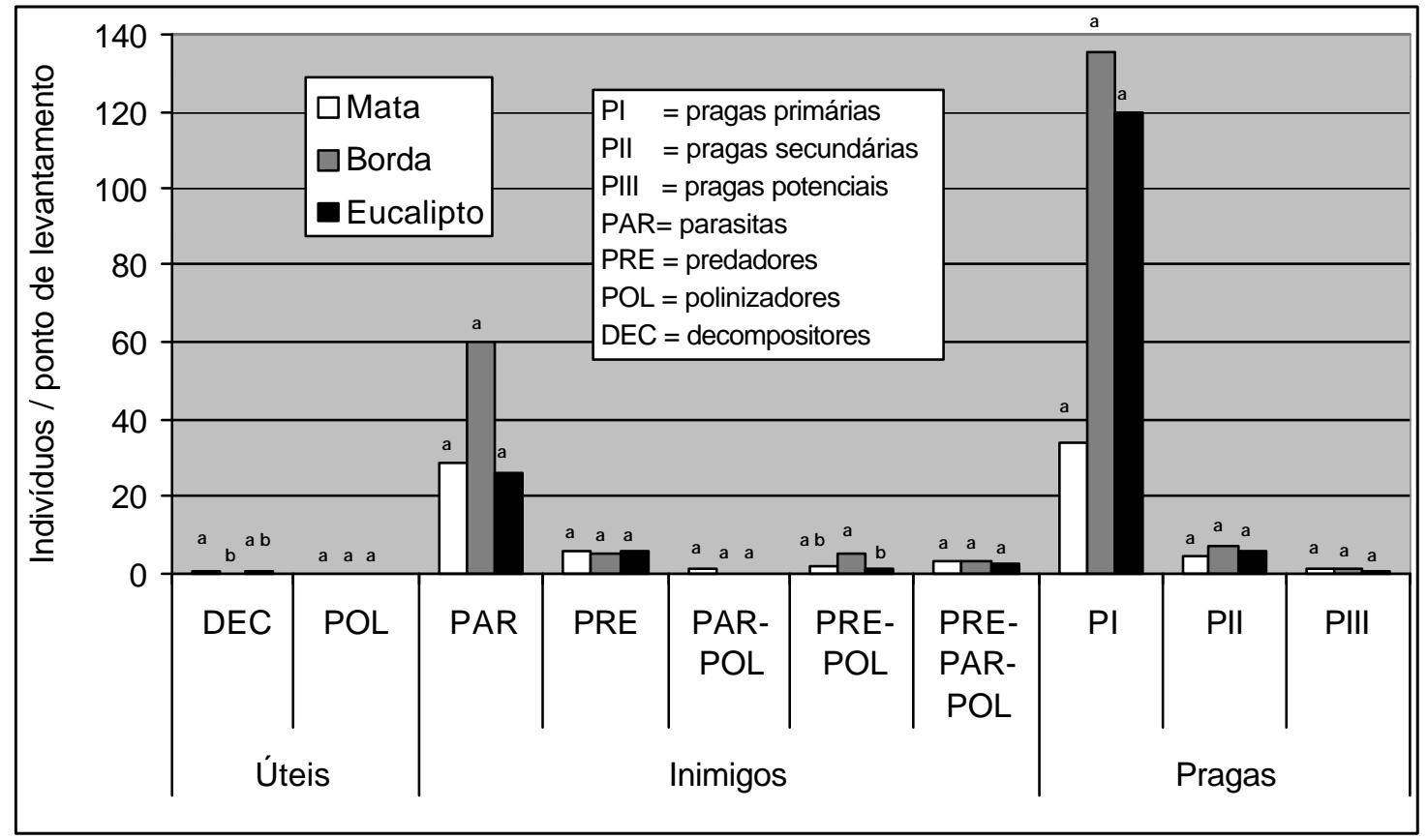

Figura 34 - Número de indivíduos, para cada guilda e ambiente, na primavera (letras semelhantes indicam valores sem diferença significativa, na comparação entre ambientes, para a mesma guilda). 
$\mathrm{Na}$ primavera, não houve diferença significativa entre os ambientes mata, eucalipto e borda (Figura 34). Apesar dos valores para pragas primárias serem elevados e diferentes entre os três ambientes, a análise considerou os dados de quatro coletas nessa estação, sendo que em apenas uma, a coleta 01, foi responsável por valores altos. Nessa coleta, houve uma alta densidade de algumas populações de pragas, principalmente da família Geometridae (Lepidoptera), destacando-se os gêneros Glena e Stenalcidia.

Nas outras três estações do ano, foi possível constatar diferenças significativas entre os três ambientes, em relação a alguns grupos de insetos.

No verão, observou-se maior quantidade de parasitas e predadorespolinizadores na borda, assim como os valores de pragas primárias e secundárias foram maiores para borda e eucalipto (Figura 35).

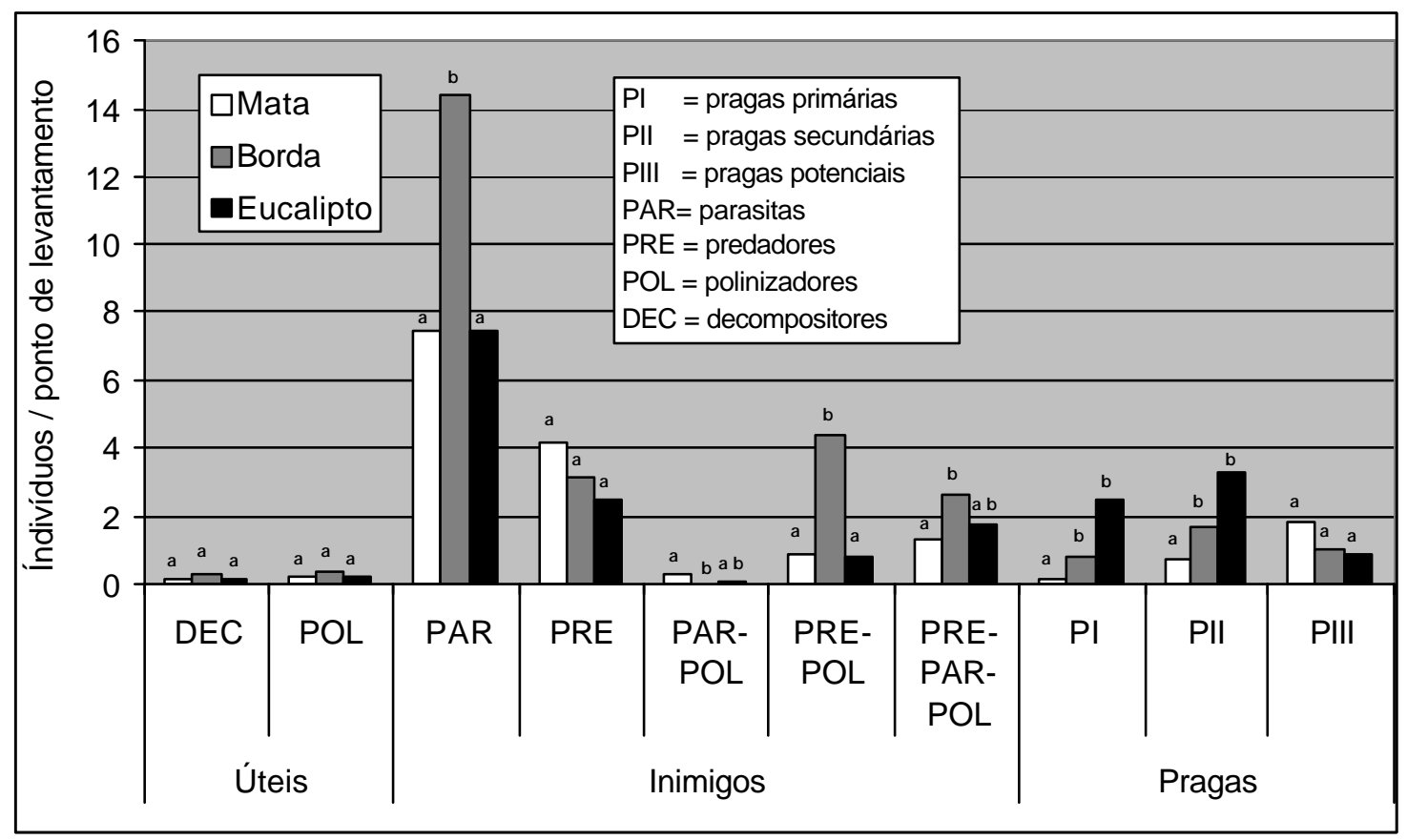

Figura 35 - Número de indivíduos, para guilda e ambiente, no verão (letras semelhantes indicam valores sem diferença significativa, na comparação entre ambientes, para a mesma guilda). 
No outono, destaca-se maior nível de parasitas na borda e, em seguida, no eucalipto, assim como valores mais elevados de pragas primárias e secundárias (Figura 36).

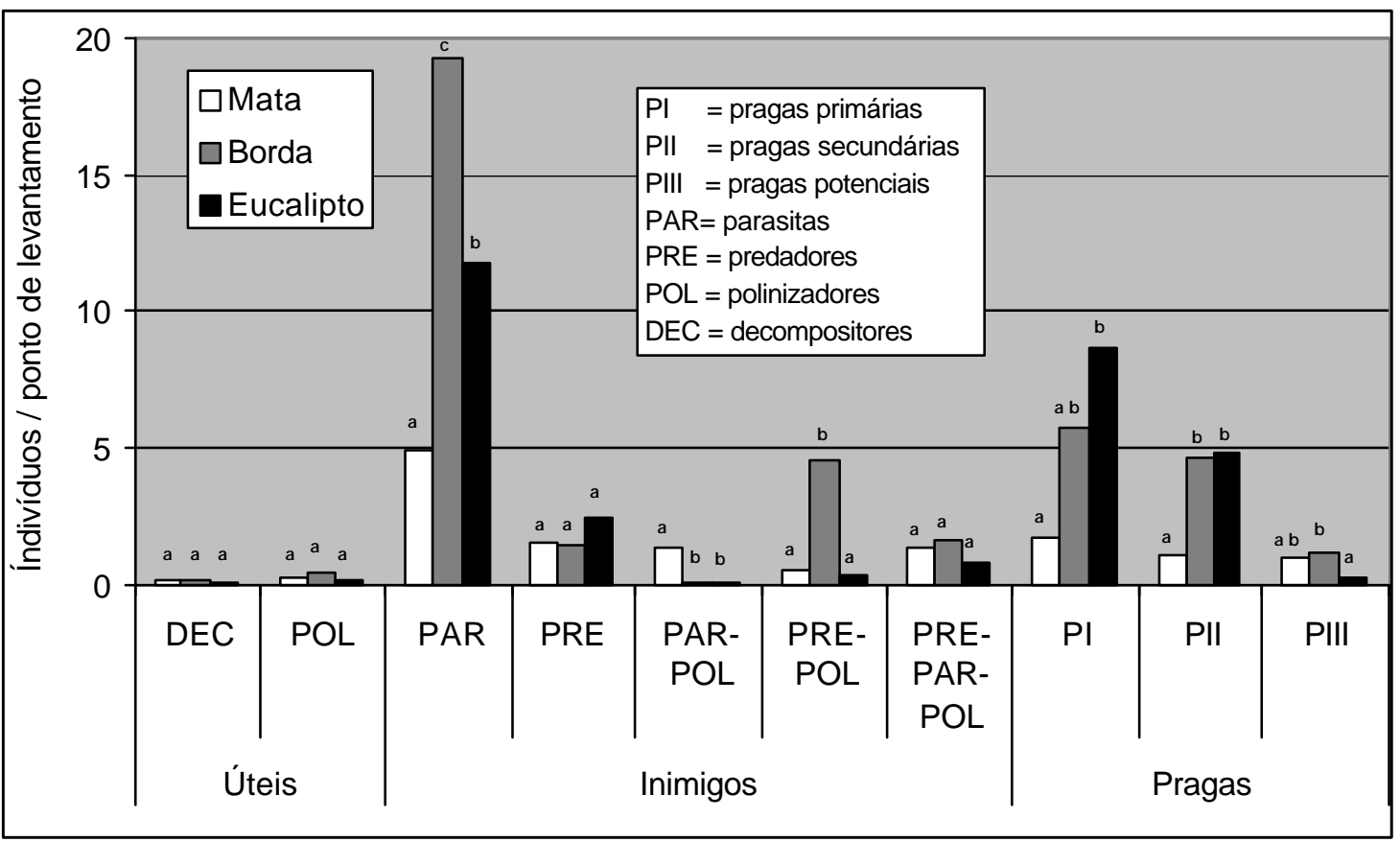

Figura 36 - Número de indivíduos, para cada guilda e ambiente, no outono (letras semelhantes indicam valores sem diferença significativa, na comparação entre ambientes, para a mesma guilda).

No inverno (Figura 37), assim como no outono, parasitas e predadores-polinizadores estiveram em maiores quantidades, na borda e eucalipto, sendo que no grupo de pragas, apenas as secundárias mostram-se significativamente superiores, nesses dois ambientes. Para pragas primárias $(\mathrm{PI})$, houve diferença significativa apenas entre mata e eucalipto.

Importante destacar que os grupos de decompositores e de polinizadores estiveram em iguais condições nos três ambientes, assim como as pragas potenciais (PIII). 


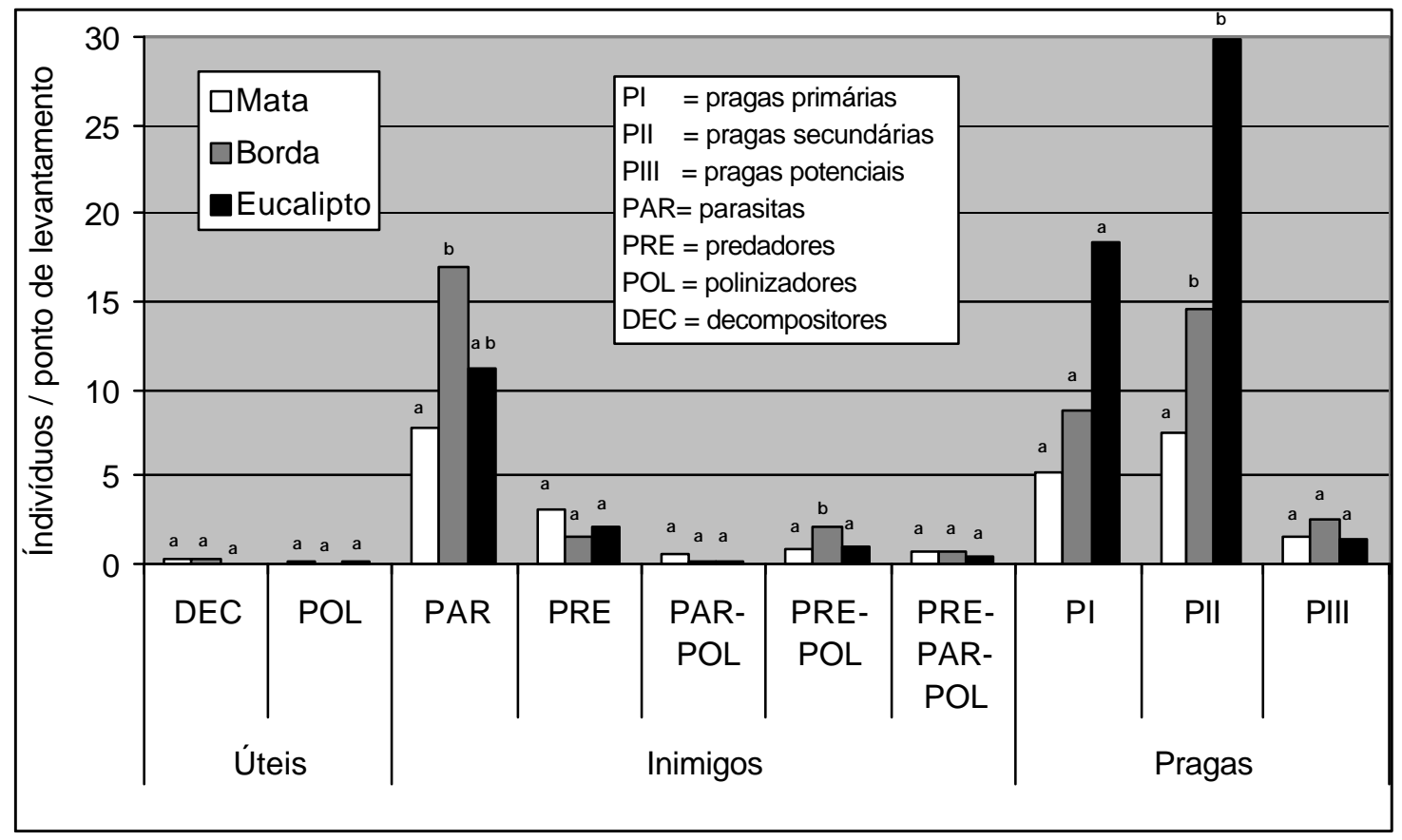

Figura 37 - Número de indivíduos, para cada guilda e ambiente, no inverno (letras semelhantes indicam valores sem diferença significativa, na comparação entre ambientes, para a mesma guilda).

Voltando-se para a riqueza, de morfoespécies, os três ambientes podem ser classificados na seguinte ordem decrescente: borda, mata e eucalipto (Figura 38).

O número de morfoespécies para o "eucalipto - total" foi sempre maior, porque envolve cinco locais monitorados com as armadilhas durante 87 coletas (códigos 3, 4, 5 e 6), enquanto que mata e borda foram estudadas em apenas um local, com 87 coletas. Como cada local sempre correspondeu a três pontos de coleta, podemos dizer que a intensidade de coleta, ou número de horas-armadilhas, no "eucalipto - total" foi cerca de quatro vezes maior. Quando a comparação é feita com a mesma intensidade de coleta, borda e mata mostram-se ambientes mais ricos do que o eucalipto (Figura 38). 


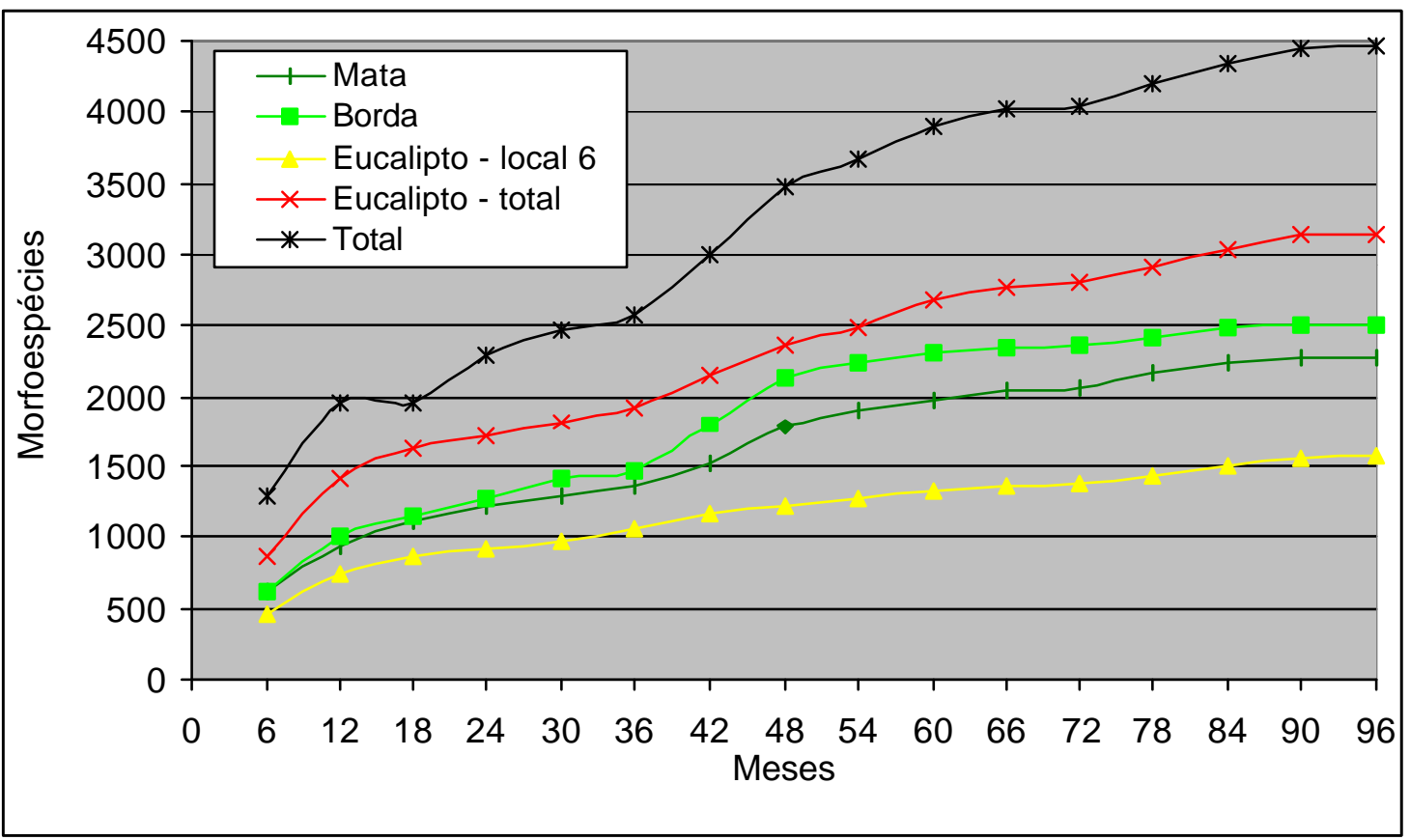

Figura 38 - Número acumulado de morfoespécies classificadas, ao longo do período de coleta (curva do coletor).

Diferentes locais de coleta no eucalipto resultam em incremento significativo do número de morfoespécies, demonstrando diversidade espacial da comunidade de insetos, mesmo dentro do eucalipto, aumentando o nível de relações entre as populações e, conseqüentemente, a estabilidade do ambiente.

O número de locais, ou intensidade do levantamento, no eucalipto, afeta significativamente o número de morfoespécies comuns com os outros dois compartimentos - mata e borda -. Considerando todos os locais estudados no eucalipto, não só o número de morfoespécies exclusivas desse ambiente é maior, em relação à mata e borda, como também o número de morfoespécies comuns com esses dois ambientes (Figura 39).

Com a mesma intensidade de monitoramento (mata, local 1, borda, local 2 e eucalipto, local 6 - Figura 39), o número de morfoespécies coletadas exclusivamente no eucalipto passa a ser menos da metade das morfoespécies coletadas na borda e mata. 


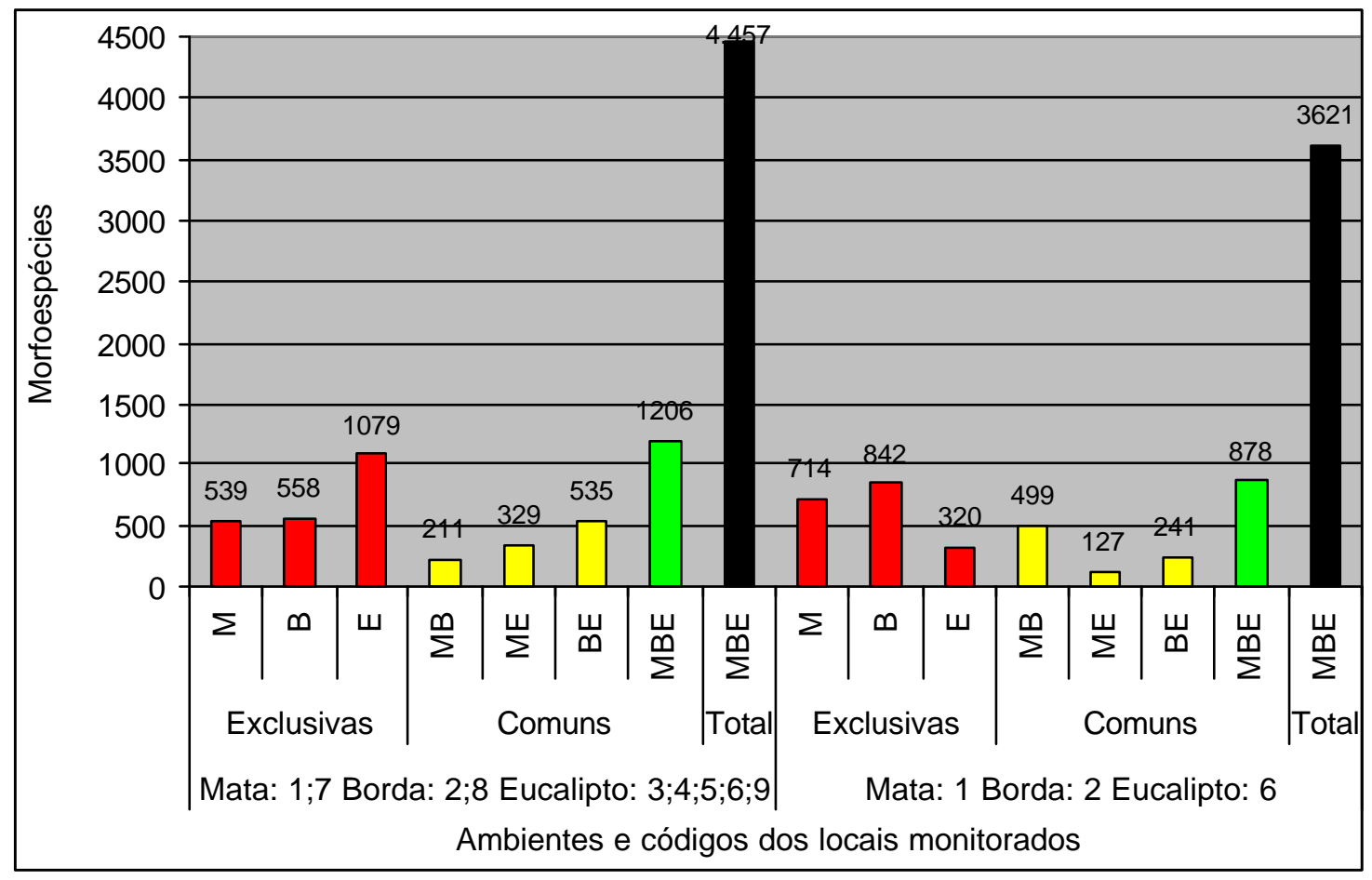

Figura 39 - Número de morfoespécies comuns e exclusivas entre ambientes ( $M=$ mata, $B=$ borda, $E=$ eucalipto).

Fazendo a mesma comparação entre locais de coleta no eucalipto, com mesma intensidade de amostragem, verifica-se que a porcentagem de morfoespécies exclusivas ficou na faixa de 13,8 a 19,5\% (Figura 40). Aplicandose a comparação dentro do local, entre pontos de levantamento, os valores são 16,4 a $21,3 \%, 13,8$ a $20,2 \%$ e 15,5 a $20,9 \%$, para mata, borda e eucalipto, respectivamente (Figura 41). 


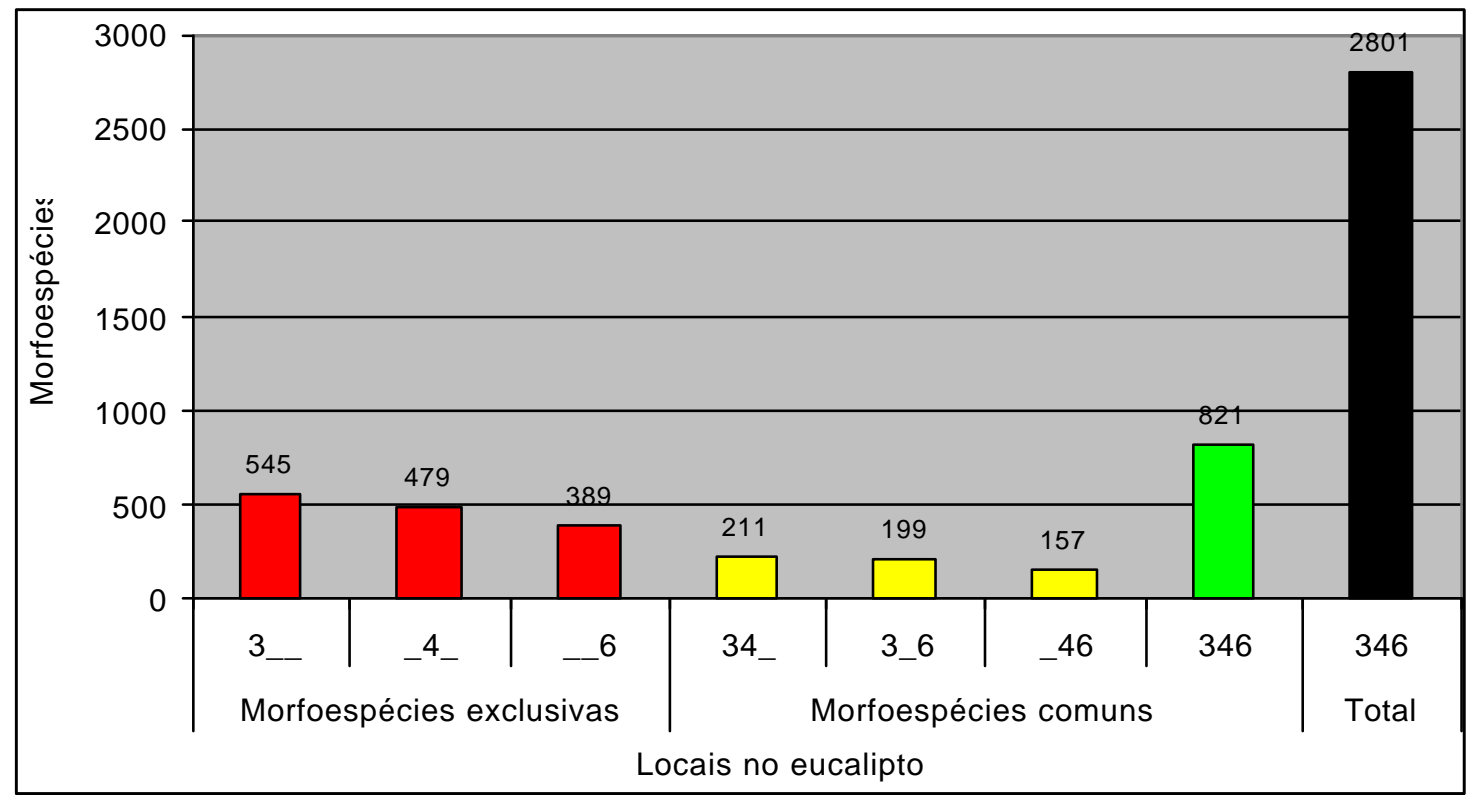

Figura 40 - Número de morfoespécies comuns e exclusivas entre locais no eucalipto (código dos locais: 3, 4 e 5, conforme padronização no capítulo 3).

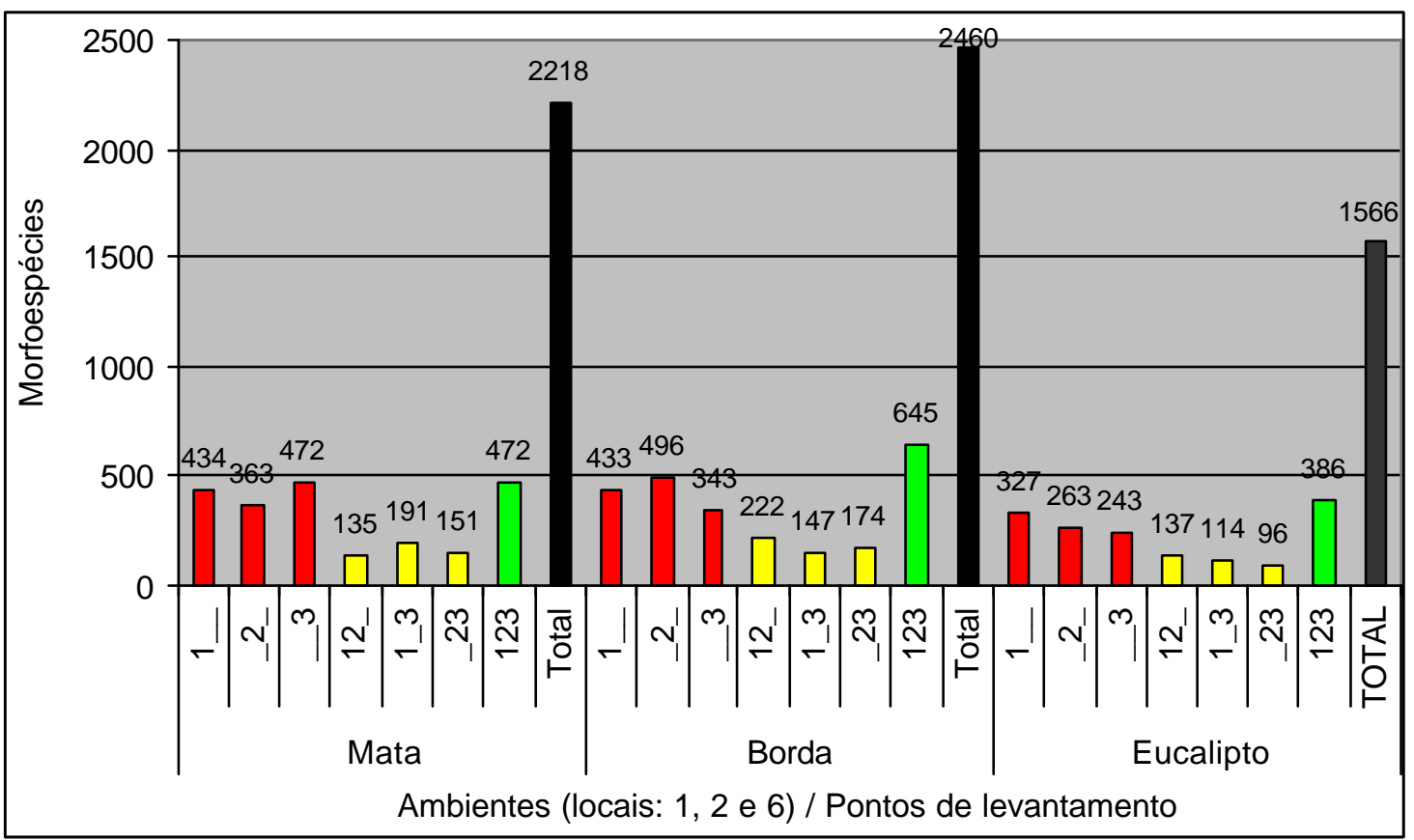

Figura 41 - Número de morfoespécies comuns e exclusivas entre pontos de levantamento, em cada ambiente ( $\mathrm{M}=$ mata, $\mathrm{B}=$ borda, $\mathrm{E}=$ =ucalipto). 
Acompanhando a evolução da proporção de morfoespécies exclusivas e comuns entre os ambientes, é possível estabelecer um padrão para o mosaico formado pela mata e eucalipto na microbacia (Figura 42).

Comparando-se apenas dois ambientes, outro padrão é obtido, como o apresentado na Figura 43, considerando mata e eucalipto. Nessas condições, foi possível adicionar à Figura 43 , os dados da comparação de dois pontos de levantamento dentro da mata, com mesma intensidade de amostragem. Assim, é possível verificar a diferença entre mata e eucalipto, tendo como referência, a diferença entre os pontos dentro da mata.

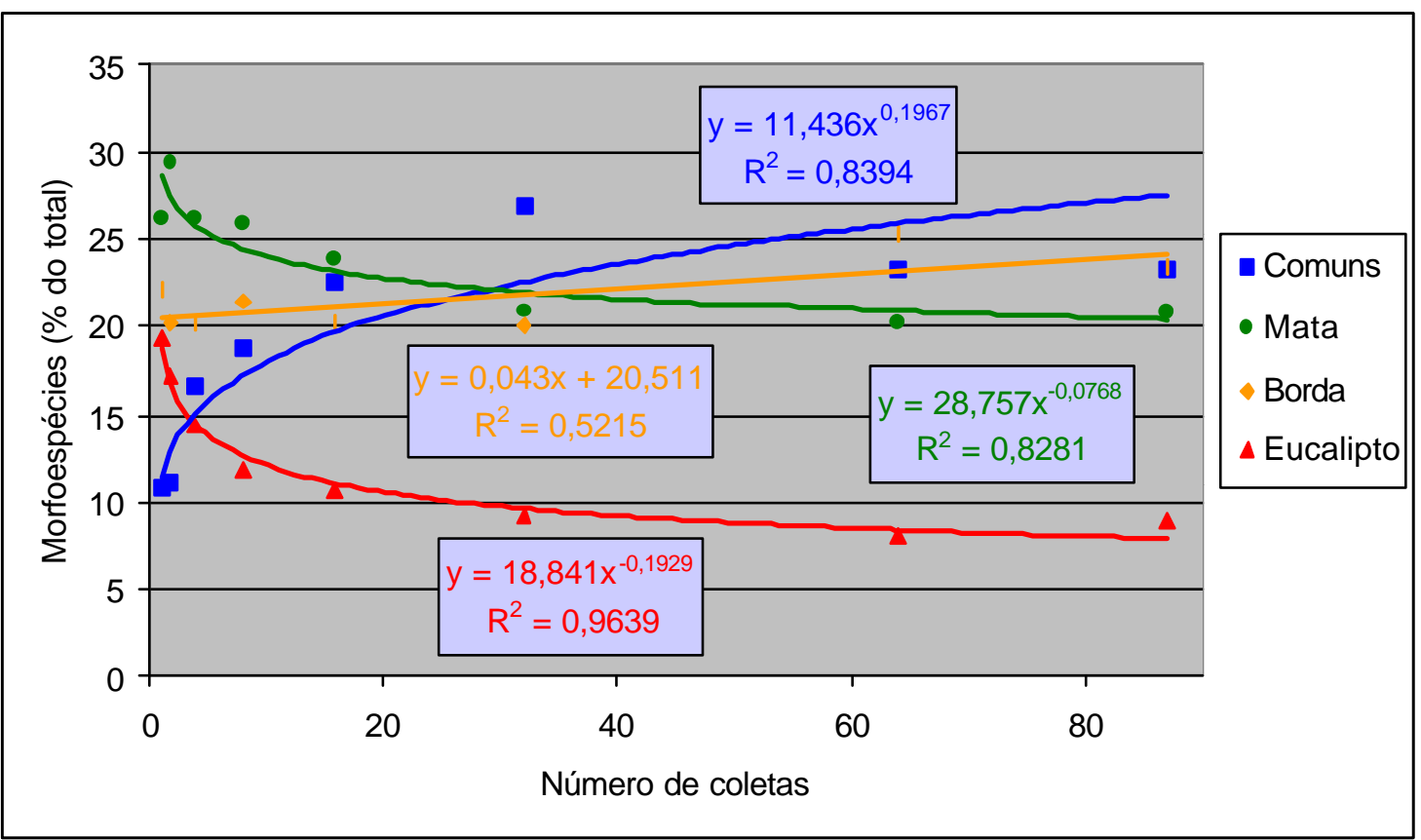

Figura 42 - Porcentagem de morfoespécies comuns e exclusivas entre mata, borda e eucalipto (local 6), em função do período de coleta. 


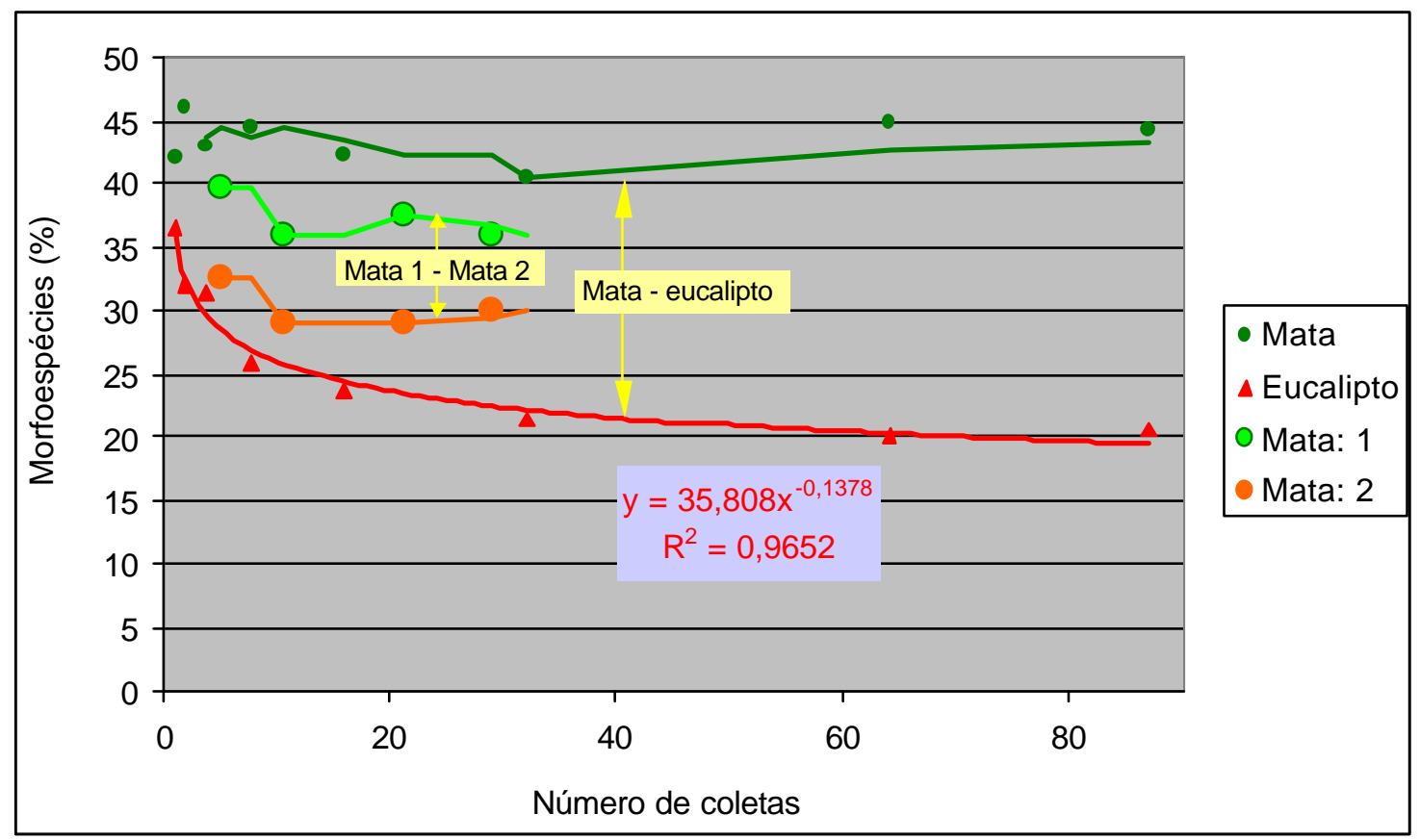

Figura 43 - Porcentagem de morfoespécies exclusivas, entre mata e eucalipto (local 6), e entre os pontos de levantamento 1 e 2, na mata, destacando a diferença entre os valores em cada comparação.

As composições, obtidas com as coletas com armadilhas, mostraram que o sistema mata-eucalipto não segue o padrão de "subconjuntos aninhados", demonstrado por Patterson (1987), onde as espécies, que compõem uma biota insular degradada, são formadas por um subconjunto de uma biota mais rica, fonte de recursos e assim por diante.

$\mathrm{Na}$ comparação de morfoespécies comuns e exclusivas, entre dois ambientes, ou locais diferentes num mesmo ambiente, três informações básicas podem ser obtidas: $1^{\mathrm{a}}$ - morfoespécies comuns; $2^{\mathrm{a}}$ - morfoespécies exclusivas do primeiro ambiente; $3^{\mathrm{a}}$ - morfoespécies exclusivas do segundo ambiente. Quanto maior o número de morfoespécies comuns, mais semelhantes serão os ambientes ou locais comparados. Obtida a porcentagem de morfoespécies comuns, as exclusivas complementam o $100 \%$. No entanto, podem completar de diferentes maneiras, por exemplo: sejam $60 \%$ as morfoespécies comuns, logo $40 \%$ são exclusivas, mas pode ocorrer desde $0 \%$ de para um 
ambiente/local e $40 \%$ para outro, até $20 \%$ para cada um. Assim, pode-se dizer que existe maior semelhança, quanto maior a igualdade das proporções entre as morfoespécies exclusivas dos dois ambientes, ou seja, quanto mais próximo de "zero" for a diferença. Neste caso, trata-se de uma semelhança em riqueza de morfoespécies, que deve ser interpretada de forma diferente, mas complementar, da semelhança proveniente da proporção de morfoespécies comuns.

Nos dados levantados neste estudo, a análise da proporção de morfoespécies comuns mostrou valores diferentes entre comparações dentro dos ambientes e comparações entre eles. Já a diferença nas morfoespécies exclusivas, mostrou dois padrões distintos entre nos dois tipos de comparações (Figura 44), apresentando valores sem diferença significativa para comparações dentro dos ambientes e valores com diferença significativa, nas comparações dentro e entre ambientes. Assim, esse índice proveniente da diferença entre morfoespécies exclusivas, mostrou-se como uma ferramenta eficaz e simples para complementar a comparação da ocorrência de morfoespécies entre dois ambientes. Permite que o padrão resultante da comparação de dois ambientes seja comparado com o padrão de outros dois ambientes, ou dos mesmos, ao longo do tempo. 


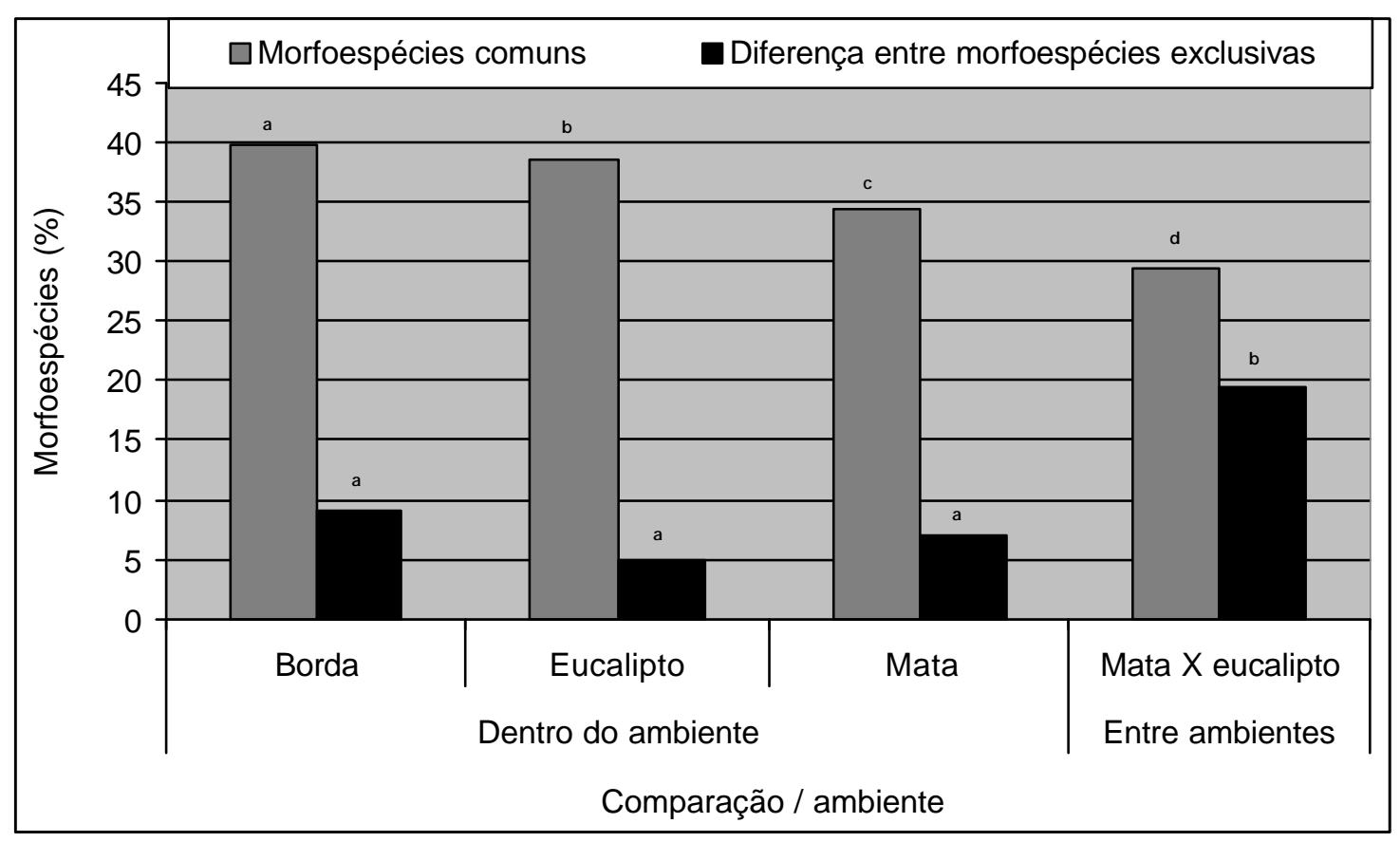

Figura 44-Porcentagem de morfoespécies comuns e diferença na porcentagem de morfoespécies exclusivas, entre pontos de levantamento dentro do ambiente e entre pontos de levantamento de ambientes diferentes: comparação de pontos de coleta dois a dois (coleta com armadilhas luminosas; letras semelhantes indicam valores, para a mesma variável, sem diferença significativa).

A análise de morfoespécies comuns e exclusivas complementa a informação sobre a riqueza e o índice de diversidade. Podem existir ambientes com mesmo número de espécies, ou mesmo índice de diversidade, mas com composição de espécies totalmente diferentes. Essa análise conjunta de riqueza de espécies e composição é fundamental para caracterizar sistemas fragmentados (Patterson, 1987).

Os resultados gerais de índice de diversidade mostram a mata com valores superiores àborda e eucalipto (Figura 45). Os valores obtidos na borda equivalem à análise global de todos os dados. Apesar da borda representar, no geral, a região de maior densidade de pragas, representa também a de maior densidade de inimigos naturais (Figuras 34 a 37) e, para complementar, com uma diversidade superior à encontrada no interior da plantação do eucalipto, 
reforçando a importância do local, nas relações interespecíficas e, conseqüentemente, seu papel na estabilidade ambiental das florestas plantadas.

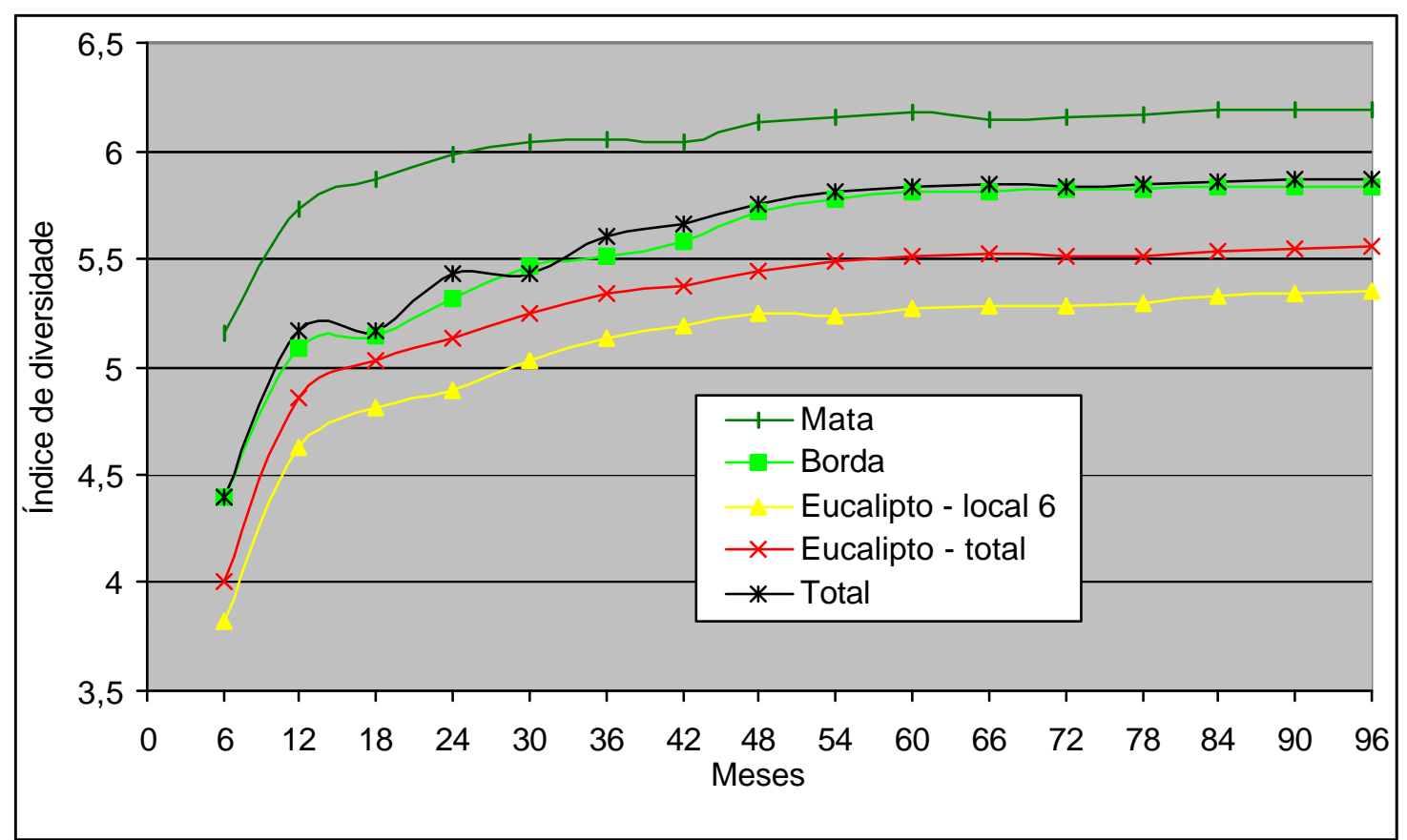

Figura 45 - Índice de diversidade para morfoespécies, acumulado ao longo do período de coleta.

O índice de diversidade aplicado para grupos de insetos úteis, inimigos naturais e pragas do eucalipto, em cada estação do ano, indica que na primavera, do mesmo modo que ocorre com o número de indivíduos, não apresenta diferença significativa entre mata, borda e eucalipto (Figura 46).

No verão, basicamente os mesmos grupos que foram mais abundantes, na borda e eucalipto, também se mostram mais diversificados e com maior aproximação entre borda e eucalipto (Figura 47). No outono, destaca-se a maior diversidade da borda e eucalipto, para parasitas, predadores-polinizadores e pragas secundárias. No inverno, continua o mesmo padrão para estes dois últimos grupos. 


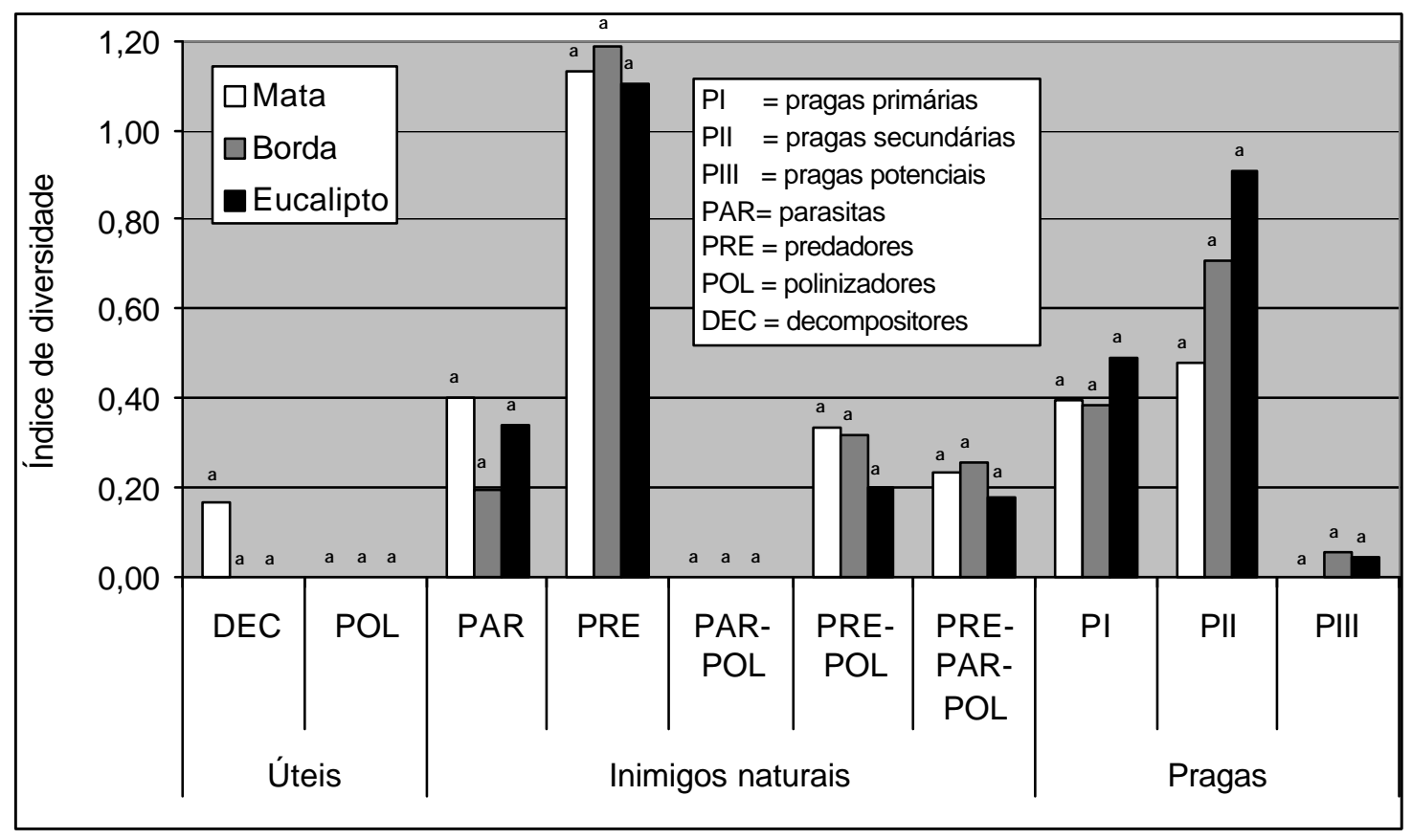

Figura 46-Índice de diversidade médio para morfoespécies, por ponto de levantamento, para cada guilda e ambiente, na primavera (letras iguais correspondem a valores sem diferença significativa, na comparação de ambientes em cada guilda). 


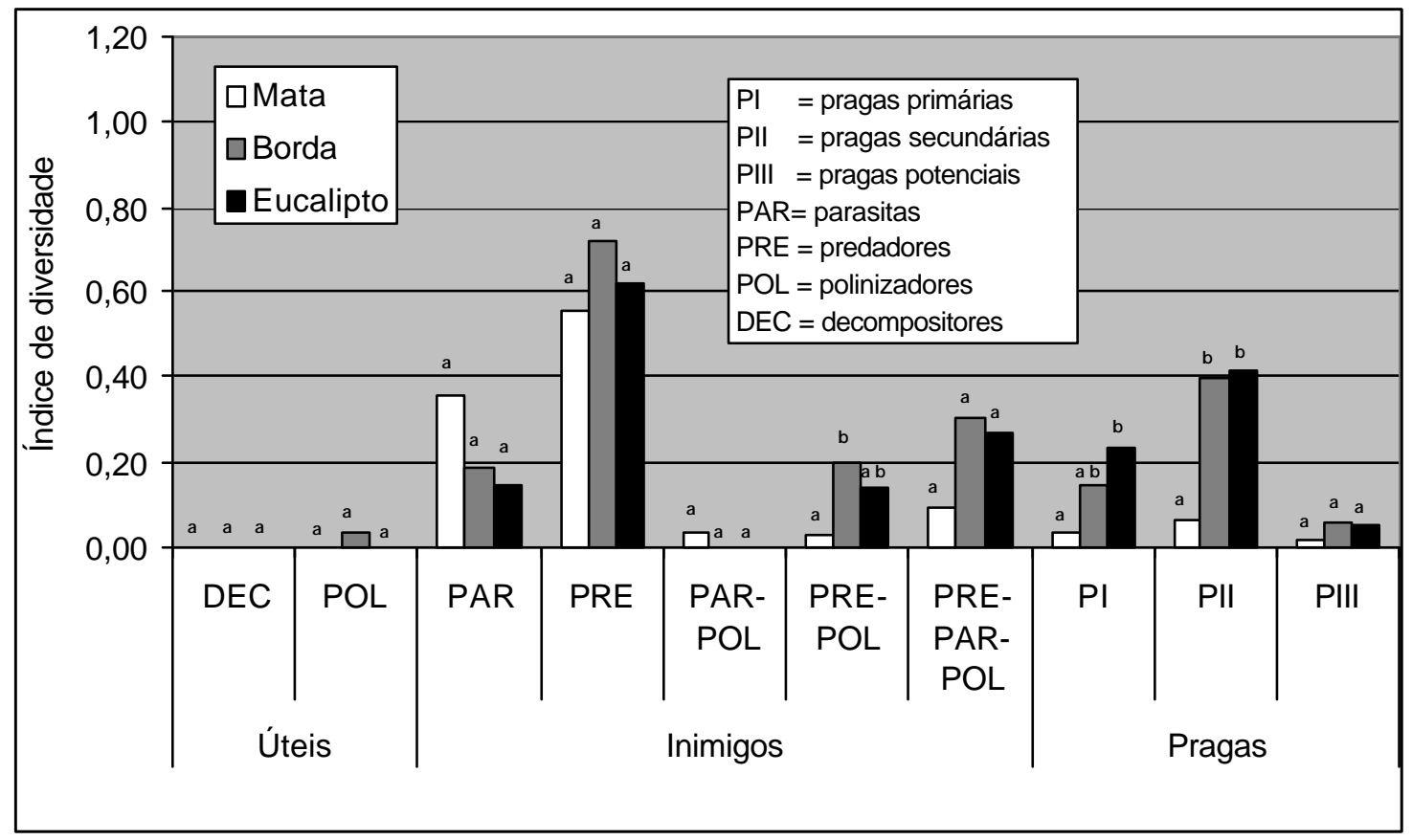

Figura 47-Índice de diversidade médio para morfoespécies, por ponto de levantamento, para cada guilda e ambiente, no verão (letras iguais correspondem a valores sem diferença significativa, na comparação de ambientes em cada guilda).

O índice de diversidade para pragas secundárias mostrou-se sempre superior ao de pragas primárias e pragas potenciais. Certamente é um grupo com grande potencial para alcançar o status de praga, dependendo dos processos adaptativos à cultura e dos fatores naturais de controle, que promovem a estabilidade. 


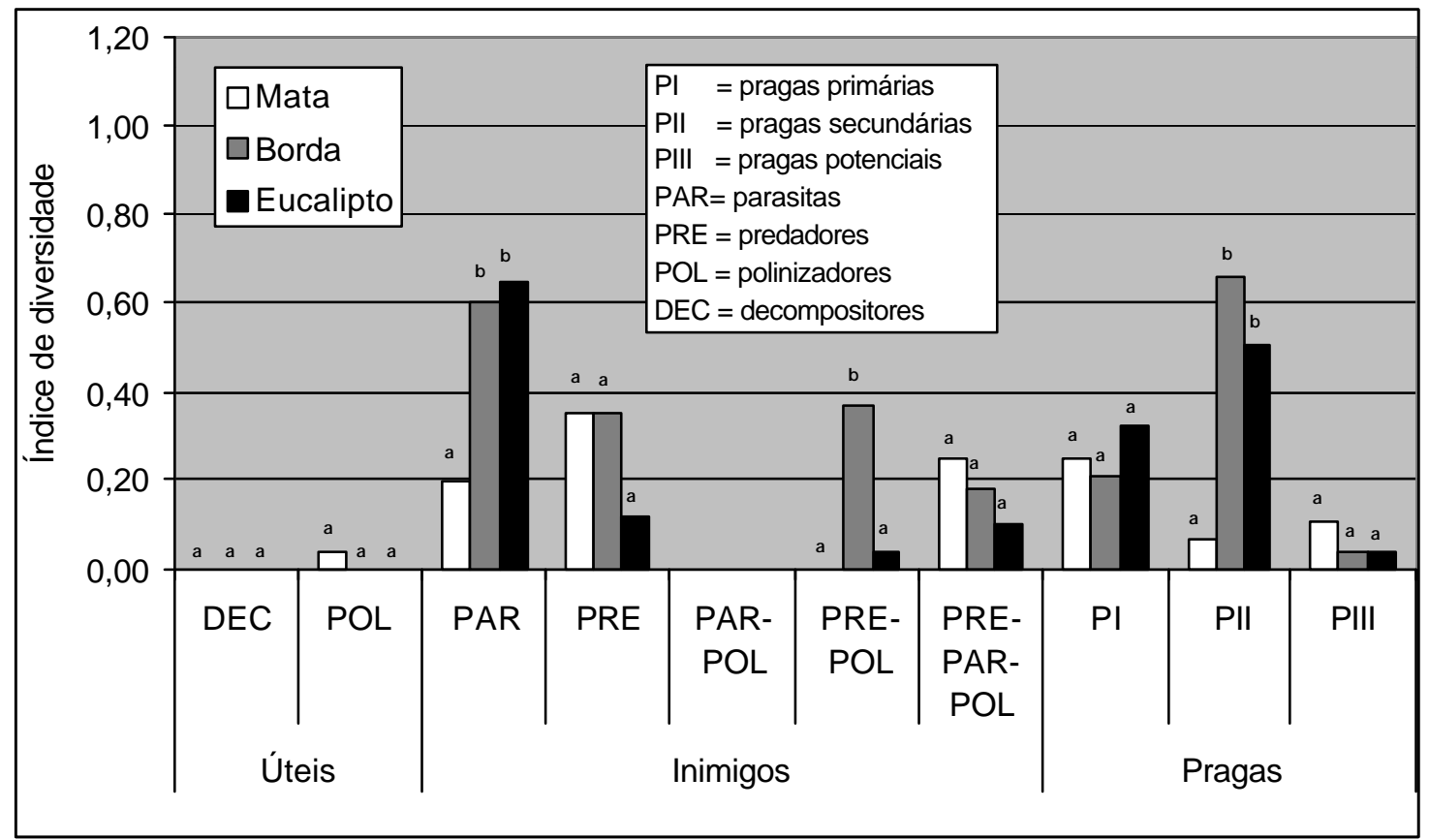

Figura 48-Índice de diversidade médio para morfoespécies, por ponto de levantamento, para cada guilda e ambiente, no outono (letras iguais correspondem a valores sem diferença significativa, na comparação de ambientes em cada guilda).

O índice de diversidade para as famílias de Coleoptera e Lepidoptera, mais representativas da diversidade total, mostrou valores superiores na mata, para quatro, das cinco famílias da primavera (Figura 50). No verão, a maioria das famílias apresentou maior valor para borda, seguida da mata (Figura 51). No outono, houve um destaque ainda maior para a borda (Figura 52). 


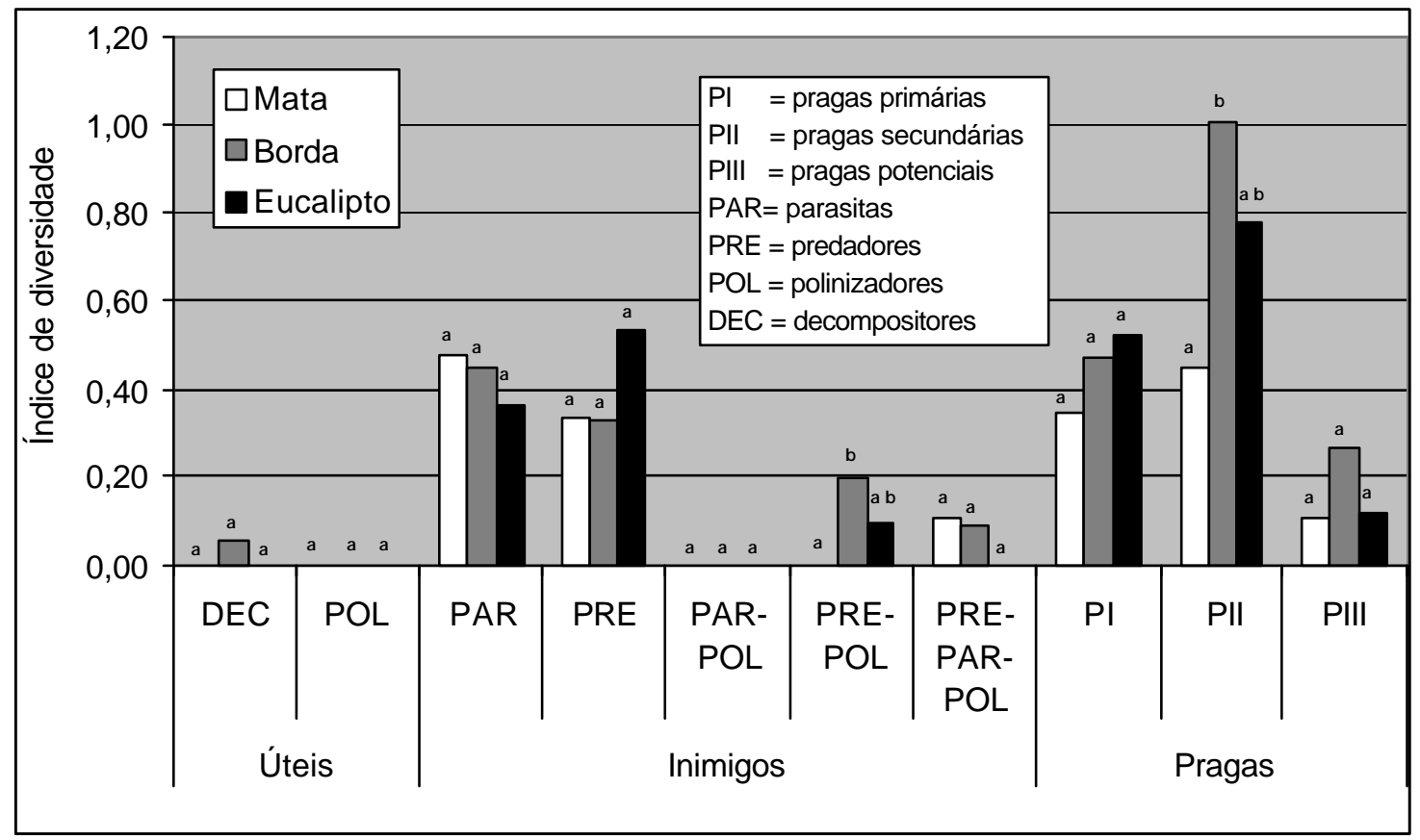

Figura 49-Índice de diversidade médio para morfoespécies, por ponto de levantamento, para cada guilda e ambiente, no inverno (letras iguais correspondem a valores sem diferença significativa, na comparação de ambientes em cada guilda). 


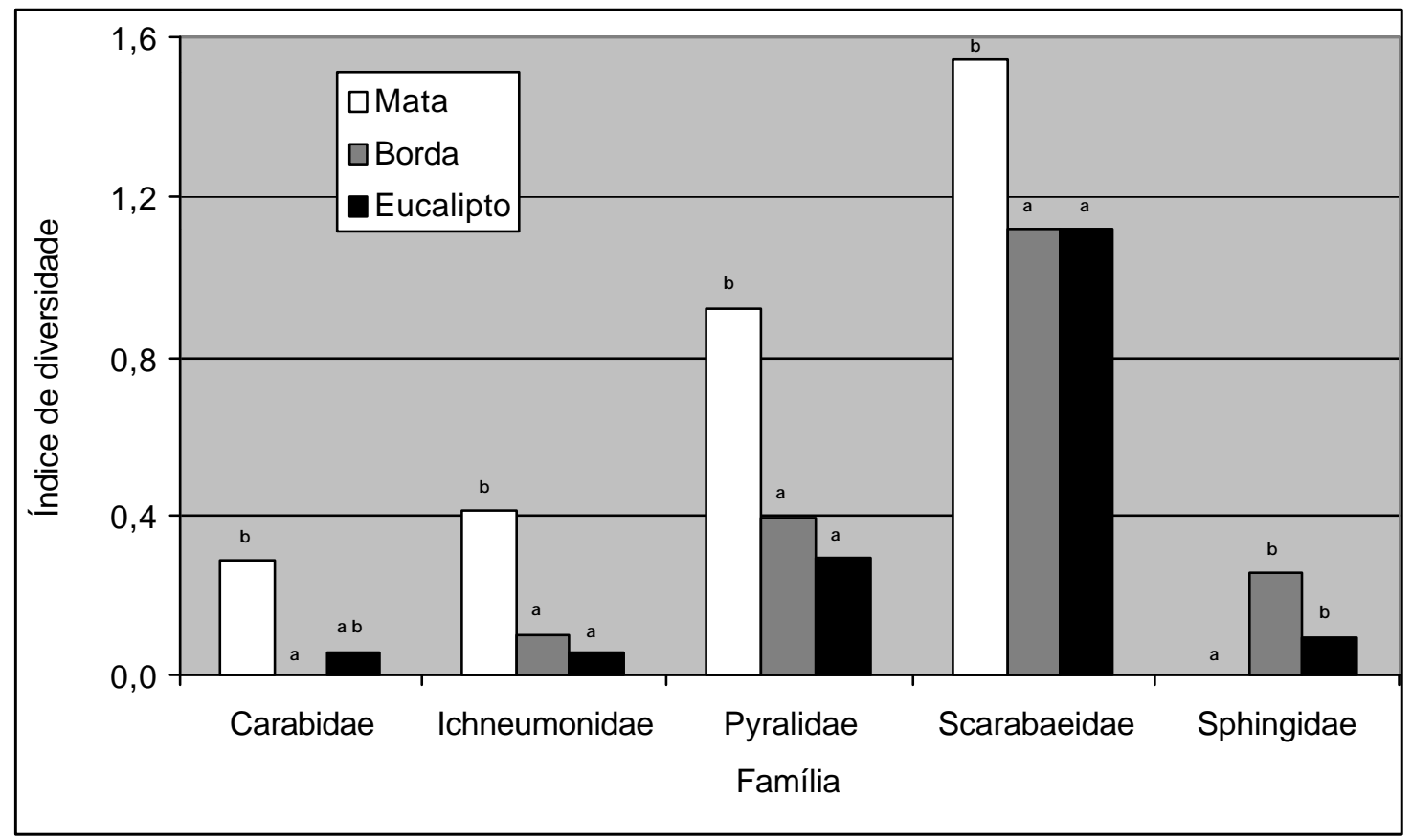

Figura 50 - Índice de diversidade médio para morfoespécies, dos pontos de levantamento, nas famílias selecionadas, por ambiente (códigos dos locais na mata, borda e eucalipto: 1, 2 e 6, respectivamente), na primavera (letras iguais correspondem a valores sem diferença significativa, na comparação de ambientes em cada família). 


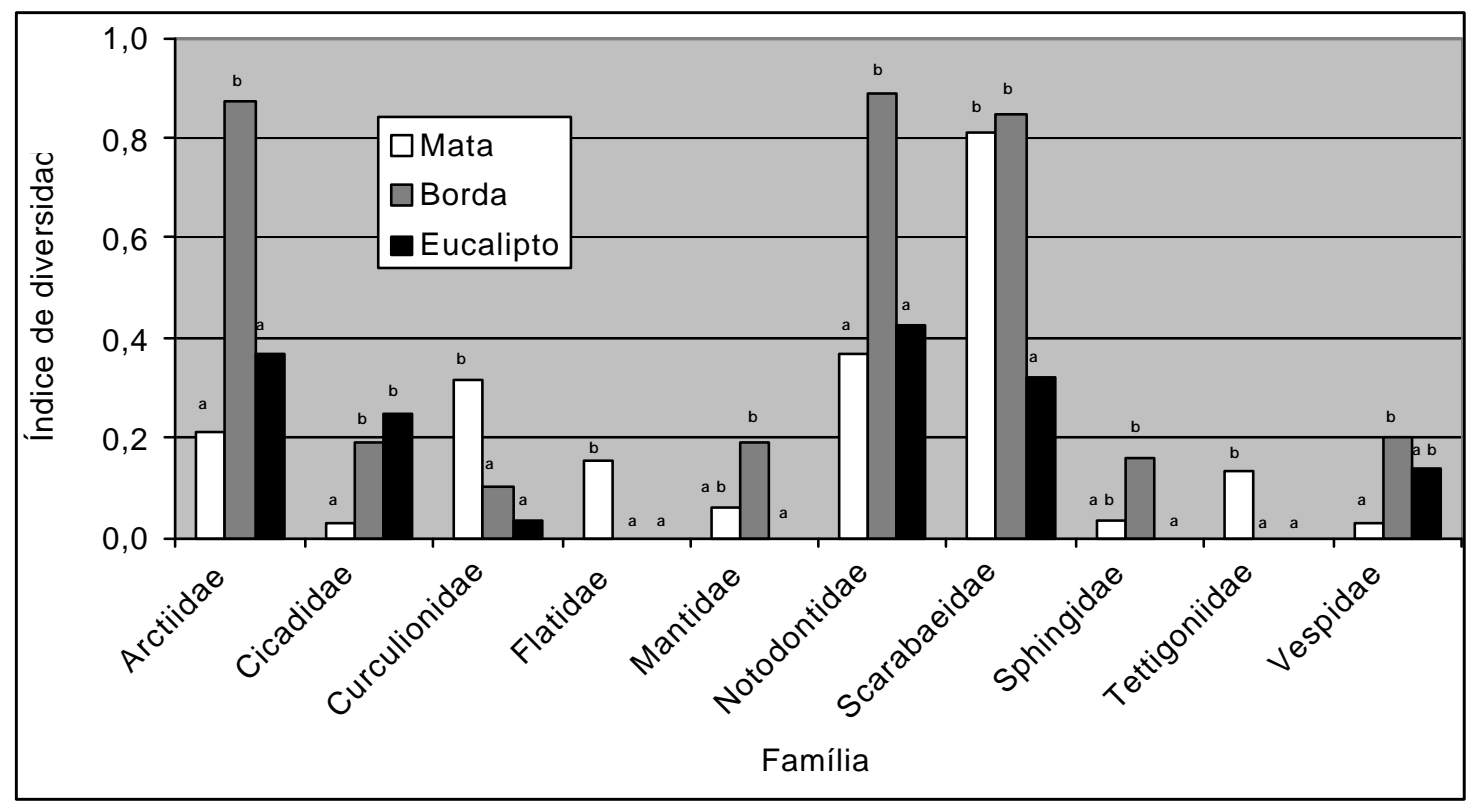

Figura 51 - Índice de diversidade médio para morfoespécies, dos pontos de levantamento, nas famílias selecionadas, por ambiente (códigos dos locais na mata, borda e eucalipto: 1, 2 e 6, respectivamente), no verão (letras iguais correspondem a valores sem diferença significativa, na comparação de ambientes em cada família).

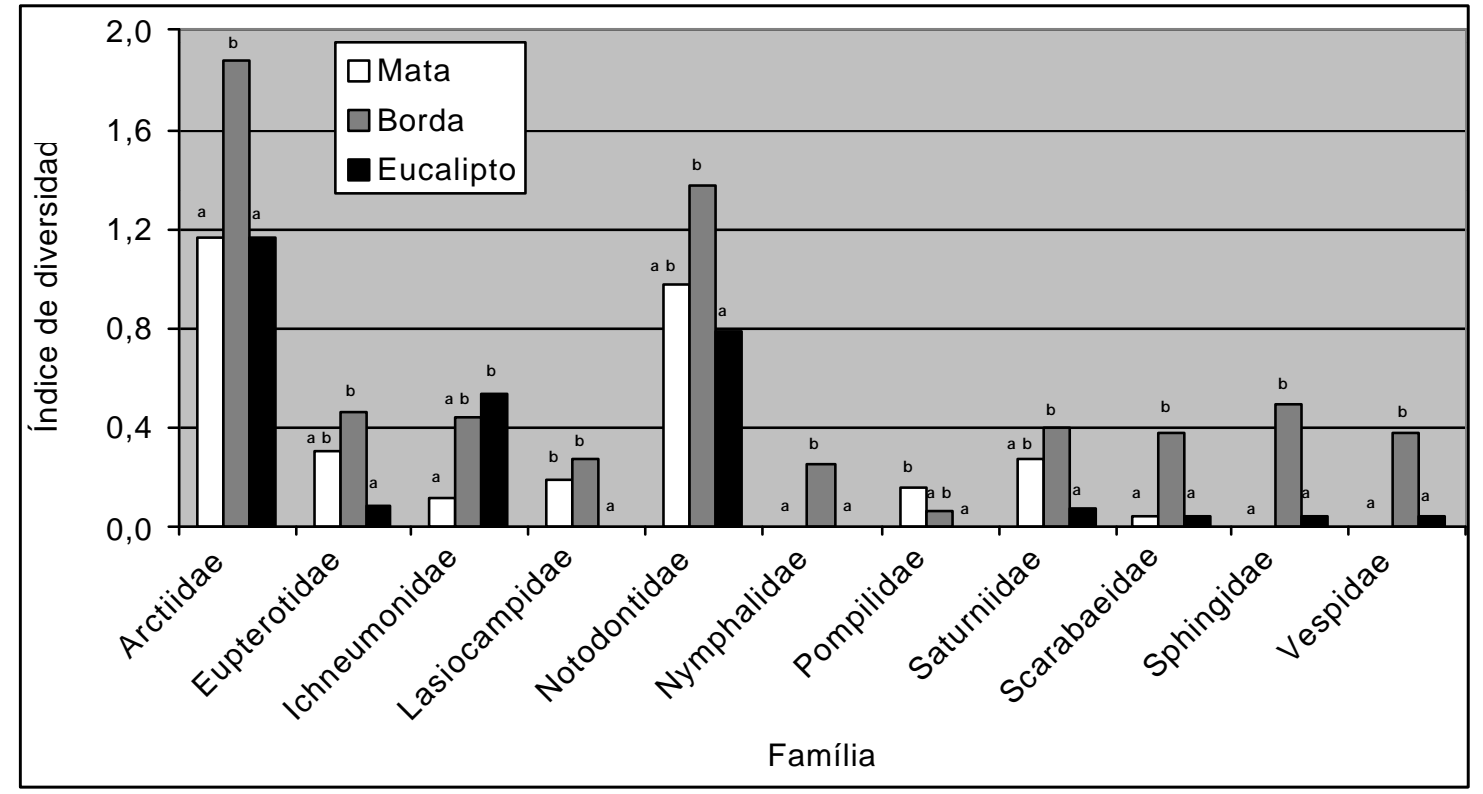

Figura 52 - Índice de diversidade médio para morfoespécies, dos pontos de levantamento, nas famílias selecionadas, por ambiente (códigos dos locais na mata, borda e eucalipto: 1, 2 e 6, respectivamente), no outono (letras iguais correspondem a valores sem diferença significativa, na comparação de ambientes em cada família). 


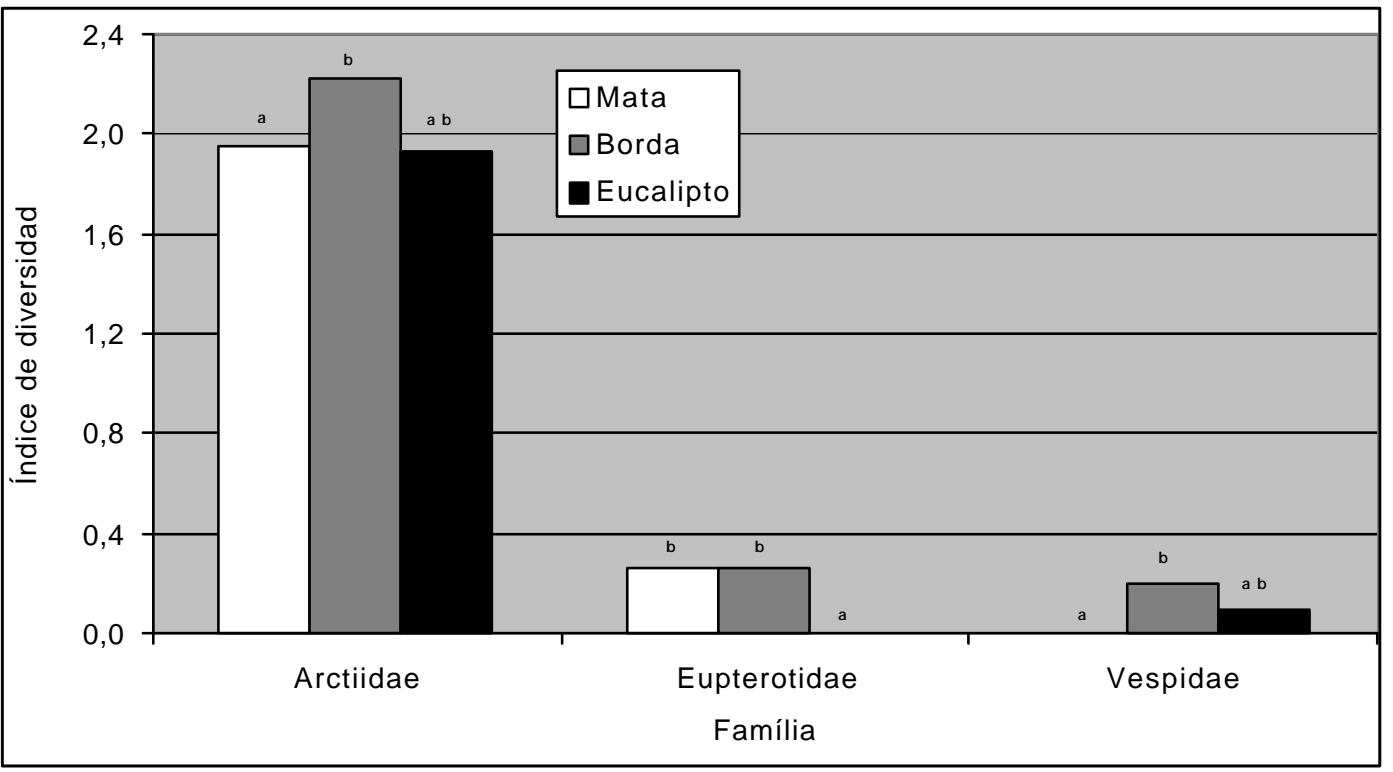

Figura 53 - Índice de diversidade médio para morfoespécies, dos pontos de levantamento, nas famílias selecionadas, por ambiente (códigos dos locais na mata, borda e eucalipto: 1, 2 e 6, respectivamente), no inverno (letras iguais correspondem a valores sem diferença significativa, na comparação de ambientes em cada família). 


\subsection{Temperatura e precipitação}

A região caracteriza-se, basicamente, por período de inverno seco e verão chuvoso (Figuras 54 e 55).

Os resultados das análises de regressão mostraram que os dados de temperatura e precipitação têm relação significativa com o número de indivíduos, com o número de morfoespécies e com o índice de diversidade (Tabela 8).

Para o número de indivíduos na primavera, observou-se efeito significativo da precipitação, apenas quando se considerou a média dos seis meses anteriores à coleta, ou seja, o número de indivíduos na primavera é dependente da precipitação no outono e inverno. No verão, onde a temperatura e precipitação são mais elevadas, esses dois fatores não tiveram efeito significativo. Já no outono, os dois fatores tiveram efeito significativo no semestre anterior à coleta. A temperatura também mostrou efeito maior em curto prazo, ou seja, existiu influência significativa do mês anterior. No inverno, apenas a temperatura, considerando os três e seis meses antes da coleta, mostrou forte evidência de efeito sobre o número de insetos.

Para o número de morfoespécies na primavera, assim como para o número de indivíduos, os dados de temperatura dos seis meses anteriores foram significativos. No entanto, para o número de morfoespécies a precipitação também mostrou relação, só que de maneira menos evidente. Do mesmo modo, foi a ação da precipitação no verão, assim como a temperatura nos meses anteriores à coleta. No outono, apenas a temperatura mostrou evidências de relação com o número de morfoespécies, considerando o período de três e, principalmente, de seis meses antes da coleta. 


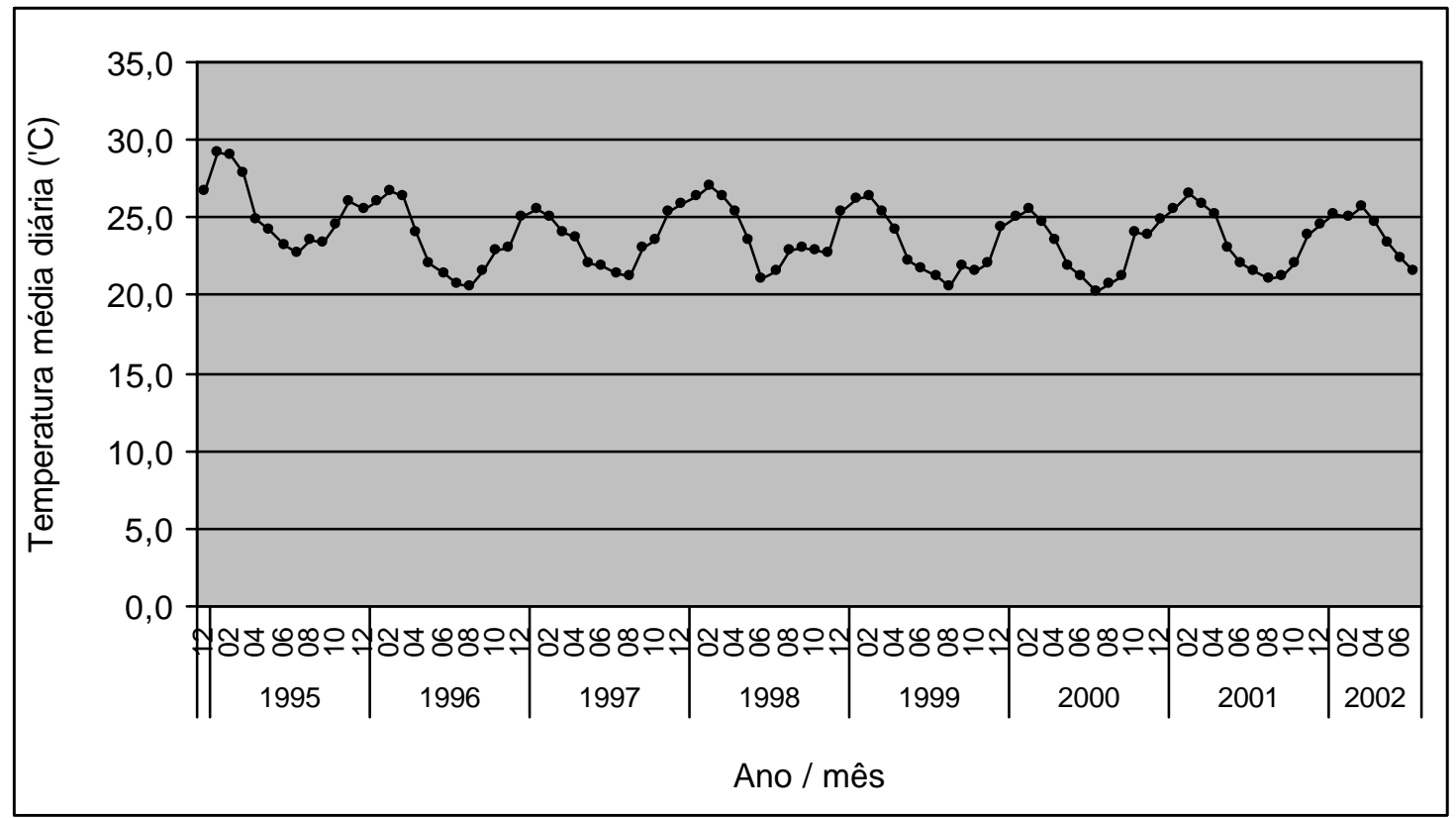

Figura 54 - Temperatura $\left({ }^{\circ} \mathrm{C}\right)$ média diária em cada mês do período de levantamento.

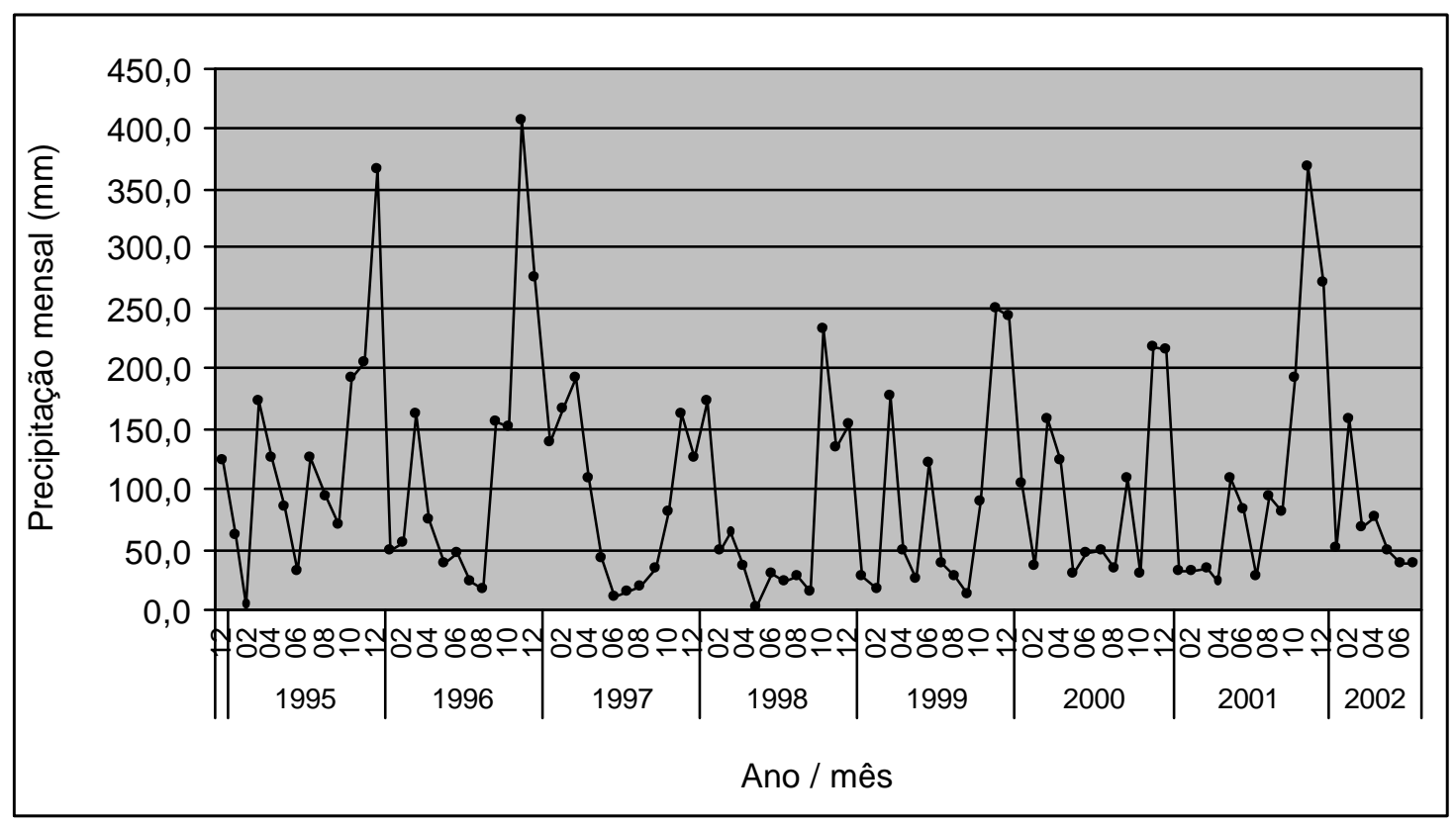

Figura 55 - Precipitação $(\mathrm{mm})$ total em cada mês do período de levantamento. 
Para o número de morfoespécies no inverno, o principal fator continuou sendo a temperatura, considerando os seus valores de um mês até seis meses antes da coleta.

Como conseqüência da ação sobre o número de indivíduos e de morfoespécies, o índice de diversidade foi afetado significativamente pela precipitação e, principalmente, pela temperatura, sendo que a estação mais afetada, continuou sendo o inverno.

A temperatura e precipitação no mês de coleta, na maioria das vezes, tiveram relação nada significativa com as variáveis estudadas da entomofauna. Duas causas prováveis podem ser levantadas. A primeira, é que a data de coleta pode ter ocorrido num período inicial do mês onde as condições climáticas foram diferentes daquelas apuradas para todo o mês. A segunda, é as que mudanças climáticas podem não ter efeito imediato sobre a geração presente das populações, ou ainda, ter efeito apenas sobre gerações futuras.

No modelo matemático analisado, o maior coeficiente de determinação foi obtido para número de morfoespécies no inverno $\left(r^{2}=0,69\right.$, Tabela 8$)$. Outros modelos podem ser aplicados, provavelmente explicando melhor os dados observados. O objetivo neste trabalho foi, unicamente, mostrar que a relação é significativa, o que pode auxiliar na explicação de outros fatores, principalmente fase ou idade da plantação de eucalipto.

Pelos dados obtidos nesta simples incursão a respeito da influência do clima, a investigação de outros modelos matemáticos apresenta perspectiva otimista para auxiliar no entendimento mais preciso a dinâmica das populações de insetos na região. É uma importante indicação para o desenvolvimento de trabalhos futuros. 
Tabela 8. Resultados da análise de regressão entre três variáveis estudadas na entomofauna e a precipitação e temperatura (modelo: variável transformada $=a+b . P 0+$ c.PM1 + d.PM3 + e.PM6 + f.T0 + g.TM1 + h.TM3 +i.TM6).

\begin{tabular}{|c|c|c|c|c|c|c|c|c|c|c|c|c|}
\hline \multirow{2}{*}{ Variável } & \multirow{2}{*}{ Estação } & \multirow{2}{*}{$\begin{array}{c}\text { Prob. }>\text { F } \\
\text { Modelo }\end{array}$} & \multirow{2}{*}{$r^{2}$} & \multirow{2}{*}{ CV } & \multicolumn{8}{|c|}{ Prob. $>\mathrm{T}$} \\
\hline & & & & & P0 & PM1 & PM3 & PM6 & TO & TM1 & TM3 & TM6 \\
\hline $\mathrm{IND}^{0,1}$ & Primavera & 0,0004 & 0,5229 & 7,24 & 0,8271 & 0,8721 & 0,6201 & 0,2557 & 0,3524 & 0,9409 & 0,6636 & 0,0118 \\
\hline $\mathrm{IND}^{0,1}$ & Verão & 0,0338 & 0,2578 & 9,07 & 0,1582 & 0,2537 & 0,9906 & 0,8613 & 0,6845 & 0,1594 & 0,6353 & 0,2568 \\
\hline $\mathrm{IND}^{0,1}$ & Outono & 0,0001 & 0,4425 & 7,53 & 0,8452 & 0,4691 & 0,0384 & 0,0137 & 0,1342 & 0,0344 & 0,1027 & 0,0062 \\
\hline $\mathrm{IND}^{0,1}$ & Inverno & 0,0001 & 0,6479 & 6,33 & 0,1324 & 0,7992 & 0,8521 & 0,1849 & 0,8661 & 0,0063 & 0,0011 & 0,0004 \\
\hline $\mathrm{SP}^{0,2}$ & Primavera & 0,0001 & 0,5597 & 10,83 & 0,7959 & 0,6278 & 0,6792 & 0,0974 & 0,0429 & 0,8471 & 0,2276 & 0,0061 \\
\hline $\mathrm{SP}^{0,2}$ & Verão & 0,0335 & 0,2582 & 13,08 & 0,3999 & 0,9107 & 0,2266 & 0,0826 & 0,3040 & 0,0741 & 0,1264 & 0,2689 \\
\hline$S P^{0,2}$ & Outono & 0,0001 & 0,4890 & 12,05 & 0,5689 & 0,1410 & 0,6432 & 0,3795 & 0,7021 & 0,3447 & 0,0846 & 0,0004 \\
\hline $\mathrm{SP}^{0,2}$ & Inverno & 0,0001 & 0,6926 & 9,82 & 0,0995 & 0,9910 & 0,7465 & 0,5810 & 0,3733 & 0,0051 & 0,0006 & 0,0001 \\
\hline$(\mathrm{H}+0,5)^{1,4}$ & Primavera & 0,0001 & 0,5844 & 26,89 & 0,3840 & 0,7649 & 0,4818 & 0,0946 & 0,0355 & 0,4728 & 0,0354 & 0,0010 \\
\hline$(\mathrm{H}+0,5)^{1,4}$ & Verão & 0,0734 & 0,2262 & 33,21 & 0,4951 & 0,6315 & 0,0328 & 0,0040 & 0,0697 & 0,0958 & 0,0928 & 0,2353 \\
\hline$(\mathrm{H}+0,5)^{1,4}$ & Outono & 0,0001 & 0,4793 & 30,92 & 0,4339 & 0,0583 & 0,6192 & 0,9437 & 0,9288 & 0,8957 & 0,1811 & 0,0015 \\
\hline$(H+0,5)^{1,4}$ & Inverno & 0,0001 & 0,6251 & 22,80 & 0,1116 & 0,9525 & 0,4235 & 0,2250 & 0,0380 & 0,0099 & 0,0095 & 0,0017 \\
\hline
\end{tabular}

Legenda: IND = número de indivíduos de insetos; $\mathrm{SP}=$ número de morfoespécies; $\mathrm{H}=$ índice de diversidade; Modelo = probabilidade $>\mathrm{F}$ para o modelo de regressão; $r^{2}=$ coeficiente de determinação; CV = coeficiente de variação (\%); P0 = precipitação (mm) no mês da coleta; $\mathrm{PM} 1=$ precipitação $(\mathrm{mm})$ no mês anterior àcoleta; $\mathrm{PM} 3=$ precipitação média mensal $(\mathrm{mm})$ no trimestre anterior àcoleta; PM6 = precipitação média mensal $(\mathrm{mm})$ no semestre anterior àcoleta; $\mathrm{T} 0=$ temperatura média diária $\left({ }^{\circ} \mathrm{C}\right)$ no mês da coleta; TM1 = temperatura média diária $\left({ }^{\circ} \mathrm{C}\right)$ no mês anterior àcoleta; TM3 = temperatura média diária $\left({ }^{\circ} \mathrm{C}\right)$ no trimestre anterior àcoleta; $\mathrm{TM} 6=$ temperatura média diária $\left({ }^{\circ} \mathrm{C}\right)$ no semestre anterior àcoleta; 


\subsection{Fase silvicultural}

A divisão das coletas em períodos complementares de nove meses e de três meses, conforme Figura 3, foi estabelecida em função do início dos levantamentos em novembro de 1994 e do período das atividades de colheita do eucalipto nos locais estudados, de agosto a outubro de 1996. Os períodos de três meses (3A a 3G, na Figura 3) correspondem à época das atividades de colheita. Os outros nove meses completam um ano. Assim, comparações entre os períodos de três meses, ou entre os de nove, são feitas em igualdade de época do ano, o que é fundamental, visto a característica sazonal de várias espécies de insetos.

A caracterização da distribuição das morfoespécies em classes de densidade relativa, nos períodos de três meses, antes, durante e depois do corte do eucalipto, mostrou padrões diferentes entre os períodos, em cada tipo de ambiente (Figura 56).

A mata, como era previsto, em função de sua maior diversidade, mostrou-se com padrões mais estáveis da distribuição da densidade relativa, entre os períodos, ou seja, ao longo do tempo. Destaca-se a resposta inversa do eucalipto, em relação à mata e borda, nos períodos correspondentes à colheita e no primeiro e no segundo anos após essa fase. No eucalipto, nota-se a redução das freqüências de morfoespécies, com valores intermediários de densidade relativa, e aumento para espécies de valores maiores. 


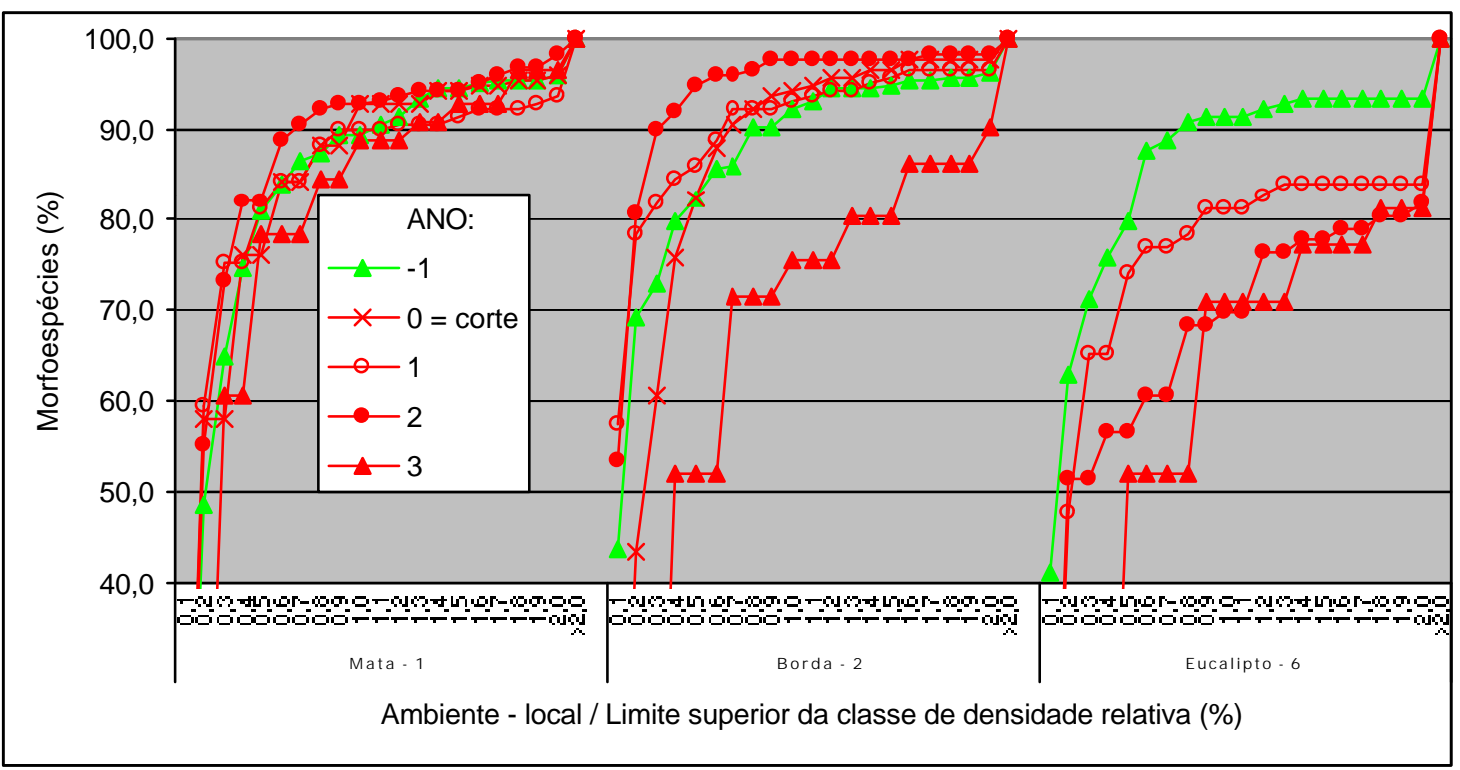

Figura 56 - Porcentagem de morfoespécies em função da classe de densidade relativa, em períodos de três meses (agosto a outubro), em cinco anos, identificados em relação ao ano do corte do eucalipto no local 6 , onde não houveram coletas durante a fase de colheita da madeira (coletas com armadilhas luminosas).

No terceiro ano após o corte do eucalipto, a tendência foi semelhante sobre os grupos de morfoespécies de valores intermediários e maiores de densidade relativa, porém ocorreu o mesmo na borda e na mata, decrescendo nessa ordem o efeito sobre os grupos de morfoespécies.

Ressalta-se que os dois últimos períodos de três meses não foram considerados na análise, pela não ocorrência de duas coletas mensais em um deles (3F) e de uma no segundo (3G), conforme apresentado na Figura 3.

Pelos dados apresentados até este ponto, não se pode afirmar que o corte teve qualquer influência sobre a distribuição de densidade relativa. A causa poderia estar relacionada com, por exemplo, o clima. De qualquer modo, verifica-se a característica de maior estabilidade na região de borda e, principalmente, na mata, seja forem ou fatores responsáveis, climáticos, biológicos, ou de manejo da floresta comercial.

O eucalipto no local 5 não teve qualquer atividade de exploração da madeira nos primeiros cinco anos de levantamento. Quando se analisa a sua 
distribuição de densidade relativa (Figura 57), verifica-se a mesma tendência entre os períodos de três meses no eucalipto com corte, local 6. Assim, existem duas hipóteses: $1^{\mathrm{a}}$ - as diferenças entre os períodos são devidas a fatores ambientais não controlados neste estudo; $2^{\mathrm{a}}$ - a distância de cerca de 600 m, entre o eucalipto do local 5 (talhão 006-04), não foi suficiente para isolar o efeito das atividades de colheita. Se a segunda hipótese for verdadeira, significa que o padrão de distribuição de densidade relativa estudado, poderá ser utilizado como uma medida do efeito do corte, sobre a vizinhança, a diferentes distâncias. Em todo o caso, a distribuição geográfica dos pontos de levantamento deste estudo, frente à atividade de colheita que ocorreram na região, não permitem uma conclusão definitiva sobre o efeito da colheita sobre a distribuição da densidade relativa.

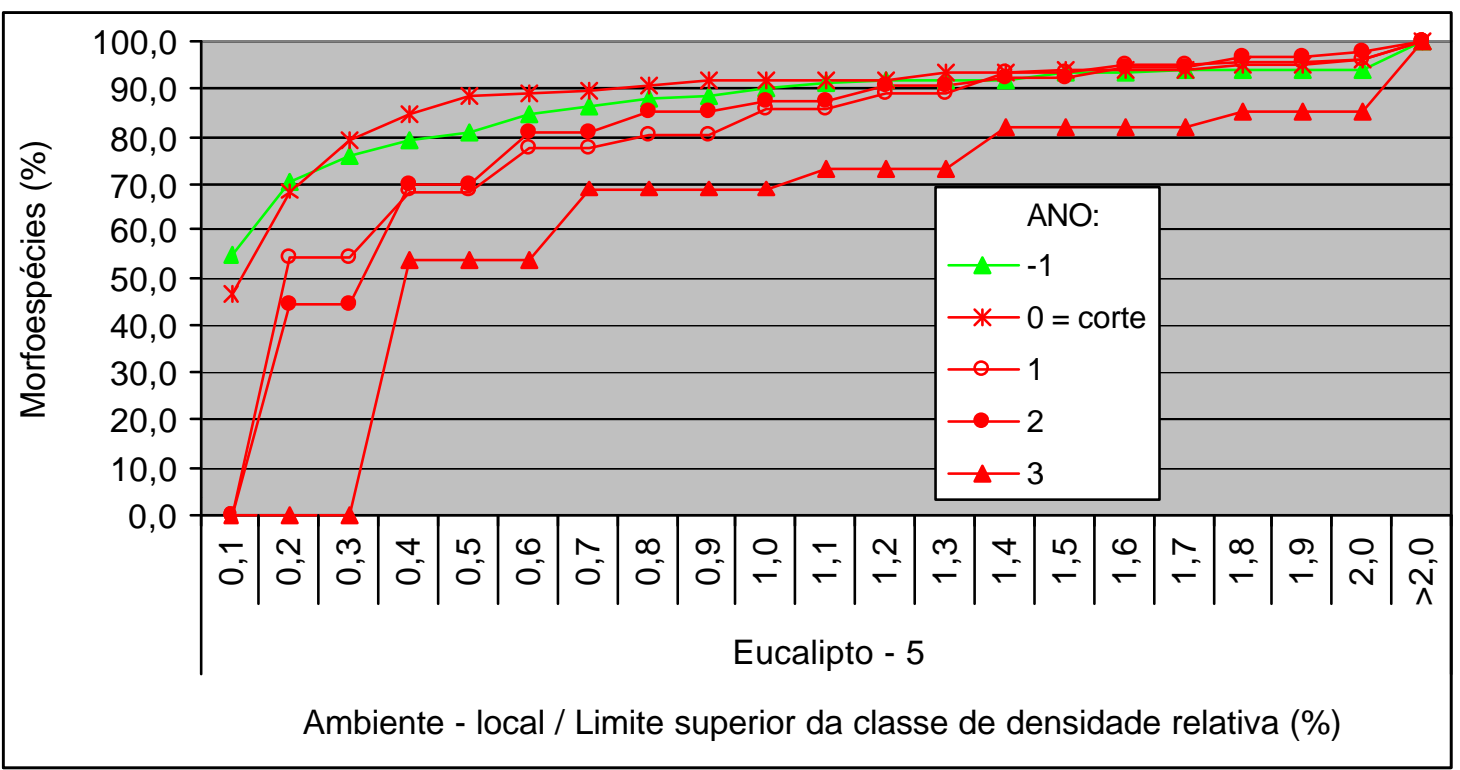

Figura 57 - Porcentagem de morfoespécies em função da classe de densidade relativa, para eucalipto no local 5 , em períodos de três meses (agosto a outubro), em cinco anos, identificados em relação ao ano do corte do eucalipto no local 6 (coletas com armadilhas luminosas).

A análise dos períodos de nove meses, especificados na Figura 3, permite uma comparação até o sexto ano após o corte do eucalipto (Figura 58). 
Até o terceiro ano depois do corte, verifica-se o mesmo comportamento já descrito para os períodos de três meses. No ano seguinte, acentua-se o padrão observado para o terceiro ano após o corte, com o mesma seqüência decrescente para eucalipto, borda e mata.

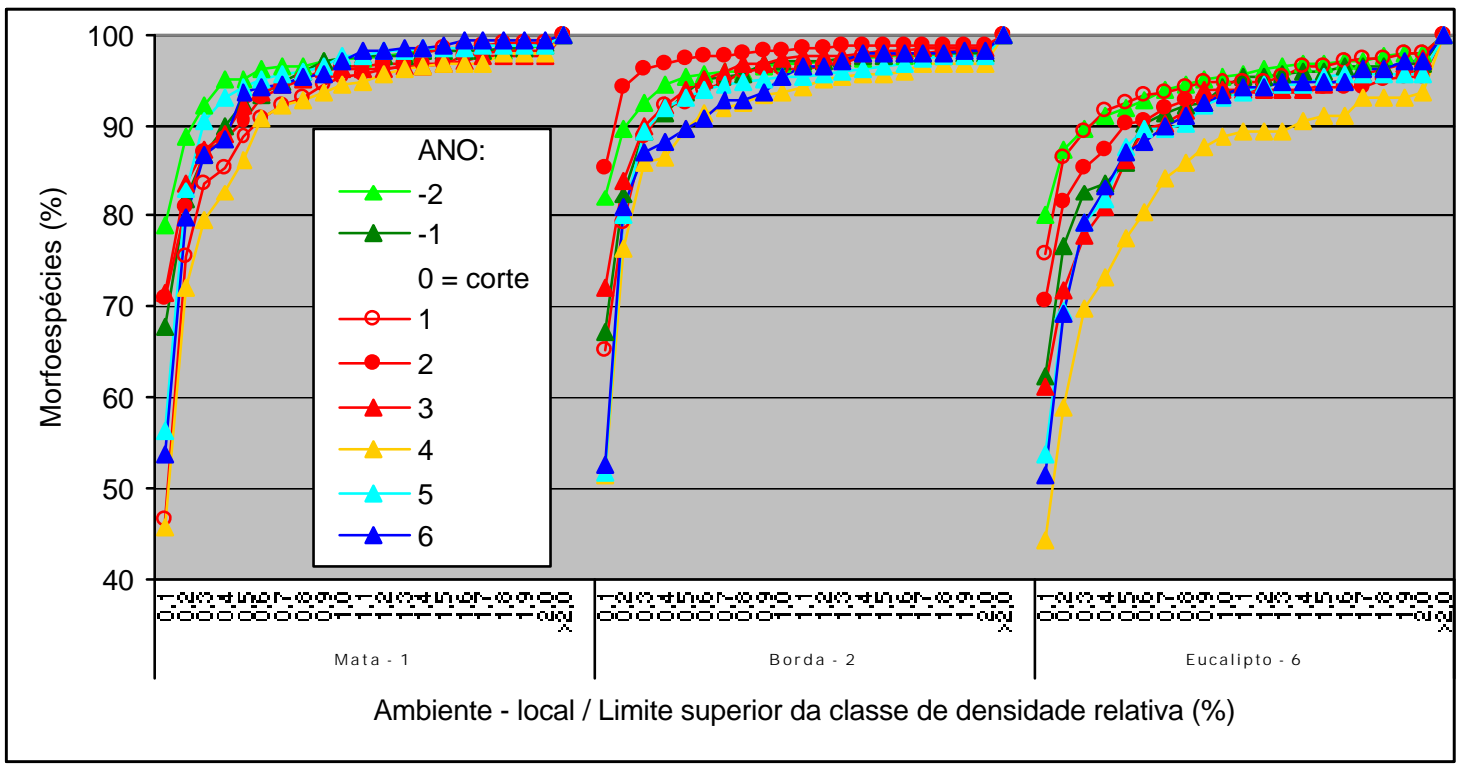

Figura 58 - Porcentagem de morfoespécies em função da classe de densidade relativa, em períodos de nove meses (novembro a julho), em sete anos, identificados em relação ao ano do corte do eucalipto no local 6 (coletas com armadilhas luminosas).

Nos dois últimos anos, observa-se a aproximação ao padrão antes do corte, nos três ambientes.

A observação da distribuição da densidade relativa, nos períodos de nove meses, para o eucalipto no local 5 , sem corte, também mostra uma aproximação dos dois últimos anos com a fase madura da floresta (Figura . 59). Ressalta-se que as curvas representam pontos de coleta, do local 5, ao invés de todo o "local", como nas figuras anteriores. Assim, verifica-se uma ampliação de diferenças entre os períodos, nos pontos de levantamento, que nos casos anteriores, compunham o todo. 


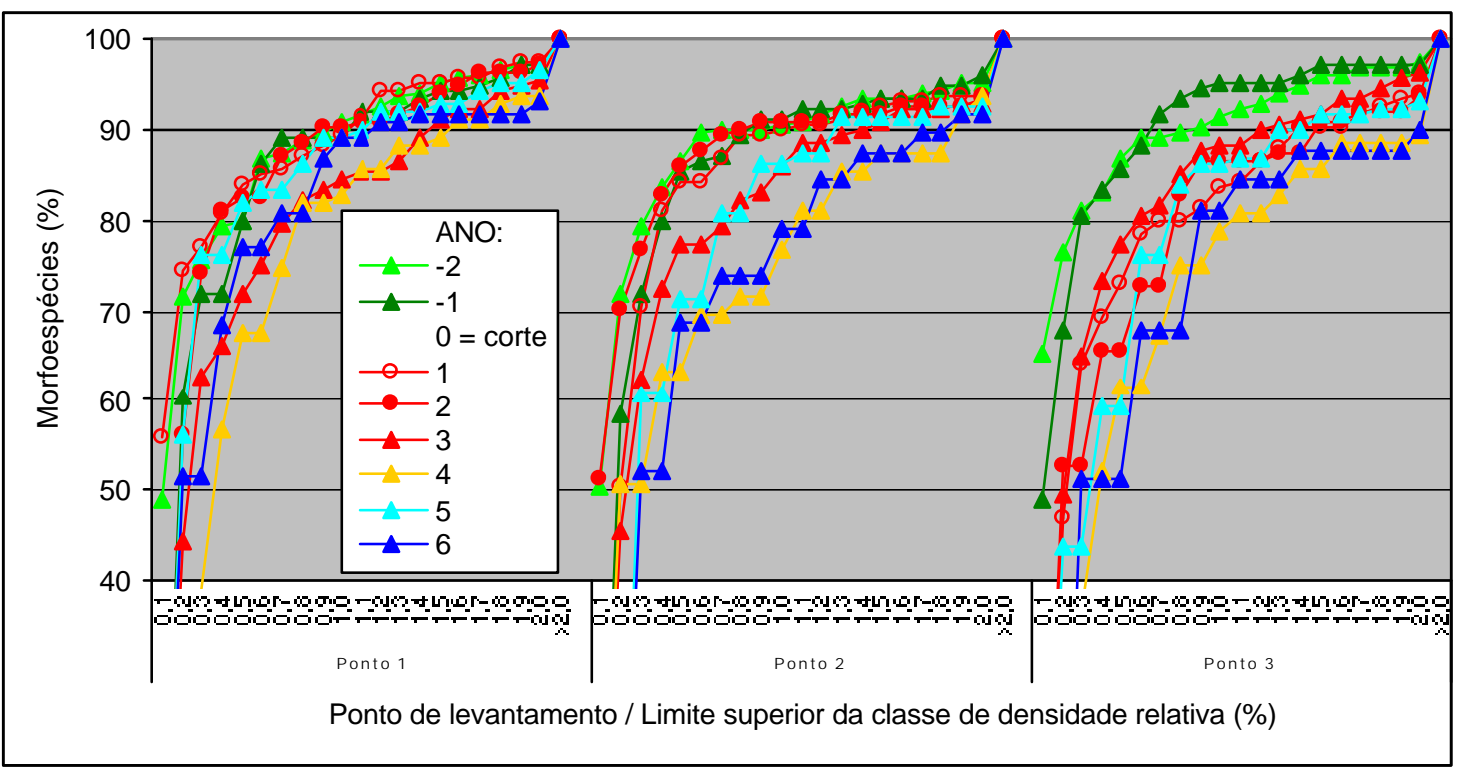

Figura 59 - Porcentagem de morfoespécies em função da classe de densidade relativa, nos três pontos de levantamento no eucalipto, local 5 (sem corte), em períodos de nove meses (novembro a julho), em sete anos, identificados em relação ao ano do corte do eucalipto no local 6 (coletas com armadilhas luminosas).

O aumento das diferenças, entre curvas de períodos diferentes, também pode ser observado nas figuras 60 e 61, que mostram os pontos de coleta da mata e borda, respectivamente.

A separação entre pontos de coleta realizada na mata visando, principalmente, verificar algum efeito diferenciado entre os pontos de levantamento 1 e 3 . O primeiro localiza-se ao lado do talhão 007-06, que teve um primeiro plantio em janeiro de 1997 e um segundo em dezembro do mesmo ano (Figura 3). Assim, o desenvolvimento da floresta plantada nesse local foi atrasado em quase um ano. O ponto 2 situou-se entre esse talhão e outro adjacente, com apenas o primeiro plantio e o ponto 3, ao lado do talhão com apenas um plantio (Figura 2). No entanto, não foi possível estabelecer nenhuma diferença que poderia estar associada com o período prolongado de fase inicial de plantação no ponto 2 e, principalmente, no 1. Existe uma curva no sexto ano no ponto um mais afastada do padrão de floresta madura, mas o ano anterior foi bem mais ajustada a ele. 


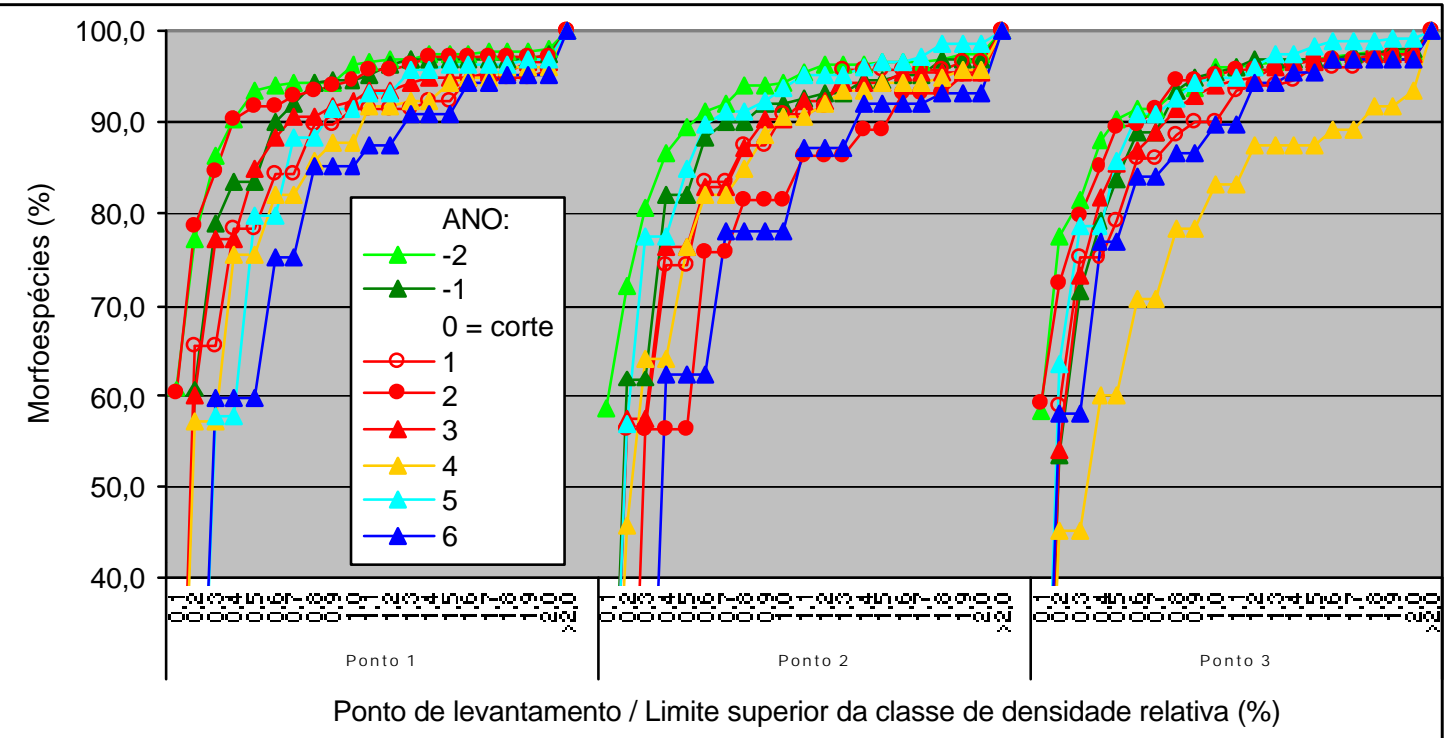

Figura 60 - Porcentagem de morfoespécies em função da classe de densidade relativa, nos três pontos de levantamento na mata, em períodos de nove meses (novembro a julho), em sete anos, identificados em relação ao ano do corte do eucalipto no local 6 (coletas com armadilhas luminosas).

Todos os três pontos na borda (Figura 61) ficaram na divisa com o talhão 007-06, que teve a fase inicial de floresta plantada prolongada por dois plantios. O que se verifica é uma variabilidade entre os próprios pontos de coleta, que dificultam a interpretação de qualquer efeito da fase da floresta. 


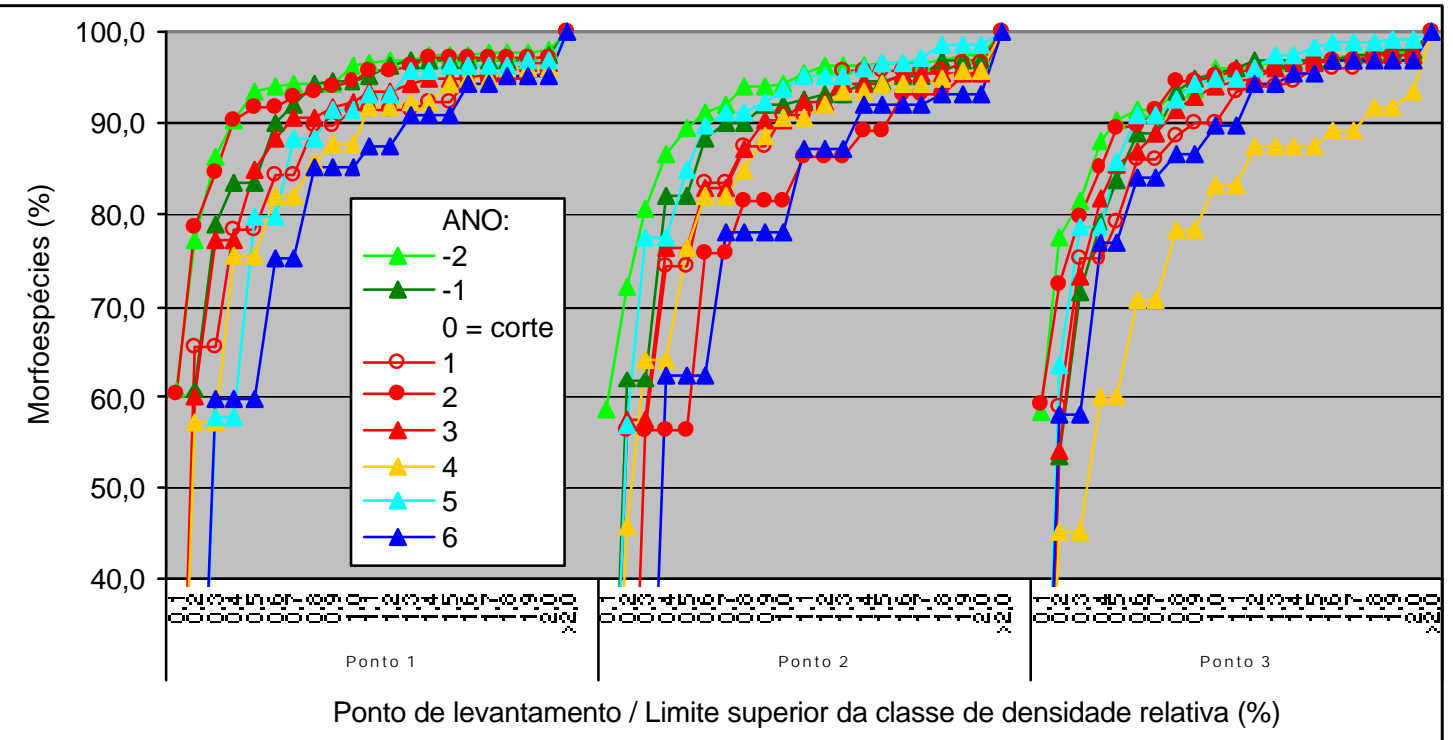

Figura 61 - Porcentagem de morfoespécies em função da classe de densidade relativa, nos três pontos de evantamento na borda mata-eucalipto, em períodos de nove meses (novembro a julho), em sete anos, identificados em relação ao ano do corte do eucalipto no local 6 (coletas com armadilhas luminosas).

As curvas de densidade relativa, na Figura 58, poderiam indicar que 0 efeito do corte foi em médio prazo, com o máximo de alteração, em relação ao padrão antes do corte do eucalipto, no quarto ano essa atividade. No entanto, observa-se nas figuras 59 e 60, principalmente em determinados pontos de coleta, uma reaproximação no padrão no quinto ano após corte e depois, novamente, um afastamento no sexto ano. Assim, fica evidente que a alteração em relação ao padrão de distribuição, não está fortemente associado ao corte.

Como já demonstrado (item 4.4), o clima teve significativo efeito sobre o número de indivíduos e espécies coletados, o que impacta diretamente na densidade relativa. Além disso, a análise das figuras 59 e 69 indica uma variação local importante.

O único fato evidente é que a mata apresenta um padrão mais estável, frente aos fatores promotores de mudanças. 
Quanto aos números de morfoespécies observados antes e depois do corte, verificam-se grandes variações, onde certamente existe efeito mais significativo de fatores não controlados neste estudo, do que a ação do corte da floresta comercial e nova fase da cultura (Figura 62 e 63).

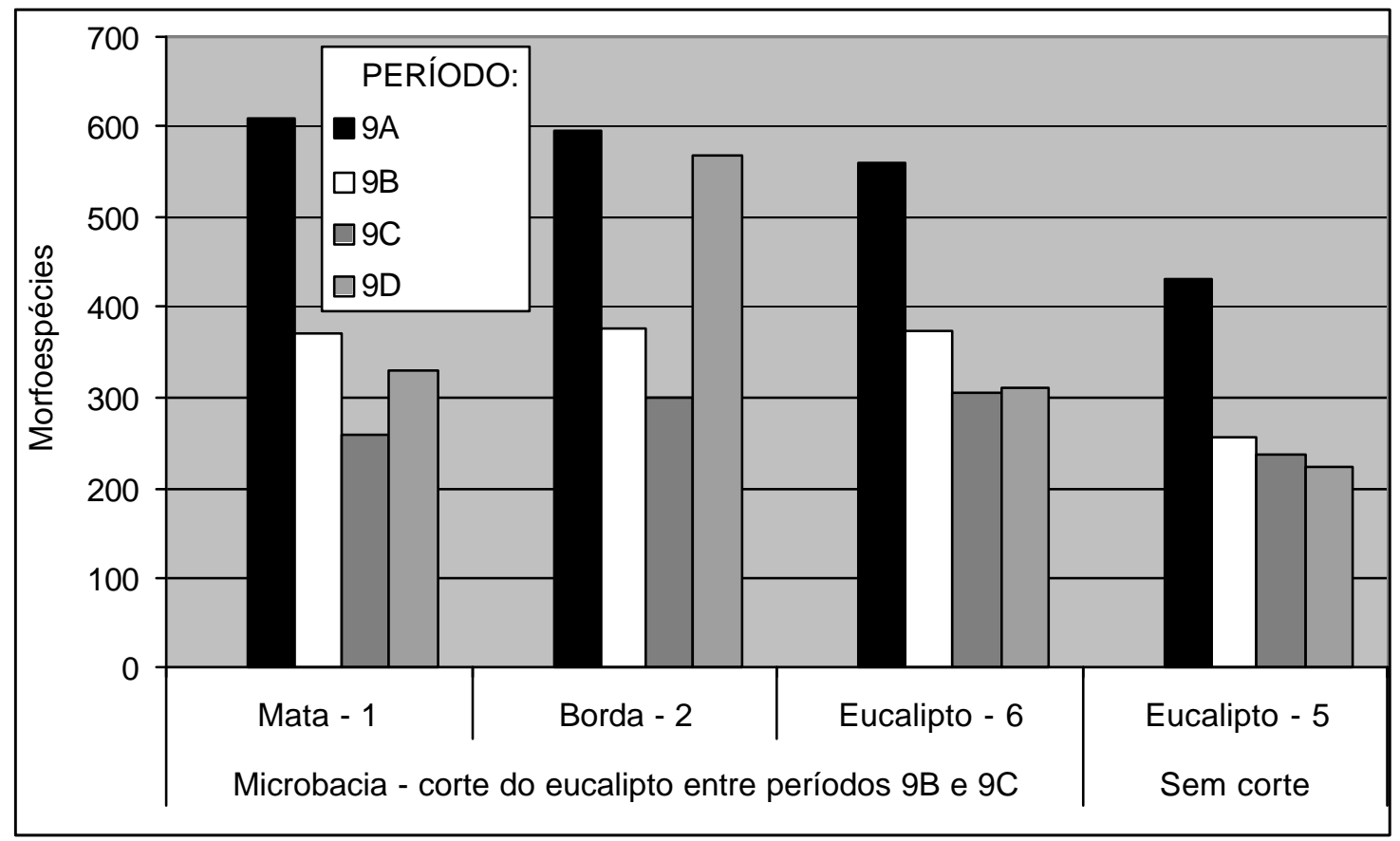

Figura 62 - Número de morfoespécies em períodos de nove meses antes (9A e 9B) e depois (9C e 9D) do corte do eucalipto no local 6 (coletas com armadilhas luminosas).

O acompanhamento do número de morfoespécies em todos os períodos de nove meses estabelecidos, antes e depois do corte do eucalipto no local 6 (microbacia), mostra uma flutuação, onde o corte pode ter participação, mas não papel determinante, frente aos inúmeros componentes bióticos e abióticos envolvidos.

Focando a análise sobre a densidade das populações de insetos, de grande importância sobre a estabilidade do ambiente estudado, agrupadas em pragas do eucalipto e inimigos naturais, constata-se a já discutida diferença entre os ambientes (4.3), principalmente entre mata e os outros dois, mas não 
fica evidenciada qualquer diferença significativa entre os períodos pré e pós corte (Figura 64).

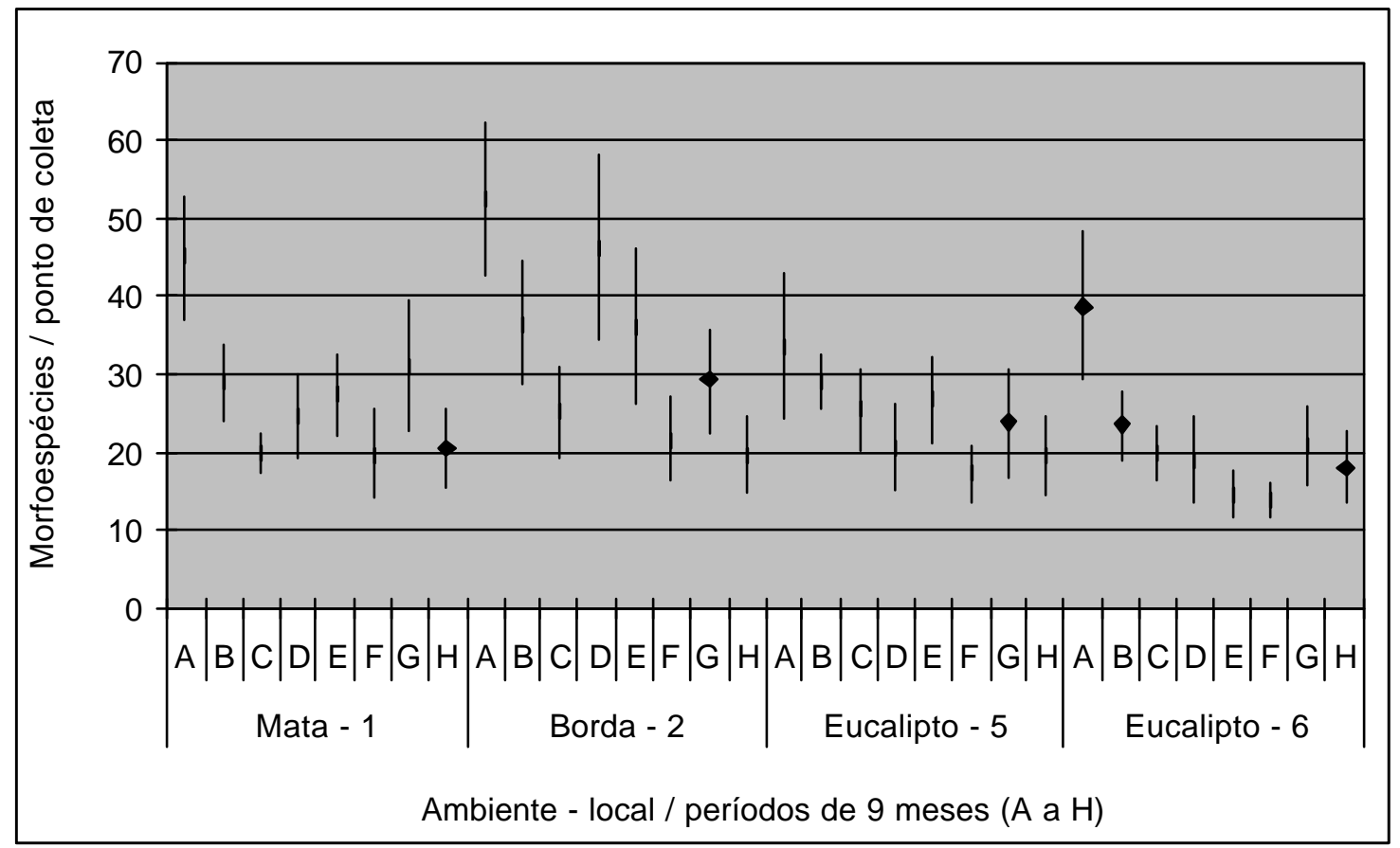

Figura 63 - Intervalo de confiança ( $5 \%$ probabilidade) do número de morfoespécies em períodos de nove meses antes (9A e 9B) e depois $(9 \mathrm{C} \mathrm{a} 9 \mathrm{H})$ do corte do eucalipto no local 6 (coletas com armadilhas luminosas). 


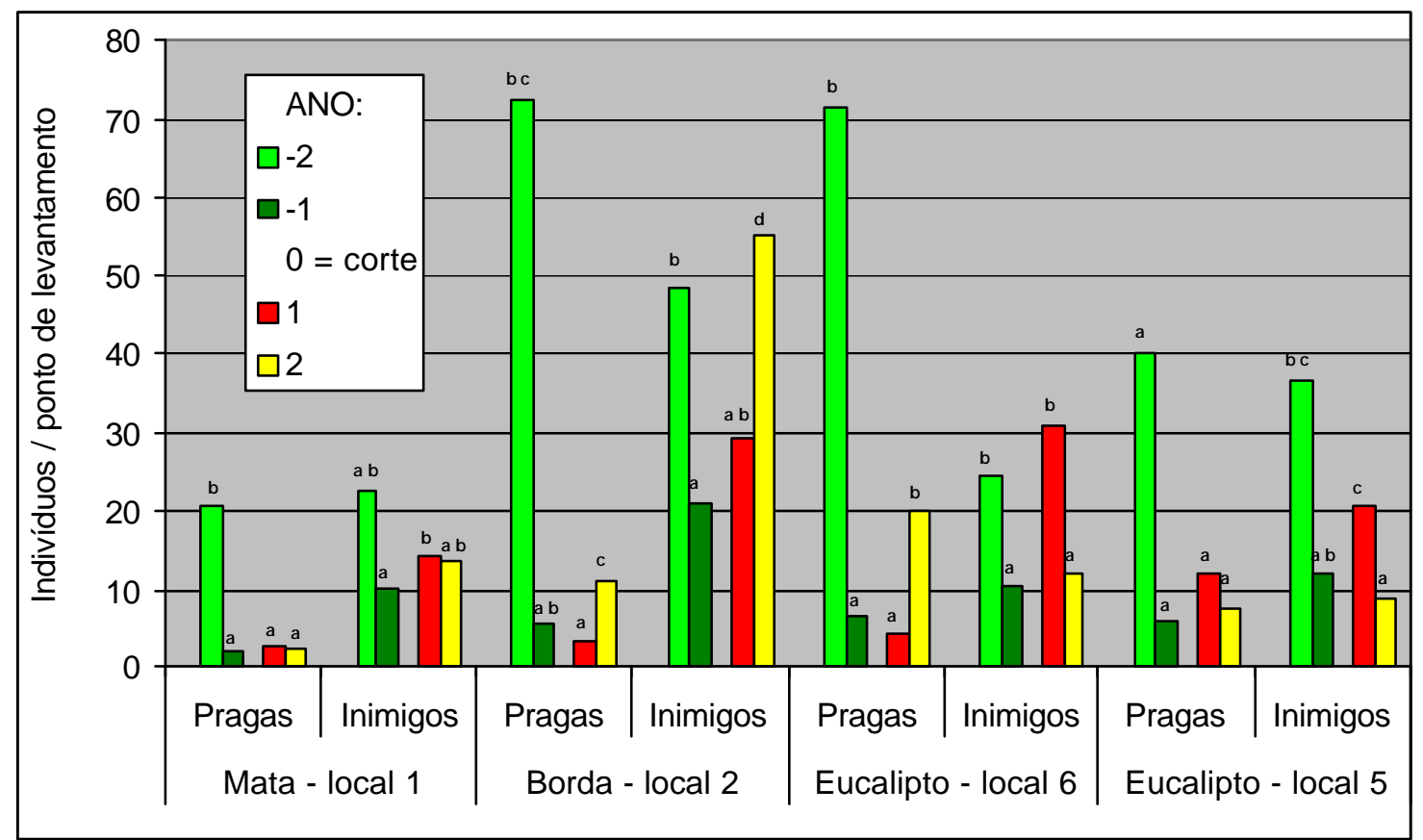

Figura 64 - Número de indivíduos pragas e inimigos naturais, em períodos de noves meses (novembro a julho, períodos 9A a 9D), em quatro anos, identificados em relação ao ano de corte do eucalipto no local 6 (coletas com armadilhas luminosas e de Malaise; letras iguais indicam valores sem diferença significativa, na comparação de períodos dentro do grupo de insetos).

A relação entre os dois grupos de insetos, pragas e inimigos naturais, também apresenta diferentes padrões entre mata, borda e, principalmente 0 eucalipto. No entanto, mais uma vez, nenhum efeito significativo dos períodos pré e pós-corte (Figura 65). 


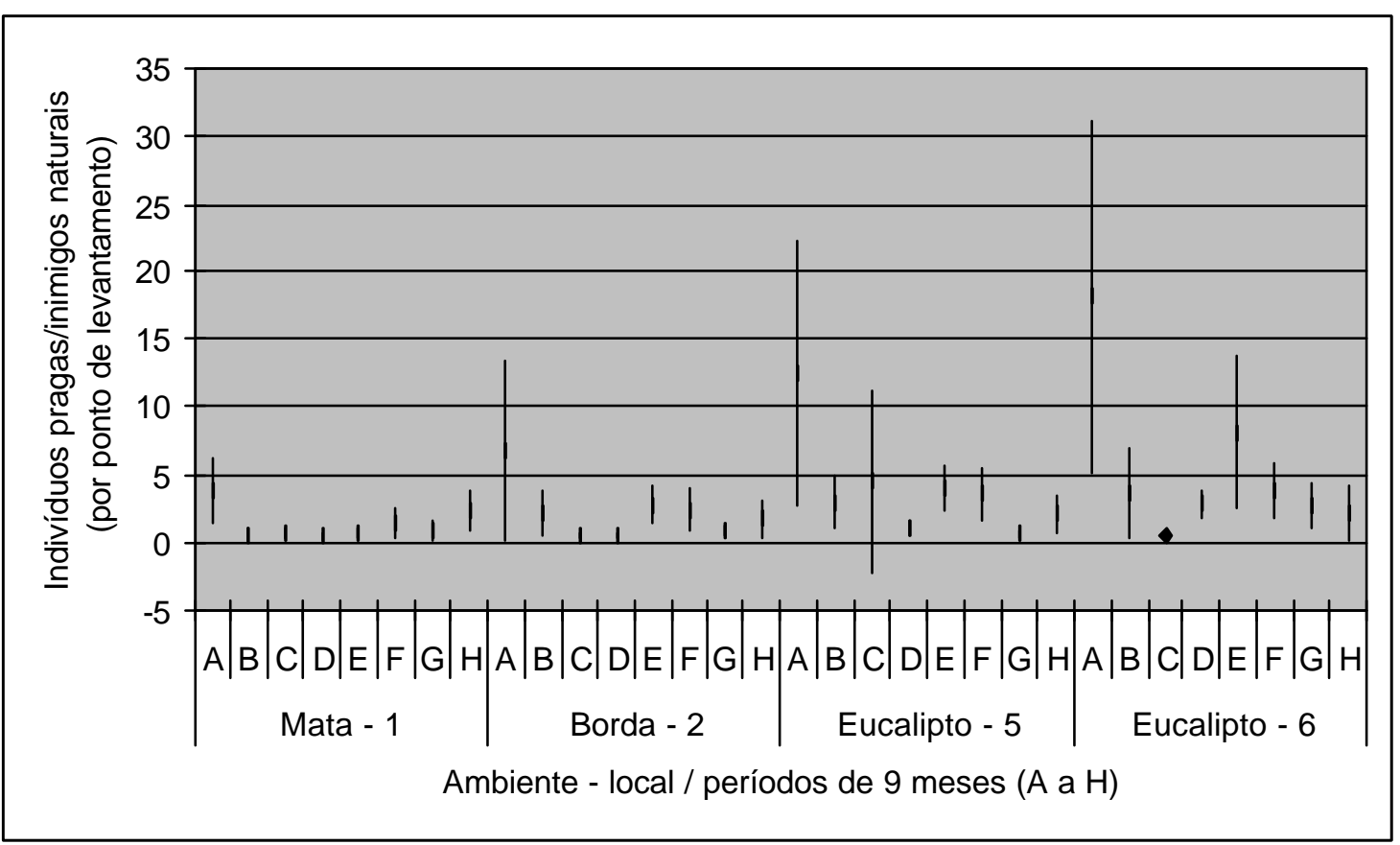

Figura 65 - Intervalo de confiança ( $5 \%$ probabilidade) da relação entre número de indivíduos pragas e o de inimigos naturais, em períodos de nove meses antes (9A e 9B) e depois $(9 \mathrm{C} \mathrm{a} 9 \mathrm{H})$ do corte do eucalipto no local 6 (coletas com armadilhas luminosas).

Mais do que a variação entre os períodos pré e pós-corte, a análise da distribuição das morfoespécies em classes de densidade relativa, do número de morfoespécies, do número de indivíduos de pragas e inimigos naturais, é a aquela existente entre ambientes, entre diferentes locais dentro de um ambiente e, neles todos, ao longo do tempo. Em cada ambiente, em cada período, observa-se um ciclo de espécies entrando e saindo, que certamente é reflexo do diversificado ambiente, no só mata, mas também plantação de eucalipto e região de borda entre os dois. 


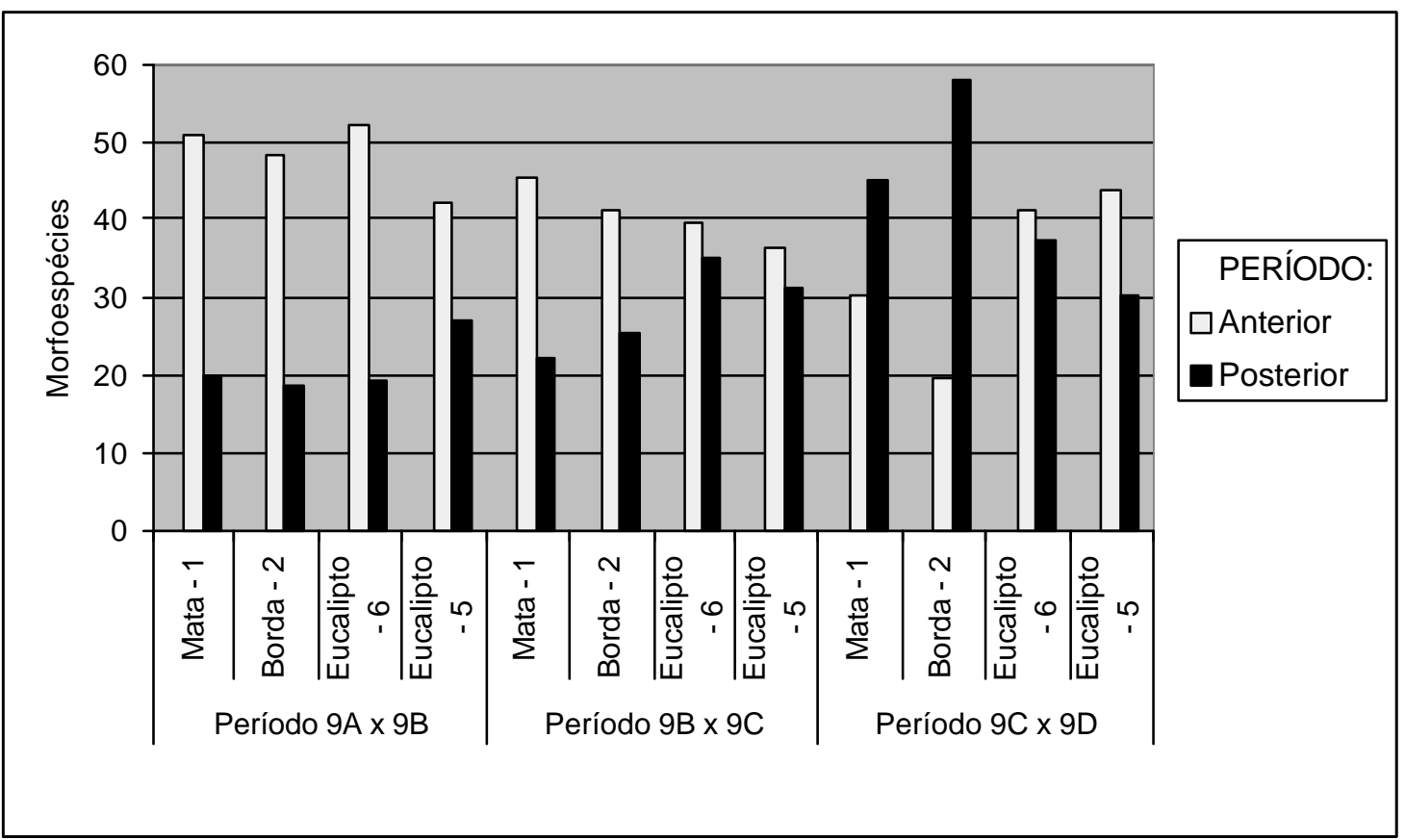

Figura 66-Número de morfoespécies exclusivas de cada período, na comparação de períodos de nove meses (julho a novembro), dois a dois.

Numa visão direcionada apenas para a análise das morfoespécies existentes antes e depois do corte, destacando as que permanecem, desaparecem e surgem após essa operação, como ilustrado nas Figura 67, se poderia concluir que após o corte muitas espécies raras desaparecem e outras surgem, indicando impacto. No entanto, os dados anteriores (Figuras 66, etc.) mostram que esse fluxo, de entrada e saída de morfoespécies, é normal e não está relacionado estritamente ao corte da floresta comercial. Outra forma de visualizar esse padrão normal e bem semelhante entre os ambientes, em termos proporcionais, é apresentada na Figura 68. Isso, com a ressalva já comentada, sobre a validade do isolamento do eucalipto no local 5 , em relação æ̀̀ áreas de corte na região. 


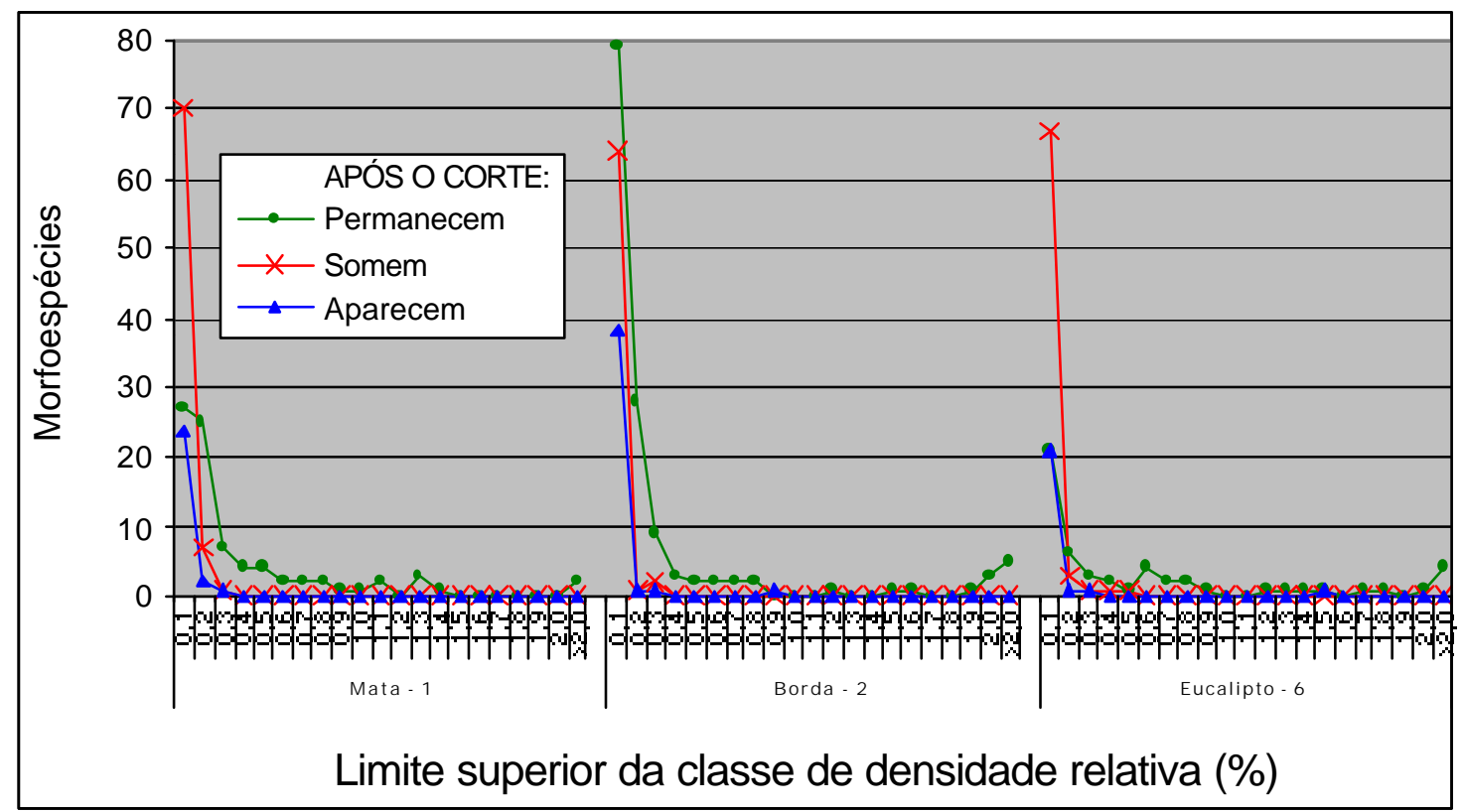

Figura 67-Número de morfoespécies por classe de densidade relativa, separadas em relação à sua ocorrência antes (períodos $9 \mathrm{~A}$ e $9 \mathrm{~B}$ ) e depois (9C e 9D) do corte do eucalipto no local 6 (armadilhas luminosas e de Malaise).

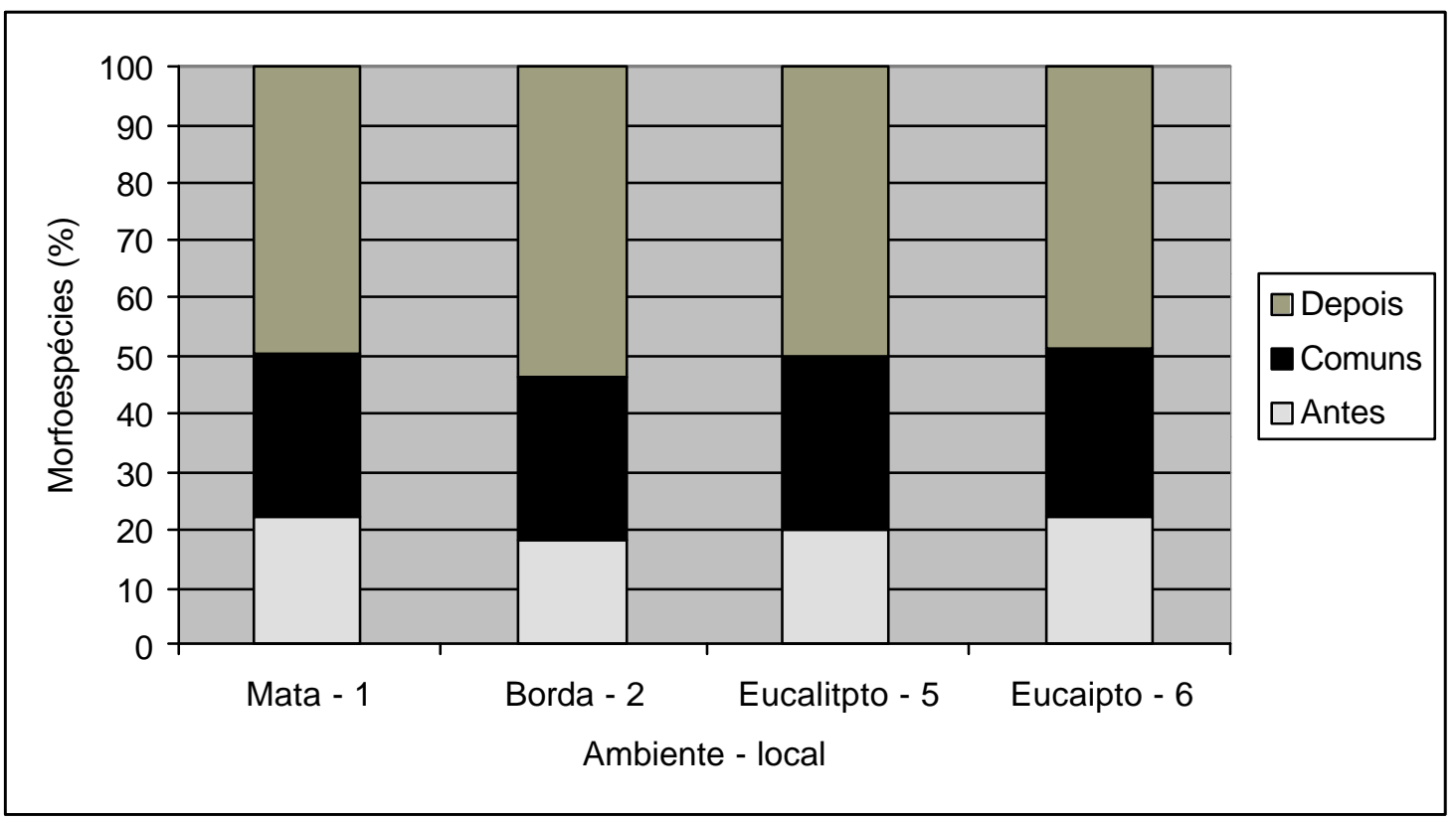

Figura 68 - Número de morfoespécies, separadas em relação à sua ocorrência antes (períodos 9A e 9B) e depois (9C e 9D) do corte do eucalipto no local 6 (armadilhas luminosas e de Malaise). 
O fluxo observado na ocorrência das morfoespécies está relacionado com a baixa freqüência e baixa abundância geral dos indivíduos (Figuras $10 \mathrm{e}$ 11), característica da alta diversidade. Assim, a medida do possível impacto precisaria se concentrar em dois tipos de análise: $1^{\circ}$ - das variações na intensidade do fluxo, dentro do ambiente e, principalmente, entre os ambientes, mata, borda e eucalipto; $2^{\circ}$ - nas morfoespécies mais abundantes que passam a ocorrer ou desaparecem após o corte do eucalipto.

Sobre os dados apresentados na Figura 67, foram selecionadas as dez morfoespécies mais abundantes de Lepidoptera, exclusivas da fase pré ou pós-corte, em um ou dois ambientes (mata, borda e eucalipto). Verificando a ocorrência dessas espécies nos três ambientes, incluindo o eucalipto no local 5, sem corte, constata-se que, com a continuidade dos levantamentos, as que eram exclusivas da fase antes do corte, passaram a ser comuns, ou seja, voltaram a ocorrer com o tempo no mesmo ambiente (Tabela 8). A única exceção é a Euglyphis deusta, que se mostrou comum apenas no eucalipto local 5.

A ocorrência de Bleptina caradrinalis (Lepidoptera, Noctuidae) apresentou uma estreita relação com o corte e desenvolvimento do novo plantio. Mostrou também, que a influência atinge da região de corte atinge o eucalipto 5 , vizinho àárea de corte (Figura 69). 
Tabela 9. Relação de espécies muito abundantes, em relação ao padrão local (Figura 12), selecionadas em função de sua ocorrência exclusiva, na fase de plantação madura de eucalipto antes do corte), ou na fase inicial até dois anos de idade (após corte) e a situação com seis anos após o corte.

\begin{tabular}{|c|c|c|c|c|c|c|c|c|c|}
\hline \multirow{2}{*}{ Código } & \multirow{2}{*}{ Família } & \multirow{2}{*}{ Espécies } & \multicolumn{3}{|c|}{2 anos antes e 2 depois } & \multicolumn{4}{|c|}{2 anos antes e 6 anos depois } \\
\hline & & & Mata & Borda & Eucalipto & Mata & Borda & Eucalipto 6 & Eucalipto 5 \\
\hline 0542 & Arctiidae (Lep.) & Pareuchaetes insulata & - & Antes & - & Comum & Comum & Comum & Comum \\
\hline 0945 & Geometridae (Lep.) & Semiothisa sp. & - & - & Antes & Comum & Comum & Comum & Comum \\
\hline 0243 & Noctuidae (Lep.) & Monodes villicosta & - & Antes & - & Comum & Comum & Comum & Comum \\
\hline 2847 & Noctuidae (Lep.) & Herminodes sp. & - & Após & - & Comum & Após & Comum & Comum \\
\hline 7440 & Noctuidae (Lep.) & Bleptina caradrinalis & - & Após & Após & Após & Após & Após & Após \\
\hline 2296 & Notodontidae (Lep.) & Dyasia viviana & - & - & Antes & Comum & Comum & Comum & Comum \\
\hline 0110 & Eupterotidae (Lep.) & Apatelodes sericea & Antes & - & - & Comum & Comum & Comum & Comum \\
\hline 0681 & Geometridae (Lep.) & Epimecis semicompleta & Antes & - & - & Comum & Comum & Antes & Antes \\
\hline 0225 & Lasiocampidae (Lep.) & Euglyphis deusta & Antes & Antes & - & Antes & Antes & Antes & Comum \\
\hline 0303 & Lymantriidae (Lep.) & Sarsina violascens & Antes & - & Antes & Comum & Comum & Comum & Comum \\
\hline
\end{tabular}

1 Período de seleção, onde a espécie ocorreu exclusivamente antes ou após o corte, em determinado ambiente, ou ambientes.

${ }^{2}$ Nova situação, com os levantamentos durante seis anos após o corte, onde a espécie que era exclusiva de uma fase pós-corte, passou a ser comum. 


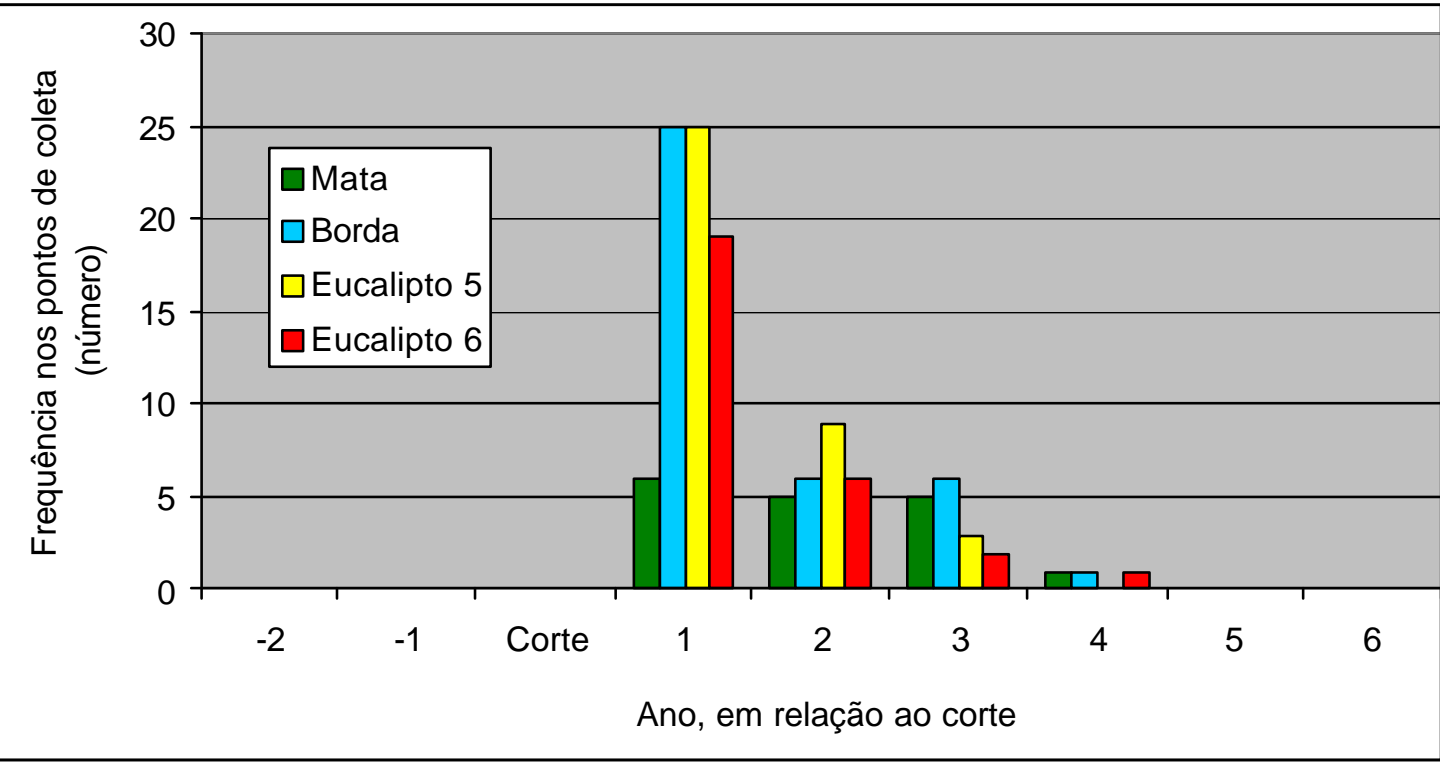

Figura 69 - Freqüência de ocorrência de Bleptina caradrinalis (Lepidoptera, Noctuidae), ao longo do período de levantamento, para vários locais.

A forma de comparação de ambientes, com base em morfoespécies comuns e exclusivas, discutida no item anterior (4.3), pode ser aplicada a diferentes períodos antes e depois do corte (Figura 69). 


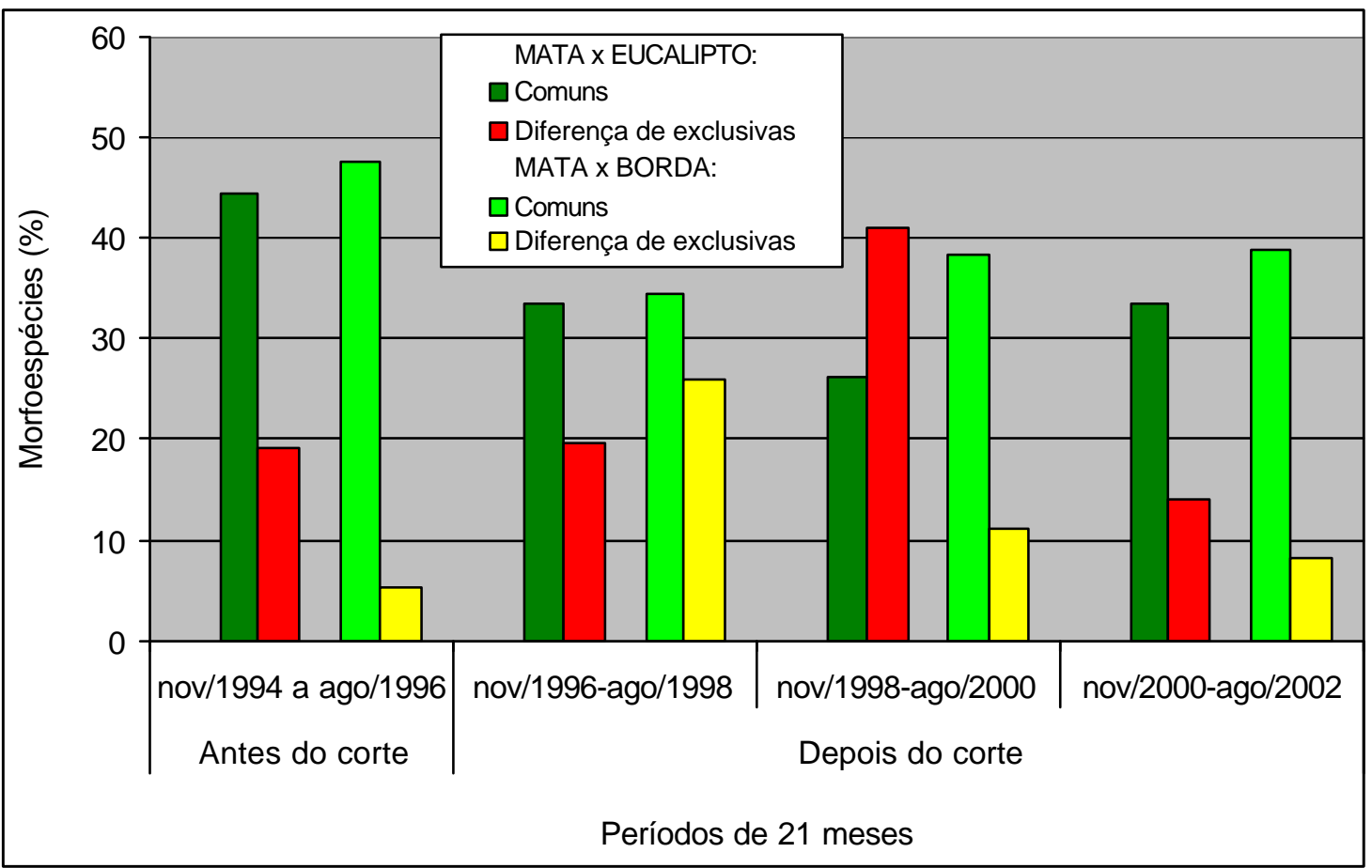

Figura 70-Porcentagem de morfoespécies comuns e diferença entre morfoespécies exclusivas, na comparação entre mata e eucalipto e entre mata e borda, em quatro períodos de 21 meses (armadilhas luminosas).

Antes do corte, o número de morfoespécies comuns foi maior, em relação aos períodos pós-corte, mostrando maior semelhança entre os ambientes comparados, mata versus eucalipto e mata versus borda. Do mesmo modo, a diferença das morfoespécies exclusivas entre os ambiente comparados, mata e eucalipto, ou mata e borda, foi menor, mostrando riquezas exclusivas mais próximas antes do que depois do corte. Na seqüência dos três períodos pós-corte, verifica-se uma crescente reaproximação dos ambientes comparados.

O fato da comparação das morfoespécies comuns e exclusivas apresentarem padrões dentro da hipótese de que o corte, seguido de uma nova fase silvicultural, afeta significativamente a comunidade de insetos, a qual vai se restabelecendo, com o desenvolvimento da plantação, até retornar novamente ao padrão da floresta madura, não significa que a seqüência apresentada na 
Figura 69 seja uma demonstração dessa hipótese. Isso devido à dinâmica da comunidade de insetos e do efeito de fatores não controlados, já apresentados.

Se o efeito principal é devido ao manejo da floresta plantada, verificase a retomada gradativa ao padrão original, o que responde positivamente a uma grande preocupação ambiental. Se ao contrário, é devido a outros fatores, é mais uma demonstração equilíbrio dinâmico do ecossistema, com seu poder de regulação e manutenção da estabilidade.

A comparação de morfoespécies comuns e exclusivas apresenta um padrão diferenciado, o que outros índices não conseguem demonstrar, como o de diversidade (Figura 70).

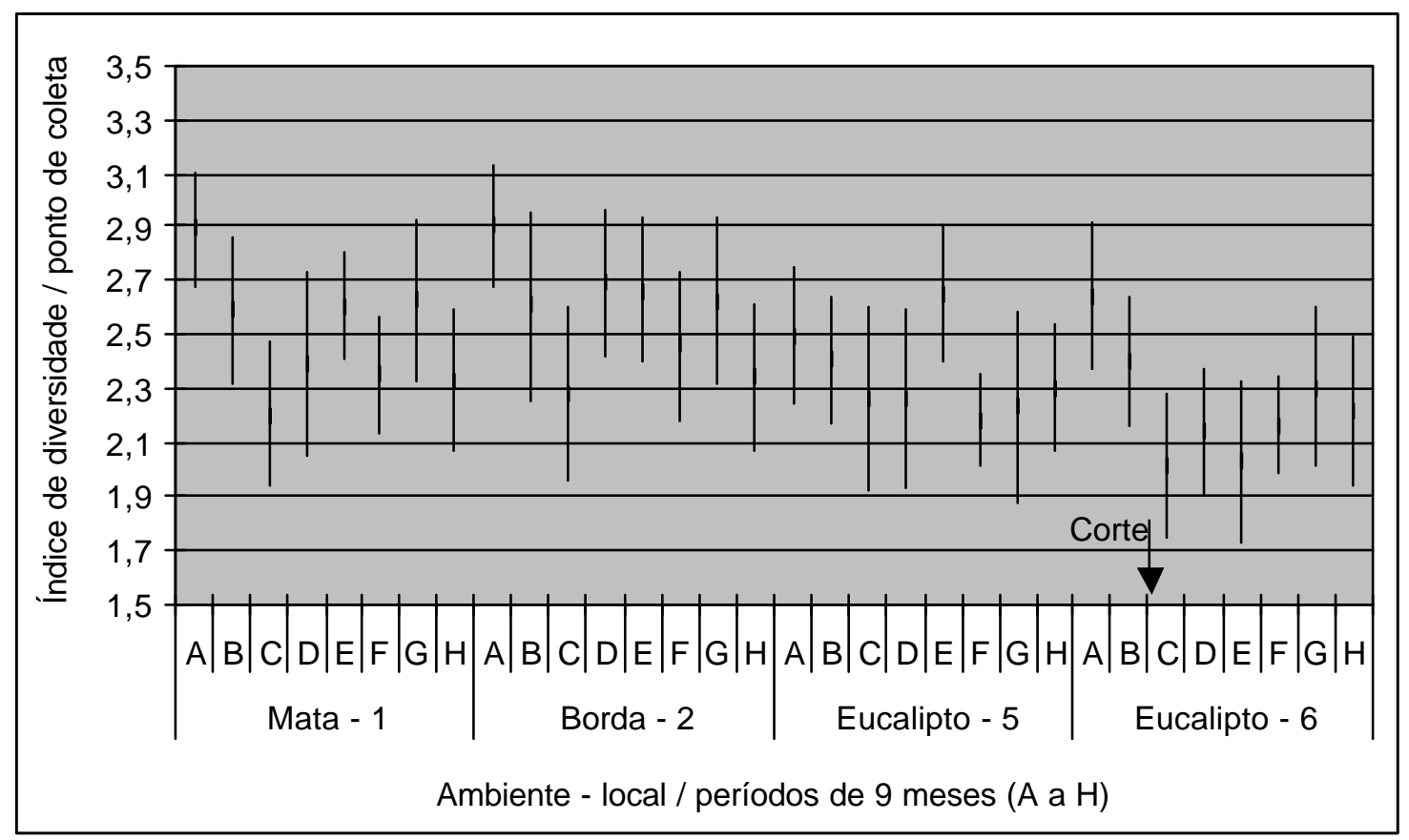

Figura 71 - Intervalo de confiança (5\% probabilidade) do índice de diversidade para morfoespécies, em períodos de nove meses antes (9A e 9B) e depois $(9 \mathrm{C}$ a $9 \mathrm{H})$ do corte no eucalipto no local 6 (coletas com armadilhas luminosas).

Não existe forte evidência de que o índice de diversidade geral, para morfoespécies, nos três ambientes, esteja ligado ao corte da floresta plantada (Figura 70). Existe uma fraca evidência de redução após o corte, no eucalipto que sofreu essa operação. 
Para o grupo de pragas do eucalipto, observa-se redução significativa do índice de diversidade na borda, por dois anos (Figura 2, períodos C e D) e no eucalipto cortado, principalmente no ano seguinte ao corte. Na borda, como já comentado, o desenvolvimento da plantação foi atrasado em cerca de um ano, pela necessidade de replantio total eucalipto adjacente, cerca de 10 meses após o primeiro plantio. Os dados seriam perfeitos, se não fosse a igual queda no índice nos dois períodos pós-corte no eucalipto no local 5, sem corte, mostrando que esse local não foi eficiente como controle do fator fase da plantação, pela proximidade à área do co rte, ou que existem fatores não controlados associados, responsáveis pela queda do índice nesses períodos.

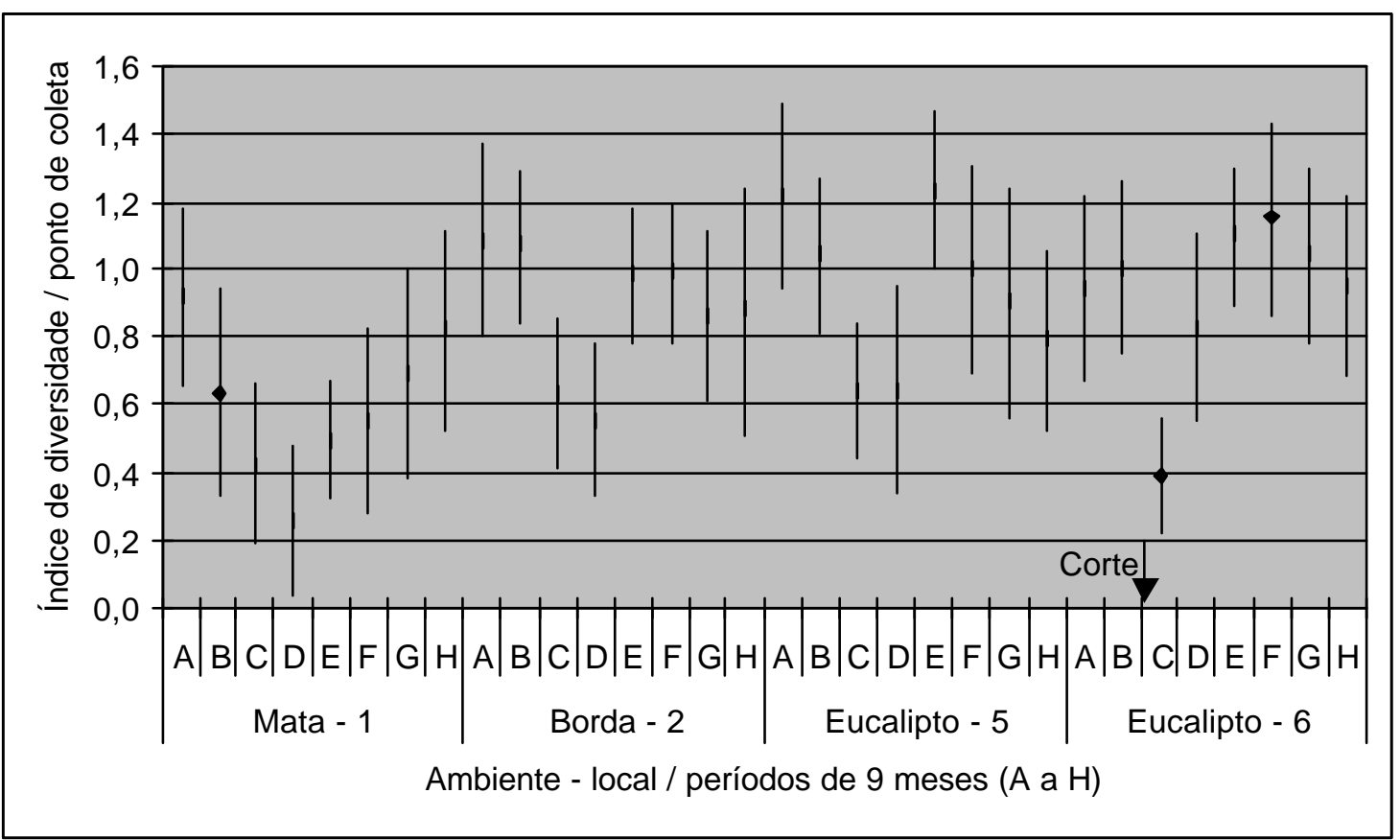

Figura $72-$ Intervalo de confiança (5\% probabilidade) do índice de diversidade para morfoespécies do grupo de pragas (primárias, secundárias e potenciais), em períodos de nove meses antes (9A e 9B) e depois (9C a $9 \mathrm{H}$ ) do corte no eucalipto no local 6 (coletas com armadilhas luminosas). 


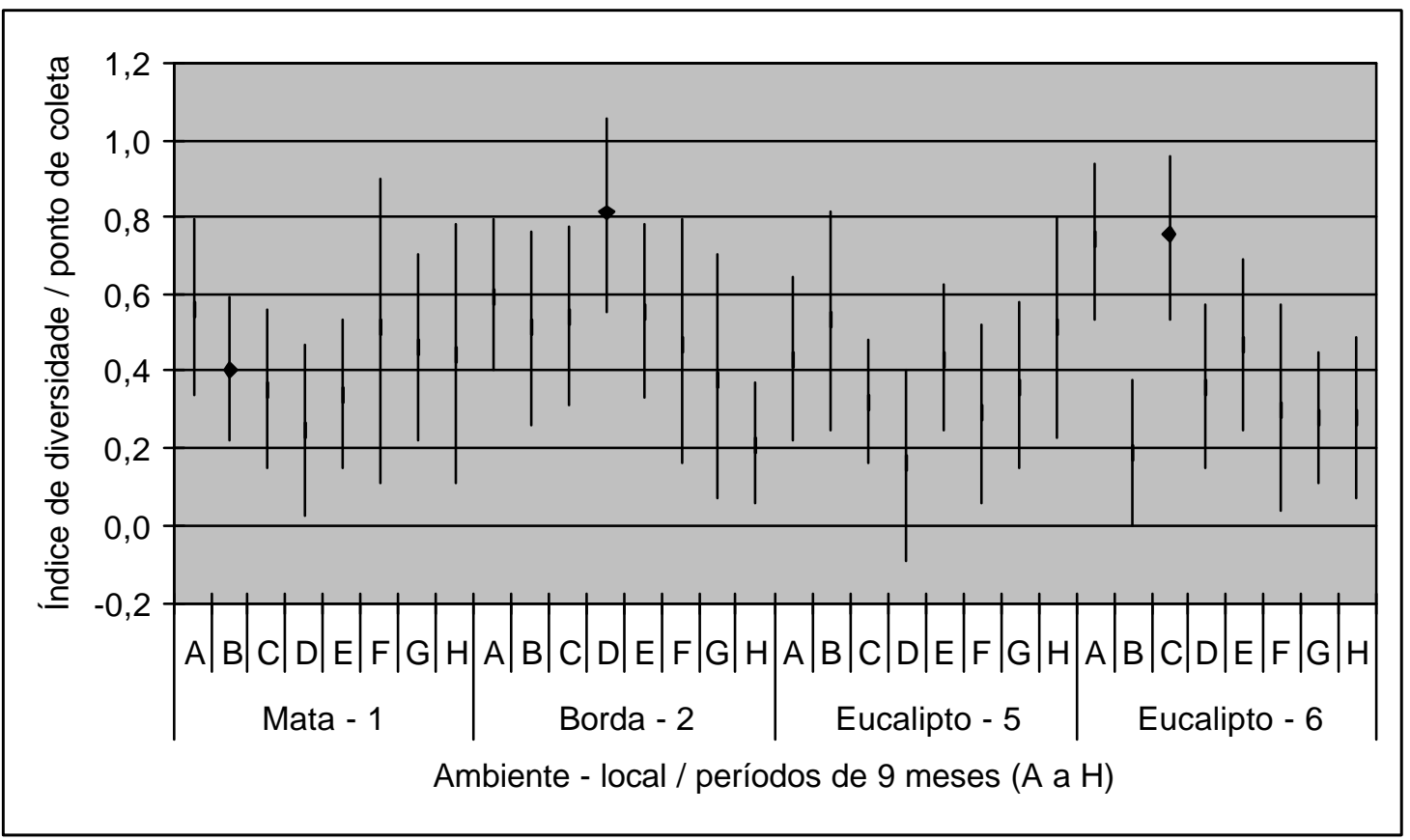

Figura 73- Intervalo de confiança (5\% probabilidade) do índice de diversidade para morfoespécies do grupo de inimigos naturais, em períodos de nove meses antes (9A e 9B) e depois $(9 \mathrm{C}$ a $9 \mathrm{H})$ do corte no eucalipto no local 6 (coletas com armadilhas luminosas).

No grupo de inimigos naturais, o índice de diversidade não mostrou nenhuma variação significativa ligada ao corte ou fase silvicultural (Figura 72).

O corte, ou fase silvicultural, não teve relação evidente para toda a coleta com armadilhas luminosas e para os grupo de pragas e inimigos naturais, mas poderia ter sobre outros grupos de insetos.

Numa primeira fase de análise (Anexo $A$ ), comparando os primeiros quatro períodos de 9 meses, dois antes do corte (9A e 9B) e dois depois do corte (9C e 9D), quanto ao índice de diversidade de 145 famílias na mata, 158 na borda e 131 no eucalipto, observou-se que:

$1^{\circ}$ - Cerca de $12 \%$, $9 \%$ e $12 \%$ e das famílias na mata, borda e eucalipto, apresentaram efeito significativo da estação do ano.

$2^{0-}$ As famílias, que apresentaram diferença significativa entre períodos na mata e borda, foram, na maioria, as mesmas do eucalipto e também aquelas de 
maior freqüência nas coletas. As famílias de baixas freqüências não permitiram determinar diferenças significativas entre os períodos.

Com base nessa primeira análise geral, foram selecionadas 18 famílias no eucalipto local 6, que apresentaram efeito do fator período. A comparação do índice de diversidade dessas famílias, entre os períodos e entre o eucalipto loca 6 , com corte e o eucalipto local 5, sem corte, mostrou que, na maioria não existem evidências de associação da variação do índice de diversidade e com a fase da floresta de eucalipto (Figura 74).

Encontram-se no Anexo $\mathrm{B}$, os resultados do teste de comparação de médias entre períodos, numa mesma estação do ano, para essas 18 famílias.
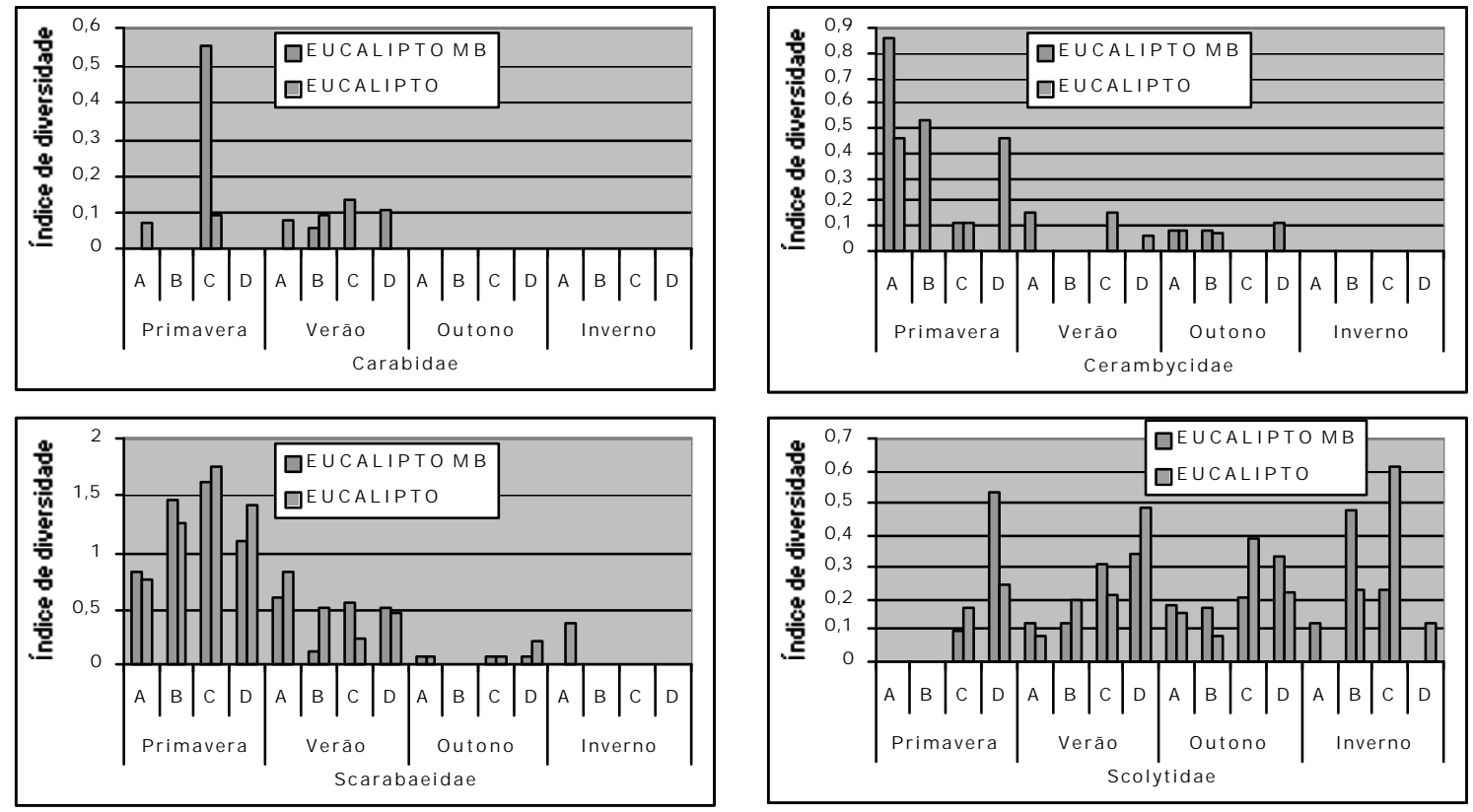

Figura 74-Índice de diversidade para morfoespécies, em cada família que apresentou diferença significativa, ao nível de $5 \%$ de probabilidade, entre pelo menos dois períodos de nove meses, dentre os quatro primeiros avaliados, dois antes $(9 \mathrm{~A}$ e $9 \mathrm{~B})$ e dois depois $(9 \mathrm{C} \mathrm{a} 9 \mathrm{H})$ do corte do eucalipto no local 6 (coletas com armadilhas luminosas). 

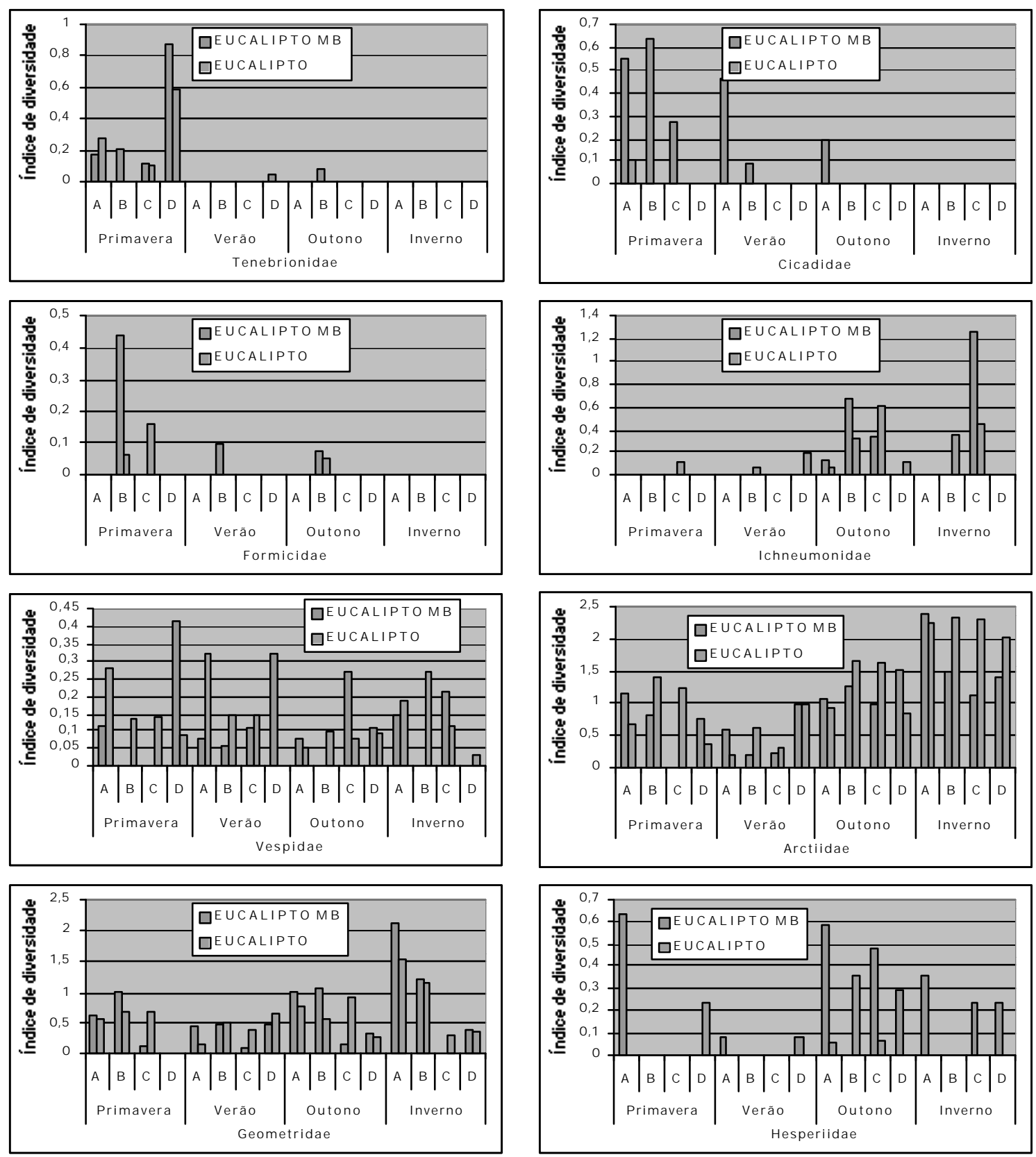

Figura 74-Índice de diversidade para morfoespécies, em cada família que apresentou diferença significativa, ao nível de $5 \%$ de probabilidade, entre pelo menos dois períodos de nove meses, dentre os quatro primeiros avaliados, dois antes (9A e 9B) e dois depois $(9 \mathrm{C} \mathrm{a} 9 \mathrm{H})$ do corte do eucalipto no local 6 (coletas com armadilhas luminosas). 

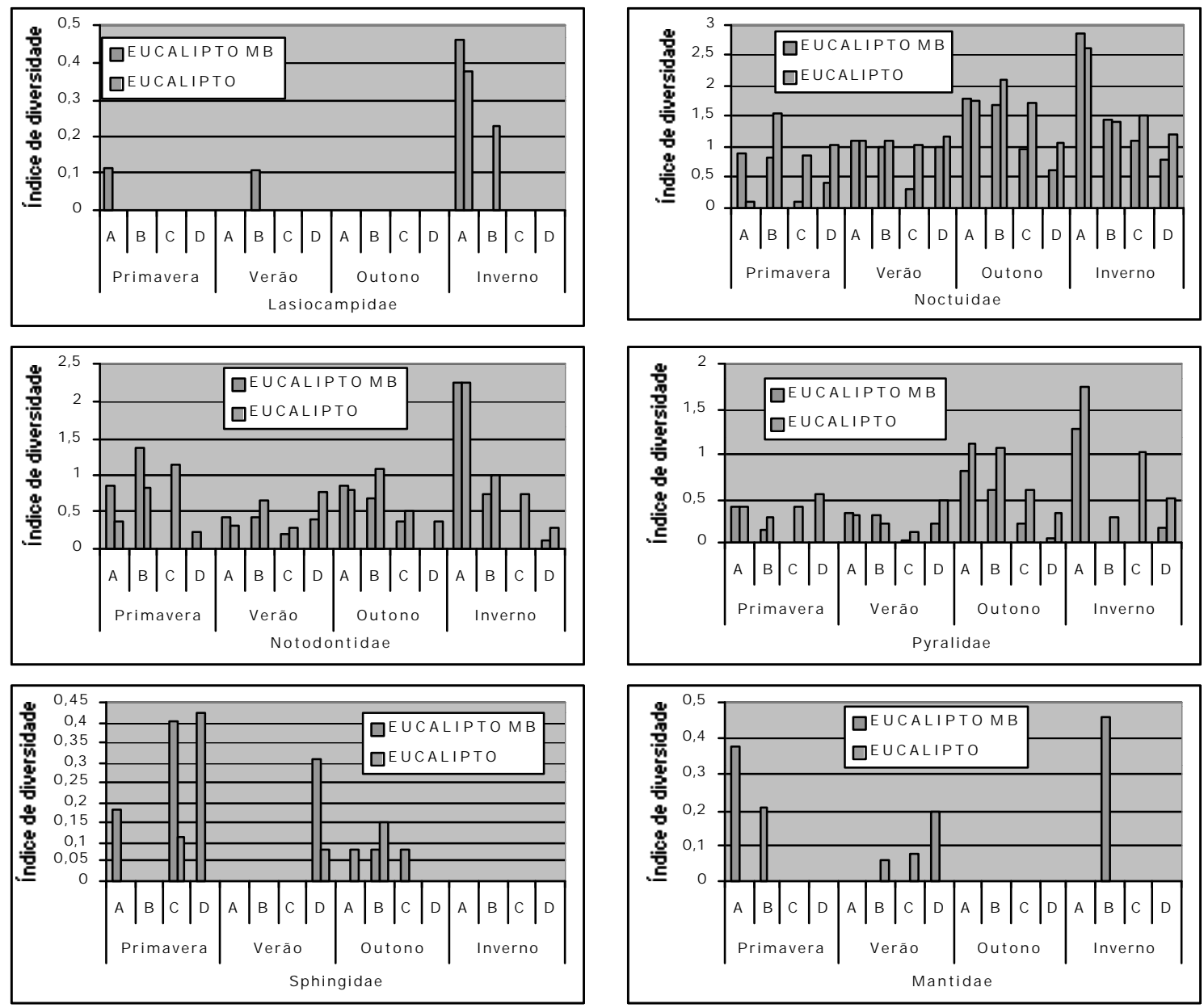

Figura 74-Índice de diversidade para morfoespécies, em cada família que apresentou diferença significativa, ao nível de $5 \%$ de probabilidade, entre pelo menos dois períodos de nove meses, dentre os quatro primeiros avaliados, dois antes (9A e 9B) e dois depois $(9 \mathrm{C} \mathrm{a} 9 \mathrm{H})$ do corte do eucalipto no local 6 (coletas com armadilhas luminosas).

Os padrões de distribuição de densidade relativa e a riqueza de morfoespécies retratam o equilíbrio dinâmico, ou fluente, num ambiente altamente diversificado. Neste caso, não se descarta o impacto de operações de colheita, as quais certamente devem existir, por efeitos como a redução da diversidade, eliminação da estratificação vertical na área plantada, alteração no 
seu microclima, como também da borda e da mata. No entanto, esses efeitos mostraram-se regulados pela própria diversidade do ecossistema.

Os efeitos da temperatura e precipitação são mais evidentes, sobre a abundância, riqueza e índice de diversidade, como demonstrado no item anterior (4.4), do que a ação da colheita e reforma da plantação do eucalipto. 


\subsection{Sub-bosque}

A análise do fator "fase silvicultural", apresentada anteriormente, além das mudanças qualitativas e estruturais na área plantada, envolve a eliminação do sub-bosque em conseqüência do corte do eucalipto, do novo plantio e do controle de ervas infestantes na fase inicial do desenvolvimento da nova plantação (Figura 5). Os resultados apresentados, englobando eliminação mais drástica do sub-bosque e associação com outros fatores de impacto, indica que a eliminação de faixa do sub-bosque, dentro de parcelas de um mesmo talhão em fase de plantação madura, não provocaria efeito significativo sobre as populações de insetos estudadas, dentro dos métodos de avaliação empregados. A comparação dos locais 3 e 4, eucalipto com e sem sub-bosque, respectivamente, confirmaram essa expectativa.

A distribuição das morfoespécies em classes de densidade relativa mostrou padrões bem semelhantes, entre os seis pontos de levantamento, três deles em cada condição de sub-bosque (Figura 75).

O mesmo ocorreu com a relação entre o número de indivíduos do grupo de pragas do eucalipto e os inimigos naturais (Figura 76). Verifica-se, no entanto, uma maior amplitude do intervalo de confiança, com média mais elevada para o local sem sub-bosque, na primavera. Esse é um reflexo de variabilidade na relação pragas/inimigos entre as coletas mensais e pontos de levantamento, na área sem sub-bosque, durante essa estação do ano. É um indicativo de maior estabilidade na área com sub-bosque, no entanto, a comparação das médias não mostra diferença significativa e o caso é restrito a uma única estação do ano. Sendo assim, não existe qualquer evidência importante da diferença entre os dois locais. 


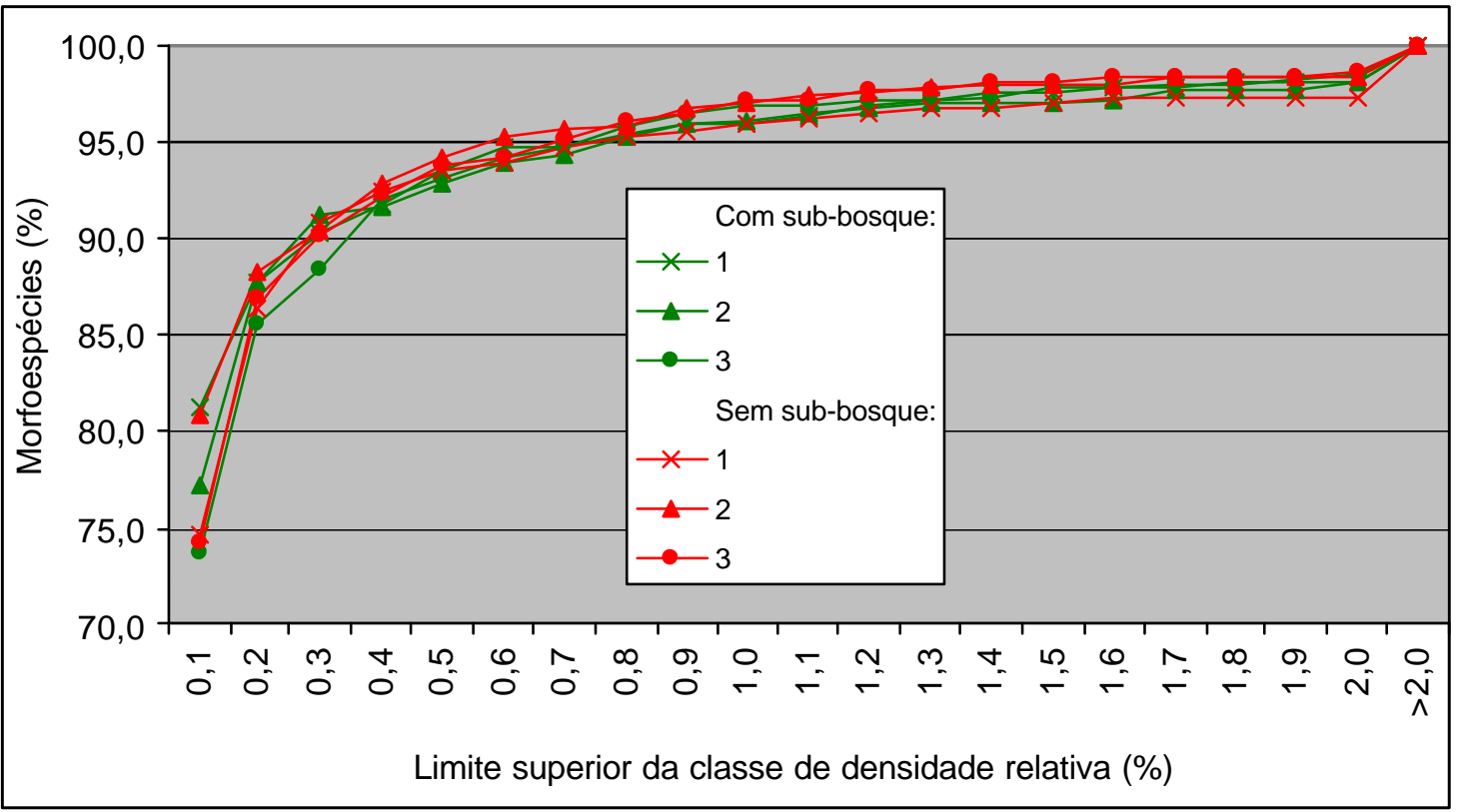

Figura 75 -Porcentagem acumulada de morfoespécies por classe de densidade relativa, para cada ponto de levantamento dos locais 3 e 4 , com e sem sub-bosque, respectivamente.

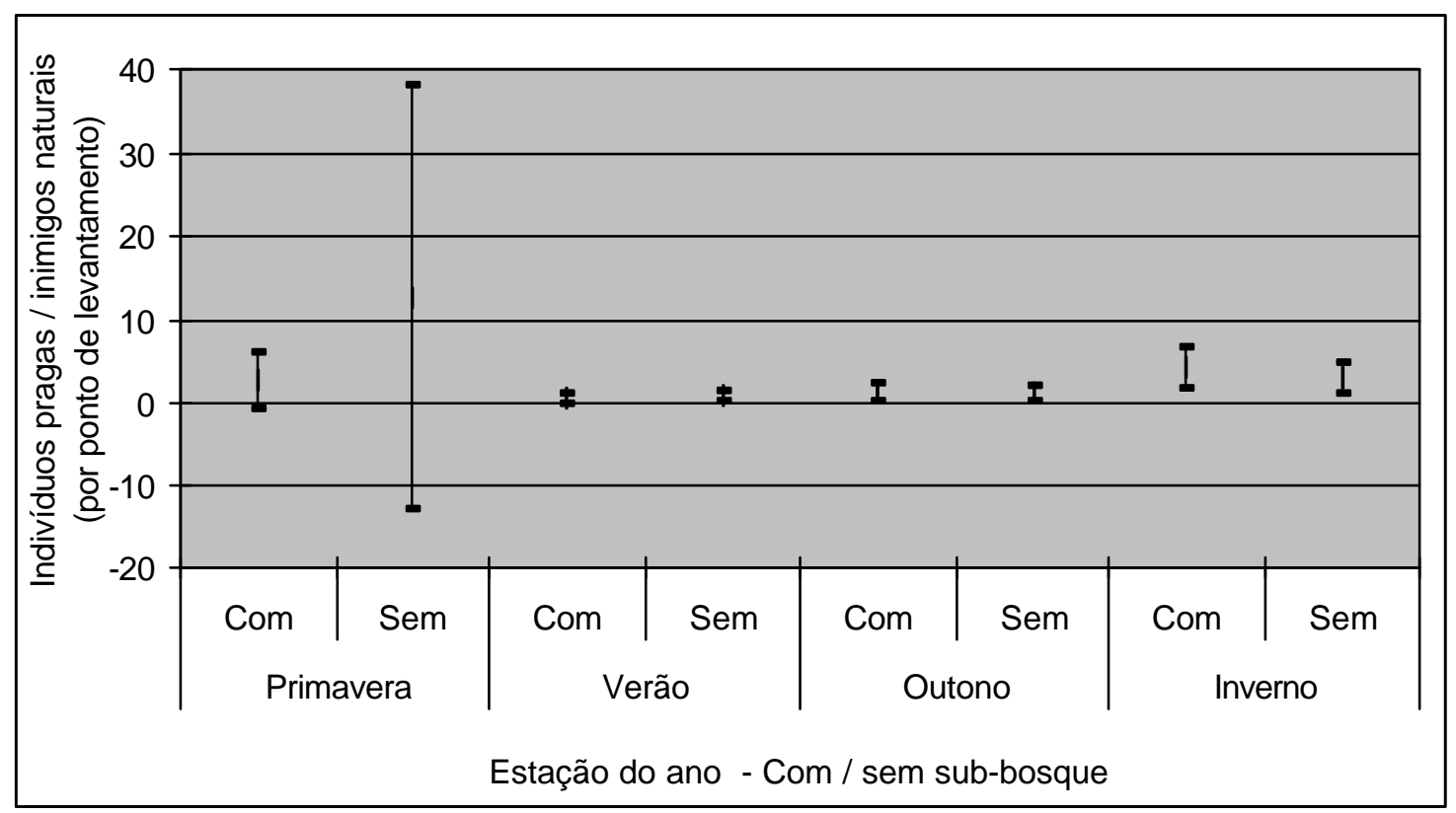

Figura 76 - Intervalo de confiança (5\% probabilidade) da relação entre número de indivíduos do grupo de pragas e o de inimigos naturais, para cada estação do ano e condição do sub-bosque. 
O número de morfoespécies também foi semelhante nas duas condições de sub-bosque. Apenas entre as estações do ano houveram diferenças significativas (Figura 77).

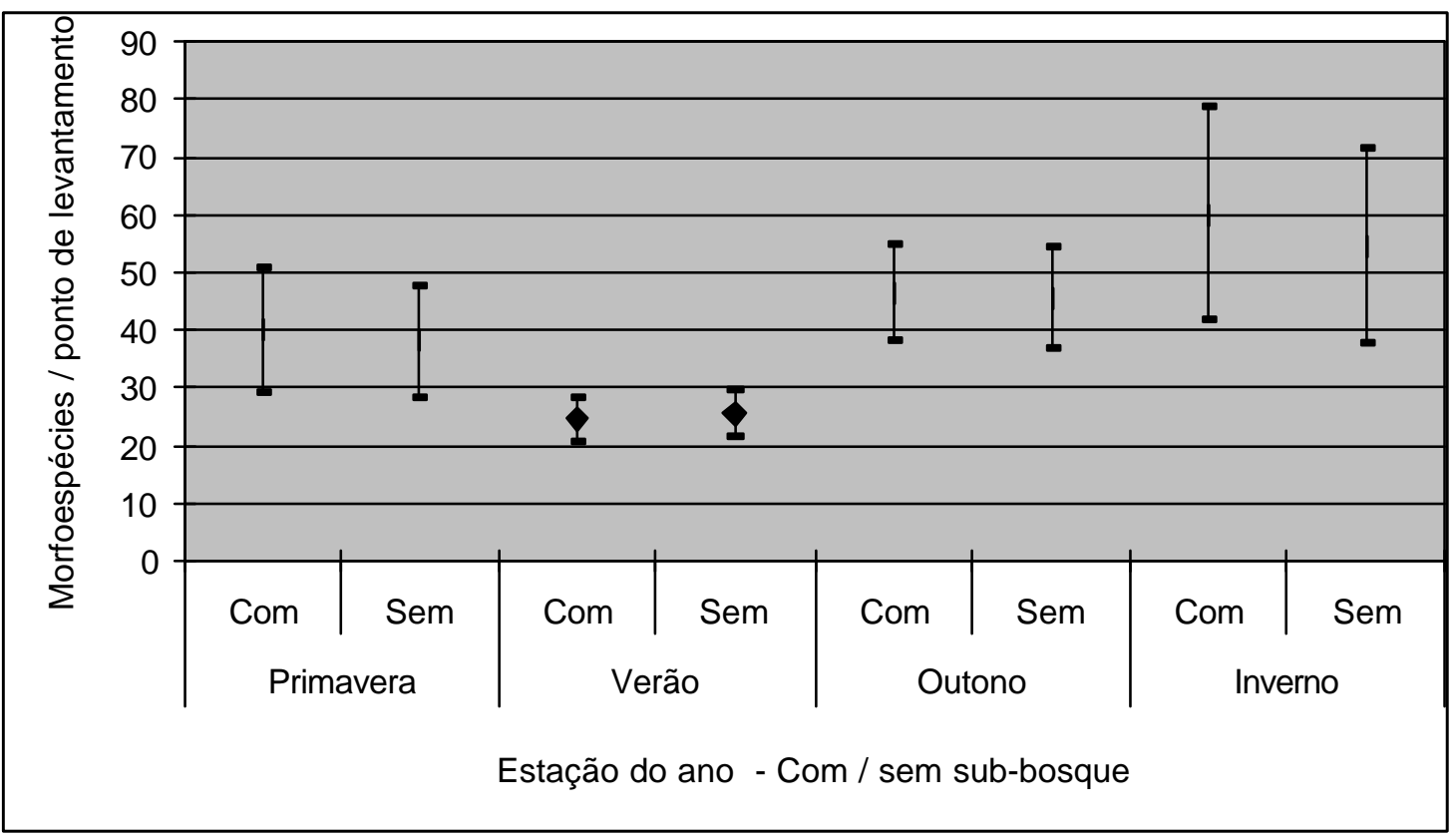

Figura 77 - Intervalo de confiança $(5 \%$ probabilidade $)$ do número de morfoespécies, por estação do ano e condição de sub-bosque (com e sem).

A análise qualitativa das espécies que ocorrem nas duas condições de sub-bosque (Figura 78), mostrou que os dois locais são tão, ou mais, semelhantes entre si, do que pontos de levantamento, em mesma condição de sub-bosque, dentro de um mesmo local estudado no eucalipto, conforme os dados contidos na Figura 41. Os locais com e sem sub-bosque apresentaram entre 30 e $35 \%$ de morfoespécies comuns nas coletas, dependendo da estação do ano, e pequena diferença de riqueza em morfoespécies exclusivas.

O índice de diversidade para morfoespécies, considerando todas elas, mostrou padrões muito semelhantes nas duas condições de sub-bosque. A diferença foi significativa apenas entre estações do ano (Figura 79). 


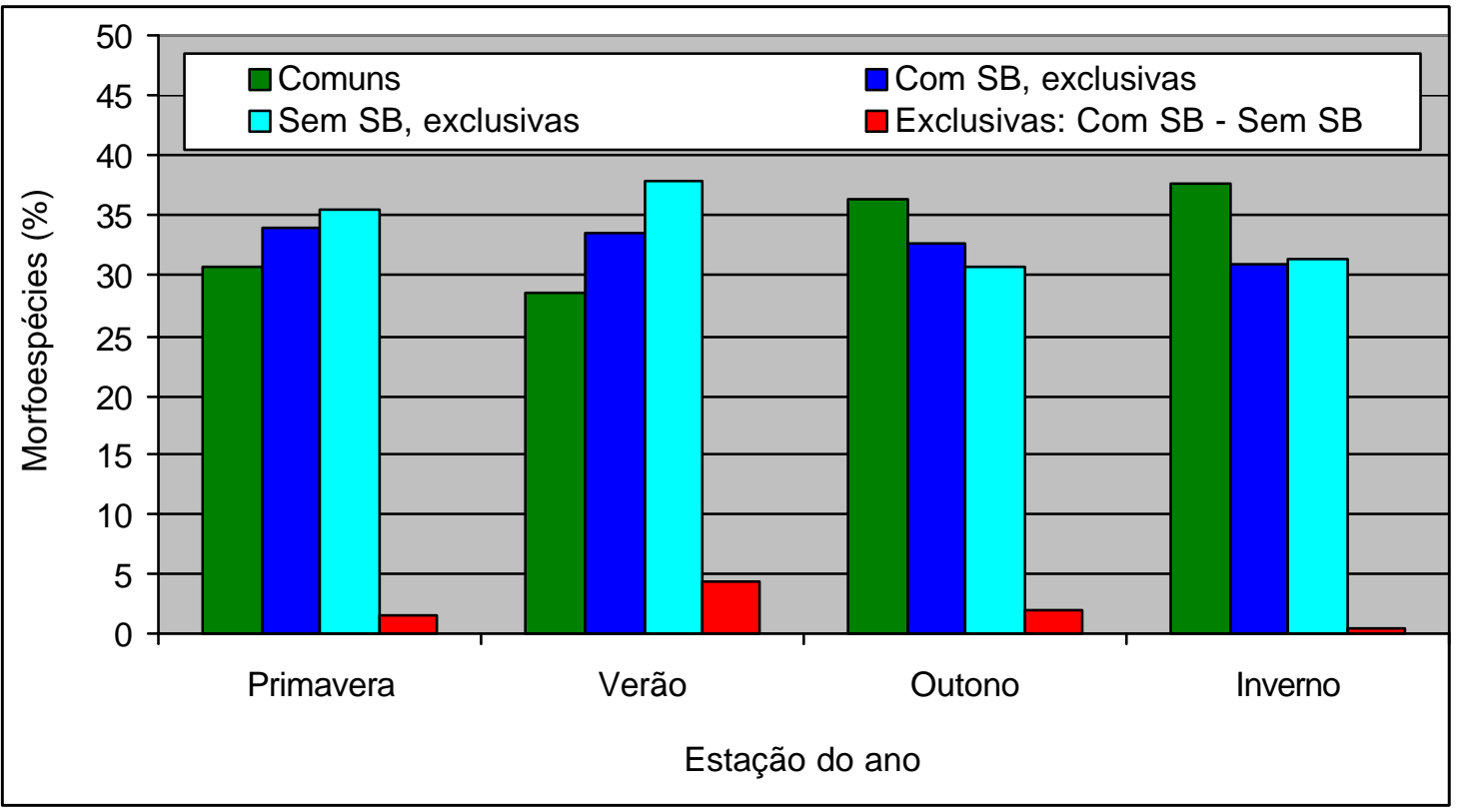

Figura 78 - Porcentagem de morfoespécies comuns e exclusivas entre os locais 3 e 4, com e sem sub-bosque, respectivamente.

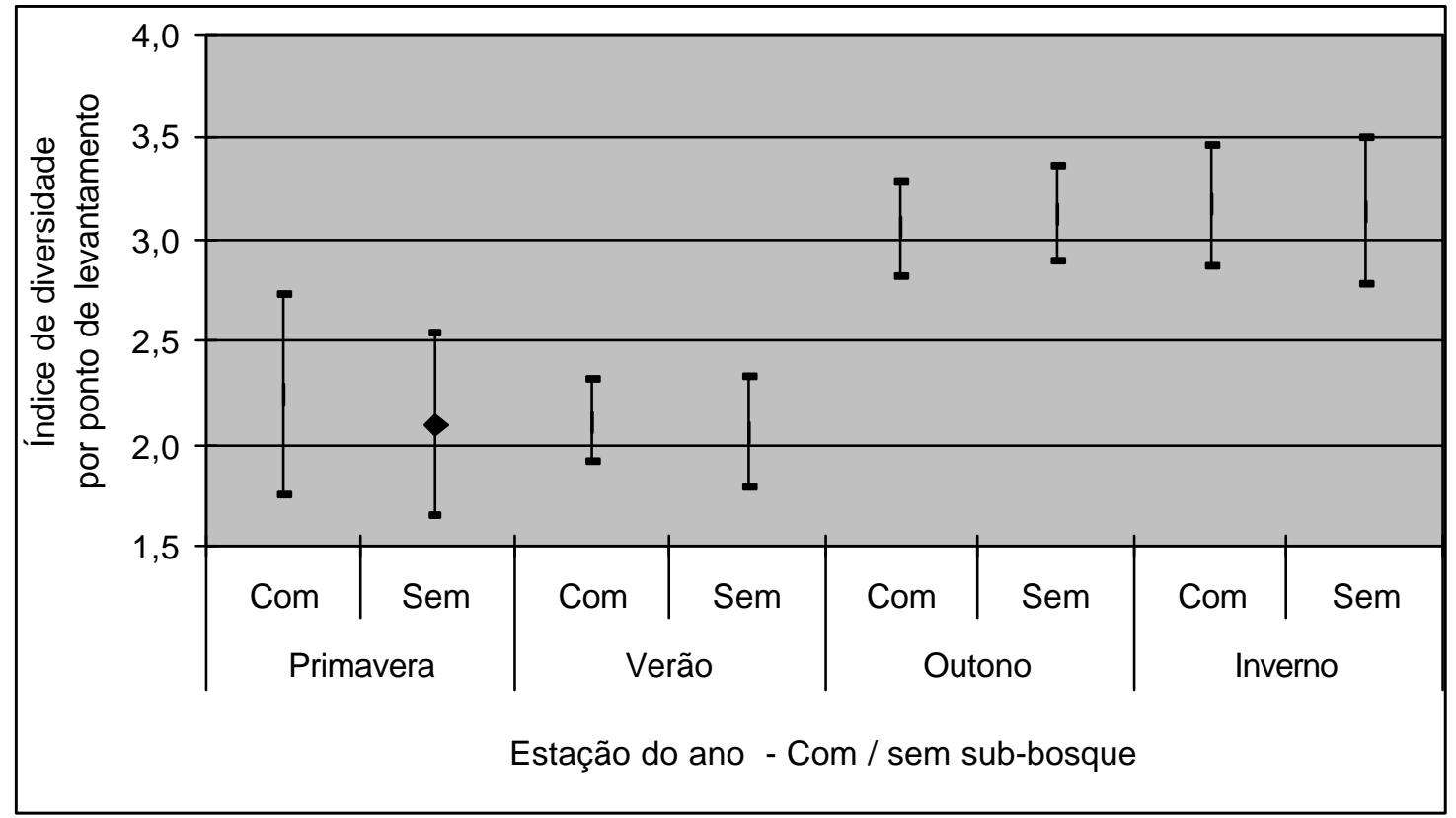

Figura 79 - Intervalo de confiança (5\% probabilidade) do índice de diversidade para todas as morfoespécies, por estação do ano e condição de subbosque (com e sem). 


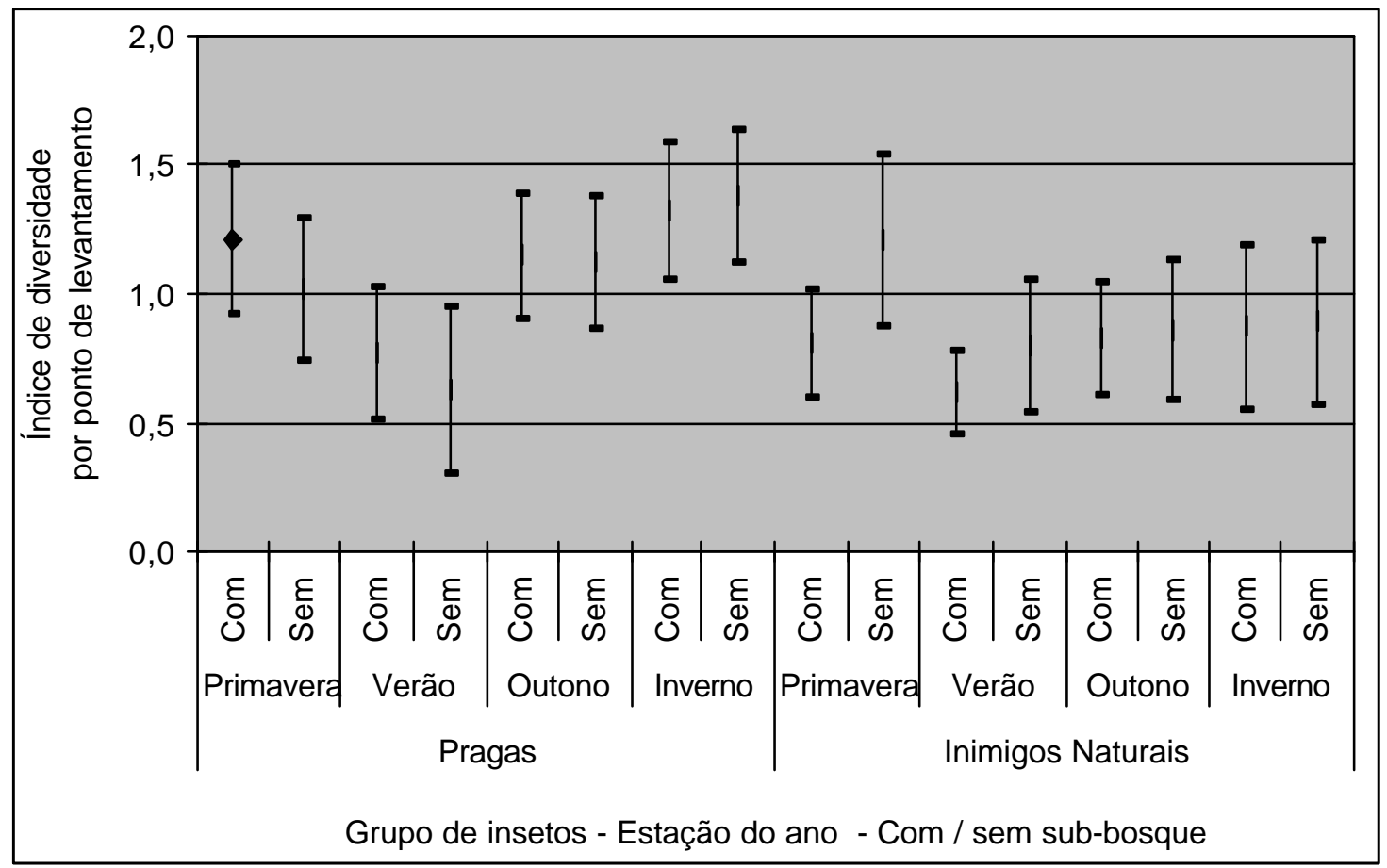

Figura 80 - Intervalo de confiança (5\% probabilidade) do índice de diversidade para morfoespécies do grupo de pragas e de inimigos naturais, por estação do ano e condição de sub-bosque (com e sem).

O índice de diversidade aplicado para o grupo de pragas do eucalipto e para inimigos naturais, também não mostrou diferença significativa entre as duas condições de sub-bosque (Figura 80). Novamente, apenas a estação fez o índice variar significativamente. Para a estação primavera, da mesma forma que para a relação pragas/inimigos (Figura 76), a área sem sub-bosque apresentou maior variação, indicando menor estabilidade. No entanto, enquanto que em termos de indivíduos, a condição sem sub-bosque apresentou maior quantidade relativa de pragas, também apresentou menor índice de diversidade para pragas e maior para inimigos naturais, estabelecendo uma relação mais positiva para essa condição sem sub-bosque.

Os resultados parecem contrariar outros estudos, onde plantações de eucalipto com sub-bosque apresentaram maior diversidade de insetos. No entanto, o resultado deste estudo aplica-se exclusivamente àcondição local, onde a interação do eucalipto, com as áreas naturais conservadas é muito grande, 
formando um mosaico, onde freqüentemente a homogeneidade do eucalipto é interrompida, aumentando a área de contato entre os dois ambientes, gerando o efeito borda.

Nas condições locais, portanto, a presença de sub-bosque mostrou menor importância do que a interação da área plantada com as reservas naturais. Esse resultado certamente é diferente, em grandes plantações contínuas, onde a distância no interior do eucalipto pode ser tal, que passa a valer a teoria de biogeografia de ilhas onde, aí sim, o sub-bosque passa a ter papel mais importante, como fonte de diversidade, aumentando as taxas de colonização e a fixação das populações de insetos. 


\section{CONCLUSÕES}

Considerando os resultados apresentados, conclui-se que:

- As armadilhas luminosas representam melhor a comunidade de insetos estudada, quando a análise é feita ao nível de gênero, espécie ou morfoespécie. Considerando uma análise ao nível de família, a contribuição da armadilha de Malaise é fundamental para representar as ordens Hymenoptera e Diptera, onde está inserida grande parte dos inimigos naturais.

- A boa representação de toda a entomofauna, apresentada pela ordem Lepidoptera, ou de apenas algumas de suas famílias, empregando-se a armadilha luminosa, é devido à quantidade de indivíduos e riqueza de espécies desse grupo, ao invés de sua relação com as variações de todo o resto da comunidade de insetos.

- A seqüência de ambientes, decrescente em riqueza de espécies, é borda, mata e eucalipto. Porém, a mata apresenta-se mais estável, o que é evidenciado pelo maior índice de diversidade e menor variação devido aos distúrbios ao longo do tempo. As diferenças, no entanto, são pequenas, a ponto de uma intensidade maior de coleta na borda ou eucalipto, mesmo após 261 dias-armadilha, considerando apenas a luminosa, na mata, pode resultar em maior diversidade na borda, assim como maior riqueza e índice de diversidade no eucalipto, em função da diversidade encontrada entre pontos dentro desses dois ambientes. 
- As flutuações das populações de insetos na mata, borda e eucalipto, apresentam uma dinâmica muito elevada, em tempo e espaço, conseqüência da alta diversidade da comunidade. Esse fato tem relação direta com os resultados de estudos feitos na mata, onde foi constatado um regime de distúrbios, com dinâmica e diversidade muito elevadas.

- Os padrões de ocorrência das populações de insetos, que evidenciam a grande dinâmica da comunidade dentro dos ambientes e ao longo do tempo, também mostraram que existe grande interação entre os ambientes. $O$ eucalipto não se comporta como uma ilha, pois além de apresentar espécies comuns com a mata, apresenta espécies exclusivas, ou seja, mais do que simplesmente uma área de colonização pobre, disponibiliza recursos próprios essenciais para algumas populações, principalmente pelo efeito borda.

- $\mathrm{Na}$ configuração de distribuição quantitativa e qualitativa da mata natural, eucalipto e seu sub-bosque, na microbacia estudada, as operações silviculturais de colheita e eliminação do sub-bosque causam menor impacto em termos quantitativos e qualitativos na comunidade de insetos, do que as variações de temperatura e precipitação ao longo do tempo. Apenas fica evidenciado, que o corte e a reforma da floresta favorecem ou diminuem a ocorrência de algumas espécies de insetos, fortemente associadas às diferentes condições de plantação madura ou de área aberta recém plantada, o que se restabelece com o desenvolvimento do novo plantio.

- A importância do sub-bosque, para promover a diversidade de insetos dentro da plantação do eucalipto, é secundária, nas condições de distribuição e riqueza das reservas naturais encontradas na microbacia estudada. 
ANEXOS 
ANEXO A - CONSTÂNCIA DAS FAMÍLIAS NAS COLETAS/PONTOS DE LEVANTAMENTO (9 MESES $X 3$ PONTOS $=27$ ) EM CADA PERÍODO DE 9 MESES (9A A 9D, CONFORME CONVENÇÃO DA FIGURA 3), RESULTADO DO TESTE DE COMPARAÇÃO DE MÉDIAS DO ÍNDICE DE DIVERSIDADE, PARA ESTAÇÃO DO ANO (Est), PARA OS QUATRO PERÍODOS (Per) E PARA OS QUATRO PERÍODOS EM CADA ESTAÇÃO DO ANO (Pri, Ver, Out E Inv), PARA OS AMBIENTES/LOCAIS, CONFORME CONVENÇÃO DA TABELA 1 (TESTE DE WILCOXON: $n s=$ NÃO SIGNIFICATIVO, * ${ }^{*}$ SIGNIFICATIVO A $10 \%$; ${ }^{* *}=$ SIGNFICATIVO 5\%).

\begin{tabular}{|c|c|c|c|c|c|c|c|c|c|c|c|c|}
\hline \multirow{2}{*}{ Local } & \multirow{2}{*}{ Ordem } & \multirow{2}{*}{ Família } & \multicolumn{4}{|c|}{ Constância (\%) } & \multicolumn{2}{|c|}{ Teste } & \multicolumn{4}{|c|}{ Teste período } \\
\hline & & & $9 \mathrm{~A}$ & $9 \mathrm{~B}$ & $9 \mathrm{C}$ & $9 D$ & Est & Per & Pri & Ver & Out & Inv \\
\hline 1 & Blattodea & Blaberidae & 11 & 22 & 7 & 13 & ns & ns & ns & ns & ns & ns \\
\hline 1 & Blattodea & Blattellidae & 19 & 15 & 15 & 21 & ns & ns & ns & ns & ns & ns \\
\hline 1 & Blattodea & Blattidae & 30 & 19 & 30 & 38 & ns & ns & ns & ns & ns & ns \\
\hline 1 & Coleoptera & Anthribidae & 26 & 7 & 0 & 0 & ns & ns & ns & ns & ns & ns \\
\hline 1 & Coleoptera & Bostrichidae & 11 & 4 & 4 & 0 & ns & ns & ns & ns & ns & ns \\
\hline 1 & Coleoptera & Brentidae & 7 & 4 & 4 & 0 & ns & ns & ns & ns & ns & ns \\
\hline 1 & Coleoptera & Buprestidae & 4 & 0 & 0 & 4 & ns & ns & ns & ns & ns & ns \\
\hline 1 & Coleoptera & Carabidae & 59 & 41 & 26 & 4 & * & ** & ns & $\mathrm{ns}$ & ns & ns \\
\hline 1 & Coleoptera & Cerambycidae & 70 & 41 & 26 & 29 & ** & ** & $\star *$ & ns & $* *$ & ns \\
\hline 1 & Coleoptera & Ceratocanthidae & 4 & 0 & 0 & 0 & ns & ns & ns & ns & ns & ns \\
\hline 1 & Coleoptera & Chrysomelidae & 11 & 22 & 7 & 4 & ns & ns & ns & ns & ns & ns \\
\hline 1 & Coleoptera & Coccinellidae & 0 & 4 & 0 & 0 & ns & ns & $\mathrm{ns}$ & ns & ns & ns \\
\hline 1 & Coleoptera & Cucujidae & 0 & 0 & 0 & 0 & ns & ns & ns & ns & ns & ns \\
\hline 1 & Coleoptera & Curculionidae & 70 & 70 & 37 & 42 & $* *$ & ** & * & ns & ns & ns \\
\hline 1 & Coleoptera & Dytiscidae & 22 & 19 & 37 & 0 & ns & ns & ns & ns & ns & ns \\
\hline 1 & Coleoptera & Elateridae & 63 & 52 & 33 & 33 & $* *$ & ns & ns & ns & ns & ns \\
\hline 1 & Coleoptera & Endomychidae & 0 & 0 & 0 & 0 & ns & ns & ns & ns & ns & ns \\
\hline 1 & Coleoptera & Erotylidae & 0 & 0 & 0 & 0 & ns & ns & $\mathrm{ns}$ & $\mathrm{ns}$ & ns & ns \\
\hline 1 & Coleoptera & Eucnemidae & 4 & 0 & 0 & 0 & ns & ns & ns & ns & ns & ns \\
\hline 1 & Coleoptera & Hydrophilidae & 30 & 33 & 30 & 13 & ns & ns & ns & ns & ns & ns \\
\hline 1 & Coleoptera & Lampyridae & 30 & 19 & 19 & 4 & ns & ns & ns & ns & ns & ns \\
\hline 1 & Coleoptera & Languriidae & 7 & 4 & 0 & 0 & ns & ns & ns & ns & ns & ns \\
\hline 1 & Coleoptera & Lucanidae & 11 & 0 & 0 & 0 & ns & ns & ns & ns & ns & ns \\
\hline 1 & Coleoptera & Lymexylidae & 0 & 0 & 0 & 4 & ns & ns & ns & ns & ns & ns \\
\hline 1 & Coleoptera & Mordellidae & 0 & 0 & 0 & 0 & ns & ns & ns & $\mathrm{ns}$ & ns & ns \\
\hline 1 & Coleoptera & Passalidae & 22 & 7 & 11 & 17 & ** & ns & ns & ns & ns & ns \\
\hline 1 & Coleoptera & Phengodidae & 0 & 0 & 0 & 4 & ns & ns & ns & $\mathrm{ns}$ & ns & ns \\
\hline 1 & Coleoptera & Platypodidae & 4 & 7 & 4 & 13 & ns & ns & ns & ns & ns & ns \\
\hline 1 & Coleoptera & Rhipiceratidae & 4 & 4 & 0 & 0 & ns & ns & ns & ns & ns & ns \\
\hline
\end{tabular}


ANEXO A - CONSTÂNCIA DAS FAMÍLIAS NAS COLETAS/PONTOS DE LEVANTAMENTO (9 MESES X 3 PONTOS $=27$ ) EM CADA PERÍODO DE 9 MESES (9A A 9D, CONFORME CONVENÇÃO DA FIGURA 3), RESULTADO DO TESTE DE COMPARAÇÃO DE MÉDIAS DO ÍNDICE DE DIVERSIDADE, PARA ESTAÇÃO DO ANO (Est), PARA OS QUATRO PERÍODOS (Per) E PARA OS QUATRO PERÍODOS EM CADA ESTAÇÃO DO ANO (Pri, Ver, Out E Inv), PARA OS AMBIENTES/LOCAIS, CONFORME CONVENÇÃO DA TABELA 1 (TESTE DE WILCOXON: $n s=$ NÃO SIGNIFICATIVO, ${ }^{*}=$ SIGNIFICATIVO A $10 \%$; ${ }^{* *}=$ SIGNFICATIVO 5\%).

\begin{tabular}{|c|c|c|c|c|c|c|c|c|c|c|c|c|}
\hline \multirow{2}{*}{ Local } & \multirow{2}{*}{ Ordem } & \multirow{2}{*}{ Família } & \multicolumn{4}{|c|}{ Constância (\%) } & \multicolumn{2}{|c|}{ Teste } & \multicolumn{4}{|c|}{ Teste período } \\
\hline & & & $9 \mathrm{~A}$ & $9 \mathrm{~B}$ & $9 \mathrm{C}$ & $9 D$ & Est & Per & Pri & Ver & Out & Inv \\
\hline 1 & Coleoptera & Scarabaeidae & 70 & 56 & 56 & 50 & $* *$ & ns & * & ns & ns & ns \\
\hline 1 & Coleoptera & Scolytidae & 59 & 44 & 63 & 63 & ns & ns & ns & ns & ns & $* *$ \\
\hline 1 & Coleoptera & Staphylinidae & 0 & 0 & 0 & 4 & ns & ns & ns & ns & ns & ns \\
\hline 1 & Coleoptera & Tenebrionidae & 52 & 33 & 33 & 33 & $* *$ & ns & ns & ns & ns & ns \\
\hline 1 & Coleoptera & Trogidae & 0 & 0 & 0 & 0 & ns & ns & ns & ns & ns & ns \\
\hline 1 & Dermaptera & Labiduridae & 0 & 0 & 0 & 4 & ns & ns & ns & ns & ns & ns \\
\hline 1 & Diptera & Asilidae & 33 & 7 & 7 & 8 & * & ** & * & ns & ns & ns \\
\hline 1 & Diptera & Bombyliidae & 0 & 0 & 0 & 0 & ns & ns & ns & $\mathrm{ns}$ & ns & ns \\
\hline 1 & Diptera & Stratiomyidae & 0 & 0 & 0 & 0 & ns & ns & ns & ns & ns & ns \\
\hline 1 & Diptera & Tabanidae & 4 & 4 & 4 & 0 & ns & ns & ns & ns & ns & ns \\
\hline 1 & Diptera & Tachinidae & 0 & 0 & 0 & 0 & ns & ns & ns & ns & ns & ns \\
\hline 1 & Hemiptera & Acanaloniidae & 26 & 0 & 0 & 0 & ns & ns & ns & $\mathrm{ns}$ & ns & ns \\
\hline 1 & Hemiptera & Achilidae & 0 & 0 & 0 & 0 & ns & ns & ns & ns & ns & ns \\
\hline 1 & Hemiptera & Alydidae & 4 & 0 & 0 & 4 & ns & ns & ns & $\mathrm{ns}$ & ns & ns \\
\hline 1 & Hemiptera & Aphrophoridae & 4 & 0 & 0 & 0 & ns & ns & ns & ns & ns & ns \\
\hline 1 & Hemiptera & Belostomatidae & 4 & 0 & 11 & 0 & ns & ns & ns & $\mathrm{ns}$ & ns & ns \\
\hline 1 & Hemiptera & Cercopidae & 4 & 4 & 4 & 4 & ns & ns & ns & ns & ns & ns \\
\hline 1 & Hemiptera & Cicadellidae & 0 & 11 & 11 & 4 & ns & ns & ns & $\mathrm{ns}$ & ns & ns \\
\hline 1 & Hemiptera & Cicadidae & 37 & 30 & 7 & 17 & $* *$ & ns & ns & ns & ns & ns \\
\hline 1 & Hemiptera & Cixiidae & 7 & 4 & 0 & 0 & ns & ns & ns & $\mathrm{ns}$ & ns & ns \\
\hline 1 & Hemiptera & Coreidae & 7 & 7 & 0 & 0 & ns & ns & ns & ns & ns & ns \\
\hline 1 & Hemiptera & Corizidae & 0 & 0 & 0 & 0 & ns & ns & ns & ns & ns & ns \\
\hline 1 & Hemiptera & Cydnidae & 7 & 0 & 0 & 4 & ns & ns & ns & ns & ns & ns \\
\hline 1 & Hemiptera & Delphacidae & 0 & 0 & 0 & 0 & ns & ns & ns & $\mathrm{ns}$ & ns & ns \\
\hline 1 & Hemiptera & Dictyopharidae & 33 & 7 & 4 & 8 & ns & ns & ns & $\mathrm{ns}$ & ns & ns \\
\hline 1 & Hemiptera & Flatidae & 44 & 15 & 22 & 56 & $* *$ & $* *$ & ns & ns & ns & ns \\
\hline 1 & Hemiptera & Fulgoridae & 78 & 37 & 30 & 17 & $* *$ & ** & $* *$ & $\mathrm{~ns}$ & ns & ns \\
\hline 1 & Hemiptera & Issidae & 4 & 0 & 0 & 4 & ns & ns & ns & ns & ns & ns \\
\hline 1 & Hemiptera & Lygaeidae & 0 & 0 & 0 & 4 & ns & ns & ns & ns & ns & ns \\
\hline
\end{tabular}


ANEXO A - CONSTÂNCIA DAS FAMÍLIAS NAS COLETAS/PONTOS DE LEVANTAMENTO (9 MESES X 3 PONTOS $=27$ ) EM CADA PERÍODO DE 9 MESES (9A A 9D, CONFORME CONVENÇÃO DA FIGURA 3), RESULTADO DO TESTE DE COMPARAÇÃO DE MÉDIAS DO ÍNDICE DE DIVERSIDADE, PARA ESTAÇÃO DO ANO (Est), PARA OS QUATRO PERÍODOS (Per) E PARA OS QUATRO PERÍODOS EM CADA ESTAÇÃO DO ANO (Pri, Ver, Out E Inv), PARA OS AMBIENTES/LOCAIS, CONFORME CONVENÇÃO DA TABELA 1 (TESTE DE WILCOXON: $n S=$ NÃO SIGNIFICATIVO, * ${ }^{*}$ SIGNIFICATIVO A $10 \%$; ${ }^{* *}=$ SIGNFICATIVO 5\%).

\begin{tabular}{|c|c|c|c|c|c|c|c|c|c|c|c|c|}
\hline \multirow{2}{*}{ Local } & \multirow{2}{*}{ Ordem } & \multirow{2}{*}{ Família } & \multicolumn{4}{|c|}{ Constância (\%) } & \multicolumn{2}{|c|}{ Teste } & \multicolumn{4}{|c|}{ Teste período } \\
\hline & & & $9 A$ & $9 \mathrm{~B}$ & $9 \mathrm{C}$ & $9 D$ & Est & Per & Pri & Ver & Out & Inv \\
\hline 1 & Hemiptera & Membracidae & 7 & 0 & 0 & 0 & ns & ns & ns & ns & ns & ns \\
\hline 1 & Hemiptera & Nogodinidae & 4 & 0 & 0 & 0 & ns & ns & ns & ns & ns & ns \\
\hline 1 & Hemiptera & Pentatomidae & 37 & 4 & 11 & 13 & ns & ns & ns & ns & ns & ns \\
\hline 1 & Hemiptera & Reduviidae & 33 & 11 & 19 & 8 & ns & ** & ns & ns & ns & ns \\
\hline 1 & Hemiptera & Tropiduchidae & 0 & 0 & 0 & 0 & ns & ns & ns & ns & ns & ns \\
\hline 1 & Hymenoptera & Anthophoridae & 0 & 4 & 0 & 0 & ns & ns & ns & ns & ns & ns \\
\hline 1 & Hymenoptera & Apidae & 15 & 19 & 15 & 13 & ns & ns & ns & ns & ns & ns \\
\hline 1 & Hymenoptera & Bethylidae & 0 & 0 & 0 & 0 & ns & ns & ns & ns & ns & ns \\
\hline 1 & Hymenoptera & Braconidae & 4 & 0 & 4 & 0 & ns & ns & ns & $\mathrm{ns}$ & ns & ns \\
\hline 1 & Hymenoptera & Chalcididae & 0 & 0 & 0 & 0 & ns & ns & ns & $\mathrm{ns}$ & ns & ns \\
\hline 1 & Hymenoptera & Chrysididae & 0 & 0 & 0 & 0 & ns & ns & ns & ns & ns & ns \\
\hline 1 & Hymenoptera & Colletidae & 0 & 0 & 0 & 8 & ns & ns & ns & ns & ns & $\mathrm{ns}$ \\
\hline 1 & Hymenoptera & Crhysididae & 0 & 0 & 4 & 0 & ns & ns & ns & $\mathrm{ns}$ & ns & ns \\
\hline 1 & Hymenoptera & Diapriidae & 0 & 0 & 0 & 0 & ns & ns & ns & ns & ns & ns \\
\hline 1 & Hymenoptera & Elasmidae & 0 & 0 & 0 & 0 & ns & ns & ns & ns & ns & ns \\
\hline 1 & Hymenoptera & Encyrtidae & 0 & 0 & 0 & 0 & ns & ns & ns & ns & ns & ns \\
\hline 1 & Hymenoptera & Eucharitidae & 0 & 0 & 0 & 0 & ns & ns & ns & ns & ns & ns \\
\hline 1 & Hymenoptera & Eucoilidae & 0 & 0 & 0 & 0 & ns & ns & ns & $\mathrm{ns}$ & ns & $\mathrm{ns}$ \\
\hline 1 & Hymenoptera & Eulophidae & 0 & 0 & 0 & 0 & ns & ns & ns & $\mathrm{ns}$ & ns & ns \\
\hline 1 & Hymenoptera & Eupelmidae & 0 & 0 & 0 & 0 & ns & ns & ns & ns & ns & ns \\
\hline 1 & Hymenoptera & Eurytomidae & 0 & 0 & 0 & 0 & ns & ns & ns & $\mathrm{ns}$ & ns & ns \\
\hline 1 & Hymenoptera & Evaniidae & 0 & 0 & 0 & 0 & ns & ns & ns & ns & ns & ns \\
\hline 1 & Hymenoptera & Formicidae & 15 & 56 & 70 & 63 & ns & ns & ns & ns & ns & ns \\
\hline 1 & Hymenoptera & Halictidae & 44 & 22 & 37 & 63 & ns & ns & ns & ns & ns & ns \\
\hline 1 & Hymenoptera & Ichneumonidae & 26 & 44 & 33 & 8 & ns & ns & ns & ns & ns & ns \\
\hline 1 & Hymenoptera & Megachilidae & 4 & 0 & 0 & 0 & ns & ns & ns & ns & ns & ns \\
\hline 1 & Hymenoptera & Mutillidae & 7 & 7 & 4 & 4 & ns & ns & ns & $\mathrm{ns}$ & ns & ns \\
\hline 1 & Hymenoptera & Mymaridae & 0 & 0 & 0 & 0 & ns & ns & ns & ns & ns & ns \\
\hline 1 & Hymenoptera & Mymarommatidae & 0 & 0 & 0 & 0 & ns & ns & ns & ns & ns & ns \\
\hline
\end{tabular}


ANEXO A - CONSTÂNCIA DAS FAMÍLIAS NAS COLETAS/PONTOS DE LEVANTAMENTO (9 MESES $X 3$ PONTOS $=27$ ) EM CADA PERÍODO DE 9 MESES (9A A 9D, CONFORME CONVENÇÃO DA FIGURA 3), RESULTADO DO TESTE DE COMPARAÇÃO DE MÉDIAS DO ÍNDICE DE DIVERSIDADE, PARA ESTAÇÃO DO ANO (Est), PARA OS QUATRO PERÍODOS (Per) E PARA OS QUATRO PERÍODOS EM CADA ESTAÇÃO DO ANO (Pri, Ver, Out E Inv), PARA OS AMBIENTES/LOCAIS, CONFORME CONVENÇÃO DA TABELA 1 (TESTE DE WILCOXON: $n s=$ NÃO SIGNIFICATIVO, ${ }^{*}=$ SIGNIFICATIVO A $10 \%$; ${ }^{* *}=$ SIGNFICATIVO 5\%).

\begin{tabular}{|c|c|c|c|c|c|c|c|c|c|c|c|c|}
\hline \multirow{2}{*}{ Local } & \multirow{2}{*}{ Ordem } & \multirow{2}{*}{ Família } & \multicolumn{4}{|c|}{ Constância (\%) } & \multicolumn{2}{|c|}{ Teste } & \multicolumn{4}{|c|}{ Teste período } \\
\hline & & & $9 A$ & $9 \mathrm{~B}$ & $9 \mathrm{C}$ & $9 D$ & Est & Per & Pri & Ver & Out & Inv \\
\hline$\overline{1}$ & Hymenoptera & Pergidae & 0 & 0 & 0 & 0 & ns & ns & ns & ns & ns & ns \\
\hline 1 & Hymenoptera & Platygasteridae & 0 & 0 & 0 & 0 & ns & ns & ns & ns & ns & ns \\
\hline 1 & Hymenoptera & Pompilidae & 7 & 37 & 59 & 38 & ** & ns & ns & ns & ns & ns \\
\hline 1 & Hymenoptera & Pteromalidae & 0 & 0 & 0 & 0 & ns & ns & ns & ns & ns & ns \\
\hline 1 & Hymenoptera & Scelionidae & 0 & 0 & 0 & 0 & ns & ns & ns & ns & ns & ns \\
\hline 1 & Hymenoptera & Scoliidae & 0 & 0 & 0 & 0 & ns & ns & ns & ns & ns & ns \\
\hline 1 & Hymenoptera & Sphecidae & 7 & 33 & 22 & 17 & ns & ns & ns & ns & ns & ns \\
\hline 1 & Hymenoptera & Tiphiidae & 11 & 22 & 19 & 25 & ns & $\mathrm{ns}$ & ns & ns & ns & ns \\
\hline 1 & Hymenoptera & Torymidae & 0 & 0 & 0 & 0 & ns & ns & ns & ns & ns & ns \\
\hline 1 & Hymenoptera & Trichogrammatidae & 0 & 0 & 0 & 0 & ns & ns & ns & ns & ns & ns \\
\hline 1 & Hymenoptera & Vespidae & 37 & 59 & 52 & 58 & ** & ns & ns & ns & ns & ns \\
\hline 1 & Isoptera & Kalotermitidae & 0 & 0 & 0 & 0 & ns & ns & ns & ns & ns & ns \\
\hline 1 & Isoptera & Rhinotermitidae & 0 & 0 & 0 & 4 & ns & ns & ns & ns & ns & ns \\
\hline 1 & Isoptera & Termitidae & 0 & 0 & 4 & 21 & ns & ** & ns & * & ns & ns \\
\hline 1 & Lepidoptera & Alucitidae & 0 & 0 & 0 & 4 & ns & ns & ns & ns & ns & ns \\
\hline 1 & Lepidoptera & Arctiidae & 78 & 74 & 70 & 83 & ** & ns & ns & ns & $\star *$ & ns \\
\hline 1 & Lepidoptera & Arrhenophanidae & 0 & 0 & 0 & 0 & ns & ns & ns & ns & ns & ns \\
\hline 1 & Lepidoptera & Cossidae & 7 & 0 & 0 & 0 & ns & ns & ns & ns & ns & ns \\
\hline 1 & Lepidoptera & Dalceridae & 7 & 0 & 0 & 0 & ns & ns & ns & ns & ns & ns \\
\hline 1 & Lepidoptera & Dioptidae & 0 & 0 & 0 & 0 & ns & ns & ns & ns & ns & ns \\
\hline 1 & Lepidoptera & Eupterotidae & 70 & 52 & 30 & 50 & ns & ** & ns & ns & * & $* *$ \\
\hline 1 & Lepidoptera & Geometridae & 81 & 78 & 56 & 63 & $* *$ & ** & $* *$ & ns & ns & $* *$ \\
\hline 1 & Lepidoptera & Hepialidae & 0 & 0 & 0 & 0 & ns & ns & ns & ns & ns & ns \\
\hline 1 & Lepidoptera & Hesperiidae & 30 & 26 & 22 & 33 & ns & ns & ns & ns & ns & ns \\
\hline 1 & Lepidoptera & Lasiocampidae & 56 & 37 & 19 & 8 & * & $* *$ & ns & ns & ns & $* *$ \\
\hline 1 & Lepidoptera & Limacodidae & 19 & 30 & 15 & 4 & ns & ns & ns & ns & ns & ns \\
\hline 1 & Lepidoptera & Lycaenidae & 15 & 0 & 0 & 0 & ns & ns & ns & ns & ns & ns \\
\hline 1 & Lepidoptera & Lymantriidae & 22 & 37 & 30 & 25 & ** & ns & ns & ns & ns & ns \\
\hline 1 & Lepidoptera & Megalopygidae & 33 & 44 & 7 & 17 & ns & ns & ns & ns & ns & ns \\
\hline
\end{tabular}


ANEXO A - CONSTÂNCIA DAS FAMÍLIAS NAS COLETAS/PONTOS DE LEVANTAMENTO (9 MESES X 3 PONTOS $=27$ ) EM CADA PERÍODO DE 9 MESES (9A A 9D, CONFORME CONVENÇÃO DA FIGURA 3), RESULTADO DO TESTE DE COMPARAÇÃO DE MÉDIAS DO ÍNDICE DE DIVERSIDADE, PARA ESTAÇÃO DO ANO (Est), PARA OS QUATRO PERÍODOS (Per) E PARA OS QUATRO PERÍODOS EM CADA ESTAÇÃO DO ANO (Pri, Ver, Out E Inv), PARA OS AMBIENTES/LOCAIS, CONFORME CONVENÇÃO DA TABELA 1 (TESTE DE WILCOXON: $n S=$ NÃO SIGNIFICATIVO, * ${ }^{*}$ SIGNIFICATIVO A $10 \%$; ${ }^{* *}=$ SIGNFICATIVO 5\%).

\begin{tabular}{|c|c|c|c|c|c|c|c|c|c|c|c|c|}
\hline \multirow{2}{*}{ Local } & \multirow{2}{*}{ Ordem } & \multirow{2}{*}{ Família } & \multicolumn{4}{|c|}{ Constância (\%) } & \multicolumn{2}{|c|}{ Teste } & \multicolumn{4}{|c|}{ Teste período } \\
\hline & & & $9 \mathrm{~A}$ & $9 \mathrm{~B}$ & $9 \mathrm{C}$ & $9 D$ & Est & Per & Pri & Ver & Out & Inv \\
\hline 1 & Lepidoptera & Mimallonidae & 11 & 4 & 0 & 0 & ns & ns & ns & ns & ns & ns \\
\hline 1 & Lepidoptera & Noctuidae & 96 & 100 & 85 & 83 & ns & ns & ns & ns & ns & ns \\
\hline 1 & Lepidoptera & Notodontidae & 93 & 89 & 85 & 59 & ** & ** & $* *$ & ns & ns & $* *$ \\
\hline 1 & Lepidoptera & Nymphalidae & 26 & 33 & 22 & 13 & * & ns & ns & ns & ns & ns \\
\hline 1 & Lepidoptera & Oecophoridae & 7 & 19 & 19 & 29 & $* *$ & * & ns & ns & ns & ns \\
\hline 1 & Lepidoptera & Pieridae & 4 & 0 & 0 & 0 & ns & ns & ns & ns & ns & ns \\
\hline 1 & Lepidoptera & Psychidae & 0 & 0 & 0 & 4 & ns & ns & ns & ns & ns & ns \\
\hline 1 & Lepidoptera & Pyralidae & 70 & 93 & 81 & 71 & ns & $* *$ & * & ns & ns & $* *$ \\
\hline 1 & Lepidoptera & Saturniidae & 67 & 48 & 37 & 25 & ns & * & * & ** & * & ns \\
\hline 1 & Lepidoptera & Sematuridae & 7 & 0 & 4 & 0 & ns & ns & ns & ns & ns & ns \\
\hline 1 & Lepidoptera & Sphingidae & 33 & 26 & 4 & 8 & ns & ns & ns & ns & ns & ns \\
\hline 1 & Lepidoptera & Tineidae & 7 & 0 & 0 & 0 & ns & ns & ns & ns & ns & ns \\
\hline 1 & Lepidoptera & Yponomeutidae & 0 & 0 & 0 & 0 & ns & ns & ns & ns & ns & ns \\
\hline 1 & Mantodea & Hymenopodidae & 7 & 0 & 0 & 0 & ns & ns & ns & ns & ns & ns \\
\hline 1 & Mantodea & Mantidae & 52 & 33 & 11 & 42 & $* *$ & ns & ns & ns & ns & ns \\
\hline 1 & Megaloptera & Corydalidae & 4 & 0 & 0 & 4 & ns & ns & ns & ns & ns & ns \\
\hline 1 & Neuroptera & Ascalaphidae & 4 & 7 & 0 & 0 & ns & ns & ns & ns & ns & ns \\
\hline 1 & Neuroptera & Chrysopidae & 4 & 0 & 0 & 4 & ns & ns & ns & $\mathrm{ns}$ & ns & ns \\
\hline 1 & Neuroptera & Myrmeleontidae & 7 & 7 & 0 & 0 & ns & ns & ns & ns & ns & ns \\
\hline 1 & Odonata & Aeshnidae & 0 & 4 & 0 & 8 & ns & ns & ns & ns & ns & ns \\
\hline 1 & Odonata & Libellulidae & 0 & 0 & 0 & 4 & ns & ns & ns & ns & ns & ns \\
\hline 1 & Orthoptera & Acrididae & 4 & 0 & 7 & 8 & ns & ns & ns & ns & ns & ns \\
\hline 1 & Orthoptera & Gryllacrididae & 4 & 0 & 0 & 0 & ns & ns & ns & ns & ns & ns \\
\hline 1 & Orthoptera & Gryllidae & 41 & 11 & 0 & 25 & ns & ns & ns & ns & ns & ns \\
\hline 1 & Orthoptera & Gryllotalpidae & 0 & 0 & 0 & 4 & ns & ns & ns & ns & ns & ns \\
\hline 1 & Orthoptera & Pyrgomorphidae & 0 & 0 & 0 & 0 & ns & ns & ns & ns & ns & ns \\
\hline 1 & Orthoptera & Tettigoniidae & 41 & 26 & 4 & 17 & * & ns & ns & $\mathrm{ns}$ & ns & ns \\
\hline 1 & Phasmatodea & Phasmatidae & 4 & 0 & 0 & 0 & ns & ns & ns & ns & ns & ns \\
\hline 1 & Phasmatodea & Phylliidae & 4 & 0 & 0 & 0 & ns & ns & ns & ns & ns & ns \\
\hline
\end{tabular}


ANEXO A - CONSTÂNCIA DAS FAMÍLIAS NAS COLETAS/PONTOS DE LEVANTAMENTO (9 MESES $X 3$ PONTOS $=27$ ) EM CADA PERÍODO DE 9 MESES (9A A 9D, CONFORME CONVENÇÃO DA FIGURA 3), RESULTADO DO TESTE DE COMPARAÇÃO DE MÉDIAS DO ÍNDICE DE DIVERSIDADE, PARA ESTAÇÃO DO ANO (Est), PARA OS QUATRO PERÍODOS (Per) E PARA OS QUATRO PERÍODOS EM CADA ESTAÇÃO DO ANO (Pri, Ver, Out E Inv), PARA OS AMBIENTES/LOCAIS, CONFORME CONVENÇÃO DA TABELA 1 (TESTE DE WILCOXON: $n S=$ NÃO SIGNIFICATIVO, * ${ }^{*}$ SIGNIFICATIVO A $10 \%$; ${ }^{* *}=$ SIGNFICATIVO 5\%).

\begin{tabular}{|c|c|c|c|c|c|c|c|c|c|c|c|c|}
\hline \multirow{2}{*}{ Local } & \multirow{2}{*}{ Ordem } & \multirow{2}{*}{ Família } & \multicolumn{4}{|c|}{ Constância (\%) } & \multicolumn{2}{|c|}{ Teste } & \multicolumn{4}{|c|}{ Teste período } \\
\hline & & & $9 \mathrm{~A}$ & $9 \mathrm{~B}$ & $9 \mathrm{C}$ & 9D & Est & Per & Pri & Ver & Out & Inv \\
\hline 2 & Blattodea & Blaberidae & 0 & 7 & 7 & 4 & ns & ns & ns & ns & ns & ns \\
\hline 2 & Blattodea & Blattellidae & 22 & 15 & 7 & 8 & ns & ns & ns & ns & ns & ns \\
\hline 2 & Blattodea & Blattidae & 22 & 11 & 7 & 8 & ns & ns & ns & ns & ns & ns \\
\hline 2 & Coleoptera & Anthribidae & 11 & 7 & 0 & 17 & ns & ns & ns & ns & ns & ns \\
\hline 2 & Coleoptera & Bostrichidae & 4 & 11 & 4 & 13 & ns & ns & ns & ns & ns & ns \\
\hline 2 & Coleoptera & Brentidae & 11 & 0 & 0 & 8 & ns & ns & ns & ns & ns & ns \\
\hline 2 & Coleoptera & Bruchidae & 7 & 0 & 0 & 0 & ns & ns & ns & ns & ns & ns \\
\hline 2 & Coleoptera & Buprestidae & 11 & 0 & 0 & 8 & ns & ns & ns & $\mathrm{ns}$ & ns & ns \\
\hline 2 & Coleoptera & Carabidae & 37 & 37 & 44 & 50 & ns & ** & ns & $\star *$ & ns & ns \\
\hline 2 & Coleoptera & Cerambycidae & 59 & 52 & 37 & 54 & $* *$ & ns & ns & ns & ns & ns \\
\hline 2 & Coleoptera & Ceratocanthidae & 0 & 0 & 0 & 8 & ns & ns & ns & ns & ns & ns \\
\hline 2 & Coleoptera & Chrysomelidae & 7 & 15 & 4 & 4 & ns & ns & $\mathrm{ns}$ & ns & ns & ns \\
\hline 2 & Coleoptera & Coccinellidae & 0 & 0 & 0 & 0 & ns & ns & ns & ns & ns & ns \\
\hline 2 & Coleoptera & Curculionidae & 52 & 54 & 52 & 42 & $* *$ & ns & * & ns & ns & ns \\
\hline 2 & Coleoptera & Dytiscidae & 0 & 11 & 11 & 0 & ns & ns & ns & ns & ns & ns \\
\hline 2 & Coleoptera & Elateridae & 63 & 33 & 33 & 54 & $* *$ & * & ns & $* *$ & $* *$ & ns \\
\hline 2 & Coleoptera & Endomychidae & 0 & 0 & 0 & 4 & ns & ns & ns & ns & ns & ns \\
\hline 2 & Coleoptera & Erotylidae & 0 & 0 & 0 & 4 & ns & ns & ns & ns & ns & ns \\
\hline 2 & Coleoptera & Eucnemidae & 0 & 0 & 0 & 0 & ns & ns & ns & ns & ns & ns \\
\hline 2 & Coleoptera & Hydrophilidae & 11 & 26 & 19 & 17 & ns & ** & ns & * & ns & ns \\
\hline 2 & Coleoptera & Lampyridae & 22 & 56 & 26 & 21 & ns & ns & ns & ns & ns & ns \\
\hline 2 & Coleoptera & Languriidae & 0 & 0 & 4 & 0 & ns & ns & ns & ns & ns & ns \\
\hline 2 & Coleoptera & Lucanidae & 11 & 0 & 4 & 0 & ns & ns & ns & ns & ns & ns \\
\hline 2 & Coleoptera & Lycidae & 4 & 0 & 0 & 0 & ns & ns & ns & ns & ns & ns \\
\hline 2 & Coleoptera & Lymexylidae & 7 & 0 & 0 & 0 & ns & ns & ns & ns & ns & ns \\
\hline 2 & Coleoptera & Mordellidae & 0 & 0 & 4 & 0 & ns & ns & ns & ns & ns & ns \\
\hline 2 & Coleoptera & Nilionidae & 0 & 0 & 0 & 0 & ns & ns & ns & $\mathrm{ns}$ & ns & ns \\
\hline 2 & Coleoptera & Passalidae & 11 & 4 & 0 & 4 & ns & ns & ns & ns & ns & ns \\
\hline 2 & Coleoptera & Platypodidae & 4 & 4 & 7 & 29 & ns & * & ns & ns & ns & ns \\
\hline
\end{tabular}


ANEXO A - CONSTÂNCIA DAS FAMÍLIAS NAS COLETAS/PONTOS DE LEVANTAMENTO (9 MESES X 3 PONTOS $=27$ ) EM CADA PERÍODO DE 9 MESES (9A A 9D, CONFORME CONVENÇÃO DA FIGURA 3), RESULTADO DO TESTE DE COMPARAÇÃO DE MÉDIAS DO ÍNDICE DE DIVERSIDADE, PARA ESTAÇÃO DO ANO (Est), PARA OS QUATRO PERÍODOS (Per) E PARA OS QUATRO PERÍODOS EM CADA ESTAÇÃO DO ANO (Pri, Ver, Out E Inv), PARA OS AMBIENTES/LOCAIS, CONFORME CONVENÇÃO DA TABELA 1 (TESTE DE WILCOXON: $n s=$ NÃO SIGNIFICATIVO, * $=$ SIGNIFICATIVO A $10 \%$; ${ }^{* *}=$ SIGNFICATIVO 5\%).

\begin{tabular}{|c|c|c|c|c|c|c|c|c|c|c|c|c|}
\hline \multirow{2}{*}{ Local } & \multirow{2}{*}{ Ordem } & \multirow{2}{*}{ Família } & \multicolumn{4}{|c|}{ Constância (\%) } & \multicolumn{2}{|c|}{ Teste } & \multicolumn{4}{|c|}{ Teste período } \\
\hline & & & $9 A$ & $9 \mathrm{~B}$ & $9 \mathrm{C}$ & $9 D$ & Est & Per & Pri & Ver & Out & Inv \\
\hline 2 & Coleoptera & Scarabaeidae & 85 & 74 & 67 & 54 & ** & ns & ns & * & ns & ns \\
\hline 2 & Coleoptera & Scolytidae & 30 & 30 & 52 & 92 & ns & ** & * & $* *$ & ** & ns \\
\hline 2 & Coleoptera & Staphylinidae & 0 & 0 & 4 & 0 & ns & ns & ns & ns & ns & ns \\
\hline 2 & Coleoptera & Tenebrionidae & 30 & 15 & 7 & 63 & ns & $* *$ & ns & * & ** & ns \\
\hline 2 & Coleoptera & Trogidae & 0 & 0 & 0 & 0 & ns & ns & ns & ns & ns & ns \\
\hline 2 & Dermaptera & Forficulidae & 4 & 0 & 0 & 0 & ns & ns & ns & ns & ns & ns \\
\hline 2 & Diptera & Asilidae & 26 & 22 & 37 & 0 & $* *$ & ns & * & ns & ns & ns \\
\hline 2 & Diptera & Bombyliidae & 0 & 0 & 0 & 8 & ns & ns & ns & $\mathrm{ns}$ & ns & ns \\
\hline 2 & Diptera & Stratiomyidae & 4 & 7 & 0 & 0 & ns & ns & ns & ns & ns & ns \\
\hline 2 & Diptera & Syrphidae & 0 & 0 & 0 & 13 & ns & ns & ns & ns & ns & ns \\
\hline 2 & Diptera & Tabanidae & 4 & 4 & 0 & 17 & ns & ns & ns & ns & ns & ns \\
\hline 2 & Diptera & Tachinidae & 0 & 0 & 0 & 0 & ns & ns & ns & $\mathrm{ns}$ & ns & ns \\
\hline 2 & Diptera & Tephritidae & 0 & 0 & 0 & 0 & ns & ns & ns & ns & ns & ns \\
\hline 2 & Hemiptera & Acanaloniidae & 19 & 0 & 7 & 13 & ns & ns & ns & $\mathrm{ns}$ & ns & ns \\
\hline 2 & Hemiptera & Achilidae & 0 & 0 & 0 & 0 & ns & ns & ns & ns & ns & ns \\
\hline 2 & Hemiptera & Alydidae & 0 & 0 & 0 & 0 & ns & ns & ns & ns & ns & ns \\
\hline 2 & Hemiptera & Belostomatidae & 0 & 0 & 7 & 0 & ns & ns & ns & ns & ns & ns \\
\hline 2 & Hemiptera & Cercopidae & 7 & 4 & 19 & 13 & ns & ns & ns & ns & ns & ns \\
\hline 2 & Hemiptera & Cicadellidae & 0 & 15 & 0 & 8 & ns & ns & ns & ns & ns & ns \\
\hline 2 & Hemiptera & Cicadidae & 48 & 33 & 26 & 25 & $* *$ & ns & ns & ns & ns & ns \\
\hline 2 & Hemiptera & Cixiidae & 11 & 0 & 0 & 4 & ns & ns & ns & ns & ns & ns \\
\hline 2 & Hemiptera & Coreidae & 11 & 0 & 0 & 0 & ns & ns & ns & ns & ns & ns \\
\hline 2 & Hemiptera & Corimelaenidae & 0 & 0 & 0 & 4 & ns & ns & ns & ns & ns & ns \\
\hline 2 & Hemiptera & Corizidae & 4 & 0 & 0 & 4 & ns & ns & ns & ns & ns & ns \\
\hline 2 & Hemiptera & Cydnidae & 0 & 0 & 0 & 8 & ns & ns & ns & ns & ns & ns \\
\hline 2 & Hemiptera & Derbidae & 4 & 0 & 0 & 0 & ns & ns & ns & ns & ns & ns \\
\hline 2 & Hemiptera & Dictyopharidae & 30 & 4 & 4 & 13 & ns & ns & ns & ns & ns & ns \\
\hline 2 & Hemiptera & Flatidae & 33 & 33 & 26 & 17 & ns & ns & ns & ns & ns & ns \\
\hline 2 & Hemiptera & Fulgoridae & 44 & 15 & 41 & 38 & ns & ns & ns & ns & ns & ns \\
\hline
\end{tabular}


ANEXO A - CONSTÂNCIA DAS FAMÍLIAS NAS COLETAS/PONTOS DE LEVANTAMENTO (9 MESES X 3 PONTOS $=27$ ) EM CADA PERÍODO DE 9 MESES (9A A 9D, CONFORME CONVENÇÃO DA FIGURA 3), RESULTADO DO TESTE DE COMPARAÇÃO DE MÉDIAS DO ÍNDICE DE DIVERSIDADE, PARA ESTAÇÃO DO ANO (Est), PARA OS QUATRO PERÍODOS (Per) E PARA OS QUATRO PERÍODOS EM CADA ESTAÇÃO DO ANO (Pri, Ver, Out E Inv), PARA OS AMBIENTES/LOCAIS, CONFORME CONVENÇÃO DA TABELA 1 (TESTE DE WILCOXON: $n s=$ NÃO SIGNIFICATIVO, ${ }^{*}=$ SIGNIFICATIVO A $10 \%$; ${ }^{* *}=$ SIGNFICATIVO 5\%).

\begin{tabular}{|c|c|c|c|c|c|c|c|c|c|c|c|c|}
\hline \multirow{2}{*}{ Local } & \multirow{2}{*}{ Ordem } & \multirow{2}{*}{ Família } & \multicolumn{4}{|c|}{ Constância (\%) } & \multicolumn{2}{|c|}{ Teste } & \multicolumn{4}{|c|}{ Teste período } \\
\hline & & & $9 \mathrm{~A}$ & $9 \mathrm{~B}$ & $9 \mathrm{C}$ & 9D & Est & Per & Pri & Ver & Out & Inv \\
\hline 2 & Hemiptera & Issidae & 0 & 0 & 0 & 0 & ns & ns & ns & ns & ns & ns \\
\hline 2 & Hemiptera & Lygaeidae & 0 & 0 & 0 & 4 & ns & ns & ns & ns & ns & ns \\
\hline 2 & Hemiptera & Membracidae & 4 & 0 & 0 & 4 & ns & ns & ns & ns & ns & ns \\
\hline 2 & Hemiptera & Miridae & 0 & 0 & 0 & 4 & ns & ns & ns & $\mathrm{ns}$ & ns & ns \\
\hline 2 & Hemiptera & Pentatomidae & 33 & 15 & 19 & 13 & * & ns & ns & ns & ns & ns \\
\hline 2 & Hemiptera & Pyrrhocoridae & 0 & 4 & 0 & 0 & ns & ns & ns & ns & ns & ns \\
\hline 2 & Hemiptera & Reduviidae & 33 & 26 & 19 & 33 & ns & * & ns & * & ns & ns \\
\hline 2 & Hemiptera & Scutelleridae & 0 & 0 & 0 & 4 & ns & ns & ns & ns & ns & ns \\
\hline 2 & Hemiptera & Tingidae & 0 & 0 & 0 & 0 & ns & ns & ns & ns & ns & ns \\
\hline 2 & Hymenoptera & Aphelinidae & 0 & 0 & 0 & 0 & ns & ns & ns & $\mathrm{ns}$ & ns & ns \\
\hline 2 & Hymenoptera & Apidae & 22 & 7 & 15 & 25 & ns & ns & ns & ns & ns & ns \\
\hline 2 & Hymenoptera & Argidae & 0 & 0 & 0 & 0 & ns & ns & ns & ns & ns & ns \\
\hline 2 & Hymenoptera & Bethylidae & 0 & 0 & 0 & 0 & ns & ns & ns & $\mathrm{ns}$ & ns & ns \\
\hline 2 & Hymenoptera & Braconidae & 4 & 11 & 0 & 8 & ns & ns & ns & ns & ns & ns \\
\hline 2 & Hymenoptera & Chalcididae & 0 & 0 & 0 & 4 & ns & ns & ns & ns & ns & ns \\
\hline 2 & Hymenoptera & Chrysididae & 0 & 0 & 0 & 0 & ns & ns & ns & ns & ns & ns \\
\hline 2 & Hymenoptera & Colletidae & 4 & 4 & 0 & 21 & ns & ns & ns & ns & ns & ns \\
\hline 2 & Hymenoptera & Cynipidae & 0 & 0 & 0 & 0 & ns & ns & ns & $\mathrm{ns}$ & ns & ns \\
\hline 2 & Hymenoptera & Diapriidae & 0 & 0 & 0 & 0 & ns & ns & ns & $\mathrm{ns}$ & ns & ns \\
\hline 2 & Hymenoptera & Dryinidae & 0 & 0 & 0 & 0 & ns & ns & ns & ns & ns & ns \\
\hline 2 & Hymenoptera & Elasmidae & 0 & 0 & 0 & 0 & ns & ns & ns & ns & ns & ns \\
\hline 2 & Hymenoptera & Encyrtidae & 0 & 0 & 0 & 0 & ns & ns & ns & ns & ns & ns \\
\hline 2 & Hymenoptera & Eucharitidae & 0 & 0 & 0 & 0 & ns & ns & ns & $\mathrm{ns}$ & ns & ns \\
\hline 2 & Hymenoptera & Eucoilidae & 0 & 0 & 0 & 0 & ns & ns & ns & $\mathrm{ns}$ & ns & ns \\
\hline 2 & Hymenoptera & Eulophidae & 0 & 0 & 0 & 0 & ns & ns & ns & ns & ns & ns \\
\hline 2 & Hymenoptera & Eupelmidae & 0 & 0 & 0 & 0 & ns & ns & ns & $\mathrm{ns}$ & ns & ns \\
\hline 2 & Hymenoptera & Eurytomidae & 0 & 0 & 0 & 0 & ns & $\mathrm{ns}$ & ns & ns & ns & ns \\
\hline 2 & Hymenoptera & Evaniidae & 0 & 0 & 0 & 0 & ns & ns & ns & ns & ns & ns \\
\hline 2 & Hymenoptera & Figitidae & 0 & 0 & 0 & 0 & ns & ns & ns & ns & ns & ns \\
\hline
\end{tabular}


ANEXO A - CONSTÂNCIA DAS FAMÍLIAS NAS COLETAS/PONTOS DE LEVANTAMENTO (9 MESES $X 3$ PONTOS $=27$ ) EM CADA PERÍODO DE 9 MESES (9A A 9D, CONFORME CONVENÇÃO DA FIGURA 3), RESULTADO DO TESTE DE COMPARAÇÃO DE MÉDIAS DO ÍNDICE DE DIVERSIDADE, PARA ESTAÇÃO DO ANO (Est), PARA OS QUATRO PERÍODOS (Per) E PARA OS QUATRO PERÍODOS EM CADA ESTAÇÃO DO ANO (Pri, Ver, Out E Inv), PARA OS AMBIENTES/LOCAIS, CONFORME CONVENÇÃO DA TABELA 1 (TESTE DE WILCOXON: $n S=$ NÃO SIGNIFICATIVO, * $=$ SIGNIFICATIVO A $10 \%$; ${ }^{* *}=$ SIGNFICATIVO 5\%).

\begin{tabular}{|c|c|c|c|c|c|c|c|c|c|c|c|c|}
\hline \multirow{2}{*}{ Local } & \multirow{2}{*}{ Ordem } & \multirow{2}{*}{ Família } & \multicolumn{4}{|c|}{ Constância (\%) } & \multicolumn{2}{|c|}{ Teste } & \multicolumn{4}{|c|}{ Teste período } \\
\hline & & & $9 A$ & $9 \mathrm{~B}$ & $9 \mathrm{C}$ & $9 D$ & Est & Per & Pri & Ver & Out & Inv \\
\hline 2 & Hymenoptera & Formicidae & 41 & 56 & 44 & 50 & * & ** & ns & * & ** & ns \\
\hline 2 & Hymenoptera & Halictidae & 0 & 7 & 11 & 75 & ns & ns & ns & ns & ns & ns \\
\hline 2 & Hymenoptera & Ichneumonidae & 15 & 52 & 52 & 25 & ns & ns & ns & ns & ns & * \\
\hline 2 & Hymenoptera & Megachilidae & 7 & 4 & 0 & 0 & ns & ns & ns & ns & ns & ns \\
\hline 2 & Hymenoptera & Mutillidae & 30 & 11 & 22 & 21 & ns & ns & ns & ns & ns & ns \\
\hline 2 & Hymenoptera & Mymaridae & 0 & 0 & 0 & 0 & ns & ns & ns & ns & ns & ns \\
\hline 2 & Hymenoptera & Mymarommatidae & 0 & 0 & 0 & 0 & ns & ns & ns & ns & ns & ns \\
\hline 2 & Hymenoptera & Perilampidae & 0 & 0 & 0 & 0 & ns & ns & ns & ns & ns & ns \\
\hline 2 & Hymenoptera & Platygasteridae & 0 & 0 & 0 & 0 & ns & ns & ns & ns & ns & ns \\
\hline 2 & Hymenoptera & Pompilidae & 11 & 19 & 56 & 42 & ns & * & ns & $* \star$ & ns & ns \\
\hline 2 & Hymenoptera & Pteromalidae & 0 & 0 & 0 & 0 & ns & ns & ns & ns & ns & ns \\
\hline 2 & Hymenoptera & Scelionidae & 0 & 0 & 0 & 0 & ns & ns & ns & ns & ns & ns \\
\hline 2 & Hymenoptera & Scolebythidae & 0 & 0 & 0 & 0 & ns & ns & ns & ns & ns & ns \\
\hline 2 & Hymenoptera & Signiphoridae & 0 & 0 & 0 & 0 & ns & ns & ns & ns & ns & ns \\
\hline 2 & Hymenoptera & Sphecidae & 30 & 59 & 44 & 21 & ns & ns & ns & ns & ns & ns \\
\hline 2 & Hymenoptera & Stephanidae & 0 & 0 & 0 & 0 & ns & ns & ns & ns & ns & ns \\
\hline 2 & Hymenoptera & Tiphiidae & 22 & 41 & 15 & 38 & ns & ns & ns & ns & ns & ns \\
\hline 2 & Hymenoptera & Torymidae & 0 & 0 & 0 & 0 & ns & ns & ns & ns & ns & ns \\
\hline 2 & Hymenoptera & Trichogrammatidae & 0 & 0 & 0 & 0 & ns & ns & ns & ns & ns & ns \\
\hline 2 & Hymenoptera & Trigonalyidae & 0 & 0 & 0 & 0 & ns & ns & ns & ns & ns & ns \\
\hline 2 & Hymenoptera & Vespidae & 78 & 74 & 89 & 96 & ns & ns & ns & * & ns & ns \\
\hline 2 & Isoptera & Kalotermitidae & 0 & 0 & 0 & 0 & ns & ns & ns & ns & ns & ns \\
\hline 2 & Isoptera & Rhinotermitidae & 0 & 0 & 0 & 4 & ns & ns & ns & ns & ns & ns \\
\hline 2 & Isoptera & Termitidae & 0 & 0 & 0 & 17 & ns & ns & ns & ns & ns & ns \\
\hline 2 & Lepidoptera & Arctiidae & 93 & 89 & 81 & 79 & ** & ns & $* *$ & ns & ** & ns \\
\hline 2 & Lepidoptera & Cossidae & 4 & 0 & 0 & 0 & ns & ns & ns & ns & ns & ns \\
\hline 2 & Lepidoptera & Dalceridae & 11 & 4 & 0 & 0 & ns & ns & ns & ns & ns & ns \\
\hline 2 & Lepidoptera & Depressariidae & 0 & 0 & 0 & 0 & ns & ns & ns & ns & ns & ns \\
\hline 2 & Lepidoptera & Eupterotidae & 70 & 56 & 41 & 33 & ns & ** & ns & ns & ns & $\star *$ \\
\hline
\end{tabular}


ANEXO A - CONSTÂNCIA DAS FAMÍLIAS NAS COLETAS/PONTOS DE LEVANTAMENTO (9 MESES $X 3$ PONTOS $=27$ ) EM CADA PERÍODO DE 9 MESES (9A A 9D, CONFORME CONVENÇÃO DA FIGURA 3), RESULTADO DO TESTE DE COMPARAÇÃO DE MÉDIAS DO ÍNDICE DE DIVERSIDADE, PARA ESTAÇÃO DO ANO (Est), PARA OS QUATRO PERÍODOS (Per) E PARA OS QUATRO PERÍODOS EM CADA ESTAÇÃO DO ANO (Pri, Ver, Out E Inv), PARA OS AMBIENTES/LOCAIS, CONFORME CONVENÇÃO DA TABELA 1 (TESTE DE WILCOXON: $n s=$ NÃO SIGNIFICATIVO, * $=$ SIGNIFICATIVO A $10 \%$; ${ }^{* *}=$ SIGNFICATIVO 5\%).

\begin{tabular}{|c|c|c|c|c|c|c|c|c|c|c|c|c|}
\hline \multirow{2}{*}{ Local } & \multirow{2}{*}{ Ordem } & \multirow{2}{*}{ Família } & \multicolumn{4}{|c|}{ Constância (\%) } & \multicolumn{2}{|c|}{ Teste } & \multicolumn{4}{|c|}{ Teste período } \\
\hline & & & $9 \mathrm{~A}$ & $9 \mathrm{~B}$ & $9 \mathrm{C}$ & 9D & Est & Per & Pri & Ver & Out & Inv \\
\hline 2 & Lepidoptera & Gelechiidae & 4 & 0 & 0 & 0 & ns & ns & ns & ns & ns & ns \\
\hline 2 & Lepidoptera & Geometridae & 70 & 93 & 81 & 71 & $* *$ & ns & ns & ns & ** & ns \\
\hline 2 & Lepidoptera & Hepialidae & 4 & 0 & 0 & 0 & ns & ns & ns & ns & ns & ns \\
\hline 2 & Lepidoptera & Hesperiidae & 48 & 59 & 67 & 46 & ** & ns & ns & ns & ns & ns \\
\hline 2 & Lepidoptera & Lasiocampidae & 67 & 56 & 15 & 25 & $* *$ & $* *$ & ns & ns & * & $* *$ \\
\hline 2 & Lepidoptera & Limacodidae & 22 & 22 & 7 & 13 & ns & ns & ns & ns & ns & ns \\
\hline 2 & Lepidoptera & Lycaenidae & 19 & 0 & 7 & 8 & $* *$ & ns & ns & ns & ns & ns \\
\hline 2 & Lepidoptera & Lymantriidae & 33 & 48 & 26 & 17 & $* *$ & ns & ns & ns & ns & $* *$ \\
\hline 2 & Lepidoptera & Megalopygidae & 30 & 26 & 19 & 13 & ns & ns & ns & ns & ns & ns \\
\hline 2 & Lepidoptera & Mimallonidae & 19 & 7 & 0 & 4 & ns & ns & ns & $\mathrm{ns}$ & ns & ns \\
\hline 2 & Lepidoptera & Noctuidae & 100 & 100 & 96 & 96 & $* *$ & ns & ns & ns & ** & * \\
\hline 2 & Lepidoptera & Notodontidae & 89 & 96 & 74 & 79 & $* *$ & ** & ns & ns & $* *$ & ns \\
\hline 2 & Lepidoptera & Nymphalidae & 52 & 89 & 67 & 75 & ns & ns & ns & ** & ns & ns \\
\hline 2 & Lepidoptera & Oecophoridae & 11 & 11 & 22 & 42 & ns & ns & ns & ns & ns & ns \\
\hline 2 & Lepidoptera & Papilionidae & 0 & 4 & 0 & 4 & ns & ns & ns & ns & ns & ns \\
\hline 2 & Lepidoptera & Pieridae & 0 & 4 & 22 & 25 & ns & ns & ns & ns & ns & ns \\
\hline 2 & Lepidoptera & Psychidae & 0 & 0 & 0 & 4 & ns & ns & ns & ns & ns & ns \\
\hline 2 & Lepidoptera & Pyralidae & 89 & 85 & 67 & 67 & $* *$ & ns & ns & ns & $* *$ & ns \\
\hline 2 & Lepidoptera & Saturniidae & 81 & 63 & 37 & 38 & ns & ** & * & $\mathrm{ns}$ & ns & ns \\
\hline 2 & Lepidoptera & Sematuridae & 11 & 0 & 0 & 4 & ns & ns & ns & ns & ns & ns \\
\hline 2 & Lepidoptera & Sessiidae & 0 & 0 & 0 & 0 & ns & ns & ns & ns & ns & ns \\
\hline 2 & Lepidoptera & Sphingidae & 70 & 44 & 48 & 71 & ns & $* *$ & ns & ** & $\star \star \star$ & ns \\
\hline 2 & Lepidoptera & Thyrididae & 4 & 0 & 0 & 4 & ns & ns & ns & ns & ns & ns \\
\hline 2 & Lepidoptera & Tineidae & 7 & 7 & 0 & 17 & ns & ns & ns & ns & ns & ns \\
\hline 2 & Lepidoptera & Yponomeutidae & 0 & 0 & 0 & 13 & ns & ns & ns & ns & ns & ns \\
\hline 2 & Mantodea & Hymenopodidae & 11 & 0 & 0 & 0 & ns & ns & ns & ns & ns & ns \\
\hline 2 & Mantodea & Mantidae & 56 & 56 & 19 & 33 & ns & ns & ns & ns & ns & ns \\
\hline 2 & Neuroptera & Ascalaphidae & 7 & 0 & 4 & 0 & ns & ns & ns & ns & ns & ns \\
\hline 2 & Neuroptera & Chrysopidae & 7 & 0 & 0 & 0 & ns & ns & ns & ns & ns & ns \\
\hline
\end{tabular}


ANEXO A - CONSTÂNCIA DAS FAMÍLIAS NAS COLETAS/PONTOS DE LEVANTAMENTO (9 MESES X 3 PONTOS = 27) EM CADA PERÍODO DE 9 MESES (9A A 9D, CONFORME CONVENÇÃO DA FIGURA 3), RESULTADO DO TESTE DE COMPARAÇÃO DE MÉDIAS DO ÍNDICE DE DIVERSIDADE, PARA ESTAÇÃO DO ANO (Est), PARA OS QUATRO PERÍODOS (Per) E PARA OS QUATRO PERÍODOS EM CADA ESTAÇÃO DO ANO (Pri, Ver, Out E Inv), PARA OS AMBIENTES/LOCAIS, CONFORME CONVENÇÃO DA TABELA 1 (TESTE DE WILCOXON: $n S=$ NÃO SIGNIFICATIVO, * $=$ SIGNIFICATIVO A $10 \%$; ${ }^{* *}=$ SIGNFICATIVO 5\%).

\begin{tabular}{|c|c|c|c|c|c|c|c|c|c|c|c|c|}
\hline \multirow{2}{*}{ Local } & \multirow{2}{*}{ Ordem } & \multirow{2}{*}{ Família } & \multicolumn{4}{|c|}{ Constância (\%) } & \multicolumn{2}{|c|}{ Teste } & \multicolumn{4}{|c|}{ Teste período } \\
\hline & & & $9 A$ & $9 B$ & $9 \mathrm{C}$ & $9 \mathrm{D}$ & Est & Per & Pri & Ver & Out & $\operatorname{lnv}$ \\
\hline 2 & Neuroptera & Myrmeleontidae & 7 & 11 & 4 & 4 & $\mathrm{~ns}$ & ns & ns & ns & ns & ns \\
\hline 2 & Odonata & Aeshnidae & 0 & 0 & 0 & 0 & ns & ns & ns & ns & ns & ns \\
\hline 2 & Odonata & Coenagrionidae & 0 & 0 & 0 & 0 & $\mathrm{~ns}$ & ns & ns & ns & ns & ns \\
\hline 2 & Odonata & Libellulidae & 11 & 0 & 7 & 8 & ns & ns & ns & ns & ns & ns \\
\hline 2 & Orthoptera & Acrididae & 11 & 11 & 22 & 8 & ns & ns & ns & ns & ns & ns \\
\hline 2 & Orthoptera & Gryllacrididae & 0 & 0 & 0 & 0 & ns & ns & ns & ns & ns & ns \\
\hline 2 & Orthoptera & Gryllidae & 7 & 7 & 0 & 29 & ns & ** & ns & ns & ** & ns \\
\hline 2 & Orthoptera & Gryllotalpidae & 7 & 0 & 0 & 17 & ns & ns & ns & ns & ns & ns \\
\hline 2 & Orthoptera & Proscopiidae & 4 & 0 & 0 & 4 & ns & ns & ns & ns & ns & ns \\
\hline 2 & Orthoptera & Tettigoniidae & 33 & 33 & 0 & 25 & ns & ns & ns & * & ns & ns \\
\hline 2 & Phasmatodea & Phasmatidae & 7 & 7 & 0 & 0 & ns & ns & ns & ns & ns & ns \\
\hline 2 & Phasmatodea & Phylliidae & 0 & 0 & 0 & 4 & ns & ns & ns & ns & ns & ns \\
\hline 2 & Thysanoptera & Thripidae & 0 & 0 & 0 & 0 & ns & ns & ns & ns & ns & ns \\
\hline
\end{tabular}


ANEXO A - CONSTÂNCIA DAS FAMÍLIAS NAS COLETAS/PONTOS DE LEVANTAMENTO (9 MESES $X 3$ PONTOS $=27$ ) EM CADA PERÍODO DE 9 MESES (9A A 9D, CONFORME CONVENÇÃO DA FIGURA 3), RESULTADO DO TESTE DE COMPARAÇÃO DE MÉDIAS DO ÍNDICE DE DIVERSIDADE, PARA ESTAÇÃO DO ANO (Est), PARA OS QUATRO PERÍODOS (Per) E PARA OS QUATRO PERÍODOS EM CADA ESTAÇÃO DO ANO (Pri, Ver, Out E Inv), PARA OS AMBIENTES/LOCAIS, CONFORME CONVENÇÃO DA TABELA 1 (TESTE DE WILCOXON: $n S=$ NÃO SIGNIFICATIVO, * ${ }^{*}$ SIGNIFICATIVO A $10 \%$; ${ }^{* *}=$ SIGNFICATIVO 5\%).

\begin{tabular}{|c|c|c|c|c|c|c|c|c|c|c|c|c|}
\hline \multirow{2}{*}{ Local } & \multirow{2}{*}{ Ordem } & \multirow{2}{*}{ Família } & \multicolumn{4}{|c|}{ Constância (\%) } & \multicolumn{2}{|c|}{ Teste } & \multicolumn{4}{|c|}{ Teste período } \\
\hline & & & $9 \mathrm{~A}$ & $9 \mathrm{~B}$ & $9 \mathrm{C}$ & $9 D$ & Est & Per & Pri & Ver & Out & Inv \\
\hline 6 & Blattodea & Blaberidae & 4 & 11 & 4 & 96 & ns & ns & ns & ns & ns & ns \\
\hline 6 & Blattodea & Blattellidae & 15 & 19 & 0 & 0 & ns & ns & ns & ns & ns & ns \\
\hline 6 & Blattodea & Blattidae & 15 & 15 & 4 & 0 & ns & ns & ns & ns & ns & ns \\
\hline 6 & Coleoptera & Anthribidae & 4 & 4 & 0 & 0 & ns & ns & ns & ns & ns & ns \\
\hline 6 & Coleoptera & Bostrichidae & 26 & 11 & 4 & 0 & ns & ns & ns & ns & ns & ns \\
\hline 6 & Coleoptera & Brentidae & 0 & 0 & 0 & 0 & ns & ns & ns & ns & ns & ns \\
\hline 6 & Coleoptera & Buprestidae & 0 & 0 & 0 & 0 & ns & ns & ns & ns & ns & ns \\
\hline 6 & Coleoptera & Carabidae & 33 & 19 & 56 & 25 & $* *$ & $* *$ & $* *$ & ns & ns & ns \\
\hline 6 & Coleoptera & Cerambycidae & 48 & 48 & 22 & 29 & $* *$ & $* *$ & * & * & ns & ns \\
\hline 6 & Coleoptera & Chrysomelidae & 11 & 7 & 0 & 0 & ns & ns & ns & ns & ns & ns \\
\hline 6 & Coleoptera & Coccinellidae & 4 & 0 & 0 & 0 & ns & ns & ns & ns & ns & ns \\
\hline 6 & Coleoptera & Cucujidae & 0 & 0 & 0 & 0 & ns & ns & ns & ns & ns & ns \\
\hline 6 & Coleoptera & Curculionidae & 30 & 41 & 26 & 13 & $* *$ & ns & ns & ns & ns & ns \\
\hline 6 & Coleoptera & Dytiscidae & 0 & 4 & 15 & 0 & ns & ns & ns & ns & ns & ns \\
\hline 6 & Coleoptera & Elateridae & 56 & 41 & 37 & 38 & ** & * & ns & ns & ns & ns \\
\hline 6 & Coleoptera & Endomychidae & 0 & 0 & 0 & 0 & ns & ns & ns & ns & ns & ns \\
\hline 6 & Coleoptera & Erotylidae & 0 & 4 & 0 & 0 & ns & ns & ns & ns & ns & ns \\
\hline 6 & Coleoptera & Hydrophilidae & 4 & 19 & 30 & 4 & $* \star$ & $* *$ & * & * & ns & ns \\
\hline 6 & Coleoptera & Lampyridae & 11 & 59 & 30 & 8 & ns & ns & ns & ns & ns & ns \\
\hline 6 & Coleoptera & Languriidae & 0 & 0 & 0 & 0 & ns & ns & ns & ns & ns & ns \\
\hline 6 & Coleoptera & Lucanidae & 0 & 0 & 4 & 0 & ns & ns & ns & ns & ns & ns \\
\hline 6 & Coleoptera & Passalidae & 4 & 0 & 7 & 8 & ns & ns & ns & ns & ns & ns \\
\hline 6 & Coleoptera & Platypodidae & 4 & 0 & 22 & 13 & ns & ns & ns & ns & ns & ns \\
\hline 6 & Coleoptera & Scarabaeidae & 67 & 48 & 78 & 58 & ** & * & $* *$ & ** & ns & ns \\
\hline 6 & Coleoptera & Scolytidae & 19 & 48 & 59 & 46 & ns & ns & $\star \star$ & ns & ns & ns \\
\hline 6 & Coleoptera & Staphylinidae & 0 & 0 & 22 & 0 & ns & ns & ns & ns & ns & ns \\
\hline 6 & Coleoptera & Tenebrionidae & 22 & 11 & 15 & 33 & ** & ns & $\star *$ & ns & ns & ns \\
\hline 6 & Coleoptera & Trogidae & 4 & 0 & 0 & 0 & ns & ns & ns & ns & ns & ns \\
\hline 6 & Dermaptera & Labiduridae & 0 & 0 & 0 & 0 & ns & ns & ns & ns & ns & ns \\
\hline
\end{tabular}


ANEXO A - CONSTÂNCIA DAS FAMÍLIAS NAS COLETAS/PONTOS DE LEVANTAMENTO (9 MESES X 3 PONTOS $=27$ ) EM CADA PERÍODO DE 9 MESES (9A A 9D, CONFORME CONVENÇÃO DA FIGURA 3), RESULTADO DO TESTE DE COMPARAÇÃO DE MÉDIAS DO ÍNDICE DE DIVERSIDADE, PARA ESTAÇÃO DO ANO (Est), PARA OS QUATRO PERÍODOS (Per) E PARA OS QUATRO PERÍODOS EM CADA ESTAÇÃO DO ANO (Pri, Ver, Out E Inv), PARA OS AMBIENTES/LOCAIS, CONFORME CONVENÇÃO DA TABELA 1 (TESTE DE WILCOXON: $n s=$ NÃO SIGNIFICATIVO, * ${ }^{*}$ SIGNIFICATIVO A $10 \%$; ${ }^{* *}=$ SIGNFICATIVO 5\%).

\begin{tabular}{|c|c|c|c|c|c|c|c|c|c|c|c|c|}
\hline \multirow{2}{*}{ Local } & \multirow{2}{*}{ Ordem } & \multirow{2}{*}{ Família } & \multicolumn{4}{|c|}{ Constância (\%) } & \multicolumn{2}{|c|}{ Teste } & \multicolumn{4}{|c|}{ Teste período } \\
\hline & & & $9 \mathrm{~A}$ & $9 \mathrm{~B}$ & $9 \mathrm{C}$ & $9 \mathrm{D}$ & Est & Per & Pri & Ver & Out & Inv \\
\hline 6 & Diptera & Asilidae & 26 & 30 & 0 & 0 & * & * & ns & * & ns & ns \\
\hline 6 & Diptera & Bombyliidae & 0 & 0 & 0 & 0 & ns & ns & ns & ns & ns & ns \\
\hline 6 & Diptera & Culicidae & 0 & 4 & 0 & 0 & ns & ns & ns & ns & ns & ns \\
\hline 6 & Diptera & Stratiomyidae & 19 & 26 & 0 & 4 & ns & ns & ns & * & ns & ns \\
\hline 6 & Diptera & Syrphidae & 0 & 0 & 0 & 0 & ns & ns & ns & ns & ns & ns \\
\hline 6 & Diptera & Tabanidae & 15 & 4 & 4 & 13 & ns & ns & ns & $\mathrm{ns}$ & ns & ns \\
\hline 6 & Diptera & Tachinidae & 4 & 0 & 0 & 0 & ns & ns & ns & ns & ns & ns \\
\hline 6 & Diptera & Tephritidae & 0 & 0 & 0 & 0 & ns & ns & ns & ns & ns & ns \\
\hline 6 & Hemiptera & Acanaloniidae & 11 & 0 & 0 & 0 & ns & ns & ns & ns & ns & ns \\
\hline 6 & Hemiptera & Alydidae & 0 & 0 & 0 & 0 & ns & ns & ns & ns & ns & ns \\
\hline 6 & Hemiptera & Belostomatidae & 4 & 4 & 37 & 0 & $\mathrm{~ns}$ & ns & ns & ns & ns & ns \\
\hline 6 & Hemiptera & Cercopidae & 7 & 7 & 26 & 4 & ns & ns & ns & ns & ns & ns \\
\hline 6 & Hemiptera & Cicadellidae & 0 & 33 & 0 & 0 & ns & ns & ns & ns & ns & ns \\
\hline 6 & Hemiptera & Cicadidae & 63 & 33 & 11 & 4 & $* *$ & ** & ns & $* *$ & ** & ns \\
\hline 6 & Hemiptera & Cixiidae & 0 & 0 & 0 & 0 & ns & ns & ns & $\mathrm{ns}$ & ns & ns \\
\hline 6 & Hemiptera & Coreidae & 4 & 0 & 0 & 0 & ns & ns & ns & ns & ns & ns \\
\hline 6 & Hemiptera & Corizidae & 0 & 0 & 0 & 8 & ns & ns & ns & ns & ns & ns \\
\hline 6 & Hemiptera & Cydnidae & 0 & 0 & 0 & 0 & ns & ns & ns & ns & ns & ns \\
\hline 6 & Hemiptera & Derbidae & 15 & 0 & 0 & 4 & ns & ns & ns & ns & ns & ns \\
\hline 6 & Hemiptera & Dictyopharidae & 41 & 26 & 4 & 4 & ns & ns & ns & ns & ns & ns \\
\hline 6 & Hemiptera & Flatidae & 41 & 26 & 4 & 4 & ns & ns & ns & ns & ns & ns \\
\hline 6 & Hemiptera & Fulgoridae & 15 & 19 & 11 & 4 & $\mathrm{~ns}$ & ns & ns & ns & ns & ns \\
\hline 6 & Hemiptera & Membracidae & 0 & 0 & 0 & 0 & ns & ns & ns & ns & ns & ns \\
\hline 6 & Hemiptera & Miridae & 0 & 0 & 0 & 0 & ns & ns & ns & ns & ns & ns \\
\hline 6 & Hemiptera & Pentatomidae & 30 & 7 & 19 & 17 & ** & ns & ns & ns & ns & $* *$ \\
\hline 6 & Hemiptera & Pyrrhocoridae & 4 & 0 & 11 & 0 & $\mathrm{~ns}$ & ns & ns & ns & ns & ns \\
\hline 6 & Hemiptera & Reduviidae & 48 & 15 & 44 & 21 & ns & ns & ns & ns & ns & ns \\
\hline 6 & Hymenoptera & Aphelinidae & 0 & 0 & 0 & 0 & ns & ns & ns & ns & ns & ns \\
\hline
\end{tabular}


ANEXO A - CONSTÂNCIA DAS FAMÍLIAS NAS COLETAS/PONTOS DE LEVANTAMENTO (9 MESES $X 3$ PONTOS $=27$ ) EM CADA PERÍODO DE 9 MESES (9A A 9D, CONFORME CONVENÇÃO DA FIGURA 3), RESULTADO DO TESTE DE COMPARAÇÃO DE MÉDIAS DO ÍNDICE DE DIVERSIDADE, PARA ESTAÇÃO DO ANO (Est), PARA OS QUATRO PERÍODOS (Per) E PARA OS QUATRO PERÍODOS EM CADA ESTAÇÃO DO ANO (Pri, Ver, Out E Inv), PARA OS AMBIENTES/LOCAIS, CONFORME CONVENÇÃO DA TABELA 1 (TESTE DE WILCOXON: $n s=$ NÃO SIGNIFICATIVO, ${ }^{*}=$ SIGNIFICATIVO A $10 \%$; ${ }^{* *}=$ SIGNFICATIVO 5\%).

\begin{tabular}{|c|c|c|c|c|c|c|c|c|c|c|c|c|}
\hline \multirow{2}{*}{ Local } & \multirow{2}{*}{ Ordem } & \multirow{2}{*}{ Família } & \multicolumn{4}{|c|}{ Constância (\%) } & \multicolumn{2}{|c|}{ Teste } & \multicolumn{4}{|c|}{ Teste período } \\
\hline & & & $9 \mathrm{~A}$ & $9 \mathrm{~B}$ & $9 \mathrm{C}$ & $9 D$ & Est & Per & Pri & Ver & Out & Inv \\
\hline 6 & Hymenoptera & Apidae & 7 & 7 & 15 & 17 & ns & ns & ns & ns & ns & ns \\
\hline 6 & Hymenoptera & Bethylidae & 0 & 0 & 0 & 0 & ns & ns & ns & ns & ns & ns \\
\hline 6 & Hymenoptera & Braconidae & 0 & 7 & 0 & 0 & ns & ns & ns & ns & ns & ns \\
\hline 6 & Hymenoptera & Chalcididae & 0 & 4 & 4 & 0 & ns & ns & ns & ns & ns & ns \\
\hline 6 & Hymenoptera & Chrysididae & 0 & 0 & 0 & 0 & ns & ns & ns & ns & ns & ns \\
\hline 6 & Hymenoptera & Colletidae & 4 & 0 & 19 & 8 & ns & ns & ns & ns & ns & ns \\
\hline 6 & Hymenoptera & Diapriidae & 0 & 0 & 0 & 0 & ns & ns & ns & ns & ns & ns \\
\hline 6 & Hymenoptera & Dryinidae & 0 & 0 & 0 & 0 & ns & ns & ns & $\mathrm{ns}$ & ns & ns \\
\hline 6 & Hymenoptera & Encyrtidae & 0 & 0 & 0 & 0 & ns & ns & ns & ns & ns & ns \\
\hline 6 & Hymenoptera & Eucharitidae & 0 & 0 & 0 & 0 & ns & ns & ns & ns & ns & ns \\
\hline 6 & Hymenoptera & Eucoilidae & 0 & 0 & 0 & 0 & ns & ns & ns & ns & ns & ns \\
\hline 6 & Hymenoptera & Eulophidae & 0 & 0 & 0 & 0 & ns & ns & ns & ns & ns & ns \\
\hline 6 & Hymenoptera & Eupelmidae & 0 & 0 & 0 & 0 & ns & ns & ns & ns & ns & ns \\
\hline 6 & Hymenoptera & Evaniidae & 0 & 0 & 0 & 0 & ns & ns & ns & $\mathrm{ns}$ & ns & ns \\
\hline 6 & Hymenoptera & Figitidae & 0 & 0 & 0 & 0 & ns & ns & ns & ns & ns & ns \\
\hline 6 & Hymenoptera & Formicidae & 26 & 56 & 19 & 0 & ns & ** & $* *$ & ns & ns & ns \\
\hline 6 & Hymenoptera & Halictidae & 0 & 7 & 4 & 13 & ns & ns & ns & ns & ns & ns \\
\hline 6 & Hymenoptera & Ichneumonidae & 26 & 48 & 33 & 13 & $\star *$ & ** & ns & ns & $* *$ & $* *$ \\
\hline 6 & Hymenoptera & Mutillidae & 26 & 7 & 52 & 17 & ns & ns & ns & ns & ns & ns \\
\hline 6 & Hymenoptera & Mymaridae & 0 & 0 & 0 & 0 & ns & ns & ns & ns & ns & ns \\
\hline 6 & Hymenoptera & Perilampidae & 0 & 0 & 0 & 0 & ns & ns & ns & ns & ns & ns \\
\hline 6 & Hymenoptera & Platygasteridae & 0 & 0 & 0 & 0 & ns & ns & ns & ns & ns & ns \\
\hline 6 & Hymenoptera & Pompilidae & 4 & 26 & 0 & 17 & ns & ns & ns & ns & ns & ns \\
\hline 6 & Hymenoptera & Pteromalidae & 0 & 0 & 0 & 0 & ns & ns & ns & ns & ns & ns \\
\hline 6 & Hymenoptera & Scelionidae & 0 & 0 & 0 & 0 & ns & ns & ns & $\mathrm{ns}$ & ns & ns \\
\hline 6 & Hymenoptera & Scolebythidae & 0 & 0 & 0 & 0 & ns & ns & ns & ns & ns & ns \\
\hline 6 & Hymenoptera & Scoliidae & 0 & 0 & 0 & 0 & ns & ns & ns & $\mathrm{ns}$ & ns & ns \\
\hline 6 & Hymenoptera & Sphecidae & 19 & 41 & 11 & 17 & ns & ns & ns & ns & ns & ns \\
\hline 6 & Hymenoptera & Stephanidae & 0 & 0 & 0 & 0 & ns & ns & ns & ns & ns & ns \\
\hline
\end{tabular}


ANEXO A - CONSTÂNCIA DAS FAMÍLIAS NAS COLETAS/PONTOS DE LEVANTAMENTO (9 MESES $X 3$ PONTOS $=27$ ) EM CADA PERÍODO DE 9 MESES (9A A 9D, CONFORME CONVENÇÃO DA FIGURA 3), RESULTADO DO TESTE DE COMPARAÇÃO DE MÉDIAS DO ÍNDICE DE DIVERSIDADE, PARA ESTAÇÃO DO ANO (Est), PARA OS QUATRO PERÍODOS (Per) E PARA OS QUATRO PERÍODOS EM CADA ESTAÇÃO DO ANO (Pri, Ver, Out E Inv), PARA OS AMBIENTES/LOCAIS, CONFORME CONVENÇÃO DA TABELA 1 (TESTE DE WILCOXON: $n s=$ NÃO SIGNIFICATIVO, ${ }^{*}=$ SIGNIFICATIVO A $10 \%$; ${ }^{* *}=$ SIGNFICATIVO 5\%).

\begin{tabular}{|c|c|c|c|c|c|c|c|c|c|c|c|c|}
\hline \multirow{2}{*}{ Local } & \multirow{2}{*}{ Ordem } & \multirow{2}{*}{ Família } & \multicolumn{4}{|c|}{ Constância (\%) } & \multicolumn{2}{|c|}{ Teste } & \multicolumn{4}{|c|}{ Teste período } \\
\hline & & & $9 A$ & $9 \mathrm{~B}$ & $9 \mathrm{C}$ & $9 D$ & Est & Per & Pri & Ver & Out & Inv \\
\hline 6 & Hymenoptera & Tiphiidae & 22 & 7 & 7 & 4 & ns & ns & ns & ns & ns & ns \\
\hline 6 & Hymenoptera & Torymidae & 0 & 0 & 0 & 0 & ns & ns & ns & ns & ns & ns \\
\hline 6 & Hymenoptera & Trichogrammatidae & 0 & 0 & 0 & 0 & ns & ns & ns & ns & ns & ns \\
\hline 6 & Hymenoptera & Vespidae & 33 & 26 & 78 & 88 & ns & ** & $* *$ & * & ns & ns \\
\hline 6 & Isoptera & Kalotermitidae & 0 & 0 & 7 & 0 & ns & ns & ns & ns & ns & ns \\
\hline 6 & Isoptera & Rhinotermitidae & 0 & 0 & 0 & 4 & ns & ns & ns & ns & ns & ns \\
\hline 6 & Isoptera & Termitidae & 0 & 0 & 11 & 4 & ns & ns & ns & * & ns & ns \\
\hline 6 & Lepidoptera & Arctiidae & 85 & 78 & 63 & 92 & $* *$ & ** & ns & ** & ns & ns \\
\hline 6 & Lepidoptera & Arrhenophanidae & 0 & 0 & 0 & 0 & ns & ns & ns & ns & ns & ns \\
\hline 6 & Lepidoptera & Cossidae & 4 & 0 & 0 & 4 & ns & ns & ns & ns & ns & ns \\
\hline 6 & Lepidoptera & Dalceridae & 11 & 0 & 0 & 0 & ns & ns & ns & ns & ns & ns \\
\hline 6 & Lepidoptera & Eupterotidae & 52 & 59 & 0 & 8 & ns & ns & ns & ns & ns & ns \\
\hline 6 & Lepidoptera & Geometridae & 74 & 93 & 44 & 50 & * & ** & * & ns & ** & $\star \star$ \\
\hline 6 & Lepidoptera & Hesperiidae & 59 & 26 & 22 & 42 & $* *$ & ** & * & ns & $* *$ & ns \\
\hline 6 & Lepidoptera & Lasiocampidae & 37 & 33 & 0 & 0 & ns & ns & ns & ns & ns & $* *$ \\
\hline 6 & Lepidoptera & Limacodidae & 33 & 22 & 4 & 0 & ns & ns & ns & ns & ns & ns \\
\hline 6 & Lepidoptera & Lycaenidae & 15 & 4 & 4 & 0 & $* *$ & ns & ns & ns & ns & ns \\
\hline 6 & Lepidoptera & Lymantriidae & 33 & 48 & 11 & 0 & * & ns & ns & $\mathrm{ns}$ & ns & $\star *$ \\
\hline 6 & Lepidoptera & Megalopygidae & 26 & 26 & 4 & 0 & ns & ns & ns & $\mathrm{ns}$ & ns & ns \\
\hline 6 & Lepidoptera & Mimallonidae & 7 & 0 & 0 & 4 & ns & ns & ns & ns & ns & ns \\
\hline 6 & Lepidoptera & Noctuidae & 100 & 100 & 78 & 92 & $* *$ & $* *$ & * & * & $* *$ & $* *$ \\
\hline 6 & Lepidoptera & Notodontidae & 93 & 74 & 67 & 50 & ns & $* *$ & $\star \star$ & ns & ** & $\star \star *$ \\
\hline 6 & Lepidoptera & Nymphalidae & 41 & 59 & 26 & 38 & ns & ns & ns & $\mathrm{ns}$ & ns & * \\
\hline 6 & Lepidoptera & Oecophoridae & 0 & 7 & 4 & 0 & ns & ns & ns & $\mathrm{ns}$ & ns & ns \\
\hline 6 & Lepidoptera & Pieridae & 7 & 4 & 11 & 17 & ns & ns & ns & ns & ns & ns \\
\hline 6 & Lepidoptera & Psychidae & 0 & 0 & 4 & 0 & ns & ns & ns & $\mathrm{ns}$ & ns & ns \\
\hline 6 & Lepidoptera & Pyralidae & 85 & 85 & 48 & 67 & ns & $* *$ & ns & $\mathrm{ns}$ & $* *$ & $* *$ \\
\hline 6 & Lepidoptera & Saturniidae & 56 & 44 & 48 & 46 & * & ns & ns & ns & ns & ns \\
\hline 6 & Lepidoptera & Sematuridae & 4 & 0 & 4 & 0 & ns & ns & ns & ns & ns & ns \\
\hline
\end{tabular}


ANEXO A - CONSTÂNCIA DAS FAMÍLIAS NAS COLETAS/PONTOS DE LEVANTAMENTO (9
MESES X 3 PONTOS = 27) EM CADA PERÍODO DE 9 MESES (9A A 9D,
CONFORME CONVENCÃO DA FIGURA 3), RESULTADO DO TESTE DE
COMPARAÇÃO DE MÉDIAS DO ÍNDICE DE DIVERSIDADE, PARA ESTAÇÃO
DO ANO (EST), PARA OS QUATRO PERÍODOS (Per) E PARA OS QUATRO
PERÍODOS EM CADA ESTAÇÃO DO ANO (Pri, Ver, OUt E InV), PARA OS
AMBIENTES/LOCAIS, CONFORME CONVENÇÃO DA TABELA 1 (TESTE DE
WILCOXON: nS = NÃO SIGNIFICATIVO, * $=$ SIGNIFICATIVO A 10\%; ** $=$
SIGNFICATIVO 5\%).

\begin{tabular}{|c|c|c|c|c|c|c|c|c|c|c|c|c|}
\hline \multirow{2}{*}{ Local } & \multirow{2}{*}{ Ordem } & \multirow{2}{*}{ Família } & \multicolumn{4}{|c|}{ Constância (\%) } & \multicolumn{2}{|c|}{ Teste } & \multicolumn{4}{|c|}{ Teste período } \\
\hline & & & $9 A$ & $9 \mathrm{~B}$ & $9 \mathrm{C}$ & $9 \mathrm{D}$ & Est & Per & Pri & Ver & Out & Inv \\
\hline 6 & Lepidoptera & Sphingidae & 37 & 15 & 44 & 33 & ** & * & ns & ** & $\mathrm{ns}$ & ns \\
\hline 6 & Lepidoptera & Tineidae & 4 & 0 & 0 & 21 & ns & ns & ns & ns & ns & ns \\
\hline 6 & Lepidoptera & Yponomeutidae & 0 & 0 & 0 & 0 & ns & ns & ns & ns & ns & ns \\
\hline 6 & Mantodea & Hymenopodidae & 4 & 0 & 0 & 0 & ns & ns & ns & ns & ns & ns \\
\hline 6 & Mantodea & Mantidae & 52 & 37 & 11 & 21 & ** & ns & ns & * & ns & $* *$ \\
\hline 6 & Neuroptera & Ascalaphidae & 0 & 7 & 4 & 4 & ns & ns & ns & ns & ns & ns \\
\hline 6 & Neuroptera & Chrysopidae & 7 & 0 & 0 & 0 & ns & ns & ns & ns & ns & ns \\
\hline 6 & Neuroptera & Myrmeleontidae & 15 & 15 & 0 & 0 & ns & ns & ns & ns & ns & ns \\
\hline 6 & Odonata & Coenagrionidae & 0 & 0 & 0 & 0 & ns & ns & ns & ns & ns & ns \\
\hline 6 & Odonata & Libellulidae & 4 & 4 & 0 & 0 & ns & ns & ns & ns & ns & ns \\
\hline 6 & Orthoptera & Acrididae & 15 & 19 & 0 & 0 & ns & ns & ns & ns & ns & ns \\
\hline 6 & Orthoptera & Gryllidae & 11 & 15 & 4 & 4 & ns & ns & ns & ns & ns & ns \\
\hline 6 & Orthoptera & Gryllotalpidae & 4 & 0 & 4 & 17 & ns & ns & ns & ns & ns & ns \\
\hline 6 & Orthoptera & Pyrgomorphidae & 0 & 0 & 0 & 0 & ns & ns & ns & ns & ns & ns \\
\hline 6 & Orthoptera & Tettigoniidae & 48 & 19 & 4 & 0 & ns & ns & ns & ns & ns & ns \\
\hline 6 & Phasmatodea & Phasmatidae & 4 & 4 & 0 & 0 & ns & ns & ns & ns & ns & ns \\
\hline
\end{tabular}


ANEXO B - RESULTADOS DA COMPARAÇÃO DE MÉDIAS, DO ÍNDICE DE DIVERSIDADE, PARA MORFOESPÉCIES, ENTRE PERÍODOS DE NOVE MESES, DOIS ANTES DO CORTE (9A e 9B) E DOIS APÓS O CORTE (9C E 9D), POR FAMÍLIA E ESTAÇÃO DO ANO (TESTE DE WILCOXON, 5\% PROBABILIDADE).

\begin{tabular}{|c|c|c|c|c|c|c|c|c|c|}
\hline \multirow{2}{*}{ Família } & \multirow{2}{*}{ Estação } & \multicolumn{4}{|c|}{ Eucalipto - local 6} & \multicolumn{4}{|c|}{ Eucalipto - local 5} \\
\hline & & $9 A$ & $9 B$ & $9 \mathrm{C}$ & 9D & $9 \mathrm{~A}$ & $9 \mathrm{~B}$ & $9 \mathrm{C}$ & 9D \\
\hline \multirow[t]{4}{*}{ Carabidae } & Primavera & $a$ & $a b$ & $b$ & $a b$ & $a$ & $\mathrm{a}$ & $a$ & $\mathrm{a}$ \\
\hline & Verão & a & $a$ & a & a & a & a & $a$ & $a$ \\
\hline & Outono & a & a & a & a & a & $a$ & $\mathrm{a}$ & $a$ \\
\hline & Inverno & a & a & a & a & a & $\mathrm{a}$ & $\mathrm{a}$ & $\mathrm{a}$ \\
\hline \multirow[t]{4}{*}{ Cerambycidae } & Primavera & a & $a b$ & $b$ & $b$ & a & $a$ & $\mathrm{a}$ & $a$ \\
\hline & Verão & a & a & a & a & a & $\mathrm{a}$ & $a$ & $a$ \\
\hline & Outono & a & a & a & a & a & $a$ & $a$ & $a$ \\
\hline & Inverno & a & a & a & a & a & a & $\mathrm{a}$ & $\mathrm{a}$ \\
\hline \multirow[t]{4}{*}{ Scarabaeidae } & Primavera & a & b & $\mathrm{bc}$ & C & a & $a b$ & $\mathrm{~b}$ & $\mathrm{~b}$ \\
\hline & Verão & a & b & $\mathrm{a}$ & $\mathrm{a}$ & a & $a b$ & $\mathrm{~b}$ & $a b$ \\
\hline & Outono & a & a & a & a & a & a & $a$ & $a$ \\
\hline & Inverno & a & a & a & a & $\mathrm{a}$ & $a b$ & $a b$ & $\mathrm{~b}$ \\
\hline \multirow[t]{4}{*}{ Scolytidae } & Primavera & a & a & a & $b$ & a & a & $a$ & $a$ \\
\hline & Verão & a & a & a & a & a & $a$ & $a$ & $a$ \\
\hline & Outono & a & a & a & a & $a b$ & a & $\mathrm{b}$ & $a b$ \\
\hline & Inverno & $a b$ & a & $a b$ & $b$ & a & $a b$ & b & $a b$ \\
\hline \multirow[t]{4}{*}{ Tenebrionidae } & Primavera & a & a & a & b & a & a & a & $a$ \\
\hline & Verão & a & $\mathrm{a}$ & $\mathrm{a}$ & $\mathrm{a}$ & a & a & $\mathrm{a}$ & $\mathrm{a}$ \\
\hline & Outono & a & $\mathrm{a}$ & a & a & a & a & $a$ & $a$ \\
\hline & Inverno & a & $\mathrm{a}$ & a & $\mathrm{a}$ & a & a & a & $a$ \\
\hline \multirow[t]{4}{*}{ Cicadidae } & Primavera & a & $\mathrm{a}$ & $\mathrm{a}$ & $\mathrm{a}$ & a & a & a & $a$ \\
\hline & Verão & a & b & $b$ & b & a & a & $a$ & $a$ \\
\hline & Outono & a & $\mathrm{a}$ & a & $\mathrm{a}$ & a & a & $\mathrm{a}$ & $\mathrm{a}$ \\
\hline & Inverno & a & a & a & a & a & a & a & $a$ \\
\hline \multirow[t]{4}{*}{ Pentatomidae } & Primavera & a & $\mathrm{a}$ & $\mathrm{a}$ & $\mathrm{a}$ & a & a & a & $a$ \\
\hline & Verão & a & $\mathrm{a}$ & $\mathrm{a}$ & $\mathrm{a}$ & a & $\mathrm{a}$ & a & $\mathrm{a}$ \\
\hline & Outono & a & $\mathrm{a}$ & a & $a$ & a & a & a & $\mathrm{a}$ \\
\hline & Inverno & a & $a b$ & $a b$ & $b$ & a & a & a & $a$ \\
\hline \multirow[t]{4}{*}{ Formicidae } & Primavera & a & $b$ & $\mathrm{a}$ & $\mathrm{a}$ & a & a & a & $a$ \\
\hline & Verão & a & $\mathrm{a}$ & a & a & a & a & a & $a$ \\
\hline & Outono & a & $\mathrm{a}$ & a & $\mathrm{a}$ & a & a & a & $\mathrm{a}$ \\
\hline & Inverno & a & $\mathrm{a}$ & a & $\mathrm{a}$ & a & a & a & $a$ \\
\hline \multirow[t]{4}{*}{ Ichneumonidae } & Primavera & a & $\mathrm{a}$ & a & $\mathrm{a}$ & a & a & a & $\mathrm{a}$ \\
\hline & Verão & a & $a$ & a & $a$ & $a$ & $a$ & a & $a$ \\
\hline & Outono & a & $b$ & $a b$ & $\mathrm{a}$ & a & $a b$ & b & $a b$ \\
\hline & Inverno & a & a & b & $\mathrm{a}$ & a & a & a & $a$ \\
\hline \multirow[t]{4}{*}{ Vespidae } & Primavera & $a b$ & $\mathrm{a}$ & a & $b$ & a & $\mathrm{a}$ & a & $a$ \\
\hline & Verão & $a b$ & a & $a b$ & b & a & $a b$ & $a b$ & $\mathrm{~b}$ \\
\hline & Outono & a & a & a & a & a & a & a & $a$ \\
\hline & Inverno & a & $\mathrm{a}$ & a & $\mathrm{a}$ & $\mathrm{a}$ & a & a & a \\
\hline
\end{tabular}


ANEXO B - RESULTADOS DA COMPARAÇÃO DE MÉDIAS, DO ÍNDICE DE DIVERSIDADE, PARA MORFOESPÉCIES, ENTRE PERÍODOS DE NOVE MESES, DOIS ANTES DO CORTE (9A Y 9B) E DOIS APÓS O CORTE (9C E 9D), POR FAMÍLIA E ESTAÇÃO DO ANO (TESTE DE WILCOXON, 5\% PROBABILIDADE).

\begin{tabular}{|c|c|c|c|c|c|c|c|c|c|}
\hline \multirow{2}{*}{ Família } & \multirow{2}{*}{ Estação } & \multicolumn{4}{|c|}{ Eucalipto - local 6} & \multicolumn{4}{|c|}{ Eucalipto - local 5} \\
\hline & & $9 A$ & $9 \mathrm{~B}$ & $9 \mathrm{C}$ & $9 D$ & $9 A$ & $9 B$ & $9 \mathrm{C}$ & $9 \mathrm{D}$ \\
\hline \multirow[t]{4}{*}{ Arctiidae } & Primavera & $a b$ & $a$ & $\mathrm{~b}$ & $a$ & $a$ & $\mathrm{a}$ & $\mathrm{a}$ & $a$ \\
\hline & Verão & $a b$ & a & $\mathrm{a}$ & $b$ & a & $a b$ & a & $b$ \\
\hline & Outono & $a b$ & $a b$ & $\mathrm{a}$ & $b$ & a & $b$ & $\mathrm{bc}$ & ac \\
\hline & Inverno & a & $b$ & $\mathrm{~b}$ & $a b$ & a & a & a & $\mathrm{a}$ \\
\hline \multirow[t]{4}{*}{ Geometridae } & Primavera & $a b$ & a & $\mathrm{b}$ & $b$ & $a b$ & $\mathrm{a}$ & $a b$ & $b$ \\
\hline & Verão & $a b$ & a & $\mathrm{b}$ & $a b$ & $\mathrm{a}$ & a & a & $\mathrm{a}$ \\
\hline & Outono & $\mathrm{ac}$ & a & $\mathrm{b}$ & $\mathrm{bc}$ & $a b$ & $a b$ & $\mathrm{a}$ & $\mathrm{b}$ \\
\hline & Inverno & a & $b$ & C & C & a & $a b$ & $b$ & b \\
\hline \multirow[t]{4}{*}{ Hesperiidae } & Primavera & a & a & a & a & a & a & $\mathrm{a}$ & $\mathrm{a}$ \\
\hline & Verão & a & a & a & a & a & a & a & $\mathrm{a}$ \\
\hline & Outono & a & $b$ & a & $a b$ & a & a & a & $\mathrm{a}$ \\
\hline & Inverno & a & a & a & a & a & a & a & $\mathrm{a}$ \\
\hline \multirow[t]{4}{*}{ Lasiocampidae } & Primavera & $\mathrm{a}$ & a & $\mathrm{a}$ & a & a & a & a & $a$ \\
\hline & Verão & a & a & a & a & a & a & a & $\mathrm{a}$ \\
\hline & Outono & a & a & a & a & a & a & a & $\mathrm{a}$ \\
\hline & Inverno & $\mathrm{a}$ & $a b$ & $a b$ & $b$ & a & $a b$ & $a b$ & $b$ \\
\hline \multirow[t]{4}{*}{ Lymantriidae } & Primavera & a & a & a & a & a & a & a & $\mathrm{a}$ \\
\hline & Verão & a & $\mathrm{a}$ & a & a & a & a & a & $a$ \\
\hline & Outono & a & a & a & a & a & a & a & $\mathrm{a}$ \\
\hline & Inverno & a & $a b$ & $a b$ & $b$ & $a b$ & a & $a b$ & $b$ \\
\hline \multirow[t]{4}{*}{ Noctuidae } & Primavera & a & $\mathrm{a}$ & $b$ & $a b$ & a & b & $\mathrm{bc}$ & c \\
\hline & Verão & $\mathrm{a}$ & a & $b$ & $\mathrm{a}$ & a & $\mathrm{a}$ & a & $\mathrm{a}$ \\
\hline & Outono & a & a & $b$ & $b$ & $a b$ & a & $b$ & $b$ \\
\hline & Inverno & $\mathrm{a}$ & $b$ & $b$ & $b$ & a & $b$ & $b$ & $b$ \\
\hline \multirow[t]{4}{*}{ Notodontidae } & Primavera & a & a & $b$ & $b$ & ac & $a b$ & $b$ & c \\
\hline & Verão & a & $a$ & a & a & $a$ & a & a & a \\
\hline & Outono & a & $\mathrm{a}$ & $a b$ & $b$ & $a b$ & a & $a b$ & $b$ \\
\hline & Inverno & a & $b$ & $\mathrm{~b}$ & $b$ & a & b & b & $b$ \\
\hline \multirow[t]{4}{*}{ Pyralidae } & Primavera & $a b$ & $a b$ & a & $b$ & a & $\mathrm{a}$ & a & a \\
\hline & Verão & $a b$ & $\mathrm{a}$ & $b$ & $a b$ & $a b$ & $a b$ & a & $b$ \\
\hline & Outono & a & $a b$ & $b$ & C & a & $a b$ & bc & c \\
\hline & Inverno & a & $b$ & b & $b$ & a & b & $a b$ & $b$ \\
\hline \multirow[t]{4}{*}{ Sphingidae } & Primavera & a & $\mathrm{a}$ & a & a & a & a & a & a \\
\hline & Verão & $\mathrm{a}$ & $\mathrm{a}$ & a & $b$ & a & a & a & a \\
\hline & Outono & $\mathrm{a}$ & $\mathrm{a}$ & a & a & a & a & a & a \\
\hline & Inverno & a & $\mathrm{a}$ & a & $\mathrm{a}$ & a & a & a & a \\
\hline \multirow[t]{4}{*}{ Mantidae } & Primavera & a & $\mathrm{a}$ & a & $a$ & a & a & a & a \\
\hline & Verão & a & a & a & $\mathrm{a}$ & a & a & a & a \\
\hline & Outono & a & $a$ & a & $a$ & a & a & a & a \\
\hline & Inverno & $a b$ & $\mathrm{a}$ & $a b$ & $b$ & a & a & a & a \\
\hline
\end{tabular}




\section{REFERÊNCIAS BIBLIOGRÁFICAS}

ADDISCOTT, T.M. Entropy and sustainability. European journal of Science, v.46, p.161-168, 1995.

ALTIERI, M. A; LETOURNEAU, D. K. Vegetation management and biological control in agroecosystems. Crop-protection, v.1, n.4, p.405-430, 1982.

ALVES, A. N. Biodiversidade de insetos entomófagos das Ordens Diptera e Hymenoptera em florestas de Eucalyptus grandis Hill ex Maiden associadas com sub-bosque e fragmentos de mata nativa. Botucatu, 1998. 97p. Dissertação (Mestrado) - Faculdade de Ciências Agronômicas, Universidade Estadual Paulista "Júlio de Mesquita Filho".

ANDOW, D.A. Vegetational diversity and arthropod population response. Annual Reviews Entomology, v.36, p.561-586, 1991.

BAENA, E.S. Controle populacional das pragas das florestas de eucaliptos e seus inimigos naturais. Silvicultura, n.22, p.42-44, 1982.

BERTI FILHO, E. Insetos associados a plantações de espécies do gênero Eucalyptus nos Estados da Bahia, Espírito Santo, Mato Grosso do Sul, Minas Gerais e São Paulo. Piracicaba, 1981. 176p. Tese (Livre-docência) - Escola Superior de Agricultura "Luiz de Queiroz", Universidade de São Paulo. 
BONHAM, K.J.; MESIBOV, R.; BASHFORD, R. Diversity and abundance of some ground-dwelling invertebrates in plantation vs. native forests in Tasmania, Australia. Forest Ecology and Management, v.158, n.1/3, p.237-247, 2002.

BRAGANÇA, M.A.L. Influência das áreas de conservação sobre Lepidoptera e Hymenoptera em eucaliptais. Viçosa, 1995. 101p. Dissertação (Mestrado) - Universidade Federal de Viçosa.

BRIENZA JÚNIOR, S.; VIELHAUER, K.; VLEK, P. L. G. Enriquecimento de capoeira: mudando a agricultura migratória na Amazônia Oriental brasileira. In: DIAS, L.E.; MELLO, J.W.V. (Ed). Recuperação de áreas degradadas. Viçosa: Sociedade Brasileira de Recuperação de Áreas Degradadas, 1998. p.177-182.

ENGEL, V.L. Aspectos das relações entre o reflorestamento com eucalipto e a estrutura e a função de ecossistemas de vegetação nativa das áreas de preservação permanente em uma microbacia piloto. Relatórios de pesquisa, 1996-1998 (Compact disc). Aracruz: Aracruz Celulose S.A, 2002.

FORTI, L.C. Ecologia no Manejo de Pragas. In.: CROCOMO, W. B. (Org.). Manejo de Pragas. São Paulo: CETESB, 1990. p.36-56.

GASTON, K.J.; BLACKBURN, T.M.; GREENWOOD, J.J.D.; GREGORY, R.D.; QUINN, R.M.; LAWSTON, J.H. Abudance - occupancy relationships. Journal of Applied ecology, v.37, p.39-59, 2000.

HOLLOWAY, J.D.; BRADLEY, J.; CARTER, J.D. CIE guides to insects of importance to man. Lepidoptera, 1. C.A.B. International, Wallinford, 1987. $262 p$.

HUNTER, M.L. Wildlife, forests and forestry: principles managing for biological diversity. New Jersey: Prentice-Hall, 1990. 370p. 
JACTEL, H.; GOULART, M.; MENASSIEU, P.; GOUJON, G. Habitat diversity in forest plantations reduces infestations of the pine stem boner Diocyctria sylvestrella. Journal of Applied Ecology, v.39, p.618-628, 2002.

KAGEYAMA, P.Y.; REIS, A.; CARPANEZZI, A.A. Potencialidades e restrições da regeneração artificial na recuperação de áreas degradadas. In: SIMPÓSIO NACIONAL SOBRE RECUPERAÇÃO DE ÁREAS DEGRADADAS, Curitiba,1992. Anais. Curitiba: UFPR/FUPEF, 1992. p116.

KNEESHAW, D.D.; LEDUC, A.; DRAPEAU, P.; GAUTHIER, S.; PARE, D.; CARIGNAN, R.; DOUCET, R.; BOUTHILLIER, L.; MESSIER, C. Development of integrated ecological standards of sustainable forest management at an operational scale. Forestry-Chronicle. /Resumo em TREECD, 2000/02-2002/04/ v.76, n.3, p.481-493, 2000.

LARSEN, J.B. Ecological stability of forests and sustainable silviculture. Forest Ecology and Management, v.73, p.85-96, 1995.

LAWTON, J.H. Entomologists and the conservation of biodiversity. In: INTERNATIONAL CONGRESS OF ENTOMOLOGY, 21, Foz do Iguassu, 2000. Abstracts of International Congress of Entomology. Londrina: Embrapa Soja, 2000. p.1-3.

LEIUS, D. Influence of wild flowers on parasitism of tent caterpillar and codling moth. Canadian Entomology, v.99, p.444-446, 1967.

MAcARTHUR, R.H. Flutuaction on animal populations and a measure of community stability. Ecology, v.36, p.533-536, 1955.

MAJER, J.D.; RECHER, H.F. Are eucalypts Brazil's friend or foe? An entomological viewpoint. Anais da Sociedade Entomológica do Brasil, v.28, n.2, 185-200, 1999. 
MATIOLI, J.C. Armadilhas luminosas: uma alternativa no controle de pragas? Informe Agropecuário, v.12, n.140, p.33-39, 1986.

MATIOLI, J.C.; SILVEIRA NETO, S. Armadilhas luminosas: funcionamento e utilização. Boletim Técnico Epamig, v.28, p.1-44, 1988.

MENEZES, E.B.; CASSINO, P.C.R.; ALVES, J.E.M.; LIMA, E.R. Flutuação populacional de Glena sp. em áreas reflorestadas na região de Aracruz. In: CONGRESSO BRASILEIRO DE ENTOMOLOGIA, 10, Rio de Janeiro, 1986. Resumos. Rio de Janeiro: SEB, 1986a. p.394.

MENEZES, E.B.; CASSINO, P.C.R.; LIMA, E.R.; ALVES, L.E.M. Associações de lepidópteros desfolhadores com plantas do gênero Eucalyptus em áreas reflorestadas na região de Aracruz, ES. Anais da Sociedade Entomológica do Brasil, v.15, n.2, p.181-188, 1986b.

MEZZOMO, J.A. Importância de faixas de vegetação sobre Lepidoptera e Coleoptera em Eucalyptus cloesiana. Viçosa, 1995. 78 p. Dissertação (Mestrado) - Universidade Federal de Viçosa.

MILLER, F.D.; STEPHEN, F.M. Effects of competing vegetation on nantucket pine tip moth (Lepidoptera: Tortricidae) populations in loblolly pine plantation in Arkansas. Environmental Entomology, v.12, n.1, p.101-104, 1983.

NAKANO, O.; LEITE, C.A. Armadilhas para insetos: pragas agrícolas e domésticas. Piracicaba: FEALQ, 2000, p.9-16.

NEPSTAD, D.C.; BROWN, I.F.; LUZ, L.; ALEXANDRE, A.; VIANA, V. Biotics impoverishment of Amazon forest by rubber tappers, loggers and cattle ranchers. Advancees in Economic Botany, v.9, p.1-14, 1992.

NEUMANN, F.G. Insect populations in eucalypt and pine forests in Northeastern Victoria. Australian Forestry Research, v.8, p.13-24, 1978. 
NORDI, J.C. Composição florística e estrutura de comunidade de plantas daninhas em cultura de Eucalyptus grandis Hill ex. Maiden. Botucatu, 1996. Dissertação (Mestrado) - Instituto de Biociências, Universidade Estadual Paulista "Júlio de Mesquita Filho".

PATTERSON, B.D. The principle of nested subsets and its implications for biological conservation. Conservation Biology, v.1, n.4, p.323-334, 1987.

PIMENTEL, D. Species diversity and insects populations outbreaks. Annals of Entomolical Society of America., v.54, p.76-86, 1961.

PIMM, S.L. Complexity and stability: another look at MacArthur's original hypothesis. Oikos, n.33, p.351-357, 1979.

PIMM, S.L. The complexity and stability of ecosystems. Nature, n.307, p.321326, 1984.

PINTO-COELHO, R.M. Fundamentos em Ecologia. Porto Alegre: Artmed Editora, 2000. 252p.

RATSIRARSON, H.; ROBERTSON, H.J.; PRICKER, M.D.; NOORT, S; VAN McGREOCH, M.A. (Ed.), SANWAYS, M.J. Indigenous forests versus exotic eucalyptus and pine plantations: a comparison of leaf-litter invertebrate communities. African Entomology, v.10, n.1, p.93-99, 2002.

RUSSEL, E.P. Enemies hypothesis: a review of the effect of vegetational diversity on predatory insects and parasitoids. Environmental Entomology, v.18, n.4, p.590-599, 1989.

SAMWAYS, J.J. Community structure of ants (Hymenoptera: Formicidae) in a series of habitats associated with citrus. Journal of Applied Ecology, v.20, p.833-847, 1983. 
SAUTTER, K.D. Meso (Acari e Collembola) e macrofauna (Oligochaeta) na recuperação de solos degradados. In: DIAS, L.E.; MELLO, J.W.V. (Ed.). Recuperação de áreas degradadas. Viçosa: Sociedade Brasileira de Recuperação de Áreas Degradadas, 1998. 251p.

SCHLITTLER, F.H.M. Composição florística e estrutura fitossociológica do subbosque de uma plantação de Eucalyptus tereticornis Sm., no município de Rio Claro - SP. Rio Claro, 1984. 142 p. Dissertação (Mestrado) - Instituto de Biociências, UniversidadeEstadual Paulista "Júlio de Mesquita Filho".

SCHUBERT, R. (Ed.). Bioindikation in terrestrischen Ökosystemen. Jena: Gustav Fischer Verlag, 1991. 338p.

SILVEIRA NETO, S.; NAKANO, O.; BARBIN, D.; VILLA NOVA, N.A. Manual de ecologia dos insetos. São Paulo: Agronômica Ceres, 1976. p.110-132.

SILVEIRA NETO, S. Armadilha luminosa. Piracicaba: ESALQ, 1989. 8p. (Informe Técnico, 3).

SIVEIRA NETO, S.; MONTEIRO, R.C.; ZUCCHI, R.A.; MORAES, R.C.B. Uso da análise faunística de insetos na avaliação de impacto ambiental. Scientia Agricola., v.52, n.1, p. 9-15, 1995.

VENDRAMIM, J.D.; ZUCCHI, R.A.; SILVEIRA NETO, S. Controle cultural, físico, por comportamento e por resistência de plantas. In: CURSO DE ENTOMOLOGIA APLICADA À AGRICULTURA. Piracicaba: FEALQ, 1992. p.113-119.

WILCKEN, C.F. Estrutura da comunidade de lepidópteros, coletados com armadillhas luminosas, que ocorrem em florestas de Eucalyptus grandis Hill ex Maiden. Piracicaba, 1991. 148p. Dissertação (Mestrado) - Escola Superior de Agricultura "Luiz de Queiroz", Universidade de São Paulo. 
ZANÚNCIO, J.C.; ALVES, J.B.; SANTOS, G.P.; CAMPOS, W.O. Levantamento e flutuação populacional de lepidópteros associados à eucaliptocultura: VI. Região Belo Oriente, Minas Gerais. Pesquisa Agropecuária Brasileira, v.28, n.10, p1121-1127, 1993a.

ZANÚNCIO, J.C.; SANTOS, G.P.; SANTANA, G.P.; SANTANA, D.L.Q. Métodos de amostragem. In: ZANÚNCIO, J.C. (Coord). Lepidoptera desfolhadores de eucalipto: biologia, ecologia e controle. Piracicaba: Instituto de Pesquisas e Estudos Florestais, Sociedade de Investigações Florestais, 1993b. 140p. 